\title{
Integration and differentiation in a hospital's logistical system
}

Citation for published version (APA):

van der Ham, A. (2022). Integration and differentiation in a hospital's logistical system. [Doctoral Thesis, Maastricht University]. ProefschriftMaken. https://doi.org/10.26481/dis.20220113ah

Document status and date:

Published: 01/01/2022

DOI:

10.26481/dis.20220113ah

Document Version:

Publisher's PDF, also known as Version of record

\section{Please check the document version of this publication:}

- A submitted manuscript is the version of the article upon submission and before peer-review. There can be important differences between the submitted version and the official published version of record.

People interested in the research are advised to contact the author for the final version of the publication, or visit the DOI to the publisher's website.

- The final author version and the galley proof are versions of the publication after peer review.

- The final published version features the final layout of the paper including the volume, issue and page numbers.

Link to publication

\footnotetext{
General rights rights.

- You may freely distribute the URL identifying the publication in the public portal. please follow below link for the End User Agreement:

www.umlib.nl/taverne-license

Take down policy

If you believe that this document breaches copyright please contact us at:

repository@maastrichtuniversity.nl

providing details and we will investigate your claim.
}

Copyright and moral rights for the publications made accessible in the public portal are retained by the authors and/or other copyright owners and it is a condition of accessing publications that users recognise and abide by the legal requirements associated with these

- Users may download and print one copy of any publication from the public portal for the purpose of private study or research.

- You may not further distribute the material or use it for any profit-making activity or commercial gain

If the publication is distributed under the terms of Article $25 \mathrm{fa}$ of the Dutch Copyright Act, indicated by the "Taverne" license above, 


\section{Untegration and Differentiation in a Mospital's Logistical}

system

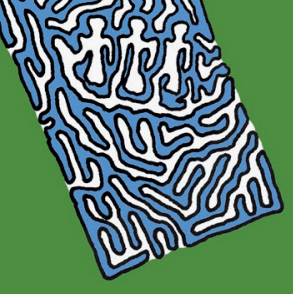

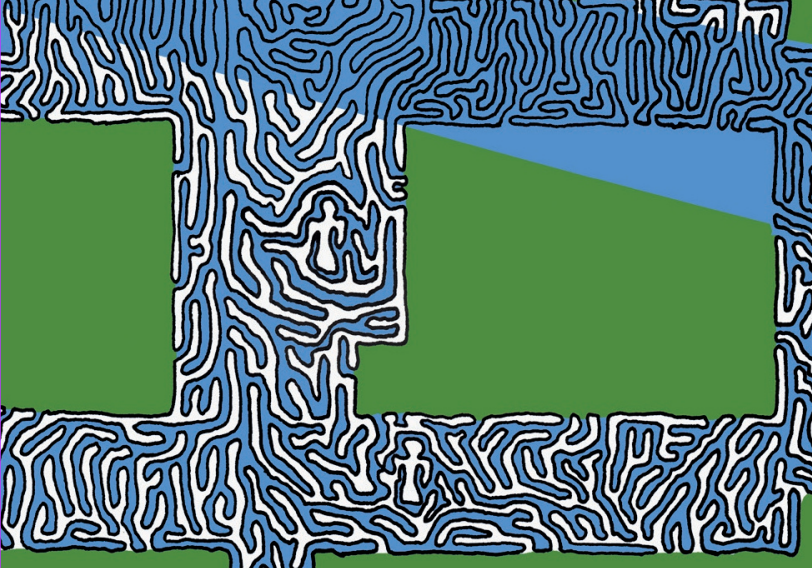

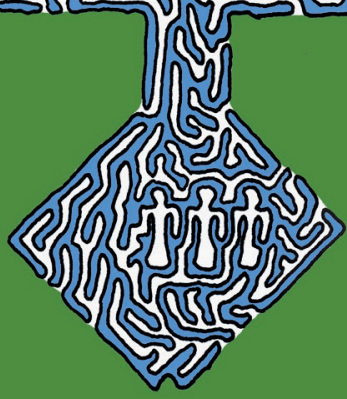

Annellies van der Ham 



\section{Integration and Differentiation in a Hospital's Logistical System}


The research presented in this dissertation was conducted at the Care and Public Health Research Institute (CAPHRI), department of Health Services Research, Maastricht University. CAPHRI is part of the Netherlands School of Primary Care (CaRe), which has been acknowledged by the Royal Netherlands Academy of Science (KNAW).

(C) Annelies van der Ham, Maastricht 2021

All rights reserved. No part of this thesis may be reproduced or transmitted in any form or by any means, without prior permission in writing by the author, or when appropriate, by the publishers of the publications.

Cover design: Erwin Frederiksen, Annelies van der Ham

Ilustrations: Roelant Siekman

Lay-out: Tiny Wouters

Printing by: Proeftschriftmaken - De Bilt

ISBN: 978-94-6423-549-4 


\title{
Integration and Differentiation in a Hospital's Logistical System
}

\author{
Proefschrift
}

Ter verkrijging van de graad van doctor aan de Universiteit Maastricht, op gezag van Rector Magnificus, Prof. dr. Rianne M. Letschert, volgens het besluit van het College van Decanen, in het openbaar te verdedigen op donderdag 13 januari 2022 om 16.00 uur

door

Annelies van der Ham 


\section{Promotores}

Prof. dr. G.G. van Merode

Prof. dr. D. Ruwaard

\section{Copromotor}

Dr. A.J.A van Raak

\section{Beoordelingscommissie}

Prof. dr. J.A.M. Maarse (voorzitter)

Prof. dr. ir. C.T.B Ahaus (Erasmus School of Health Policy \& Management)

Prof. dr. W.F. Buhre

Prof. dr. M. van Houdenhoven (Radboud Universiteit)

Dr. D. D. Westra 
'The flexibility and weakness of water make it stronger than strength'

François Jullien 



\section{CONTENTS}

Chapter 1 General Introduction

Chapter 2 Identifying Logistical Parameters in Hospitals: Does literature reflect integration in hospitals? A scoping study

Chapter 3 Identifying Integration and Differentiation in a Hospital's

Logistical System: A social network analysis of a case study

Chapter 4 Explaining Integration and Differentiation by Identifying the Rules and Coordination Mechanisms in a Hospital's Logistical System

Chapter 5 Evaluating Changes in Integration, Differentiation, Rules, 187 Coordination and Performance Following the Introduction of a Hospital Planning Centre: A case study

Chapter 6 General Discussion 249

Summary 269

Samenvatting 277

Impact 285

Dankwoord 295

About the author 303

List of publications 307 




\section{GENERAL INTRODUCTION}

"Next week, we will have four patients reporting hip fractures. They are not expecting to break their hip, but they will. We know, because we always have 4 cases at least, and sometimes 5, or even 10 . We treat 300 hip fractures every year. This number is rising a bit, but not dramatically. So, we are able to plan accordingly."

"I have a schedule and I look at it to see what I will be doing this week and when. There is no point in looking further ahead, because everything will change anyway."

These two seemingly contradictory statements from a surgeon in Slingeland Hospital nicely illustrate what organizing healthcare is about. As John Lennon put it, 'life often happens to you while you're busy making other plans'․ While healthcare is about life, about preserving and improving it, organizing healthcare is about making sure that the resources to do so are there at the right place and time, even when, or rather, in particular when 'things happen'. From the perspective of large numbers of people having similar and more or less predictable life cycles, healthcare could perhaps be planned. For individual people with specific needs or experiencing extraordinary events such as accidents or long-term illness, adaptation to specific and changing circumstances is key. And, as healthcare services have become increasingly specialized and patient centered, patients more and more have become unique cases. In this context offering affordable and accessible healthcare services on a large scale has become a tremendous challenge.

Worldwide, there have been concerns on how to maintain and improve the accessibility and affordability of healthcare. In the past decades concerns were raised with regard to increased healthcare expenditure. In most countries affiliated with the Organisation for Economic Co-operation and Development (OECD) health spending rises faster than economic growth ${ }^{2}$. The health spending per capita is estimated to grow further at an average annual rate of $2.7 \%$ up to an average of $10.2 \%$ of the gross domestic product (GDP) by $2030^{2}$.

More recently, the Covid-19 pandemic showed that in many countries healthcare delivery to all people in need of care was put under heavy pressure3. In particular hospitals were struggling to provide the healthcare that was asked for and it was observed that even advanced health systems were stretched beyond their capacity4. Given these circumstances we believe that new organizational concepts or models are required for keeping our healthcare system 'healthy', i.e., effective, affordable and accessible. This applies in particular for hospitals, because hospitals are a major cost item ${ }^{5,6}$. 
Fortunately, several researchers before us have thought about hospitals and studied how they can be improved. It is often argued that more attention should be given to hospital logistics and operations, thereby following industries outside the field of healthcare ${ }^{7-9}$. The development of traditionally fragmented logistics in the army ${ }^{10}$ to total system integration through concepts such as supply chain management (SCM) is often mentioned as an example for hospitals ${ }^{7,11-13}$. In a hospital context, the concept of integration includes the hospital-wide alignment and coordination of activities along the patient or material flow. In integrated hospitals, patient processes and resources are planned from the perspective of the total system ${ }^{14}$, in which the coordination of operations between the different members of the chain should improve the entire patient flow $^{15}$. Hospital-wide cooperation is a key issue in achieving high efficiency and quality in hospitals ${ }^{16}$.

Literature also states that despite the much advocated integration in literature, the question of how integration is achieved in practice is relatively unaddressed, and improving hospitals is considered complex ${ }^{8}$, hard ${ }^{12}$, extremely challenging ${ }^{17,18}$ or even problematic $^{11}$. Inspired by the work of Jullien ${ }^{19}$, who explains that a full understanding of factors that determine the course of things is important for achieving effective transformation, we therefore ought to take a deep dive into hospital practice. As described by Jullien in the context of warfare, this means that 'any operation to be undertaken before engaging in battle must be an operation not of planning but of 'evaluation', or more precisely, 'assessment'19. Therefore, the main part of the research undertaken for this thesis involves the assessment of functioning of hospitals and of integration and the inextricably linked differentiation in particular. The concepts underlying this assessment are introduced in this chapter and summarized in Table 1.1.

\section{Integration, differentiation and fragmentation}

Much has been written on integration, and it is used by people in different meanings ${ }^{20}$. Because little research has been conducted on how integration is achieved in a healthcare context ${ }^{11}$, we look at other fields of research, where the concept of integration has been more developed. The word is related to the Latin verb 'integer', which means 'to complete'. It has to do with bringing things together, things that would have been otherwise separated. With regard to organizations, Drupsteen et. al. ${ }^{21}$ state that integration involves aligning different departments in such a way that an organization functions 'as a unified whole'. In the context of organizations, integration is typically referred to in terms of interaction, collaboration, and cooperation ${ }^{20}$. 
Lawrence and Lorsch ${ }^{22}$ have studied integration in several industries and found that both integration and differentiation are essential in order for organizations to perform effectively. They made a major contribution to contingency theory, which views organizations as open systems in which the behaviour of members are interrelated. They define integration as 'achieving unity of effort among the various subsystems in the accomplishment of the organization's task'22. Differentiation refers to the state of segmentation of the organizational system into subsystems'22. Subsystems execute a part of the organization's task and 'develop particular attributes in relation to the requirements posed by their relevant external environment'22. Subsystems and how these are defined, therefore depend on the requirements of the external (sub)environment and how tasks are divided into subtasks and this may change over time. When subsystems perform subtasks individually, without the efforts of each subsystem being integrated to achieve unity of effort, there is fragmentation. Subsystems can develop a primary concern with their own goals when dealing with their particular (sub)environment. This may lead to different parameters being used and pursued by different parts in one organization.

\section{Social network analysis}

The more recent research field of social network analysis (SNA) also addresses integration. Social network analysis offers a means of mapping connections between agents, e.g., people or organizations, in a mathematical way. Many of the concepts in SNA are derived from graph theory ${ }^{23}$, as points and lines represent agents and their connections, called ties. SNA includes several metrics that characterize the nature of the network and the positions of agents in it, as defined in Table 1.1.

For integration in organizations, several authors ${ }^{23-25}$ mention network metrics to indicate integration or networks, thereby often referring to coordination between people, groups or organizations. Differentiation is also mentioned in literature pertaining to social network analysis, when referring to tasks being differentiated ${ }^{24,26}$, but there are no specific metrics used that refer to differentiation explicitly. In his book, Kilduff ${ }^{23}$ states in a chapter on social network analysis that 'we await a full-blown contingency theory analysis of how trust-based coordinating mechanisms facilitate differentiation and integration'. The fact that this theory doesn't yet exist could be attributed to the widely reported 'embryonic' stage ${ }^{27}$ of social network analysis, as shown by two literature reviews ${ }^{27,28}$.

At the same time, several studies view social network analysis as promising ${ }^{23-27,29,30}$. Benham-Hutchins and Clancy ${ }^{29}$ view social network analysis as a new and creative 
method that is required to meet the complex problems of leaders in modern healthcare organizations. In multiple, mostly exploratory studies, a relation between network structure and the performance of healthcare organizations or networks has been reported, both in terms of quality of care as well as efficiency. For example, Provan and Sebastian ${ }^{24}$ indicate that organizations perform more effectively when integration is established through small groups of highly connected agents, when agents are included in multiple groups. Haythornwaite ${ }^{30}$ points out that groups with strong relationships facilitate information exchange. Several authors mention the utility of 'brokers' or 'integrative devices' that join groups which are disconnected ${ }^{22-24,30}$. Various studies report tentative results in which a link is made between the network structure and performance parameters such as surgery lead time ${ }^{31}$, hospitalization $\operatorname{cost}^{26,32}$, process efficiency33, readmission rate $^{26}$ and patient quality and safety outcomes ${ }^{34}$. At the same time, these studies are said to provide weak evidence, which is attributed to the fact that social network analysis is an upcoming method $^{28}$.

\section{Rules and coordination mechanisms}

In both social network theory and literature pertaining to integration often coordination is mentioned as a core activity ${ }^{22-25,35}$. According to Mintzberg35, different types of coordination connect differentiated activities, which result from the division of labor. For each coordination mechanism, as defined in Table 1.1, different interaction between agents is required.

Coordination mechanisms are based on rules. For example, direct supervision (Table 1.1) is based on hierarchical rules, i.e., who is given the authority to make decisions and issue directives. Standardization of work (Table 1.1) is based on rules on how to perform tasks, which may result in interaction between those who design work processes and those who perform the tasks defined in it. According to Mintzberg, healthcare organizations are typically characterized as 'professional bureaucracies' because much of the coordination is taken care of by standardization of skills and knowledge ${ }^{36}$. As a result of their training, health care professionals know what to expect from one another, often work alone, and consultations between colleagues are limited to 'a few words scribbled on a paper' ${ }^{36}$. Put differently, and in line with the surgeon's statement at the start of this chapter, healthcare professionals simply know what to expect, based on their professional training and experience. 
Table 1.1: Definition of concepts.

\begin{tabular}{|c|c|}
\hline Concept & Definition \\
\hline Integration & $\begin{array}{l}\text { The coordination and alignment of tasks, thus achieving 'unity of } \\
\text { effort among the various subsystems in the accomplishment of the } \\
\text { organization's task'22 }\end{array}$ \\
\hline Differentiation & $\begin{array}{l}\text { The state of segmentation of the organizational system into } \\
\text { subsystems' }{ }^{\prime 22}\end{array}$ \\
\hline Fragmentation & $\begin{array}{l}\text { The state in which subsystems perform subtasks individually and } \\
\text { no effort is made to achieve unity of effort, while demands from the } \\
\text { environment require integration. }\end{array}$ \\
\hline \multicolumn{2}{|l|}{ Social network analysis } \\
\hline Node & An agent \\
\hline Tie & $\begin{array}{l}\text { A communication link between two agents via email, text message, } \\
\text { telephone or face-to-face. }\end{array}$ \\
\hline Clique & A set of agents who are all connected to one another. \\
\hline Density & $\begin{array}{l}\text { The number of ties a set of agents has in relation to the number of } \\
\text { possible ties they can have. }\end{array}$ \\
\hline Clique overlap & $\begin{array}{l}\text { The percentage of agents who are members of more than one } \\
\text { clique for a specific task. }\end{array}$ \\
\hline Degree & The number of ties of one agent. \\
\hline Betweenness centrality & $\begin{array}{l}\text { The number of times a node (agent) lies on the shortest path } \\
\text { between other nodes (agents). }\end{array}$ \\
\hline Multiplexity & $\begin{array}{l}\text { The percentage of agents in a clique for a task who are also } \\
\text { members of cliques for other tasks }\end{array}$ \\
\hline \multicolumn{2}{|c|}{ Rules and coordination mechanisms } \\
\hline Rule & $\begin{array}{l}\text { A defined, accepted or agreed way of performing tasks, which } \\
\text { includes what is done, how it is done and what is allowed and what } \\
\text { is not allowed. }\end{array}$ \\
\hline Mutual adjustment & $\begin{array}{l}\text { An agent interacts with other agents about a rule; i.e., what it } \\
\text { entails or how to apply it in a specific situation or the application of } \\
\text { the rule requires interaction. }\end{array}$ \\
\hline Direct supervision & A rule is set and monitored by people with formal authority. \\
\hline $\begin{array}{l}\text { Standardization of work } \\
\text { processes }\end{array}$ & Rules result from specified or programmed working processes. \\
\hline Standardization of output & $\begin{array}{l}\text { Rules include specified output in terms of predetermined } \\
\text { standards for services or performance. }\end{array}$ \\
\hline Standardization of skills & Rules include specified skills and knowledge. \\
\hline Standardization of norms & $\begin{array}{l}\text { Rules result from a common culture or ideology and specify norms } \\
\text { for behaviour. }\end{array}$ \\
\hline
\end{tabular}

However, the much advocated integration in hospitals suggests that there is more to hospital effectiveness than the healthcare professionals' confidence in knowing what to expect. By identifying all coordination mechanisms in the hospital, the interaction between agents is explained, thereby mapping the information processing structure. As a consequence, the network structure, i.e., integration and differentiation, is explained. 


\section{AIM AND OUTLINE}

\section{Aim}

The aim of this thesis is to thoroughly understand how a hospital's logistical system works, i.e., to what extent there is integration and differentiation and how rules and coordination mechanisms shape the hospital's network structure. To this end, the current state of affairs in literature with regard to hospital logistics and operations was studied, and three case studies were conducted in Slingeland Hospital. More specifically, four steps were undertaken for this research, each with a more specific aim:

1. To understand the state of affairs in hospitals with respect to logistics and integration and, in particular, identify logistical parameters that are mentioned in the international literature with regard to hospital logistics and the way literature reflects integration in hospitals.

2. To understand how a hospital's logistical system works in practice and in particular to what extent there is integration and differentiation.

3. To explain the integration and differentiation in a hospital by studying the rules and coordination mechanisms that facilitate differentiation and integration.

4. To evaluate whether integration, differentiation, coordination mechanisms and performance change after an organizational intervention that involves the introduction of a hospital planning centre (HPC).

Important to underline is that even though much has been written on the concepts introduced in this chapter and defined in Table 1.1, we take the stance that before we are able to say anything on how integration and differentiation may improve the performance of hospitals, we first need to know how a hospital and, in particular, its logistical system works in practice from a system-wide perspective. The concepts as introduced, are instrumental to this, and not regarded as a proven concept or model. Therefore, a naturalistic inquiry37 approach as described by De Vries and Beuving, was followed, which basically involves 'studying people in their everyday circumstances'37, thereby taking 'society as it presents itself naturally'37. This approach is particularly suitable for exploration of relatively unknown phenomena and for which a step-wise research planning is required, by defining each research step on the basis of the findings of the previous step. 


\section{Outline}

The current state-of-affairs with regard to integration in hospitals is presented in Chapter 2 by identifying the logistical parameters that are mentioned in international literature on hospital logistics.

Chapter 3 describes how a hospital organizes logistical processes and identifies the agents and the interactions for organizing logistical processes; it establishes the extent to which there is differentiation, and whether these tasks are coordinated and aligned, thus achieving integration. Chapter 4 explains the integration and differentiation according to Chapter 3 by describing the rules and coordination mechanisms that agents in a hospital network use. Chapter 5 evaluates the changes in integration, differentiation, coordination mechanisms and performance after a hospital planning centre (HPC) was introduced. In Chapter 6, the main findings of this study are described and the theoretical and methodological aspects of this study are reflected upon. In addition, in Chapter 6 future directions for practice, policy and research are discussed. 


\section{REFERENCES}

1. Lennon J. Beautiful Boy. Geffen, 1980.

2. OECD. Health at a Glance 2019: OECD Indicators. OECD Publishing, Paris, 2019.

3. Weismann GE, Crane-Droesch A, Chivers C, Luong T, Hanish A, Levy MZ. Locally informed simulation to predict hospital capacity needs during the COVID-19 pandemic. Ann Inter Med. 2020; 173(1):21-28.

4. Cavallo JJ, Donoho DA, Forman HP. Hospital capacity and operations in the coronavirus disease 2019 (COVID-19) pandemic - Planning for the Nth patient. JAMA Health Forum. Published online March 17, 2020. doi:10.1001/jamahealthforum.2020.0345.

5. Morgan D, Astolfi R. Financial impact of the GFC: health care spending across the OECD. Health Econ Policy Law. 2015; 10:7-19.

6. OECD/European Union. Health expenditure in hospitals. Health at a Glance. OECD Publishing, Paris/European Union, Brussels, 2018.

7. Feibert DC and Jacobsen P. Measuring process performance within healthcare logistics - a decision tool for selecting track and trace technologies. Acad Strategic Manag J 2015; 14:33-57.

8. Aronsson H, Abrahamsson M and Spens K. Developing lean and agile health care supply chains. Supp Chain Manag 2011; 16: 176-183.

9. Meijboom B, Schmidt-Bakx S and Westert G. Supply chain management practices for improving patient-oriented care. Supp Chain Manag 2011; 16:166-175.

10. Ballou RH. The evolution and future of logistics and supply chain management. Eur Bus Rev 2007; 9:332-348.

11. De Vries J and Huijsman R. Supply chain management in health services: an overview. Supp Chain Manag 2011; 16:159-165.

12. Ellram LM and Cooper MC. Supply chain management: it's all about the journey, not the destination. J Supply Chain Manag 2014; 50:8-20.

13. Shiau WL, Dwivedi $\mathrm{Y}$ and Tsai $\mathrm{CH}$. Supply chain management: exploring the intellectual structure. Scientometrics 2015; 105:215-230.

14. Van Merode GG, Groothuis S, Hasman A. Enterprise resource planning for hospitals. Int J Med Inform. 2004; 73:493-501.

15. Villa S, Prenestini A and Guisepi I. A framework to analyze hospital-wide patient flow logistics: evidence from an Italian comparative study. Health Policy 2014; 115:196-205.

16. Ludwig M, Van Merode GG and Groot W. Principal agent relationships and the efficiency of hospitals. Eur J Health Econ 2010; 11:291-304.

17. Bhattacharjee P and Ray PK. Patient flow modelling and performance analysis of healthcare delivery processes in hospitals: a review and reflections. Comput Ind Eng 2014; 78: 299-312.

18. Matta ME and Patterson S. Evaluating multiple performance measures across several dimensions at a multi-facility outpatient center. Health Care Manage Sci 2007; 10:173-194.

19. Jullien F, Lloyd J. A Treatise on Efficacy: Between Western and Chinese Thinking. Honolulu: University of Hawai'i Press, 2004.

20. Kodner DL, Spreeuwenberg C. Integrated care: meaning, logic, applications and implications a discussion paper. Int $J$ Integr Care 2002. https://doi.org/10.5334/ijic.67.

21. Drupsteen J, Van der Vaart $\mathrm{T}$ and Van Donk DP. Integrative practices in hospitals and their impact on patient flow. Int J Op Prod Manag 2013; 33:912-933. 
22. Lawrence PRL, Lorsch JW. Differentiation and integration in complex organizations. Adm Sci Q. 1967; 12:1-47.

23. Kilduff M, Tsai W. Social networks and organizations. London: SAGE; 2003. Accessed 6 Sept 2018.

24. Provan KG, Sebastian JG. Networks within networks: service link overlap, organizational cliques, and network effectiveness. Acad Manag J. 1998; 41(4):453-63.

25. Monge PR, Contractor N. Emergence of communication networks. In: Jablin FM, Putman LL, editors. The new handbook of organizational communication. Thousand Oaks: Sage publications; 2011. p. 440-502.

26. Uddin MS, Hossain L. Social networks enabled coordination model for cost management of patient hospital admissions. J Healthc Qual. 2011; 33:37-48.

27. Benton DC, Pérez-Raya F, Fernández MP, González-Jurado MA. A systematic review of nurserelated social network analysis studies. Int Nurs Rev. 2015; 62:321-39.

28. Chambers D, Wilson P, Thompson C, Harden M, Coiera E. Social network analysis in healthcare settings: a systematic scoping review. PLoS One. 2012;7:e41911.

29. Benham-Hutchins M, Clancy TR. Social networks as embedded complex adaptive systems. JONA. 2010; 40:352-6.

30. Haythornthwaite C. Social network analysis: an approach for the study of information exchange. LISR 1996; 18:323-42.

31. Anderson C, Talsma A. Characterizing the structure of operating room staffing using social network analysis. Nurs Res. 2011; 60:378-85.

32. Uddin S, Hossain L, Alam A, Hamra J. A study of physician collaborations through social network and exponential random graph. BMC Health Serv Res. 2013; 13:234.

33. Samarth CN, Gloor PA. Process efficiency. Redesigning social networks to improve surgery patient flow. $J$ Healthc Inform Manag. 2009; 23:20-6.

34. Effken JA, Carley KM, Gephart S, Verran JA, Bianchi D, Reminga J, Brewer BB. Using ORA to explore the relationship of nursing unit communication to patient safety and quality outcomes. Int J Med Inform. 2011; 80:507-17.

35. Mintzberg, H. Structure in Fives: Designing Effective Organizations. Englewoods Cliffs: Prentice Hall, 1983.

36. Mintzberg H. Managing the Myths of Health Care. Oakland: Berrett-Koehler Publishers, 2012.

37. Beuving J and De Vries G. Doing Qualitative Research: The Craft of Naturalistic Inquiry. Amsterdam: Amsterdam University Press, 2015. 



\section{CHAPTER 2}

\section{IDENTIFYING LOGISTICAL PARAMETERS IN}

HOSPITALS: DOES LIFERATURE REFLECT INTEGRATION IN HOSPITALS?

\section{A SCOPING STUDY}

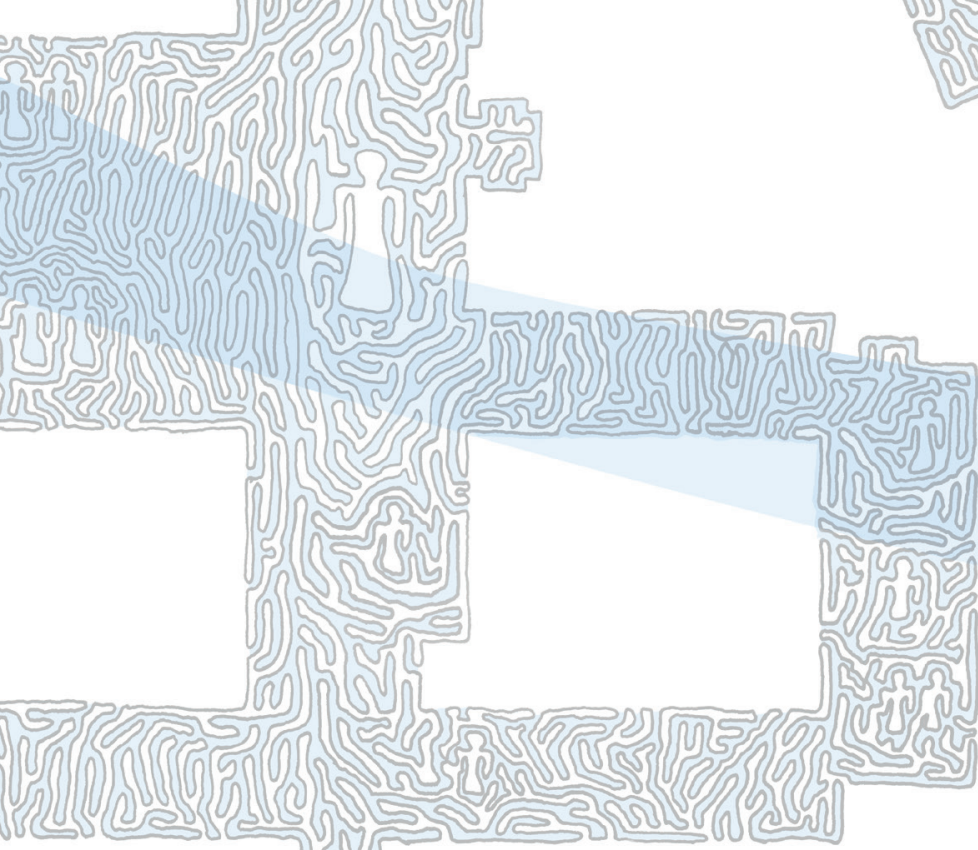

Annelies van der Ham, Henri Boersma, Arno van Raak, Dirk Ruwaard and Frits van Merode Health Serv Manage Res 2019;32(3):158-165. 


\section{ABSTRACT}

In order to improve the quality and efficiency of hospitals, they can be viewed as a logistical system in which integration is a critical factor for performance. This paper describes the results of a scoping study that identifies the logistical parameters mentioned in international research on hospitals and indicates whether literature reflects system integration. When subsystems collaborate in order to accomplish the task of the entire organization, there is integration. A total number of 106 logistical parameters are identified in our study. In addition, the flow type - patients, materials and staff - and hospital subsystems were registered. The results presented in international literature show that logistics is highly fragmented in hospitals. Studies also show integration, though this takes place mainly within the subsystems of hospitals. A multi-agent perspective on hospitals is proposed, following the view that both integration and differentiation are essential for effective organizational performance. Given the widely recognised importance of controlling hospital costs and the potential of logistics to help in this process, it is important to gain more knowledge of hospitals as network organizations, as well as knowledge regarding the degree of integration and the logistical parameters that are required for better hospital performance. 


\section{INTRODUCTION}

Healthcare costs are increasing in many countries ${ }^{1}$. Governments are looking for ways to control healthcare costs to guarantee, maintain or even improve the quality, accessibility and affordability of their healthcare systems ${ }^{2}$. There is increasing concern about the growth of healthcare spending3. Hospitals are a major cost item ${ }^{4}$, so there is a particular focus on hospitals when it comes to controlling the costs of health care.

In many industries outside the field of health care it is argued that well-functioning logistics positively affects the operations of an organization ${ }^{5}$. Logistical optimisation has led to cost efficiency, quality improvement and customer satisfaction. It is argued that this can also be applied to hospitals ${ }^{6,7}$.

In the literature it is argued that, although a well-functioning logistical system is critical for the overall functioning of healthcare operations, this support service is largely underestimated in hospitals ${ }^{8}$. Further, it is stated that 30 to $40 \%$ of hospital expenses are invested in various logistical activities5,6,9, and that almost half of the costs associated with supply chain processes could be eliminated through the use of best practices. These claims suggest that logistics is not given the attention it deserves.

Before the 1950s, logistics was thought of in military terms ${ }^{10}$. In those years, activities that are currently associated with logistics were organised in a fragmented way. There have been many changes since then; over time, a more integrated and broader perspective on logistics has been adopted5,11. With the introduction of Supply Chain Management (SCM), the perspective changed from that of total cost integration to total system integration. SCM includes a chain orientation ${ }^{11}$, encompassing all activities from their origin to the point of consumption5; it aims to increase performance through the better use of internal and external capabilities ${ }^{12}$ and is about everything that adds value for the customer and enhances competitive advantages ${ }^{13}$. In addition to SCM, there have been other theories and methods, such as lean six sigma, that promote integration ${ }^{14}$.

Healthcare logistics has been addressed in several studies, including overviews of literature on healthcare logistics $5,6,11,15$ and operations management ${ }^{16}$. These studies consistently point out that academic research in this field is lacking6,16 and that existing knowledge in the field is fragmented. It is suggested that health care is behind with respect to implementing SCM practices ${ }^{11}$. 
The alignment of activities along the patient or material flow, often referring to the concept of integration, is central in the literature pertaining to logistics, SCM and lean perspectives in hospitals. Several papers state that the lack of integration within a hospital setting is attributable to the functional organization of medical disciplines and their facilitating departments, which do not share fixed resources ${ }^{16-18}$. In integrated hospitals, patient processes and resources are planned from the perspective of the total system ${ }^{19}$, in which the coordination of operations between the different members of the chain improves the entire patient flow ${ }^{20}$. Aronsson states that in order for an organization to be effective, a supply chain strategy is required for the system as a whole ${ }^{6}$. In a more integrated perspective, attention is claimed for all hospital processes and resources ${ }^{21}$, instead of focusing on an individual department, such as the Operating Room (OR) or the Intensive Care Unit (ICU). On a regional level, Poulin claims that horizontal interorganizational arrangements in relation to supply chain management are largely understudied 9 . It is not surprising that the literature argues that a systematic logistical approach to hospital strategy would lead to more efficient hospitals ${ }^{6,20}$. With regard to cooperation, Ludwig, Van Merode and Groot $^{17}$ state that cooperation is a key issue in achieving high efficiency and quality in hospitals, not only on a departmental, but also on a hospital-wide level. Evidence was found that efficient departments in a hospital did not necessarily make the entire hospital efficient ${ }^{10}$. Inter-departmental cooperation not only increases efficiency but also leads to better service for patients ${ }^{22,23}$. Accordingly, cooperation is considered essential for hospital efficiency on a departmental as well as on the hospital-wide level.

Despite the evident need for more integration, De Vries ${ }^{11}$ remarks that the question of how integration can be achieved is relatively unaddressed in healthcare settings. In addition, he states that the application of SCM is considered to be more complex in healthcare settings and may require a different approach than in other industries.

Lawrence and Lorsch state that both integration and differentiation are essential in order for an organization to perform effectively ${ }^{24}$. They define integration as 'achieving unity of effort among the various subsystems in the accomplishment of the organization's task'. Differentiation refers to 'the state of segmentation of the organizational system into subsystems'. Subsystems execute a part of the organization's task and 'develop particular attributes in relation to the requirements posed by their relevant external environment'. A subsystem therefore is not necessarily a fixed part of the organization, but its definition depends on the requirements of the external (sub)environment and how tasks are divided into subtasks ${ }^{24}$. 
When subsystems perform subtasks individually, without the efforts of each subsystem being integrated to achieve unity of effort, there is fragmentation. Therefore, when studying hospital logistics, all the relevant parts of the system should be included, rather than examining the contribution of each department individually ${ }^{16}$. A strong emphasis on process orientation in research ${ }^{11}$, instead of focusing on functional silos, is in line with this perspective.

According to Lawrence and Lorsch ${ }^{24}$, subsystems can develop a primary concern with their own goals when dealing with their particular (sub)environment. This may lead to different parameters being used and pursued by different parts in one organization. Given the recommendations in the literature on logistical approaches and more integration in hospitals, it would be interesting to know which logistical parameters are used in hospitals. Therefore, in order to thoroughly understand the state of affairs in hospitals with respect to logistics and system integration, this research addresses two questions. Which logistical parameters are mentioned in the international literature with regard to hospital logistics? In what way does the literature reflect system integration in hospitals?

\section{METHODS}

As hospital logistics is a broad topic, a scoping study was conducted. As opposed to a systematic review, this type of literature research addresses broader topics in which many different study designs are applicable ${ }^{25}$.

Given the breadth of the concepts included, it was considered unlikely that we would be able to address very specific research questions or that we would be able to assess the quality of the studies included, as most systematic reviews aim to do. It is argued that scoping studies can be undertaken as methods in their own right, especially in the case of complex topics that have not been extensively reviewed previously ${ }^{25}$. We believe that this is the case with our research. The main goal of the scoping study is to summarise and thus disseminate our findings to strategy and policy makers, as well as to hospital practitioners.

Identifying relevant studies was done through a number of searches in PubMed, Ebscohost and JSTOR. PubMed was selected because it includes a large number of international and clinical articles. Ebscohost is also internationally oriented and has a large number of articles, but is focused on business economics. In addition, JSTOR was used for both areas, as business and life sciences are included in this database, as well as mathematics and statistics, which are often used in logistics. 
Only articles written in English and from the period 2006-2016 were included. Even with these restrictions, initial searches using the keywords 'Logistics' and 'Hospital' led to over 400,000 articles. It was therefore decided to start with a search for these keywords in the Title and Abstract of articles only. The argument was that this would result in a set of articles for which the main topic would be logistics in hospitals.

The first search for 'Hospital' and 'Logistics' in PubMed, Ebscohost and JSTOR resulted in 414 articles. In order to identify other search terms, articles referenced in the 414 articles were analysed. Through an iterative process of searching, the following keyword searches identified:

- Hospital AND Logistics

- Hospital AND Process AND Flow

- Hospital AND Supply Chain Management

- Hospital AND Operations Management

The articles found in these searches were all recorded in an Endnote database. All articles were screened for logistical parameters by reading the abstract. For each article, the parameters mentioned were noted. These could be parameters that were explicitly studied or parameters considered relevant to the research topic.

For each of the articles that mention logistical parameters, not only was the parameter captured in a database, but the logistical flow type in hospitals - patients, materials and staff - was also noted. The first argument for this was to see what parameters were used in the context of each flow type and to see whether there were similarities or differences in the parameters between these different flows and processes. The second argument was to see whether these flows, which come together at the end of the supply chain in, for example, the operating room, have been studied in relation to one another. In cases where a combination of these flow types was included in the article, such data was registered as well. In addition to this, for each article it was noted whether the logistical parameters were used in a hospital-wide context or in a specific part of the hospital. In case the abstract did not reveal the context, the full text of the article was read. The part of a hospital a study focuses on was also included in the database.

The logistical parameters found were then clustered into concepts. The concepts were identified by first splitting all logistical parameters into separate words - i.e. 'Transport Distance' resulted in two words: transport and distance. All words that represent a variable that could be quantified were labelled as a performance variable. Thus, in the example of 'Transport Distance', 'Distance' was labelled as a variable. All parameters that 
included the same variable were clustered into a concept. In the example of 'Transport Distance', all parameters including the term 'distance' were clustered in the concept of 'Distance'.

In order to establish the saturation level in a systematic way, the number of new parameters accumulated with each search was counted. One search is defined as one unique combination of keywords in one database (PubMed, Ebscohost, JSTOR), i.e. 'Hospital and Logistics' in PubMed. Saturation was reached when, in two searches, no new parameters were found. In addition to this, the number of new logistical parameters accumulated with each article in relation to the other articles was also calculated.

The parameter occurrence was measured as follows:

$P_{n}=p_{x} / n$ the number of times a unique parameter is mentioned $\left(p_{1} \ldots p_{106}\right)$ in relation to the total number of articles $(n)$, presented as a percentage.

An independent reviewer assessed the search results by reproducing them. In addition, the reviewer took samples from the article database to see whether the logistical parameters identified matched those in the articles. The saturation level and the results were also verified by the reviewer. To ensure saturation was still established when using Web of Science, we selected and screened the abstracts of papers using the defined keyword searches.

\section{RESULTS}

\section{Articles}

The searches led to a total of 1,093 articles in the three above-mentioned databases (Figure 2.1). Of the 1,093 articles, 47 duplicates were excluded. All the remaining 1,046 articles were screened for logistical parameters by reading the abstract. No logistical parameters were found in 759 articles, so these articles were thus excluded from further analysis. In 287 articles, logistical parameters were mentioned (Figure 2.1). For these 287 articles, included in Appendix 2.1, the parameters mentioned were noted. These could be parameters that were explicitly studied or parameters considered relevant to the research topic. 


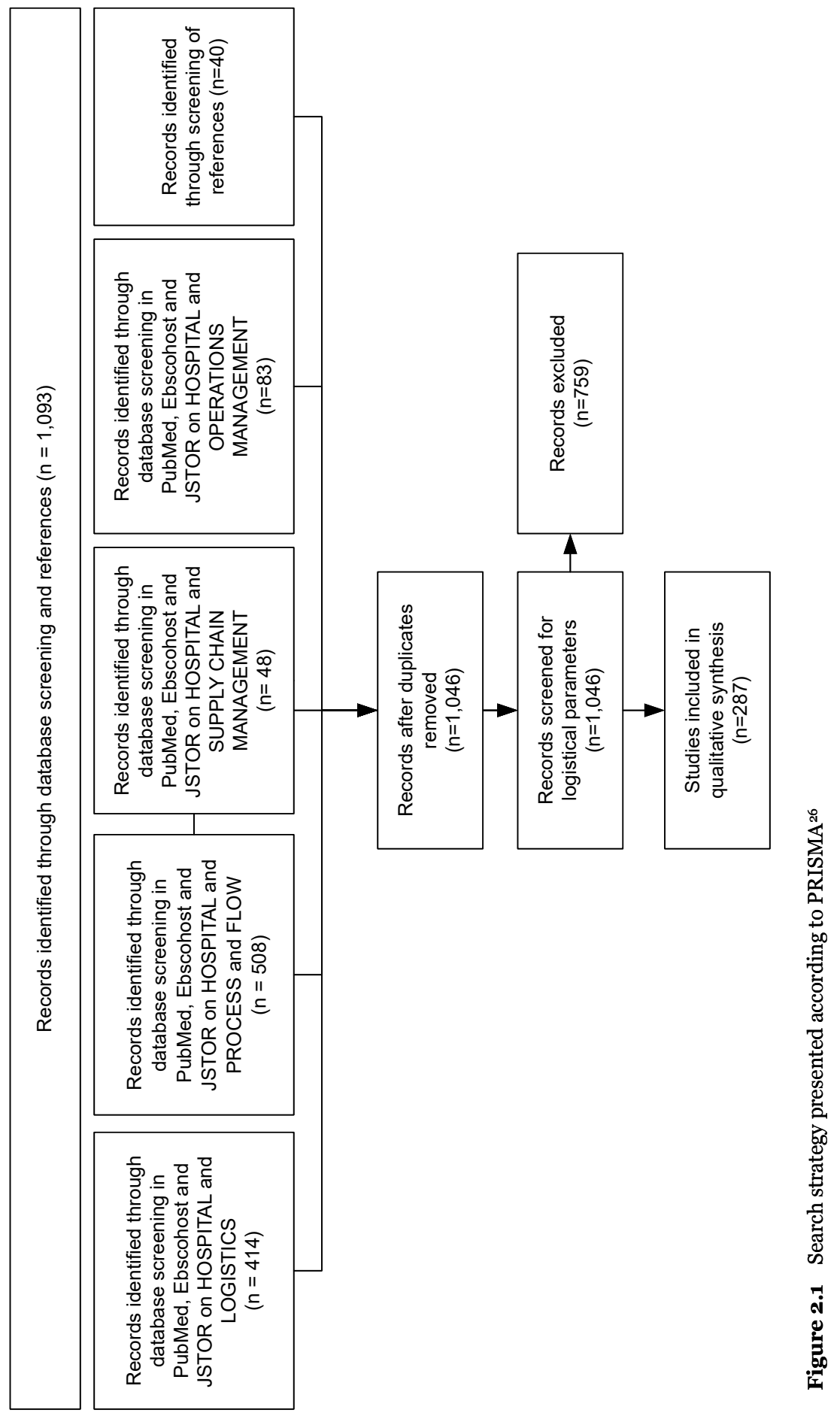




\section{Logistical parameters}

In the 287 articles, 106 different logistical parameters were found. The saturation level was reached when at some point no new parameters were found in the consecutive screening of abstracts. Another indication that no other logistical parameters were to be found and saturation had been reached was the fact that in 82 articles a new parameter was found and in 209 articles no new parameters were found. Based on this, it was considered unlikely that more new logistical parameters would be found and saturation was established. This was confirmed by an independent reviewer. In Appendix 2.2, all 106 parameters are presented in alphabetical order, including the relative number of times that a parameter was, as a percentage, mentioned in the set of 287 articles.

In total, 24 parameters comprise $80 \%$ of the total number of times a parameter was found in an article. The remaining $20 \%$ is made up of 81 different parameters. It is also observed that 79 parameters are mentioned in less than $1 \%$ of all articles. This suggests a relatively large variety of logistical parameters, which, perhaps, are not frequently used under the same name.

To provide an overview on the parameters mentioned most, Figure 2.2 shows the 27 parameters that are mentioned in more than $1 \%$ of the articles. Length of stay is the most mentioned parameter, cited in $30 \%$ of the 287 articles, followed by waiting time and wait time (28\% in total), resource utilisation (18\%) and lead time (16\%). Cost and delay are also mentioned frequently, in $15 \%$ and $10 \%$, respectively, of the articles.

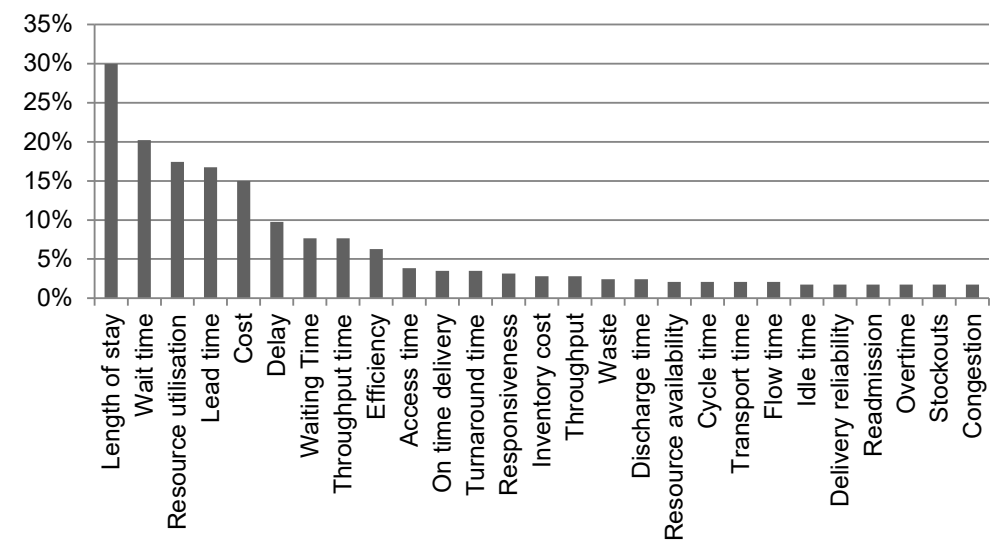

Figure 2.2 Parameter occurrence $\left(P_{n}\right)$ of 27 parameters in relation to the total number of articles (\%) 
Looking at all the parameters, it is noticeable that the same or similar words are used in the names of different parameters. In all 106 logistical parameters, 11 words referring to a performance variable were used in the name of more than one parameter: Time, Cost, Availability, Utilisation, Distance, Spent, Throughput, Efficiency, Length, Occupancy and Reliability. These terms refer to concepts, in which the parameters could be clustered. In the definition of the concepts, 'Spent' and 'Occupancy' were eliminated as separate concepts. 'Spent' was eliminated as a cluster, since it refers to either time or money (cost) spent. 'Length' was also not considered as cluster, because it refers to time or distance. 'Occupancy' was seen as similar to 'Utilisation'. This resulted in eight clusters. In total 81 logistical parameters fit into one of these concepts. Another nine parameters referred to four additional concepts that were then added: Waste, Responsiveness, Rework and Waiting patients. The remaining 16 parameters were not clustered into a concept, but labelled as 'Miscellaneous'.

In total 90 parameters could be clustered into 12 concepts. The results of the clustering are presented in Appendix 2.3. Time is clearly the concept mentioned most: 39 logistical parameters refer to time and 14 of the most mentioned parameters (Figure 2.2) are related to time. Note that 'Length of stay' and 'Delay' are included in the concept of Time. In this case, it is clear that 'length' does not refer to distance but to time duration. 'Delay' is also clearly expressed as time duration.

Cost also seems to be important, as parameters related to cost are mentioned in $11 \%$ of all the parameters noted. Utilisation and availability both refer to resources; the resources mentioned in the logistical parameters are beds, materials (e.g. inventory, stock), space, infrastructure (e.g. floors, elevators, warehouse) and staff.

Given the argument that logistics includes an integral way of thinking, it is remarkable that $47 \%$ of the articles refer to one parameter. Two parameters are mentioned in $26 \%$ of the articles and more than three different parameters are mentioned in $27 \%$ of the articles.

\section{Logistical parameters according to flow types}

Most articles found are on patients, as shown in Figure 2.3. In 83\% of the articles, patient flows are the only logistical flow mentioned. Almost $12 \%$ of the articles are on materials. The minority of articles is on staff ( $2 \%$ ) or had no specific focus (2\%). In $1 \%$ of the articles, both materials and patients were mentioned. 


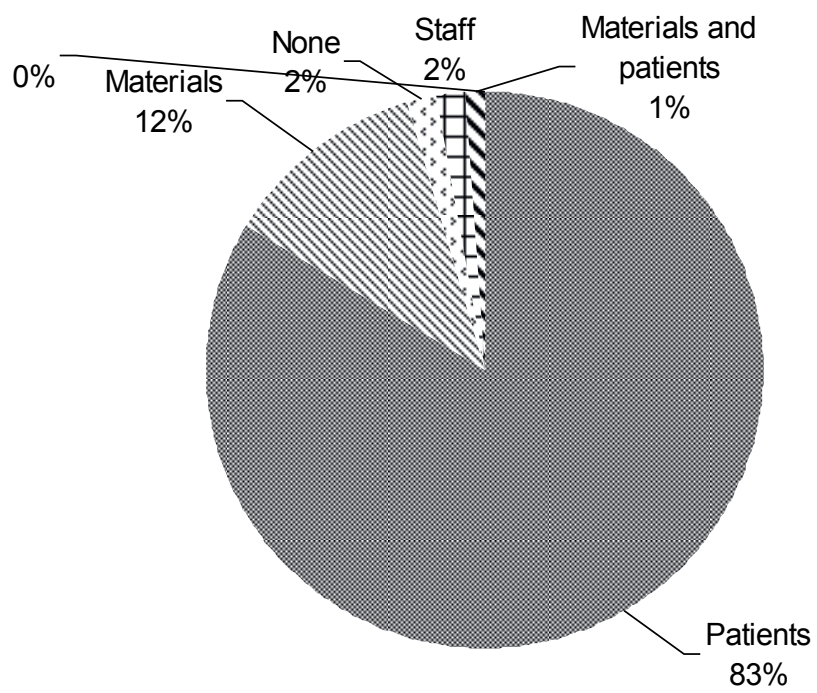

Figure 2.3 Flow types in the articles.

By observing what logistical parameters are mentioned for each flow type, it can be observed that each flow type has both different and similar parameters. First of all, it is remarkable that the terminology used in a patient flow context is different from the terminology used in a material or staff flow context. If we look at the ten most mentioned parameters per flow type, 'Efficiency' and 'Lead time' are the only two parameters which are mentioned in all three contexts of patients, materials and staff. In addition to this being a difference in terminology, it suggests different priorities per flow type.

Figure 2.4 shows how many logistical parameters are mentioned in the context of each flow. A total of 76 parameters are mentioned in the context of one flow type: 57 parameters in the context of patient flow, 15 in materials and four in staff flows. Twelve parameters are mentioned in all flow type contexts, i.e. in patient, material and staff flows. 


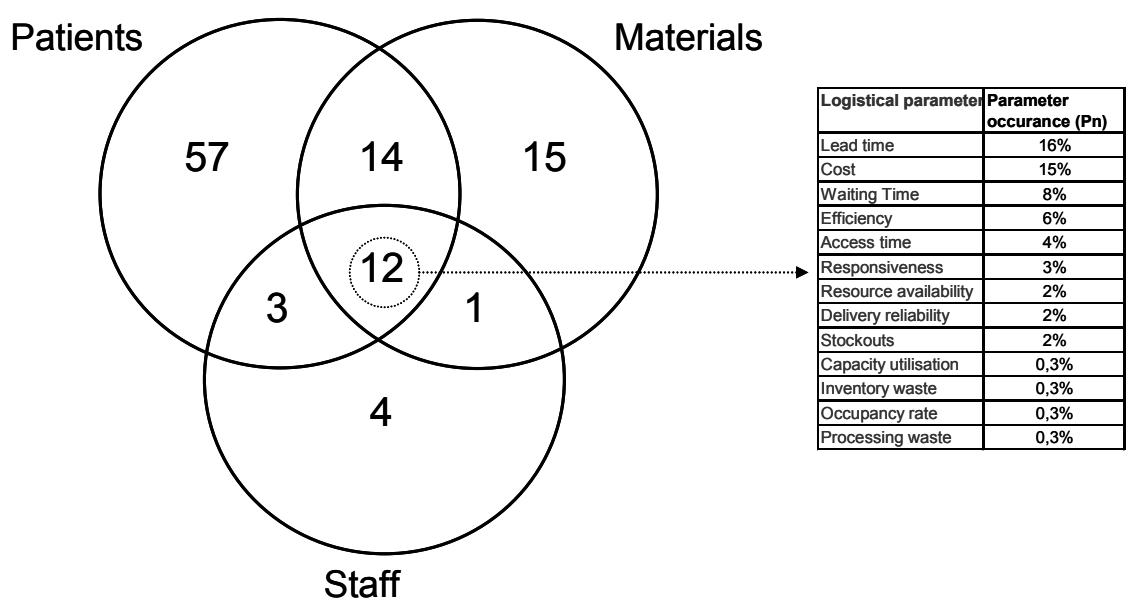

Figure 2.4 Number of logistical parameters per flow type or combination of flow types.

\section{Hospital-wide or subsystem}

Looking at the context of the studies in the 287 articles, $15 \%$ of all articles mention logistical parameters in a hospital-wide context ${ }^{20,27,28}$. The other $85 \%$ of the articles mention logistical parameters in a specific context or subsystem of a hospital. We regard a subsystem as a part of the organization that performs a portion of the organization's task. We found three types of subsystems: a department, flow type and process type.

There are several studies on the Emergency department (18\%), the Operating Theatre department (6\%), the Intensive Care department (3\%) and Nursing departments (3\%).

Studies on specific flow types focus, for example, on blood logistics (2\%) or orthopaedic patients (1\%). There are also studies on specific processes, such as the discharge process (2\%) or the internal transport process $(2 \%)$.

In total we identified 92 subsystems in 287 articles, as presented in Appendix 2.4. For 64 subsystems (22\%), there was only one article in that specific context mentioning logistical parameters. As an example, we mention ten subsystems for which our database includes one article: ancillary services departments, the process of giving injections, paediatric cardiac patients, hip fracture patients, the pre-operative department, HIV/aids patients, ambulatory surgery patients, the inpatient rehabilitation department, patient transfer, laparoscopic patients, the sterilisation department and medical equipment. 


\section{DISCUSSION}

The results of this scoping study indicate that there is fragmentation of logistics in hospitals, as reported in the international literature. The 106 parameters could be clustered into 12 concepts, but the fact that these parameters are used in 92 subsystems leaves us with questions as to whether logistical parameters have the same meaning or serve the same purpose in these different subsystems. A clear integrated view of hospital performance control or improvement could not be derived from the international literature on logistical parameters.

It is also observed that many logistical parameters were either defined in an ambiguous way or were not defined at all in the literature. Wait time and waiting time are clearly two words with the same meaning, but lead time and throughput time are, perhaps, not. Moreover, in a patient flow context, lead time could be measured in a different way than when examined in a material flow context. In many articles this was neither explained nor specified.

Fragmentation is also demonstrated as almost $50 \%$ of the articles mention only one parameter, indicating that many studies fail to analyse performance along more than one dimension. In addition, different parameters seem to be important to different logistical flows. Frameworks that have been developed in the past provide structure, but employ a limited perspective on material flows ${ }^{29}$ and/or on patient flows ${ }^{30}$.

At the same time, there is a certain integration included in the studies analysed in this scoping study. Several studies apply an integrative approach to a part of the hospital. This could be a department, flow type or process. However, integration of patient and material flows within one department or process does not necessarily mean that an entire hospital's performance will increase. If a study shows, for example, that the integration of the healthcare process for acute patients improves the hospital's performance for these patients, it is not clear whether this benefits the entire hospital. The articles found show separate parameters without cohesion. There does not seem to be a clear concept on how logistics for the hospital should function as a whole and how integration and differentiation of tasks contribute to the hospital's performance overall.

From this scoping study we therefore conclude that logistical parameters are numerous, ambiguous, and used in very different contexts in the international literature. When combined, these do not reflect an integrated approach with regard to (the study of) 
hospital logistics. This leads to the question of the possible reasons for this, especially when considering that integration is regarded as essential.

We could argue that research has not yet given much attention to logistics from the perspective of integration. However, given the many articles that claim the necessity for integration in hospitals, logistics does not appear to be irrelevant to hospitals. In a patient context, there is certainly attention shown in the international literature for improving both length of stay and waiting times, as illustrated by the 143 articles that mention these parameters. Also, numerous studies have been conducted on logistics in Emergency Departments. Moreover, frameworks have been developed for assessing logistical performance, clearly indicating a need for controlling and improving hospital logistics. Repeatedly, the relevance of an integrated perspective on hospitals is presented in the literature $6,11,17,19,20,22$.

Several studies note that logistics in a hospital could be too hard to oversee. Researchers state that understanding and improving hospitals is complex ${ }^{6}$, hard ${ }^{32}$, extremely challenging ${ }^{30,31}$ and problematic ${ }^{11}$. This scoping study supports evidence for this argument. Studying 106 different parameters in three different flow types and in 92 subsystems appears to be something of a 'mission impossible' for researchers. This might explain why there is no complete, empirical-based theory of hospital logistics.

The challenges faced by researchers on hospital logistics might also have serious implications for the management of a hospital, particularly for strategic management. Given the large investments made in hospitals, and the need to control healthcare costs, we consider an integrative perspective on hospitals and the inclusion of logistical parameters in strategic decision making to be important. However, we agree with De Vries $^{11}$ that there is a current need to better understand how to do so. We would like to add the question of what integration is in a hospital.

We believe integration includes coordination and cooperation between entities that function together as a unified whole. Hospitals should be seen as a network of more or less dependent agents. Agents are capable of autonomous actions and base their actions on the environment in which they are situated in order to meet their own objectives ${ }^{33}$. To what extent integration is required depends on what services are demanded from agents by their environment and to what extent they need to align and coordinate their activities with those of other agents in order to deliver the required service.

It is also important to state that integration should serve a purpose. The purpose depends largely on what demands agents in the hospital's environment put to the hospital or its 
agents. Agents in the environment could be patients, general practitioners or entire communities. In theory, there could be too much integration, especially when it does not add further value. Following the same reasoning, fragmentation could be effective if an agent is capable of providing good service without having to coordinate with other agents. In that case we should rather speak of differentiation ${ }^{24}$.

It would be interesting to gain more knowledge of the cases in which integration and differentiation are essential for hospital performance and what circumstances play a role in this. We need to know what agents are part of a hospital, to what degree they should or should not act independently, and to what extent integration or alignment between agents is required for improvement of a hospital's overall performance. Further research should lead to new frameworks, consisting of multiple parameters relating to the interests of individual agents, as well as, on hospital-wide level, relating to the various demands stemming from the hospital's environment.

This scoping study certainly has its limitations: the international literature does not, by definition, reflect what really happens in hospitals. It could be the case that multiple agents in the hospital interact, negotiate or coordinate activities, but that this is not known publicly, perhaps for reasons of confidentiality. Another reason could be that there is literature on integrative approaches, but that it is not described in logistical terms. This could be explained by the fact that most people working in hospitals - i.e., doctors, nurses - do not use logistical terms. Further empirical research on how logistical networks of agents in hospitals work, what parameters they use, and whether and when integration or differentiation are detrimental or in fact beneficial to a hospital's performance is therefore recommended.

This study provides an overview of all possible logistical parameters in hospitals; these are used in several contexts and need further structuring in order to be useful in practice. It should therefore be seen as a starting point for further research in which these findings are explored from a multi-agent perspective. In future research, hospital agents could be identified, as well as the various networks of agents interacting in subsystems. The study of what logistical parameters they use for optimising their interests and how these should be used and managed in an integrated way could make an important contribution to the improvement of hospital performance. 


\section{REFERENCES}

1. OECD. Health spending (indicator), https://data.oecd.org/healthres/health-spending.htm (2017, accessed 30 March 2017).

2. Przywara B. Projecting future health care expenditure at European level: drivers, methodology and main results. Brussels: European Commission Directorate-General for Economic and Financial Affairs, 2010.

3. Peiro $\mathrm{S}$ and Maynard A. Variations in health care delivery within the European Union. European Journal of Public Health 2015; 25: 1-2.

4. Morgan D and Astolfi R. Financial impact of the GFC: health care spending across the OECD. Health Economics, Policy and Law 2015; 10: 7-19.

5. Feibert DC and Jacobsen P. Measuring process performance within healthcare logistics - a decision tool for selecting track and trace technologies. Academy of Strategic Management Journal 2015; 14: 33-57.

6. Aronsson H, Abrahamsson M and Spens K. Developing lean and agile health care supply chains. Supply Chain Management: An International Journal 2011; 16: 176-183.

7. Meijboom B, Schmidt-Bakx S and Westert G. Supply chain management practices for improving patient-oriented care. Supply Chain Management: An International Journal 2011; 16: $166-175$.

8. Granlund A and Wiktorsson M. Automation in healthcare internal logistics: a case study on practice and potential. International Journal of Innovation \& Technology Management 2013; 10: 1-20.

9. Poulin E. Benchmarking the hospital logistics process. CMA Management 2003; 77: 20-23.

10. Ballou RH. The evolution and future of logistics and supply chain management. European Business Review 2007; 19: 332-348.

11. De Vries J and Huijsman R. Supply Chain Management in health services: an overview. Supply Chain Management: An International Journal 2011; 16: 159-165.

12. Ellram LM and Cooper MC. Supply chain management: it's all about the journey, not the destination. Journal of Supply Chain Management 2014; 50: 8-20.

13. Shiau WL, Dwivendi $\mathrm{Y}$ and Tsai $\mathrm{CH}$. Supply chain management: exploring the intellectual structure. Scientometrics 2015; 105: 215-230.

14. Womack PW, Jones TJ and Roos D. The Machine that changed the world. New York: Free Press, 1990.

15. Sanders E, Harten $\mathrm{W}$ and Lent W. Exploring improvements in patient logistics in Dutch hospitals with a survey. BMC Health Services Research [Online] 2012; 12, https://www. ncbi.nlm.nih.gov/pmc/articles/PMC3496592/

16. Drupsteen J, Van der Vaart $\mathrm{T}$ and Van Donk DP. 2013. Integrative practices in hospitals and their impact on patient flow. International Journal of Operations \& Production Management 2013; 33: 912-933.

17. Ludwig M, Van Merode GG and Groot W. Principal agent relationships and the efficiency of hospitals. Eur J Health Econ 2010; 11: 291-304.

18. Villa S, Barbieri M and Lega F. Restructuring patient flow logistics around patient care needs: implications and practicalities from three critical cases. Health Care Manag Sci 2009; 12(2): 155-165. 
19. Van Merode GG, Groothuis S and Hasman A. Enterprise resource planning for hospitals. International Journal of Medical Informatics 2004; 73(6): 493-501

20. Villa S, Prenestini A and Guisepi I. A framework to analyze hospital-wide patient flow logistics: evidence from an Italian comparative study. Health Policy 2014; 115: 196-205.

21. Samaranayake P, Dadich A, Hayes K, et al. Patient-journey modelling and simulation in computed tomography. Business Process Management Journal 2015; 21: 988-1014.

22. Litvak N, Van Rijsbergen M, Boucherie RJ, et al. Managing the overflow of intensive care patients. European Journal of Operational Research 2008; 185: 998-1010.

23. Van Houdenhoven, M, Van Oostrum, Wullink G, et al. Fewer intensive care unit refusals and a higher capacity utilization by using a cyclic surgical case schedule. Journal of Critical Care $2008 ; 23,222-226$.

24. Lawrence PRL, Lorsch JW, Differentiation and Integration in Complex Organizations, Administrative Science Quarterly 1967; 12: 1-47.

25. Arksey H and O'Malley L. Scoping studies: towards a methodological framework. International Journal of Social Research Methodology 2005; 8: 19-32.

26. PRISMA 2009 Flow Diagram. http://www.prisma-statement.org/Default.aspx. (2009, accessed 16 February 2017).

27. Kriegel J, Jehle F, Dieck M and Tuttle-Weidinger L. Optimizing patient flow in Austrian hospitals - Improvement of patient-centered care by coordinating hospital-wide patient trails. International Journal of Healthcare Management 2015; 8: 89-99.

28. Ravikumar TS et al. A validated value-based model to improve hospital-wide perioperative outcomes: adaptability to combined medical/surgical inpatient cohorts. Ann Surg 2010; 252(3): 486-96; discussion 496-8.

29. Lega F, Marsilio $M$ and Villa S. An evaluation framework for measuring supply chain performance in the public healthcare sector: evidence from the Italian NHS. Production Planning \& Control 2013, 24, 931-947.

30. Bhattacharjee P and Ray PK. Patient flow modelling and performance analysis of healthcare delivery processes in hospitals: A review and reflections. Computers \& Industrial Engineering 2014; 78, 299-312.

31. Matta ME and Patterson S. Evaluating multiple performance measures across several dimensions at a multi-facility outpatient center. Health Care Management Science 2007; 10: 173-194.

32. Ellram LM. Supply chain management: the industrial organization perspective. International Journal of Physical Distribution \& Logistics Management 1991; 21: 13-22.

33. Wooldridge M. An Introduction to Multi Agent Systems. England: John Wiley and Sons Ltd., 2002. 


\section{APPENDIX 2.1: REFERENCES RESULTING FROM THE SCOPING STUDY}

1. Adeyemi S, Chaussalet TJ, Xie H and Asaduzaman M. Random effects models for operational patient pathways. Journal of Applied Statistics 2010;37:691-701.

2. Aguilar-Escobar VG and Garrido-Vega P. Lean logistics management in healthcare: a case study. Rev Calid Asist 2013;28:42-9.

3. Aguilar-Escobar VG, Garrido-Vega P and Godino-Gallego N. Improving a hospital's supply chain through lean management. Rev Calid Asist 2013;28:337-44.

4. Ahmed A., Surgical hand scrub: lots of water wasted. Ann Afr Med, 2007;6(1):31-3.

5. Ahmed Z, Elmekkawy $\mathrm{T}$ and Bates S. Developing an efficient scheduling template of a chemotherapy treatment unit: A case study. Australas Med J, 2011;4:575-88.

6. Ankomah $\mathrm{J}$ et al. Strategic assessment of the availability of pediatric trauma care equipment, technology and supplies in Ghana. J Pediatr Surg 2015;50(11):1922-7.

7. Ali S, Muzslay M, Bruce M, Jeanes A, Moore G and Wilson AP. Efficacy of two hydrogen peroxide vapour aerial decontamination systems for enhanced disinfection of meticillinresistant Staphylococcus aureus, Klebsiella pneumoniae and Clostridium difficile in single isolation rooms. $J$ Hosp Infect 2016; 93:70-7.

8. Alikhan LM, Howard RJ and Bowry R. From a project to transformation: how "going against the flow" led to improved access and patient flow in an academic hospital. Healthc Manage Forum 2009; 22: 20-6.

9. Ang E, Kwasnick S, Bayati M, Plambeck EL and Aratow M. Accurate Emergency Department Wait Time Prediction. Manufacturing and Service Operations Management, 2016; 18: 141-156.

10. Aptel O, Pomberg $\mathrm{M}$ and Pourjalali H. Improving Activities of Logistics Departments in Hospitals: A Comparison of French and U.S. Hospitals. Journal of Applied Management Accounting Research 2009; 7: 1-20.

11. Aronsson H, Abrahamsson M and Spens K. Developing lean and agile health care supply chains. Supply Chain Management 2011; 16: 176-183.

12. Arun K, Linet $O$, and Chun Ning Z, Supply chain redesign in the healthcare industry of Singapore. Supply Chain Management 2008; 13(2): 95-103.

13. Atinga RA, Mensah SA, Asenso-Boadi F and Adjei FX. Migrating from user fees to social health insurance: exploring the prospects and challenges for hospital management. BMC Health Serv Res 2012; 12: 174.

14. Aydin D, Klit J, Jacobsen S, Troelsen A and Husted H. No major effects of preoperative education in patients undergoing hip or knee replacement--a systematic review. Dan Med $J$ $2015 ; 62$.

15. Azadeh A et al. Optimization of healthcare supply chain in context of macro-ergonomics factors by a unique mathematical programming approach. Appl Ergon 2016; 55: 46-55.

16. Bahadori $\mathrm{M}$ et al. Using queuing theory and simulation model to optimize hospital pharmacy performance. Iran Red Crescent Med $J$ 2014; 16(3): e16807.

17. Bakshi SM. Business process re-engineering a cardiology department. World Hosp Health Serv 2014; 50: 40-5.

18. Balachandran R et al. Stage one Norwood procedure in an emerging economy: initial experience in a single center. Ann Pediatr Cardiol 2013; 6(1): 6-11. 
19. Bamford D and Griffin M. A case study into operational team-working within a UK hospital. International Journal of Operations and Production Management 2008; 28: 215-237.

20. Baumlin KM, Shapiro JS, Weiner C, Gottlieb B, Chawla N and Richardson LD. Clinical information system and process redesign improves emergency department efficiency. Jt Comm $J$ Qual Patient Saf, 2010; 36: 179-85.

21. Beaudry A, Laporte G, Melo T and Nickel S. Dynamic transportation of patients in hospitals. OR Spectrum 2010; 32: 77-107.

22. Berhanemeskel E, Beedemariam G and Fenta TG. HIV/AIDS related commodities supply chain management in public health facilities of Addis Ababa, Ethiopia: a cross-sectional survey. $J$ Pharm Policy Pract 2016; 9: 11.

23. Bert M, Saskia SB and Gert W. Supply chain management practices for improving patient-oriented care. Supply Chain Management: An International Journal 2011; 16(3): 166175 .

24. Bhattacharjee P and Ray PK. Patient flow modelling and performance analysis of healthcare delivery processes in hospitals: A review and reflections. Computers and Industrial Engineering 2014; 78: 299-312.

25. Bhavsar R, Ryhammer PK, Greisen J, Rasmussen LA and Jakobsen CJ. Remifentanil compared with sufentanil does not enhance fast-track possibilities in cardiac surgery-a randomized study. J Cardiothorac Vasc Anesth 2015.

26. Birdsey M, Islam MR, and Barmare A, Sporting injuries, seasonal trend and impact on rural Australian hospitals: Implications and recommendations. Aust J Rural Health 2016.

27. Bonalumi NM, Bhattacharya A, Edwards C, Fasnacht A, Mazzone L, Stephens K, Whiteman K and Swanson-Bierman B. Impact of a planned workflow change: super track improves quality and service for low-acuity patients at an inner-city hospital. J Emerg Nurs 2016.

28. Bonastre J, Noel E, Chevalier J, Gerard JP, Lefkopoulos D, Bourhis J, Bensadoun RJ and De Pouvourville G. Implications of learning effects for hospital costs of new health technologies: the case of intensity modulated radiation therapy. Int $J$ Technol Assess Health Care 2007; 23: 248-54.

29. Bonča PD and Tajnikar M. Using the business process model of a hospital to implement organisational and management changes to increase its business performance and efficiency. Conference Proceedings: International Conference of the Faculty of Economics Sarajevo (ICES) 2010: 1-11.

30. Boyer KK, Gardner JW and Schweikhart S. Process quality improvement: an examination of general vs. outcome-specific climate and practices in hospitals. Journal of Operations Management 2012; 30: 325-339.

31. Browder C, Eberth JM, Schooley B. and Porter NR. Mobile mammography: an evaluation of organizational, process, and information systems challenges. Healthc (Amst) 2015; 3: 49-55.

32. Bryan B. Keep 'Em Moving. Health Facilities Management 2009; 22: 35-37.

33. Bullard, MJ et al. Tracking emergency department overcrowding in a tertiary care academic institution. Healthc Q 2009; 12(3): 99-106.

34. Buttigieg SC, Dey PK and Cassar MR. Combined quality function deployment and logical framework analysis to improve quality of emergency care in Malta. Int $J$ Health Care Qual Assur 2016; 29: 123-40. 
35. Cagliano AC, Rafele C, Singh M. Improving hospital supply chains by managing risk flows. 16th International Annual EurOMA Conference, Göteborg (Sweden) 2009.

36. Cankovic M, Varney RC, Whiteley L, Brown, R, D'angelo R, Chitale D and Zarbo RJ. The Henry Ford production system: LEAN process redesign improves service in the molecular diagnostic laboratory: a paper from the 2008 William Beaumont hospital symposium on molecular pathology. J Mol Diagn 2009; 11, 390-9.

37. Cesta T. Case management insider. Managing length of stay using patient flow - Part 4. Hosp Case Manag 2013; 21: 79-82.

38. Chan CK. Applying Lean Management to Improve the Pre-Consultation Patient Journey in Outpatient Services: a Hong Kong case study. Asia Pacific Journal of Health Management 2012; 7(1): 28-33.

39. Chand S, Moskowitz H, Norris JB, Shade S and Willis DR. Improving patient flow at an outpatient clinic: study of sources of variability and improvement factors. Health Care Management Science 2009; 12: 325-340.

40. Chandra $\mathrm{H}$ et al. Supply chain management with cost-containment \& financial-sustainability in a tertiary care hospital. $J$ Health Hum Serv Adm 2013; 36(1): 3-23.

41. Chemweno P, Brackenier L, Thijs V, Pintelon L, Van Horenbeek A and Michiels D. Optimising the complete care pathway for cerebrovascular accident patients. Computers and Industrial Engineering 2016; 93: 236-251.

42. Chiodo A et al. Using Lean principles to manage throughput on an inpatient rehabilitation unit. Am J Phys Med Rehabil 2012; 91(11): 977-83.

43. Choi YL, Sun JM, Cho J, Rampal S, Han J, Parasuraman B, Guallar E, Lee G, Lee J and Shim YM. EGFR mutation testing in patients with advanced non-small cell lung cancer: a comprehensive evaluation of real-world practice in an East Asian tertiary hospital. PLoS One 2013; 8: e56011.

44. Claeys MJ, Sinnaeve PR, Convens C, Dubois P, Boland J, Vranckx P, Gevaert S, Coussement P, Beauloye C, Renard M, Vrints C and Evrard P. Inter-hospital variation in length of hospital stay after ST-elevation myocardial infarction: results from the Belgian STEMI registry. Acta Cardiol 2013; 68: 235-9.

45. Conway JB. Practitioner Application - Managing Variation in Demand: Lessons from the UK National Health Service. Journal of healthcare management 2006; 51: 309.

46. Cook G, Depares J, Singh M and McElduff P. Readmission after hysterectomy and prophylactic low molecular weight heparin: retrospective case-control study. BMJ: British Medical Journal 2006; 332: 819-820.

47. Coustasse A, Tomblin S. and Slack C. Impact of radio-frequency identification (RFID) technologies on the hospital supply chain: a literature review. Perspect Health Inf Manag 2013; 10: $1 \mathrm{~d}$.

48. Criily JL, Boyle J, Jessup M, Wallis M, Lind J, Green D and Fitzgerald G. The Implementation and evaluation of the patient admission prediction tool: assessing its impact on decisionmaking strategies and patient flow outcomes in 2 Australian hospitals. Quality Management in Health Care 2015; 24: 169-176.

49. De Andrade L et al. System dynamics modeling in the evaluation of delays of care in ST-segment elevation myocardial infarction patients within a tiered health system. PLoS One 2014; 9(7): e103577. 
50. De Regge M, Gemmel P, Hommez G, Trybou J, Duyck P and Claerhout I. Improving care processes through optimized design of the operating system. Academy of Management Annual Meeting Proceedings, 2015; 1-1.

51. Delisle DR, Jaffe K and Jefferson T. Let It Flow. Six Sigma Forum 2015; 14(2): 10-15.

52. Devapriya $P$ et al. StratBAM: a discrete-event simulation model to support strategic hospital bed capacity decisions. J Med Syst 2015; 39(10): 130.

53. Devaraj S, Ow TT and Kohli R. Examining the impact of information technology and patient flow on healthcare performance: A Theory of Swift and Even Flow (TSEF) perspective. Journal of Operations Management, 2013; 1: 181-192.

54. Dhiliwal SR and Salins N. Smartphone applications in palliative homecare. Indian $J$ Palliat Care 2015; 21(1): 88-91.

55. Dhingra VK, Saini S and Basu S. How a tertiary medical nuclear medicine department at the Himalayan area in India can be established and function in an exemplary manner. Basic rules revisited. Hell J Nucl Med 2015; 18: 252-6.

56. Dobson G, Hsiao-Hui L, Sainathan A and Tilson V. A Queueing Model to Evaluate the Impact of Patient "Batching" on Throughput and Flow Time in a Medical Teaching Facility. Manufacturing and Service Operations Management 2012; 14: 584-599.

57. Dogan K, Kraaij L, Aarts EO, Koehestanie P, Hammink E, Van Laarhoven CJ, Aufenacker TJ, Janssen IM and Berends FJ. Fast-track bariatric surgery improves perioperative care and logistics compared to conventional care. Obes Surg 2015; 25: 28-35.

58. Doorgakant A and Mkandawire NC. The management of isolated closed femoral shaft fractures in a district hospital in Malawi. Trop Doct 2012; 42: 8-12.

59. Drake RG. The nurse rostering problem: from operational research to organizational reality? $J$ Adv Nurs 2014; 70: 800-10.

60. Drupsteen J, Van Der Vaart T and Van Donk DP. Integrative practices in hospitals and their impact on patient flow. International Journal of Operations and Production Management 2013; 33: 912-933.

61. Duan Q and Liao TW. Optimization of blood supply chain with shortened shelf lives and ABO compatibility. International Journal of Production Economics 2014; 153: 113-129.

62. Duncan E, Best C and Hagen S. Shared decision making interventions for people with mental health conditions. Cochrane Database Syst Rev 2010; 1: Cdoo7297.

63. Durvasula R, Kayihan A, Del Bene S, Granich M, Parker G, Anawalt BD and Staiger T. A multidisciplinary care pathway significantly increases the number of early morning discharges in a large academic medical center. Qual Manag Health Care 2015; 24: 45-51.

64. Eagle AMY. Minutes count. Health Facilities Management 2015; 28: 16-21.

65. Edward GM, Razzaq S, De Roode A, Boer F, Hollmann MW, Dzoljic M and Lemaire LC. Patient flow in the preoperative assessment clinic. Eur J Anaesthesiol 2008; 25: 280-6.

66. Ekeskär A and Rudberg M. Third-party logistics in construction: the case of a large hospital project. Construction Management \& Economics 2016; 34(3): 174-191.

67. Elkhuizen SG, Van Sambeek JR, Hans EW, Krabbendam KJ and Bakker PJ. Applying the variety reduction principle to management of ancillary services. Health Care Manage Rev 2007; 32: 37-45.

68. Elshove-Bolk J, Ellensen VS and Baatrup G. Logistics and outcome in urgent and emergency colorectal surgery. Colorectal Dis 2010; 12: e255-9. 
69. Enyinda CI, Gebremikael F and Ogbuehi AO. An Analytical Model for Healthcare Supply Chain Risk Management. African Journal of Business and Economic Research 2014; 9: 13-27.

70. Epley EE, Stewart RM, Love P, Jenkins D, Siegworth GM, Baskin TW, Flaherty S and Cocke R. A regional medical operations center improves disaster response and inter-hospital trauma transfers. Am J Surg 2006; 192: 853-9.

71. Fedeli LG, Vidigal PG, Leite CM, Castilhos CD, Pimentel RA, Maniero VC, Mill JG, Lotufo PA, Pereira AC and Bensenor IM. Logistics of collection and transportation of biological samples and the organization of the central laboratory in the ELSA-Brasil] Rev Saude Publica 2013; 47: Suppl 2 63-71.

72. Feibert DC and Jacobsen P. Measuring Process Performance Within Healthcare Logistics - A Decision Tool For Selecting Track and Trace Technologies. Academy of Strategic Management Journal 2015; 14: 33-57.

73. Fogarty E, Saunders $\mathrm{J}$ and Cummins F. The effect of boarders on emergency department process flow. $J$ Emerg Med 2014; 46: 706-10.

74. Foglia RP, Alder AC and Ruiz G. Improving perioperative performance: the use of operations management and the electronic health record. $J$ Pediatr Surg 2013; 48: 95-8.

75. Fontaine MJ, Chung YT, Rogers WM, Sussmann HD, Quach P, Galel SA, Goodnough L T and Erhun F. Improving platelet supply chains through collaborations between blood centers and transfusion services. Transfusion 2009; 49: 2040-7.

76. Francis E, Gayathri S, Vaidyanathan B, Kannan BR and Kumar RK. Emergency balloon dilation or stenting of critical coarctation of aorta in newborns and infants: An effective interim palliation Ann Pediatr Cardiol 2009; 2: 111-5.

77. Fung Kon Jin PH, Dijkgraaf MG, Alons CL, Van Kuijk C, Beenen LF, Koole GM and Goslings JC. Improving CT scan capabilities with a new trauma workflow concept: simulation of hospital logistics using different CT scanner scenarios. Eur J Radiol 2011; 80: 504-9.

78. Gadzama GB, Bawa SB, Ajinoma Z, Saidu MM and Umar AS. Injection safety practices in a main referral hospital in Northeastern Nigeria. Niger J Clin Pract 2014; 17: 134-9.

79. Galletly C, Bell S, Burton C and Turnbull C. Bed accessibility in a private psychiatric hospital. Australas Psychiatry 2011; 19: 160-2.

80. Garcia Collado C, Madrid Paredes A, Jimenez Morales A and Calleja Hernandez MA.. Improvement of the outpatient clinics after the implementation of an automated robot for delivery. Farm Hosp 2012; 36: 525-30.

81. Garg L, Mcclean S I, Barton M, Meenan B J and Fullerton K. Intelligent Patient Management and Resource Planning for Complex Heterogeneous, and Stochastic Healthcare Systems. IEEE Transactions on Systems Man and Cybernetics: Part A 2012; 42: 1332-1345.

82. Ghosh M and Sobek Ii DK. A problem-solving routine for improving hospital operations. $J$ Health Organ Manag 2015; 29: 252-70.

83. Giles K, Harris J and Parker L. Improving Margins Through a Patient Access Initiative. Health Care Registration: The Newsletter for Health Care Registration Professionals 2010; 20: 8-11.

84. Gilfillan C, Newnham E, Nagappan R, Evans J and Compton, J. A 7-day team-based model of care in general medicine: implementation and outcomes at 12 months. Intern Med $J$ 2016; 46: $79-85$. 
85. Gonzalez-Castro A, Ortiz-Melon F, Suberviola B, Holanda MS, Dominguez MJ, Blanco-Huelga C and Munoz C. Impact of a new model of intensive care medicine upon healthcare in a department of intensive care medicine. Med Intensiva 2013; 37: 27-32.

86. Gospodarevskaya E and Churilov L. Process performance indicators in redesigning the patient care process. Business Process Management Journal 2011; 17: 1012-1038.

87. Graham J Aitken ME and Shirm S. Correlation of measures of patient acuity with measures of crowding in a pediatric emergency department. Pediatr Emerg Care 2011; 27: 706-9

88. Granlund A and Wiktorsson M. Automation In Healthcare Internal Logistics: A Case Study On Practice and Potential. International Journal of Innovation and Technology Management 2013; 10 (3): 1-20.

89. Grouse AI et al. A stream for complex, ambulant patients reduces crowding in an emergency department. Emerg Med Australas 2014; 26(2): 164-9.

90. Guedon AC et al. Where are my instruments? Hazards in delivery of surgical instruments. Surg Endosc 2016; 30(7): 2728-35.

91. Guerriero F and Guido R. Operational research in the management of the operating theatre: a survey. Health Care Manag Sci 2011; 14: 89-114.

92. Gunpinar S and Centeno G . Stochastic integer programming models for reducing wastages and shortages of blood products at hospitals. Computers \& Operations Research 2015; 54: 129-141.

93. Hadji B, Meyer R, Melikeche S, Escalon S and Degoulet, P 2014. Assessing the relationships between hospital resources and activities: a systematic review. J Med Syst 38127.

94. Hall R, Belson D, Murali P and Dessouky M. Modeling Patient Flows Through the Healthcare System. In: HALL R. W. (ed.) Patient Flow: Reducing Delay in Healthcare Delivery 2006; Boston MA: Springer US.

95. Hanne T, Melo T and Nickel S. Bringing Robustness to Patient Flow Management through Optimized Patient Transports in Hospitals. Interfaces 2009; 39: 241-255.

96. Harnett MJ, Correll DJ, Hurwitz S, Bader AM and Hepner DL. Improving efficiency and patient satisfaction in a tertiary teaching hospital preoperative clinic. Anesthesiology 2010; 112: 66-72.

97. Haxton $J$ and Fahy K. Reducing Length Of Stay For women who present as outpatients to delivery suite: A clinical practice improvement project. Women Birth 2009; 22: 119-27.

98. Heijnen RW, Evers SM, Van Der Weijden TD, Limburg M and Schols JM. The cost effectiveness of an early transition from hospital to nursing home for stroke patients: design of a comparative study. BMC Public Health 2010; 10: 279.

99. Hendrich A, Chow MP, Skierczynski BA and Lu Z. A 36-Hospital Time and Motion Study: How Do Medical-Surgical Nurses Spend Their Time? The Permanente Journal 2008; 12: 25-34.

100. Henriksen $\mathrm{K}$ et al. The role of the physical environment in crossing the quality chasm Jt Comm $J$ Qual Patient Saf 2007; 33(11 Suppl): 68-80.

101. Heydari A, Najar AV and Bakhshi M 2015. Resource Management Among Intensive Care Nurses: An Ethnographic Study. Mater Sociomed 2008; 27: 390-4.

102. Hintzen BL, Knoer SJ, Van Dyke CJ and Milavitz BS. Effect of lean process improvement techniques on a university hospital inpatient pharmacy. Am $J$ Health Syst Pharm 2009; 66: 2042-7.

103. Hjollund NH et al. Use of Patient-Reported Outcome (PRO) Measures at Group and Patient Levels: Experiences From the Generic Integrated PRO System WestChronic. Interact $J$ Med Res 2014; 3(1): e5. 
104. Holtby MA. Know how it works before you fix it: a data analysis strategy from an inpatient nephrology patient-flow improvement project. Cannt j 2007; 17: 30-6.

105. Holzhacker MR, Krishnan and Mahlendorf MD Unraveling the Black Box of Cost Behavior: An Empirical Investigation of Risk Drivers, Managerial Resource Procurement, and Cost Elasticity. Accounting Review 2015; 90(6): 2305-2335.

106. Homeming LJ, Kuipers $P$ and Nihal A. Orthopaedic podiatry triage: process outcomes of a skill mix initiative. Aust Health Rev 2012; 36: 457-60.

107. Howell E, Bessman E, Kravet S, Kolodner K, Marshall R and Wright S. Active bed management by hospitalists and emergency department throughput. Ann Intern Med 2008; 149: 804-11.

108. Hsiao CY, Hsu CP, Chen WY, Wu FY, Chen IM, Lai ST and Shih, CC. Early outcome of endovascular repair for contained ruptured abdominal aortic aneurysm. J Chin Med Assoc 2011; 74: 105-9.

109. Hung GR, Whitehouse SR, O'Neill C, Gray AP and Kissoon N. Computer modeling of patient flow in a pediatric emergency department using discrete event simulation. Pediatr Emerg Care 2007; 23: 5-10.

110. Hussain M and Malik M. Prioritizing lean management practices in public and private hospitals. $J$ Health Organ Manag 2016; 30: 457-74.

111. Jaideep G, Simulation Model For Emergency Department. Proceedings of the International May Conference on Strategic Management 2015; 18-32.

112. Jenkins J. Eliminating common PACU delays. $J$ Healthe Inf Manag, 2007; 21: 53-8.

113. Jenkins J and Gisler P. Let my patients flow. Industrial Engineer: IE 2012; 44: 39-44.

114. Jensen $\mathrm{K}$ and Crane J. Improving patient flow in the emergency department. Healthcare Financial Management 2008; 62: 104-108.

115. Jin S Jeong S, Kim J and Kim K. A logistics model for the transport of disaster victims with various injuries and survival probabilities. Annals of Operations Research 2015; 230: 17-33.

116. Johnson M and Capasso V. Improving Patient Flow Through a Better Discharge Process. Journal of Healthcare Management 2012; 57: 89-93.

117. Johnson RL. Practitioner Application. Journal of Healthcare Management 2011; 56: 267-268.

118. Jorgensen P, Jacobsen $P$ and Poulsen JH. Identifying the potential of changes to blood sample logistics using simulation. Scand J Clin Lab Invest 2013; 73: 279-85.

119. Juwana YB, Wirianta J, Ottervanger JP, Dambrink JH, Van 't Hof AW, Gosselink AT, Hoorntje J, De Boer MJ and Suryapranata H. Primary coronary intervention for ST-elevation myocardial infarction in Indonesia and the Netherlands: a comparison. Neth Heart $J$ 2009; 17: 418-21.

120. Jweinat $J$ et al. The safe patient flow initiative: a collaborative quality improvement journey at Yale-New Haven Hospital. Jt Comm J Qual Patient Saf 2013; 39(10): 447-59.

121. Katsaliaki K. Cost-effective practices in the blood service sector. Health Policy 2008; 86: 276287.

122. Kaushal NK et al. Using efficiency analysis and targeted intervention to improve operational performance and achieve cost savings in the endoscopy center. Gastrointest Endosc 2014; 79(4): 637-45.

123. Khanna S, Boyle J, Good N and Lind J. New emergency department quality measure: from access block to National Emergency Access Target compliance. Emerg Med Australas 2013; 25: $565-72$. 
124. Khubulava GG et al. Results Of Application Of The Method Of Sternal Infection Elimination In Cardiosurgical Patients. Vestn Khir Im I I Grek 2015; 174(5): 57-60.

125. King DL, Ben-Tovim DI and Bassham J. Redesigning emergency department patient flows: application of Lean Thinking to health care. Emerg Med Australas 2006; 18: 391-7.

126. Kitsiou S, Matopoulos A, Manthou V and Vlachopoulou M. Evaluation of integration technology approaches in the healthcare supply chain. International Journal of Value Chain Management 2007; 1: 325-343.

127. Klundert J, Muls $\mathrm{P}$ and Schadd M. Optimizing sterilization logistics in hospitals. Health Care Management Science 2008; 11: 23-33.

128. Knight HE, Self A and Kennedy SH. Why are women dying when they reach hospital on time? A systematic review of the 'third delay'. PLoS One 2013. 8(5): e63846.

129. Kolker A. Process modeling of emergency department patient flow: effect of patient length of stay on ED diversion. $J$ Med Syst 2008; 32: 389-401.

130. Konstantinos D, Abdul R and Panayiotis HK. The applicability of a multi-attribute classification framework in the healthcare industry. Journal of Manufacturing Technology Management 2006; 17: 772-785.

131. Korsten P, Sliwa B, Kuhn M, Muller GA and Blaschke S. Impact of professional quality management on interdisciplinary emergency care units. Eur J Emerg Med 2014; 21: 98-104.

132. Kosar S, Seelen HA, Hemmen B, Evers SM and Brink PR. Cost-effectiveness of an integrated 'fast track' rehabilitation service for multi-trauma patients involving dedicated early rehabilitation intervention programs: design of a prospective, multi-centre, non-randomised clinical trial. $J$ Trauma Manag Outcomes 2009; 3: 1.

133. Krall S, O'Connor RE and Maercks L. Higher inpatient medical surgical bed occupancy extends admitted patients' stay. West J Emerg Med 2009; 10: 93-6.

134. Kriegel J, Jehle F, Dieck M and Tuttle-Weidinger L. Optimizing patient flow in Austrian hospitals - Improvement of patient-centered care by coordinating hospital-wide patient trails. International Journal of Healthcare Management 2015; 8: 89-99.

135. Kumar S. Modeling patient flow operation of a US urban county hospital. Technol Health Care 2011; 19: 247-60.

136. Kumar S, Livermont G and McKewan G. Stage implementation of RFID in hospitals. Technol Health Care 2010; 18(1): 31-46.

137. Kuper M, Gold SJ, Callow C, Quraishi T, King S, Mulreany A, Bianchi M and Conway DH. Quality Improvement Report: Intraoperative fluid management guided by oesophageal Doppler monitoring. BMJ: British Medical Journal 2011; 342: 1256-1260.

138. Lai $\mathrm{R}$ et al. Risk factors for anastomotic leakage following anterior resection for colorectal cancer: the effect of epidural analgesia on occurrence. Int J Colorectal Dis 2013; 28(4): 485-92.

139. Lapierre SD and Ruiz AB. Scheduling logistic activities to improve hospital supply systems. Computers \& Operations Research 2007; 34(3): 624-641.

140. Larsson I and Kart T. Evaluation of sources to document extended shelf lives of compounded cytostatics. J Oncol Pharm Pract 2013; 19: 355-64.

141. Law KMY. How schedule issues affect drug logistics operations: an empirical study in hospitals in China. Industrial Management and Data Systems 2016; 116: 369-387. 
142. Leaver CA, Guttmann A, Zwarenstein M, Rowe BH, Anderson G, Stukel T, Golden B, Bell R, Morra D, Abrams H and Schull MJ. Development of a minimization instrument for allocation of a hospital-level performance improvement intervention to reduce waiting times in Ontario emergency departments. Implement Sci 2009; 4: 32.

143. Lee EK et al. Transforming Hospital Emergency Department Workflow and Patient Care. Interfaces 2015; 45(1): 58-82.

144. Lega F, Marsilio M and Villa S. An evaluation framework for measuring supply chain performance in the public healthcare sector: evidence from the Italian NHS. Production Planning and Control 2013; 24: 931-947.

145. Lemos P, Pinto A, Morais G, Pereira J, Loureiro R, Teixeira S and Nunes CS. Patient satisfaction following day surgery. $J$ Clin Anesth 2009; 21: 200-5.

146. Lesselroth BJ, Adams K, Tallett S, Wood SD, Keeling A, Cheng K, Church VL, Felder R and Tran H. Design of admission medication reconciliation technology: a human factors approach to requirements and prototyping. Herd 2013; 6: 30-48.

147. Ley-Chavez A et al. Layout Improvement Study to Reduce Staff Walking Distance in a Large Health Care Facility: How to Not Walk an Extra 4740 Miles. Qual Manag Health Care 2016; 25(3): 134-40.

148. Liao HC, Chen YK, Chang HH. The APP strategies selected in SCM of the hospital. International Journal of Services Technology and Management 2014; 15: 298.

149. Liao H-C and H-H Chang. The optimal approach for parameter settings based on adjustable contracting capacity for the hospital supply chain logistics system. Expert Systems with Applications 2011; 38(5): 4790-4797.

150. Liao HC, Chen YK and Wang YH. The Study of an Optimal Robust Design and Adjustable Ordering Strategies in the HSCM. Comput Math Methods Med 2015; 517245.

151. Lillrank P, Groop J and Venesmaa J. Processes, episodes and events in health service supply chains. Supply Chain Management: An International Journal 2011; 16: 194-201.

152. Lin F, Chaboyer W, Wallis M and Miller A. Factors contributing to the process of intensive care patient discharge: an ethnographic study informed by activity theory. Int $J$ Nurs Stud 2013; 50: 1054-66.

153. Lin R-H and Ho P-Y. The study of CPFR implementation model in medical SCM of Taiwan. Production Planning \& Control 2014; 25(3): 260-271.

154. Lindholm C Sterner E, Romanelli M, Pina E, Torra Y Bou J, Hietanen H, Iivanainen A, Gunningberg L, Hommel A, Klang B and Dealey C. Hip fracture and pressure ulcers - the PanEuropean Pressure Ulcer Study - intrinsic and extrinsic risk factors. Int Wound $J$ 2008; 5: 31528.

155. Litvak E and Bisognano M. More Patients, Less Payment: Increasing Hospital Efficiency In The Aftermath Of Health Reform. Health Affairs 2011; 30: 76-80.

156. Litvak N, Van Rijsbergen M, Boucherie RJ and Van Houdenhoven M. Managing the overflow of intensive care patients. European Journal of Operational Research 2008; 185: 998-1010.

157. Liu H, Park D, Hwang SM, Lee GY, Lim OK, Kim M, Lee DH, Park W, Koo HW, Yang K and Suh DC. Outpatient Day-care Neuroangiography and Neurointervention of Unruptured Intracranial Aneurysms. Neurointervention 2016; 11: 37-41. 
158. Love RA, Murphy JA, Lietz TE and Jordan KS. The effectiveness of a provider in triage in the emergency department: a quality improvement initiative to improve patient flow. Adv Emerg Nurs $J$ 2012; 34: 65-74.

159. Lowthian J, Curtis A, Straney L, McKimm A, Keogh M and Stripp A. Redesigning emergency patient flow with timely quality care at the Alfred. Emerg Med Australas 2015; 27: 35-41.

160. Luedi MM, Kauf P, Mulks L, Wieferich K, Schiffer R and Doll D. Implications of Patient Age and ASA Physical Status for Operating Room Management Decisions. Anesth Analg 2016; 122: 1169-77.

161. Lyons M, Brown R and Wears R. Factors that affect the flow of patients through triage. Emerg Med $J$ 2007; 24: 78-85.

162. Madsen C, Lough D, Lim A, Harshbarger RJ, 3rd and Kumar AR. Cleft and Craniofacial Care During Military Pediatric Plastic Surgery Humanitarian Missions. J Craniofac Surg 2015; 26: 1097-101.

163. Maina-Gathigi L et al. Utilization of folic acid and iron supplementation services by pregnant women attending an antenatal clinic at a regional referral hospital in Kenya. Matern Child Health $J$ 2013; 17(7): 1236-42.

164. Maloney CG et al. A tool for improving patient discharge process and hospital communication practices: the "Patient Tracker". AMIA Annu Symp Proc 2007: 493-7.

165. Manojlovich $\mathrm{M}$ et al. Using A3 thinking to improve the STAT medication process. $J$ Hosp Med 2014; 9(8): 540-4.

166. Mantecchini L et al. Transportation of Organs by Air: Safety, Quality, and Sustainability Criteria. Transplant Proc 2016; 48(2): 304-8

167. Matta ME and Patterson S. Evaluating multiple performance measures across several dimensions at a multi-facility outpatient center. Health Care Management Science 2007; 10: 173-194.

168. Mattoo AM, Zia-Ur-Rehman M and Rashid M. Hospital Management Information System: An Approach to Improve Quality and Clinical Practices in Pakistan. International Journal of Management and Innovation 2013; 5: 11-23.

169. May EL. Reaching Excellence in Healthcare. Healthcare Executive 2011; 26: 38-46.

170. Mazur L and Chen S-J. Understanding and reducing the medication delivery waste via systems mapping and analysis. Health Care Management Science 2008; 11(1): 55-65.

171. Mazzocato P, Holden RJ, Brommels M, Aronsson H, Backman U, Elg M and Thor J. How does lean work in emergency care? A case study of a lean-inspired intervention at the Astrid Lindgren Children's hospital Stockholm Sweden. BMC Health Serv Res 2012; 12: 28.

172. McCaughey D, Erwin CO and Dellifraine JL. Improving Capacity Management in the Emergency Department: A Review of the Literature 2000-2012. J Healthc Manag 2015; 60: 6375 .

173. McDermott AM, Kidd P, Gately M, Casey R, Burke H, O'Donnell P, Kirrane F, Dinneen SF and O'Brien T. Restructuring of the Diabetes Day Centre: a pilot lean project in a tertiary referral centre in the West of Ireland. BMJ Qual Saf 2013; 22: 681-8.

174. McDermott C and Stock GN. Hospital operations and length of stay performance. International Journal of Operations and Production Management 2007; 27: 1020-1042.

175. McDowell AL and Huang YL. Selecting a pharmacy layout design using a weighted scoring system. Am J Health Syst Pharm 2012; 69(9): 796-804. 
176. McHugh M, Van Dyke KJ, Howell E, Adams F, Moss D and Yonek J. Changes in patient flow among five hospitals participating in a learning collaborative. $J$ Healthc Qual 2013; 35: 21-9.

177. Meguerditchian AN, Krotneva S, Reidel K, Huang A and Tamblyn R. Medication reconciliation at admission and discharge: a time and motion study. BMC Health Serv Res 2013; 13: 485.

178. Merisalo LJ. ED Excellence Begins at the Front Door. Health Care Registration: The Newsletter for Health Care Registration Professionals 2011; 20: 1-12.

179. Morris MK and Carter KF. A Blended Transfer and Communications Center: Designing a Stateof-the-Art Mission Control. Nurs Adm Q 2015; 39: 357-61.

180. Muntlin Athlin A, Von Thiele Schwarz U and Farrohknia N. Effects of multidisciplinary teamwork on lead times and patient flow in the emergency department: a longitudinal interventional cohort study. Scand J Trauma Resusc Emerg Med 2013; 21: 76.

181. Naesens K and Gelders L. Reorganising a service department: Central Patient Transportation. Production Planning and Control 2009; 20: 478-483.

182. Navarro Suay R, Bartolome Cela E, Jara Zozaya I, Hernandez Abadia De Barbara A, Gutierrez Ortega C, Garcia Labajo JD, Planas Roca A and Gilsanz Rodriguez F. Even more critical medicine: a retrospective analysis of casualties admitted to the intensive care unit in the Spanish Military Hospital in Herat (Afghanistan). Med Intensiva 2011; 35: 157-65.

183. New PW, Andrianopoulos N, Cameron PA, Olver JH and Stoelwinder JU. Reducing the length of stay for acute hospital patients needing admission into inpatient rehabilitation: a multicentre study of process barriers. Intern Med $J$ 2013a; 43: 1005-11.

184. New PW, Cameron PA, Olver JH and Stoelwinder JU. Defining barriers to discharge from inpatient rehabilitation classifying their causes and proposed performance indicators for rehabilitation patient flow. Arch Phys Med Rehabil 2013b; 94: 201-8.

185. Ng D, Vail G, Thomas S and Schmidt N. Applying the Lean principles of the Toyota Production System to reduce wait times in the emergency department. Cjem 2010; 12: 50-7.

186. Nickel S and Schmidt U-A. Process Improvement in Hospitals: A Case Study in a Radiology Department. Quality Management In Health Care 2009a; 18: 326-338.

187. Nyaga GN, Young GJ and Zepeda ED. An Analysis of the Effects of Intra- and Interorganizational Arrangements on Hospital Supply Chain Efficiency. Journal of Business Logistics 2015; 36(4): 340-354.

188. Olivares MC, Terwiesch C and Cassorla L. Structural Estimation of the Newsvendor Model: An Application to Reserving Operating Room Time. Management Science 2008; 54(1): 41-55.

189. O'Reilly O, Cianci F, Casey A, Croke E, Conroy C, Keown AM, Leane G, Kearns B, O'Neill S and Courtney G. National Acute Medicine Programme - improving the care of all medical patients in Ireland. $J$ Hosp Med 2015; 10: 794-8.

190. Orellana Garcia A, Perez Alfonso D and Larrea Armenteros OU. Analysis of Hospital Processes with Process Mining Techniques. Stud Health Technol Inform 2015; 216 310-4.

191. Ozer R and Richards G. Optimizing Surgical Capacity for a Rural Hospital Through Monte Carlo Simulation. J Healthc Qual 2015.

192. Özkil AG et al. Service Robots for Hospitals: A Case Study of Transportation Tasks in a Hospital. IEEE 2009.

193. Pamaby J and Towill DR. Engineering cellular organisation and operation for effective healthcare delivery supply chains. International Journal of Logistics Management 2009; 20: 529. 
194. Pan ZX and Pokharel S. Logistics in hospitals: a case study of some Singapore hospitals. Leadersh Health Serv (Bradf Engl) 2007; 20: 195-207.

195. Parks JK, Engblom P, Hamrock E, Satjapot S and Levin S. Designed to fail: how computer simulation can detect fundamental flaws in clinic flow. $J$ Healthc Manag 2011; 56: 135-44, discussion 145-6.

196. Pate DC and Puffe M. Improving Patient Flow. Physician Executive 2007; 33: 32-36.

197. Perez CR. Emergency response to earthquake in Chile: experience of a Cuban field hospital. MEDICC Rev 2015; 17: 39-42.

198. Perimal-Lewis L, Hakendorf $\mathrm{PH}$ and Thompson $\mathrm{CH}$. Characteristics favouring a delayed disposition decision in the emergency department. Intern Med $J$ 2015; 45: 155-9.

199. Pham D-N and Klinkert A. Surgical case scheduling as a generalized job shop scheduling problem. European Journal of Operational Research 2008; 185(3): 1011-1025.

200. Pines JM and Bernstein SL. Solving the worldwide emergency department crowding problem what can we learn from an Israeli ED? Isr J Health Policy Res 2015; 4: 52.

201. Polonski L et al. What has changed in the treatment of ST-segment elevation myocardial infarction in Poland in 2003-2009? Data from the Polish Registry of Acute Coronary Syndromes (PL-ACS). Kardiol Pol 2011; 69(11): 1109-18

202. Potter S Govindarajulu S, Shere M, Braddon F, Curran G, Greenwood R, Sahu AK Cawthorn SJ. Referral patterns cancer diagnoses, and waiting times after introduction of two week wait rule for breast cancer: prospective cohort study $B M J$ 2007; 335: 288

203. Popovich MA, Boyd C, Dachenhaus T and Kusler D. Improving stable patient flow through the emergency department by utilizing evidence-based practice: one hospital's journey. $J$ Emerg Nurs 2012; 38: 474-8.

204. Preyde M, Crawford K and Mullins L. Patients' satisfaction and wait times at Guelph General Hospital Emergency Department before and after implementation of a process improvement project. Cjem 2012; 14: 157-68.

205. Proczko M, Kaska, L, Twardowski P and Stepaniak P. Implementing enhanced recovery after bariatric surgery protocol: a retrospective study. $J$ Anesth 2016; 30 170-3.

206. Quinn GR, Le E, Soni K, Berger G, Mak YE and Pierce R. "Not so fast!" the complexity of attempting to decrease door-to-floor time for emergency department admissions. Jt Comm $J$ Qual Patient Saf 2014; 40 30-8.

207. Quintana JM, Gonzalez N, Bilbao A, Aizpuru F, Escobar A, Esteban C, San-Sebastian JA, De-LaSierra E and Thompson A. Predictors of patient satisfaction with hospital health care. BMC Health Serv Res 2006; 6: 102.

208. Raaber N, Duvald I, Riddervold I, Christensen EF and Kirkegaard H. Geographic information system data from ambulances applied in the emergency department: effects on patient reception. Scand J Trauma Resusc Emerg Med 2016; 24: 39.

209. Raemer DB. Ignaz Semmelweis redux? Simul Healthc 2014; 9 153-5.

210. Rahimi B, Mizrahi R and Magnezi R. The challenges and opportunities of implementing outsourcing in private and public hospitals in Israel. Harefuah 2011; 150: 56-60 66.

211. Rasheed F, Lee Y H, Kim SH and Park IC. Development of emergency department load relief area--gauging benefits in empirical terms. Simul Healthc 2012; 7: 343-52.

212. Ravichandran N, Ahmad S. Carrying the carry with best practices: Delhi State Cancer Institute International Journal of Healthcare Management 2014; 7: 5-13. 
213. Ravikumar TS et al. A validated value-based model to improve hospital-wide perioperative outcomes: adaptability to combined medical/surgical inpatient cohorts. Ann Surg 2010; 252(3): 486-96; discussion 496-8.

214. Reynolds SL, Crulcich MM, Sullivan G and Stewart MT. Developing a practical algorithm for a pediatric emergency department's response to radiological dispersal device events. Pediatr Emerg Care 2013; 29: 814-21.

215. Rice AN, Muckler VC, Miller WR and Vacchiano CA. Fast-tracking ambulatory surgery patients following anesthesia. $J$ Perianesth Nurs 2015; 30: 124-33.

216. Robbert $M$ et al. Time intervals from aneurysmal subarachnoid hemorrhage to treatment and factors contributing to delay. $J$ Neurol 2014; 261(3): 473-9.

217. Robinson JC and Brown TT. Quantifying opportunities for hospital cost control: medical device purchasing and patient discharge planning. Am J Manag Care 2014; 20: e418-24.

218. Romero H, Dellaert N, Geer S, Frunt M, Jansen-Vullers M and Krekels G.. Admission and capacity planning for the implementation of one-stop-shop in skin cancer treatment using simulation-based optimization. Health Care Management Science 2013a; 16: 75-86.

219. Rutledge J, Xu M and Simpson J. Application of the Toyota Production System improves core laboratory operations. Am J Clin Pathol 2010; 133: 24-31.

220. Ryckman FC, Yelton PA, Anneken M, Kiessling PE, Schoettker PJ and Kotagal UR. Redesigning intensive care unit flow using variability management to improve access and safety. Jt Comm $J$ Qual Patient Saf 2009; 35: 535-43.

221. Saad M, Karam B, Faddoul G, Douaihy YE, Yacoub H, Baydoun H, Boumitri C, Barakat I, Saifan C, El-Charabaty E and Sayegh SE. Is kidney function affecting the management of myocardial infarction? A retrospective cohort study in patients with normal kidney function, chronic kidney disease stage III-V, and ESRD. Int J Nephrol Renovasc Dis 2016; 9: 5-10.

222. Safdar KA, Emrouznejad A and Dey PK. Assessing the Queuing Process Using Data Envelopment Analysis: an Application in Health Centres. J Med Syst 2016; 40: 32.

223. Samaranayake P, Dadich A, Hayes KJ and Sloan T. Patient-journey modelling and simulation in computed tomography. Business Process Management Journal 2015; 21 988-1014.

224. Sanders E, Harten W and Lent W. Exploring improvements in patient logistics in Dutch hospitals with a survey. BMC Health Services Research 2012; 12.

225. Sayah A et al. Minimizing ED Waiting Times and Improving Patient Flow and Experience of Care. Emerg Med Int 2014; 981472.

226. Scott IA. Public hospital bed crisis: too few or too misused? Aust Health Rev 2010; 34: 317-24.

227. Seim AR, Andersen B, Berger DL, Sokal SM and Sandberg WS. The effect of direct-fromrecovery room discharge of laparoscopic cholecystectomy patients on recovery room workload. Surg Innov 2006; 13: 257-64.

228. Shah R, Goldstein SM, Unger BT and Henry TD. Explaining Anomalous High Performance in a Health Care Supply Chain. Decision Sciences 2008; 39: 759-789.

229. Sharma V et al. Simulation application for resource allocation in facility management processes in hospitals. Facilities 2007; 25(13/14): 493-506

230. Shi J, Erdem E, Peng Y, Woodbridge P and Masek C. Performance analysis and improvement of a typical telephone response system of VA hospitals. International Journal of Operations and Production Management 2015; 35: 1098-1124. 
231. Shim SJ and Kumar A. Computer Simulation for Re-engineering Medical Supply Distribution in Hospitals. Physician Executive 2013; 39: 46-51.

232. Siegel B, Wilson MJ and Sickler D. Enhancing work flow to reduce crowding. Jt Comm J Qual Patient Saf 2007; 33: 57-67.

233. Silber JH, Rosenbaum PR, Rosen AK, Romano PS, Itani KMF, Cen L, Mi L, Halenar MJ, EvenShoshan O and Kevin G. Prolonged Hospital Stay and the Resident Duty Hour Rules of 2003. Med Care 2009; 47(12): 1191-1200.

234. Singh Kc D and Terwiesch C. The Effects of Focus on Performance: Evidence from California Hospitals. Management Science 2011; 57: 1897-1912.

235. Sirvent JM, Gil M, Alvarez T, Martin S, Vila N, Colomer M, March E, Loma-Osorio P and Metje $\mathrm{T}$. Lean techniques to improve the flow of critically ill patients in a health region with its epicenter in the intensive care unit of a reference hospital. Med Intensiva 2016; 40: 266-272.

236. Sobkowski M and Opala T. Practical aspects of change management at the Obstetrics and Gynecology Clinic at the University Hospital of Medical Sciences in Poznan, Poland. Ann Agric Environ Med 2014; 21: 314-9.

237. Southard PB, Chandra C and Kumar S. RFID in healthcare: a Six Sigma DMAIC and simulation case study. Int $J$ Health Care Qual Assur 2012; 25(4): 291-321.

238. Spreckelsen C, Schmidt R and Geisler S. Decision support for hospital bed management using adaptable individual length of stay estimations and shared resources. BMC Medical Informatics and Decision Making [Online] 2013; 13.

239. Stanger SHW et al. What drives perishable inventory management performance? Lessons learnt from the UK blood supply chain. Supply Chain Management 2012; 17(2): 107-123.

240. Su WL, Chen YH, Chen CW, Yang SH, Su CL, Perng WC, Wu CP and Chen JH. Involuntary cough strength and extubation outcomes for patients in an ICU. Chest 2010; 137: 777-82.

241. Swol J et al. Veno-venous extracorporeal membrane oxygenation in obese surgical patients with hypercapnic lung failure. Acta Anaesthesiol Scand 2014; 58(5): 534-8.

242. Takagi H, Kanai $\mathrm{Y}$ and Misue K. Queueing network model for obstetric patient flow in a hospital. Health Care Manag Sci 2016.

243. Terwiesch C, Diwas KC and Kahn JM. Working with capacity limitations: operations management in critical care. Crit Care 2011; 15(4): 308.

244. Thompson SM, Nunez M, Garfinkel R, Dean DD. OR Practice-Efficient Short-Term Allocation and Reallocation of Patients to Floors of a Hospital During Demand Surges. Operations Research 57 2009; 2: 261-73.

245. Thortveit E T, Boe M G, Ljostad U, Mygland A and Tveiten A. Organizational changes aiming to reduce iv tPA door-to-needle time. Acta Neurol Scand 2014; 130: 248-52.

246. Tomer G, Choi S, Montalvo A, Sutton S, Thompson J and Rivas Y. Improving the timeliness of procedures in a pediatric endoscopy suite. Pediatrics 2014; 133: e428-33.

247. Toustrup K, Lambertsen K, Birke-Sorensen H, Ulhoi B, Sorensen L and Grau C. Reduction in waiting time for diagnosis and treatment of head and neck cancer - a fast track study. Acta Oncol 2011; 50: 636-41.

248. Trebilcock B. Health care reform. Modern Materials Handling 2012; 67: 38-42.

249. Tschudi O and Schupfer G. OR-Management - Essentials. Anasthesiol Intensivmed Notfallmed Schmerzther 2014; 49: 610-5. 
250. Turegano-Fuentes F, Perez-Diaz D, Sanz-Sanchez M and Ortiz Alonso J. Overall Asessment of the Response to Terrorist Bombings in Trains Madrid 11 March 2004. Eur J Trauma Emerg Surg 2008; 34: 433.

251. Van Der Vaart, T, Vastag G and Wijngaard J. Facets of operational performance in an emergency room (ER). International Journal of Production Economics 2011; 133: 201-211.

252. Van Houdenhoven $M$ et al. Fewer intensive care unit refusals and a higher capacity utilization by using a cyclic surgical case schedule. $J$ Crit Care 2008; 23(2): 222-6.

253. Van Lent WA, De Beer RD and Van Harten WH. International benchmarking of specialty hospitals. A series of case studies on comprehensive cancer centres. BMC Health Serv Res 2010; 10: 253 .

254. Van Lent WA, Goedbloed N and Van Harten WH. Improving the efficiency of a chemotherapy day unit: applying a business approach to oncology. Eur J Cancer 2009; 45: 800-6.

255. Van Oostrum JM, Bredenhoff E and Hans EW. Suitability and managerial implications of a Master Surgical Scheduling approach. Annals of Operations Research 2010; 178(1): 91-104.

256. Van Raak A et al. Shifting stroke care from the hospital to the nursing home: explaining the outcomes of a Dutch case. $J$ Eval Clin Pract 2010; 16(6): 1203-8.

257. Vandborg M P, Edwards K, Kragstrup J, Vedsted P, Hansen DG and Mogensen O. A new method for analyzing diagnostic delay in gynecological cancer. Int $J$ Gynecol Cancer 2012; 22: 712-7.

258. Villa S, Barbieri M, and Lega F. Restructuring patient flow logistics around patient care needs: implications and practicalities from three critical cases. Health Care Manag Sci 2009; 12(2): $155-65$.

259. Villa S, Prenestini A and Giusepi I. A Framework To Analyze hospital-wide patient flow logistics: evidence from an Italian comparative study. Health Policy 2014; 115: 196-205.

260. Vos L, Groothuis S and Van Merode GG. Evaluating hospital design from an operations management perspective. Health Care Manag Sci 2007; 10: 357-64.

261. Wagner K. Patient throughput collaborative yields positive results for New Jersey hospitals. Healthcare Financial Management 2015; 69: 90-94.

262. Wang HQ, Zhou TS, Zhang YF, Chen L and Li, JS. Research and Development of Semanticsbased Sharable Clinical Pathway Systems. J Med Syst 2015; 39: 73.

263. Wang J, Li J and Howard P. A system model of work flow in the patient room of hospital emergency department. Health Care Management Science 2013; 16(4): 341-351.

264. Wang J, Li J, Tussey K and Ross K. Reducing Length of Stay in Emergency Department: A Simulation Study at a Community Hospital. IEEE Transactions on Systems Man and Cybernetics: Part A 2012; 42: 1314-1322.

265. Waring TS and Alexander M. Innovations in inpatient flow and bed management. International Journal of Operations and Production Management 2015; 35: 751-781.

266. Warner CJ, Walsh DB, Horvath AJ, Walsh TR, Herrick DP, Prentiss SJ and Powell RJ. Lean principles optimize on-time vascular surgery operating room starts and decrease resident work hours. $J$ Vasc Surg 2013; 58: 1417-22.

267. Welch S and Savitz L. Exploring strategies to improve emergency department intake. $J$ Emerg Med 2012; 43: 149-58.

268. White BA, Baron JM, Dighe AS, Camargo CA Jr, and Brown DF. Applying Lean methodologies reduces ED laboratory turnaround times. Am J Emerg Med 2015; 33: 1572-6. 
269. White CM et al. Using quality improvement to optimise paediatric discharge efficiency. $B M J$ Qual Saf 2014; 23(5): 428-36.

270. Williams TA, Leslie GD, Brearley L, Leen T and O'Brien K. Discharge delay, room for improvement? Aust Crit Care 2010; 23: 141-9.

271. Wu J, Zhang Y, Luo X, Zhang Q and Zhu J. Research of regional medical consumables reagent logistics system in the modern hospital. Zhongguo Yi Liao Qi Xie Za Zhi 2013; 37: 382-5.

272. Xie $\mathrm{Y}$ and Peng Q. Integration of value stream mapping and agent-based modeling for OR improvement. Business Process Management Journal 2012; 18: 585-599.

273. Yang M, Fry MJ and Scurlock C. The ICU will see you now: efficient-equitable admission control policies for a surgical ICU with batch arrivals. IIE Transactions 2015; 47: 586-599.

274. Ygal B, Harold B and Richard P. Redesigning the replenishment process of medical supplies in hospitals with RFID. Business Process Management Journal 2010; 16: 991-1013.

275. Yi L, Hao A, Hu M, Huang P, Yuan H and Xing M. Construction and Application of a Refined Hospital Management Chain. Cell Biochem Biophys 2015; 72: 19-22.

276. Young GJ, Nyaga GN and Zepeda ED. Hospital employment of physicians and supply chain performance: An empirical investigation. Health Care Manage Rev 2016; 41: 244-55.

277. Yunqu H and Klassen KJ. Using Six Sigma, Lean, and Simulation to Improve the Phlebotomy Process. Quality Management Journal 2016; 23(2): 6-21

278. Zepeda ED, Nyaga GN and Young GJ. Supply chain risk management and hospital inventory: Effects of system affiliation. Journal of Operations Management 2016; 44: 30-47.

279. Zuidgeest J, Jonkheijm A, Van Dijk M and Van As A. Is the golden hour optimally used in South Africa for children presenting with polytrauma? S Afr Med $J$ 2013; 103: 166-7.

280. Improving patient flow, patient satisfaction and patient safety. HandHN: Hospitals and Health Networks 2007; 81: 28-29.

281. Christiana's flow improvement. Health Facilities Management 2009; 22: 36-36.

282. Process changes cut LOS by 100 minutes. ED Manag 2009; 21: 99-100.

283. ED improves on already impressive wait times. ED Manag 2010: 22: 6-7.

284. Patients can text EDs for wait times. ED Manag 2010; 22: 64-5.

285. Lean-driven improvements slash wait times drive up patient satisfaction scores. ED Manag 2012; 24: 79-81.

286. Lean-driven solutions slash ED wait times LOS. ED Manag 2012; 24: 139-41.

287. Hospital operations management: improving organizational efficiency. Hosp Health Netw 2013; 87: 49-59 2. 


\section{APPENDIX 2.2: LOGISTICAL PARAMETERS FOUND IN THE SCOPING STUDY}

In this appendix all 106 parameters are presented in alphabetical order including the percentage of 287 articles in which each of the parameters is mentioned at least once. The parameters with a higher percentage of occurrence are presented in darker colours.

Table A2.2.1 Logistical parameters

\begin{tabular}{lc}
\hline Logistical parameter & Parameter occurrence $\boldsymbol{P}_{\mathbf{n}}$ \\
\hline Access block & $0.35 \%$ \\
Access time & $3.83 \%$ \\
Admission time & $0.70 \%$ \\
Admission wait time & $0.35 \%$ \\
Admittance rate & $0.35 \%$ \\
Bed assignment time & $0.35 \%$ \\
Bed availability & $1.39 \%$ \\
Bed occupancy & $1.39 \%$ \\
Bed turn time & $0.35 \%$ \\
Bed utilisation & $0.35 \%$ \\
Cancelled procedures & $0.35 \%$ \\
Capacity utilisation & $0.70 \%$ \\
Congestion & $1.74 \%$ \\
Cost & $14,98 \%$ \\
Crowding & $0.35 \%$ \\
Cycle time & $2.09 \%$ \\
Dead-bed time & $0.35 \%$ \\
Delay & $9.76 \%$ \\
Delivery reliability & $1.74 \%$ \\
Delivery time & $0.35 \%$ \\
Discharge rate & $0.35 \%$ \\
Discharge time & $2.44 \%$ \\
Distance cost & $0.35 \%$ \\
Down time & $0.35 \%$ \\
Efficiency & $6.27 \%$ \\
Fleet operating costs & $0.70 \%$ \\
Floors travelled on elevators & $0.35 \%$ \\
Flow efficiency & $0.35 \%$ \\
Flow time & $2.09 \%$ \\
Hospital cost & $0.35 \%$ \\
Hospital occupancy & $0.35 \%$ \\
Idle time & $2.09 \%$ \\
Immobilized stock & $0.35 \%$ \\
Inventory cost & $2.79 \%$ \\
Inventory performance & $0.35 \%$ \\
Inventory waste & $0.35 \%$ \\
Lead time & $16.72 \%$ \\
Left without being seen & $0.35 \%$ \\
Length of stay & $29.97 \%$ \\
\hline & \\
\hline
\end{tabular}


Table A2.2.1 (continued)

\section{Logistical parameter}

Parameter occurrence $\boldsymbol{P}_{\boldsymbol{n}}$

Management cost

$0.35 \%$

Material availability

$0.35 \%$

Number of waiting patients

$1.05 \%$

Number of waits

$0.70 \%$

Occupancy rate

$0.35 \%$

On time

$0.35 \%$

On time delivery

$3.48 \%$

On time start

$0.35 \%$

Operating cost

$0.35 \%$

Outdated inventory

$0.35 \%$

Overtime

$1.74 \%$

Overtime cost

$0.35 \%$

Patient throughput

$0.35 \%$

Processing time

$0.70 \%$

Processing waste

$0.35 \%$

Product availability

$0.70 \%$

Productivity

$0.35 \%$

Queue length

$0.35 \%$

Readmission

$1.74 \%$

Reliability

$0.35 \%$

Reoperation

$0.70 \%$

Resource availability

$2.09 \%$

Resource utilisation

Response time

$0.70 \%$

Responsiveness

$3.14 \%$

Safety stock

$0.35 \%$

Shelf life

$0.70 \%$

Shortage

$0.70 \%$

Shortage rate

0.35\%

Space availability

0. $35 \%$

Space utilisation

$0.35 \%$

Staff time spent on logistics

$1.05 \%$

Stock cost

$0.35 \%$

Stock level

$1.39 \%$

Stockouts

$1.74 \%$

Supply cost

$0.35 \%$

Surgery time

$0.70 \%$

Throughput

$2.79 \%$

Throughput time

$7.67 \%$

Time needed to deliver the service

$0.35 \%$

Time spent

$0.35 \%$

Time spent on patient

$0.35 \%$

Timeliness

$0.35 \%$

Total distance traveled

$0.35 \%$

Transfer process time

$0.35 \%$

Transfer time

$0.70 \%$

Transport cost

$1.05 \%$

Transport distance

$0.70 \%$

Transport frequency

$0.35 \%$ 
Table A2.2.1 (continued)

Logistical parameter

Transport time

Transport volume

Transportation cost

Transportation time

Treatment time

True completion time

Turnaround time

Turnover ratio

Turnover time

Usage rate

Utilisation of staff

Wait time

Waiting patients

Waiting Time

Walking distance

Warehouse operation cost

Waste

Work time spent on work orders
Parameter occurrence $\boldsymbol{P}_{\boldsymbol{n}}$

$2.09 \%$

$0.35 \%$

$0.35 \%$

$0.35 \%$

$1.39 \%$

$0.35 \%$

$3.48 \%$

$0.35 \%$

1.05\%

$0.35 \%$

0.35\%

20,21\%

$0.35 \%$

$7.67 \%$

$0.35 \%$

$0.35 \%$

$2.44 \%$

$0.35 \%$ 


\section{APPENDIX 2.3: 106 LOGISTICAL PARAMETERS CLUSTERED INTO 12 PARAMETER CONCEPTS AND 'MISCELLANEOUS'}

Table A2.3.1 Logistical parameters clustered

\begin{tabular}{|c|c|c|}
\hline $\begin{array}{l}\text { Parameter } \\
\text { concept }\end{array}$ & \multicolumn{2}{|c|}{ Logistical parameter by original name } \\
\hline Time & $\begin{array}{l}\text { Access time } \\
\text { Admission time } \\
\text { Admission wait time } \\
\text { Bed assignment time } \\
\text { Bed turn time } \\
\text { Cycle time } \\
\text { Dead-bed time } \\
\text { Delay } \\
\text { Delivery time } \\
\text { Discharge time } \\
\text { Down time } \\
\text { Flow time } \\
\text { Idle time } \\
\text { Lead time } \\
\text { Length of stay } \\
\text { On time } \\
\text { On time delivery } \\
\text { On time start } \\
\text { Overtime } \\
\text { Processing time }\end{array}$ & $\begin{array}{l}\text { Response time } \\
\text { Staff time spent on logistics } \\
\text { Surgery time } \\
\text { Throughput time } \\
\text { Time needed to deliver the service } \\
\text { Time spent } \\
\text { Time spent on patient } \\
\text { Timeliness } \\
\text { Transfer process time } \\
\text { Transfer time } \\
\text { Transport time } \\
\text { Transportation time } \\
\text { Treatment time } \\
\text { True completion time } \\
\text { Turnaround time } \\
\text { Turnover time } \\
\text { Wait time } \\
\text { Waiting time } \\
\text { Work time spent on work orders }\end{array}$ \\
\hline Cost & $\begin{array}{l}\text { Cost } \\
\text { Distance cost } \\
\text { Fleet operating costs } \\
\text { Hospital cost } \\
\text { Inventory cost } \\
\text { Management cost } \\
\text { Operating cost }\end{array}$ & $\begin{array}{l}\text { Overtime cost } \\
\text { Stock cost } \\
\text { Supply cost } \\
\text { Transport cost } \\
\text { Transportation cost } \\
\text { Warehouse operation cost }\end{array}$ \\
\hline Utilisation & $\begin{array}{l}\text { Bed occupancy } \\
\text { Bed utilisation } \\
\text { Capacity utilisation } \\
\text { Hospital occupancy } \\
\text { Immobilized stock }\end{array}$ & $\begin{array}{l}\text { Occupancy rate } \\
\text { Resource utilisation } \\
\text { Space utilisation } \\
\text { Utilisation of staff } \\
\text { Usage rate }\end{array}$ \\
\hline Availability & $\begin{array}{l}\text { Bed availability } \\
\text { Material availability } \\
\text { Product availability } \\
\text { Resource availability } \\
\text { Safety stock }\end{array}$ & $\begin{array}{l}\text { Shortage } \\
\text { Shortage rate } \\
\text { Space availability } \\
\text { Stock level } \\
\text { Stockouts }\end{array}$ \\
\hline Efficiency & Efficiency & Flow efficiency \\
\hline Responsiveness & Responsiveness & \\
\hline Throughput & Throughput & Patient throughput \\
\hline Waste & $\begin{array}{l}\text { Inventory waste } \\
\text { Processing waste }\end{array}$ & Waste \\
\hline
\end{tabular}


Table A2.3.1 (continued)

\begin{tabular}{lll}
\hline $\begin{array}{l}\text { Parameter } \\
\text { concept }\end{array}$ & Logistical parameter by original name \\
\hline Waiting patients & $\begin{array}{l}\text { Number of waiting patients } \\
\text { Number of waits } \\
\text { Waiting patients }\end{array}$ \\
\hline Reliability & $\begin{array}{l}\text { Delivery reliability } \\
\text { Reliability }\end{array}$ \\
\hline Rework & Readmission & \\
& Reoperation & \\
\hline Distance & Total distance travelled & \\
& Transport distance & \\
& Walking distance & Left without being seen (LWBS) \\
& Access block & Outdated inventory \\
Adiscellaneous & Productivity \\
& Cancelled procedures & Queue length \\
& Congestion & Shelf life \\
& Crowding & Transport frequency \\
& Discharge rate & Transport volume \\
& Floors traveled on elevators & \\
& Inventory performance & Turnover ratio \\
\hline
\end{tabular}




\section{APPENDIX 2.4: OVERVIEW OF CONTEXTS IN WHICH LOGISTICAL PARAMETERS ARE APPLIED}

Table A2.4.1 Contexts in which logistical parameters are applied

\begin{tabular}{|c|c|c|c|}
\hline Logistical parameter & Flow type & $\begin{array}{l}\text { Object of } \\
\text { study }\end{array}$ & Specification object \\
\hline 1.. Access block & Patients & Department & Emergency department \\
\hline \multirow[t]{8}{*}{ 2. Access time } & \multirow[t]{8}{*}{ Patients } & \multirow[t]{6}{*}{ Department } & Ancillary services department \\
\hline & & & Emergency department \\
\hline & & & Department of Otorhinolaryngology \\
\hline & & & Nursing departments \\
\hline & & & Operating Room Department \\
\hline & & & Outpatient department \\
\hline & & Flow group & Low acuity patients \\
\hline & & Hospital wide & - \\
\hline \multirow[t]{2}{*}{ 3. Admission time } & \multirow[t]{2}{*}{ Patients } & \multirow[t]{2}{*}{ Flow group } & $\begin{array}{l}\text { Emergency colorectal surgery } \\
\text { patients }\end{array}$ \\
\hline & & & Emergency patients \\
\hline 4. Admission wait time & Patients & Department & Nursing departments \\
\hline 5. Admittance rate & Patients & Department & Emergency department \\
\hline 6. Bed assignment time & Patients & Hospital wide & - \\
\hline \multirow[t]{4}{*}{ 7. Bed availability } & \multirow[t]{4}{*}{ Patients } & Department & Nursing departments \\
\hline & & Flow group & Critical care patients \\
\hline & & Hospital wide & - \\
\hline & & Process specific & Discharge process \\
\hline \multirow[t]{3}{*}{ 8. Bed occupancy } & \multirow[t]{2}{*}{ Patients } & Department & Gynaecology department \\
\hline & & & $\begin{array}{l}\text { Inpatient departments } \\
\text { Intensive care department }\end{array}$ \\
\hline & Staff & Flow group & Nurses \\
\hline 9. Bed turn time & Patients & Department & Emergency department \\
\hline 10. Bed utilisation & Patients & Flow group & Cancer patients \\
\hline 11. Cancelled procedures & Patients & Process specific & Discharge process \\
\hline \multirow[t]{2}{*}{ 12. Capacity utilisation } & $\begin{array}{l}\text { Materials, } \\
\text { patients and } \\
\text { staff }\end{array}$ & Hospital wide & - \\
\hline & Patients & Flow group & Psychiatric patients \\
\hline \multirow[t]{3}{*}{ 13. Congestion } & \multirow[t]{3}{*}{ Patients } & Department & Emergency department \\
\hline & & & Outpatient department \\
\hline & & Hospital wide & - \\
\hline
\end{tabular}


Table A2.4.1 (continued)

\begin{tabular}{|c|c|c|c|}
\hline \multirow[t]{25}{*}{ 14. Cost } & All & Hospital wide & - \\
\hline & \multirow[t]{9}{*}{ Materials } & \multirow[t]{2}{*}{ Department } & Laboratory department \\
\hline & & & Pharmacy department \\
\hline & & \multirow[t]{6}{*}{ Flow group } & Assets \\
\hline & & & Blood \\
\hline & & & Building materials \\
\hline & & & Medical equipment \\
\hline & & & Medical supplies \\
\hline & & & Medication \\
\hline & & Process specific & Transport \\
\hline & \multirow{2}{*}{$\begin{array}{l}\text { Materials and } \\
\text { patients }\end{array}$} & Department & Pharmacy department \\
\hline & & Process specific & Discharge process \\
\hline & $\begin{array}{l}\text { Materials, } \\
\text { patients and } \\
\text { staff }\end{array}$ & Hospital wide & - \\
\hline & \multirow[t]{12}{*}{ Patients } & \multirow[t]{6}{*}{ Department } & Emergency department \\
\hline & & & Endoscopy department \\
\hline & & & $\begin{array}{l}\text { Medical nuclear medicine } \\
\text { department }\end{array}$ \\
\hline & & & Nursing departments \\
\hline & & & Operating Room Department \\
\hline & & & Outpatient department \\
\hline & & \multirow[t]{5}{*}{ Flow group } & Emergency patients \\
\hline & & & Gynaecology patients \\
\hline & & & Outpatient surgery patients \\
\hline & & & Palliative care patient \\
\hline & & & Radiation therapy patients \\
\hline & & Hospital wide & - \\
\hline 15. Crowding & Patients & Department & Emergency department \\
\hline \multirow[t]{6}{*}{ 16. Cycle time } & Materials & Department & Nursing departments \\
\hline & \multirow[t]{5}{*}{ Patients } & Department & $\begin{array}{l}\text { Department of Otorhinolaryngology } \\
\text { and nephrology department }\end{array}$ \\
\hline & & \multirow[t]{2}{*}{ Flow group } & Cardiology patients \\
\hline & & & Outpatient surgery patients \\
\hline & & \multirow[t]{2}{*}{ Process specific } & Discharge process \\
\hline & & & Transport \\
\hline 17. Dead-bed time & Patients & Department & Emergency department \\
\hline \multirow[t]{19}{*}{ 18. Delay } & \multirow[t]{18}{*}{ Patients } & \multirow[t]{7}{*}{ Department } & Cardiology department \\
\hline & & & Emergency department \\
\hline & & & Endoscopy department \\
\hline & & & Intensive care department \\
\hline & & & Operating Room Department \\
\hline & & & Outpatient department \\
\hline & & & PACU \\
\hline & & \multirow[t]{7}{*}{ Flow group } & Acute patients \\
\hline & & & Cardiology patients \\
\hline & & & Emergency patients \\
\hline & & & Gynaecology patients \\
\hline & & & Nephrology patients \\
\hline & & & Neurosurgery patients \\
\hline & & & Pregnant women \\
\hline & & Hospital wide & - \\
\hline & & \multirow[t]{3}{*}{ Process specific } & Discharge process \\
\hline & & & Perioperative process \\
\hline & & & Transport \\
\hline & Staff & Flow group & Nurses \\
\hline
\end{tabular}


Table A2.4.1 (continued)

\begin{tabular}{|c|c|c|c|}
\hline \multirow[t]{5}{*}{ 19. Delivery reliability } & \multirow[t]{2}{*}{ Materials } & \multirow[t]{2}{*}{ Flow group } & Medical instruments \\
\hline & & & Medication \\
\hline & \multirow[t]{2}{*}{ Patients } & Department & Nursing departments \\
\hline & & Process specific & Transport \\
\hline & Staff & Process specific & Cleaning \\
\hline 20. Delivery time & Materials & Flow group & Medication \\
\hline 21. Discharge rate & Patients & Department & Nursing departments \\
\hline \multirow{6}{*}{ 22. Discharge time } & \multirow{6}{*}{ Patients } & Hospital wide & - \\
\hline & & Department & Inpatient departments \\
\hline & & Flow group & Cardio surgical patients \\
\hline & & & Emergency patients \\
\hline & & & Paediatric patients \\
\hline & & Process specific & Discharge process \\
\hline 23. Distance cost & Patients & Process specific & Transport \\
\hline 24. Down time & Materials & Department & Pharmacy department \\
\hline \multirow[t]{9}{*}{ 25. Efficiency } & \multirow[t]{2}{*}{ Materials } & Hospital wide & - \\
\hline & & Process specific & Transport \\
\hline & $\begin{array}{l}\text { Materials, } \\
\text { patients and } \\
\text { staff }\end{array}$ & Hospital wide & - \\
\hline & \multirow[t]{4}{*}{ Patients } & Department & $\begin{array}{l}\text { Emergency department } \\
\text { Intensive care department } \\
\text { Operating Room Department }\end{array}$ \\
\hline & & Flow group & Mamma patients \\
\hline & & Hospital wide & - \\
\hline & & Process specific & $\begin{array}{l}\text { Patient transfer } \\
\text { Transport }\end{array}$ \\
\hline & $\begin{array}{l}\text { Patients and } \\
\text { Materials }\end{array}$ & Hospital wide & - \\
\hline & Staff & Flow group & Nurses \\
\hline 26. Fleet operating costs & Patients & Process specific & Transport \\
\hline $\begin{array}{l}\text { 27. Floors travelled on } \\
\text { elevators }\end{array}$ & Staff & Flow group & Nurses \\
\hline 28. Flow efficiency & Patients & Department & Operating Room Department \\
\hline \multirow[t]{2}{*}{ 29. Flow time } & \multirow[t]{2}{*}{ Patients } & Department & \begin{tabular}{|l|} 
Emergency department \\
Operating Room Department \\
\end{tabular} \\
\hline & & Hospital wide & - \\
\hline 30. Hospital cost & Patients & Flow group & Neurosurgery patients \\
\hline 31. Hospital occupancy & Patients & Department & Emergency department \\
\hline \multirow[t]{2}{*}{ 32. Idle time } & \multirow[t]{2}{*}{ Patients } & Department & $\begin{array}{l}\text { Outpatient cancer department } \\
\text { Radiology department }\end{array}$ \\
\hline & & Process specific & Transport \\
\hline 33. Immobilized stock & Materials & Department & Outpatient department \\
\hline \multirow[t]{3}{*}{ 34. Inventory cost } & \multirow[t]{3}{*}{ Materials } & Department & \begin{tabular}{|l} 
Logistics department \\
Nursing departments \\
Pharmacy department \\
Sterilization department \\
\end{tabular} \\
\hline & & Flow group & $\begin{array}{l}\text { Doctors employment } \\
\text { Medical supplies }\end{array}$ \\
\hline & & Hospital wide & - \\
\hline 35. Inventory performance & Materials & Flow group & Blood \\
\hline 36. Inventory waste & $\begin{array}{l}\text { Materials, } \\
\text { patients and } \\
\text { staff }\end{array}$ & Hospital wide & - \\
\hline
\end{tabular}


Table A2.4.1 (continued)

\begin{tabular}{|c|c|c|c|}
\hline \multirow[t]{32}{*}{ 37. Lead time } & All & Hospital wide & - \\
\hline & \multirow[t]{4}{*}{ Materials } & \multirow[t]{2}{*}{ Department } & Nursing departments \\
\hline & & & Pharmacy department \\
\hline & & \multirow[t]{2}{*}{ Flow group } & Medical supplies \\
\hline & & & Medication \\
\hline & $\begin{array}{l}\text { Materials and } \\
\text { patients }\end{array}$ & Department & Pharmacy department \\
\hline & \multirow[t]{25}{*}{ Patients } & \multirow[t]{10}{*}{ Department } & Ancillary services department \\
\hline & & & CT department \\
\hline & & & Emergency department \\
\hline & & & Inpatient rehabilitation department \\
\hline & & & Laboratory department \\
\hline & & & Nursing departments \\
\hline & & & Operating Room Department \\
\hline & & & Outpatient cancer department \\
\hline & & & Patient transport department \\
\hline & & & Radiology department \\
\hline & & \multirow[t]{9}{*}{ Flow group } & Acute patients \\
\hline & & & Cardiology patients \\
\hline & & & Emergency patients \\
\hline & & & Head and neck cancer patients \\
\hline & & & Hip fracture patients \\
\hline & & & Mental patients \\
\hline & & & Nephrology patients \\
\hline & & & Orthopaedic patients \\
\hline & & & Psychiatric patients \\
\hline & & Hospital wide & - \\
\hline & & \multirow[t]{5}{*}{ Process specific } & Discharge process \\
\hline & & & Perioperative process \\
\hline & & & Phlebotomy process \\
\hline & & & Preoperative assessment \\
\hline & & & Triage process \\
\hline & Staff & Process specific & Cleaning \\
\hline $\begin{array}{l}\text { 38. Left Without Being Seen } \\
\text { (LWBS) }\end{array}$ & Patients & Department & Emergency department \\
\hline
\end{tabular}


Table A2.4.1 (continued)

\begin{tabular}{|c|c|c|c|}
\hline \multirow[t]{29}{*}{ 39. Length of stay } & $\begin{array}{l}\text { Materials and } \\
\text { patients }\end{array}$ & Process specific & Discharge process \\
\hline & \multirow[t]{28}{*}{ Patients } & Department & \begin{tabular}{|l} 
Emergency department \\
$\begin{array}{l}\text { Emergency dept, OR, bed } \\
\text { management }\end{array}$ \\
Inpatient departments \\
Intensive care department \\
Nursing departments \\
Operating Room Department \\
Stroke department \\
\end{tabular} \\
\hline & & \multirow[t]{25}{*}{ Flow group } & Acute patients \\
\hline & & & Ambulatory surgery patients \\
\hline & & & Bariatric surgery patients \\
\hline & & & Cardiac patients \\
\hline & & & Cardiology patients \\
\hline & & & Cardiac surgical patients \\
\hline & & & Cardiovascular patients \\
\hline & & & Colorectal cancer patients \\
\hline & & & Critical care patients \\
\hline & & & Emergency patients \\
\hline & & & Gynaecology patients \\
\hline & & & Kidney patients \\
\hline & & & Laparoscopic patients \\
\hline & & & Low acuity patients \\
\hline & & & Nephrology patients \\
\hline & & & Neurosurgery patients \\
\hline & & & Obese lung patients \\
\hline & & & Obstetric patients \\
\hline & & & Orthopaedic patients \\
\hline & & & Paediatric cardiac patients \\
\hline & & & Paediatric patients \\
\hline & & & Plastic surgery patients \\
\hline & & & Stroke patients \\
\hline & & & Surgery patients \\
\hline & & & Trauma patients \\
\hline & & Hospital wide & - \\
\hline & & Process specific & Discharge process \\
\hline 40. Management cost & $\begin{array}{l}\text { Materials and } \\
\text { patients }\end{array}$ & - & - \\
\hline 41. Material availability & Materials & Flow group & Medical supplies \\
\hline \multirow{2}{*}{$\begin{array}{l}\text { 42. Number of waiting } \\
\text { patients }\end{array}$} & \multirow[t]{2}{*}{ Patients } & Department & Emergency department \\
\hline & & Flow group & Orthopaedic patients \\
\hline \multirow[t]{2}{*}{ 43. Number of waits } & \multirow[t]{2}{*}{ Patients } & Department & Emergency department \\
\hline & & Flow group & Emergency patients \\
\hline 44. Occupancy rate & $\begin{array}{l}\text { Materials, } \\
\text { patients and } \\
\text { staff }\end{array}$ & Hospital wide & - \\
\hline 45. On time & Patients & Hospital wide & - \\
\hline \multirow[t]{9}{*}{ 46. On time delivery } & \multirow[t]{3}{*}{ Materials } & Department & Nursing departments \\
\hline & & Flow group & Medication \\
\hline & & Process specific & Transport \\
\hline & \multirow[t]{6}{*}{ Patients } & Department & Emergency department \\
\hline & & & Endoscopy department \\
\hline & & & Intensive care department \\
\hline & & & Operating Room Department \\
\hline & & Hospital wide & - \\
\hline & & Process specific & Transport \\
\hline
\end{tabular}


Table A2.4.1 (continued)

\begin{tabular}{|c|c|c|c|}
\hline 47. On time start & Patients & Department & Operating Room Department \\
\hline 48. Operating cost & Patients & Department & Gynaecology department \\
\hline 49. Outdated inventory & Materials & Department & Laboratory department \\
\hline \multirow[t]{4}{*}{ 50. Overtime } & \multirow[t]{4}{*}{ Patients } & \multirow[t]{4}{*}{ Department } & Chemotherapy department \\
\hline & & & Outpatient cancer department \\
\hline & & & Outpatient department \\
\hline & & & Radiology department \\
\hline 51. Overtime cost & Staff & Flow group & Nurses \\
\hline 52. Patient throughput & Patients & Process specific & Discharge process \\
\hline \multirow[t]{2}{*}{ 53. Processing time } & \multirow[t]{2}{*}{ Patients } & Flow group & Outpatient surgery patients \\
\hline & & Process specific & Transport \\
\hline 54. Processing waste & $\begin{array}{l}\text { Materials, } \\
\text { patients and } \\
\text { staff }\end{array}$ & Hospital wide & - \\
\hline \multirow[t]{2}{*}{ 55. Product availability } & Materials & Flow group & Medical supplies \\
\hline & Patients & Process specific & Giving injections \\
\hline 56. Productivity & Patients & Department & Operating Room Department \\
\hline 57. Queue length & Patients & Department & Pharmacy department \\
\hline \multirow[t]{4}{*}{ 58. Readmission } & \multirow[t]{4}{*}{ Patients } & Department & Emergency department \\
\hline & & \multirow[t]{3}{*}{ Flow group } & Bariatric surgery patients \\
\hline & & & Hysterectomy patients \\
\hline & & & Surgery patients \\
\hline 59. Reliability & Patients & Process specific & Transport \\
\hline \multirow[t]{2}{*}{ 60. Reoperation } & \multirow[t]{2}{*}{ Patients } & \multirow[t]{2}{*}{ Flow group } & Hysterectomy patients \\
\hline & & & Surgery patients \\
\hline \multirow[t]{6}{*}{ 61. Resource availability } & Materials & Department & Intensive care department \\
\hline & \multirow[t]{3}{*}{ Patients } & Department & Emergency department \\
\hline & & Flow group & Emergency patients \\
\hline & & Process specific & Transport \\
\hline & \multirow[t]{2}{*}{ Staff } & Flow group & Nurses \\
\hline & & Process specific & Cleaning \\
\hline \multirow[t]{26}{*}{ 62. Resource utilisation } & \multirow[t]{3}{*}{ Materials } & \multirow[t]{2}{*}{ Department } & Nursing departments \\
\hline & & & Pharmacy department \\
\hline & & Flow group & Medical supplies \\
\hline & \multirow[t]{23}{*}{ Patients } & \multirow[t]{13}{*}{ Department } & Ancillary services department \\
\hline & & & Chemotherapy department \\
\hline & & & Emergency department \\
\hline & & & Inpatient departments \\
\hline & & & Intensive care department \\
\hline & & & Nursing departments \\
\hline & & & Operating Room Department \\
\hline & & & Outpatient cancer department \\
\hline & & & Outpatient department \\
\hline & & & Patient transport department \\
\hline & & & Pharmacy department \\
\hline & & & Radiology department \\
\hline & & & Stroke department \\
\hline & & Flow group & Acute patients \\
\hline & & & Cardiovascular patients \\
\hline & & & Emergency patients \\
\hline & & & Outpatient surgery patients \\
\hline & & & Paediatric patients \\
\hline & & Hospital wide & - \\
\hline & & Process specific & Discharge process \\
\hline & & & Telephone communication \\
\hline & & & Transport \\
\hline & & - & - \\
\hline
\end{tabular}


Table A2.4.1 (continued)

\begin{tabular}{|c|c|c|c|}
\hline \multirow[t]{2}{*}{ 63. Response time } & \multirow[t]{2}{*}{ Patients } & Hospital wide & - \\
\hline & & Process specific & Transport \\
\hline \multirow{7}{*}{ 64. Responsiveness } & All & Hospital wide & - \\
\hline & \multirow[t]{2}{*}{ Materials } & Department & Nursing departments \\
\hline & & Process specific & Transport \\
\hline & \multirow[t]{3}{*}{ Patients } & Flow group & Emergency patients \\
\hline & & Hospital wide & - \\
\hline & & Process specific & Transport \\
\hline & Staff & Flow group & Nurses \\
\hline 65. Safety stock & Materials & Flow group & Medication \\
\hline \multirow{2}{*}{ 66. Shelf life } & Materials & Flow group & Blood \\
\hline & Patients & Flow group & Cytostatics \\
\hline \multirow[t]{2}{*}{ 67. Shortage } & \multirow[t]{2}{*}{ Materials } & \multirow[t]{2}{*}{ Flow group } & Blood \\
\hline & & & Medication \\
\hline 68. Shortage rate & Materials & Flow group & Medication \\
\hline 69. Space availability & Patients & Department & Emergency department \\
\hline 70. Space utilisation & Patients & Department & Laboratory department \\
\hline \multirow{3}{*}{$\begin{array}{l}\text { 71. Staff Time spent on } \\
\text { logistics }\end{array}$} & Materials & Process specific & Transport \\
\hline & \multirow[t]{2}{*}{ Staff } & Department & Operating Room Department \\
\hline & & Process specific & Transport \\
\hline 72. Stock cost & Materials & Flow group & Medication \\
\hline \multirow[t]{3}{*}{ 73. Stock level } & \multirow[t]{2}{*}{ Materials } & Department & Nursing departments \\
\hline & & Flow group & Medical supplies \\
\hline & Patients & Hospital wide & - \\
\hline \multirow[t]{5}{*}{ 74. Stockouts } & All & Hospital wide & - \\
\hline & \multirow[t]{3}{*}{ Materials } & Department & Paediatric trauma department \\
\hline & & Flow group & Pregnant women \\
\hline & & Hospital wide & - \\
\hline & Patients & Flow group & HIV/aids patients \\
\hline 75. Supply cost & Patients & Flow group & Medical supplies \\
\hline \multirow[t]{2}{*}{ 76. Surgery time } & \multirow[t]{2}{*}{ Patients } & Department & Operating Room Department \\
\hline & & Process specific & Transport \\
\hline \multirow[t]{3}{*}{ 77. Throughput } & \multirow[t]{3}{*}{ Patients } & Department & Emergency department \\
\hline & & & Outpatient cancer department \\
\hline & & Hospital wide & - \\
\hline \multirow[t]{13}{*}{ 78. Throughput time } & $\begin{array}{l}\text { Materials and } \\
\text { patients }\end{array}$ & Department & Pharmacy department \\
\hline & Patients & Department & Emergency department \\
\hline & & & Operating Room Department \\
\hline & & & Pharmacy department \\
\hline & & Flow group & $\begin{array}{l}\text { Closed femoral shaft fractures } \\
\text { patients }\end{array}$ \\
\hline & & & Diabetes patients \\
\hline & & & Emergency patients \\
\hline & & & Lung cancer patients \\
\hline & & & Medication \\
\hline & & & Outpatient surgery patients \\
\hline & & & Skin cancer patients \\
\hline & & Hospital wide & 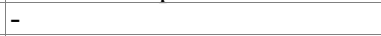 \\
\hline & & Process specific & Discharge process \\
\hline $\begin{array}{l}\text { 79. Time needed to deliver } \\
\text { the service }\end{array}$ & Patients & Flow group & Outpatient surgery patients \\
\hline 80. Time spent & Patients & Flow group & Outpatient surgery patients \\
\hline 81. Time spent on patient & Patients & Department & Emergency department \\
\hline 82. Timeliness & Patients & Flow group & Outpatient surgery patients \\
\hline 83. Total distance travelled & Staff & Department & Operating Room Department \\
\hline 84. Transfer process time & Patients & Flow group & Trauma patients \\
\hline
\end{tabular}


Table A2.4.1 (continued)

\begin{tabular}{|c|c|c|c|}
\hline \multirow[t]{2}{*}{ 85. Transfer time } & \multirow[t]{2}{*}{ Patients } & Department & Operating Room Department \\
\hline & & Hospital wide & - \\
\hline \multirow[t]{3}{*}{ 86. Transport cost } & Materials & Department & Sterilization department \\
\hline & Patients & Department & Laboratory department \\
\hline & & Process specific & Transport \\
\hline \multirow[t]{2}{*}{ 87. Transport distance } & Materials & Department & Pharmacy department \\
\hline & Patients & Hospital wide & - \\
\hline 88. Transport frequency & Materials & Process specific & Transport \\
\hline \multirow[t]{5}{*}{ 89. Transport time } & Patients & Department & Patient transport department \\
\hline & & Flow group & Medical supplies \\
\hline & & Hospital wide & - \\
\hline & & Process specific & Transport \\
\hline & Staff & Flow group & Nurses \\
\hline 90. Transport volume & Materials & Process specific & Transport \\
\hline 91. Transportation cost & Patients & Process specific & Transport \\
\hline 92. Transportation time & Patients & Process specific & Transport \\
\hline \multirow[t]{3}{*}{ 93. Treatment time } & \multirow[t]{3}{*}{ Patients } & Department & Emergency department \\
\hline & & Flow group & Bariatric surgery patients \\
\hline & & & Emergency patients \\
\hline 94. True Completion Time & Patients & Department & Endoscopy department \\
\hline \multirow[t]{6}{*}{ 95. Turnaround time } & Materials & Department & Nursing departments \\
\hline & \multirow[t]{5}{*}{ Patients } & Department & Emergency department \\
\hline & & & Laboratory department \\
\hline & & & Operating Room Department \\
\hline & & Flow group & Bariatric surgery patients \\
\hline & & Hospital wide & - \\
\hline 96. Turnover ratio & Patients & Hospital wide & - \\
\hline \multirow[t]{3}{*}{ 97. Turnover time } & \multirow[t]{3}{*}{ Patients } & Department & Endoscopy department \\
\hline & & & Nursing departments \\
\hline & & & Operating Room Department \\
\hline 98. Usage rate & Materials & Department & Pharmacy department \\
\hline 99. Utilisation of staff & Materials & Department & Nursing departments \\
\hline \multirow[t]{24}{*}{ 100. Wait time } & Materials & Flow group & Blood \\
\hline & \multirow[t]{23}{*}{ Patients } & \multirow[t]{9}{*}{ Department } & Chemotherapy department \\
\hline & & & Emergency department \\
\hline & & & $\begin{array}{l}\text { Department of Otorhinolaryngology } \\
\text { and nephrology department }\end{array}$ \\
\hline & & & Nursing departments \\
\hline & & & Operating Room Department \\
\hline & & & Outpatient department \\
\hline & & & Pharmacy department \\
\hline & & & Preoperative department \\
\hline & & & Radiology department \\
\hline & & \multirow[t]{7}{*}{ Flow group } & Cardiology patients \\
\hline & & & $\begin{array}{l}\text { Emergency colorectal surgery } \\
\text { patients }\end{array}$ \\
\hline & & & Emergency patients \\
\hline & & & Head and neck cancer patients \\
\hline & & & Hip fracture patients \\
\hline & & & Low acuity patients \\
\hline & & & Mamma patients \\
\hline & & Hospital wide & - \\
\hline & & \multirow[t]{6}{*}{ Process specific } & Consultation with a doctor and \\
\hline & & & pharmacy \\
\hline & & & Discharge process \\
\hline & & & Preoperative assessment \\
\hline & & & Transport \\
\hline & & & Triage process \\
\hline
\end{tabular}


Table A2.4.1 (continued)

\begin{tabular}{|c|c|c|c|c|}
\hline 101. & Waiting patients & Patients & Department & Emergency department \\
\hline \multirow[t]{14}{*}{102.} & Waiting Time & $\begin{array}{l}\text { Materials, } \\
\text { patients and } \\
\text { staff }\end{array}$ & Hospital wide & - \\
\hline & & Patients & Department & Emergency department \\
\hline & & & & Operating Room Department \\
\hline & & & & Outpatient cancer department \\
\hline & & & & Patient transport department \\
\hline & & & & Radiology department \\
\hline & & & Flow group & Breast cancer patients \\
\hline & & & & Cardiovascular patients \\
\hline & & & & Critical care patients \\
\hline & & & & Psychiatric patients \\
\hline & & & & Skin cancer patients \\
\hline & & & Hospital wide & - \\
\hline & & & Process specific & Discharge process \\
\hline & & & & Telephone communication \\
\hline 103. & Walking distance & Staff & Flow group & Nurses \\
\hline 104. & $\begin{array}{l}\text { Warehouse operation } \\
\text { cost }\end{array}$ & Patients & Process specific & Transport \\
\hline \multirow[t]{6}{*}{105.} & Waste & Materials & Department & Pharmacy department \\
\hline & & & Flow group & Blood \\
\hline & & & & Medication \\
\hline & & $\begin{array}{l}\text { Materials and } \\
\text { patients }\end{array}$ & Department & Pharmacy department \\
\hline & & Patients & Department & Emergency department \\
\hline & & & & Operating Room Department \\
\hline 106. & $\begin{array}{l}\text { Work time spent on } \\
\text { work orders }\end{array}$ & Information & Process specific & Service management process \\
\hline
\end{tabular}





\section{ABSTRACT}

\section{Background}

Integration, the coordination and alignment of tasks, has been promoted widely in order to improve the performance of hospitals. Both organization theory and social network analysis offer perspectives on integration. This exploratory study research aims to understand how a hospital's logistical system works, and in particular to what extent there is integration and differentiation. More specifically, it first describes how a hospital organizes logistical processes; second, it identifies the agents and the interactions for organizing logistical processes, and, third, it establishes the extent to which tasks are segmented into subsystems, which is referred to as differentiation, and whether these tasks are coordinated and aligned, thus achieving integration.

\section{Methods}

The study is based on case study research carried out in a hospital in the Netherlands. All logistical tasks that are executed for surgery patients were studied. Using a mixed method, data were collected from the Hospital Information System (HIS), documentation, observations and interviews. These data were used to perform a social network analysis and calculate the network metrics of the hospital network.

\section{Results}

This paper shows that 23 tasks are executed by 635 different agents who interact through 31,499 interaction links. The social network of the hospital demonstrates both integration and differentiation. The network appears to function differently from what is assumed in literature, as the network does not reflect the formal organizational structure of the hospital, and tasks are mainly executed across functional silos. Nurses and physicians perform integrative tasks and two agents who mainly coordinate the tasks in the network, have no hierarchical position towards other agents. The HIS does not seem to fulfill the interactional needs of agents.

\section{Conclusions}

This exploratory study reveals the network structure of a hospital. The cross-functional collaboration, the integration found, and position of managers, coordinators, nurses and doctors suggests a possible gap between organizational perspectives on hospitals and reality. This research sets a basis for further research that should focus on the relation between network structure and performance, on how integration is achieved and in what way organization theory concepts and social network analysis could be used in conjunction with one another. 


\section{BACKGROUND}

Literature in the field of health care calls for more integrative approaches to the logistical or operational system of hospitals ${ }^{1-3}$. Such an approach includes aligning activities and planning resources from the perspective of the total system, taking hospital-wide processes and resources into account ${ }^{4}$. This is considered important because of a widely felt need to improve the quality, accessibility and affordability of healthcare systems 5 and of hospitals in particular, given the fact that hospitals are a major cost item of the healthcare system ${ }^{6}$. There is a wide consensus in literature that an integrated perspective on hospitals, which is a central concept in supply chain management, and in lean and other operations management theories, can contribute to the improvement of hospital performance ${ }^{4,7-12}$. Integrated hospitals plan patient processes and resources from the perspective of the total system ${ }^{9}$. A lack of integration is attributed to the functionalistic organization structure of medical disciplines and departments, often referred to as functional silos ${ }^{1,4,8,10}$. Ludwig et. al. found evidence that hospitals that perform well score high on cooperation, while efficient departments within a hospital don't necessarily contribute to the hospital's overall efficiency ${ }^{8}$. There are, however, a few studies that show system-wide performance improvement when adapting integrative practices such as lean ${ }^{12}$. In an earlier scoping study ${ }^{13}$ we found that research on logistics in hospitals typically focuses on one specific logistical flow (patients, material or staff) or on specific departments, but not on a system-wide level. The fact that 106 logistical performance parameters were identified which were applied in 92 subsystems ${ }^{13}$, illustrates the absence of a hospital-wide performance framework for logistics. In addition, De Vries and Huijsman ${ }^{7}$ point out that little is known on how to achieve integration in healthcare settings, and that this may require a different approach than in other industries.

Both contingency theory and social network theory offer perspectives on integration that could be useful in further exploring integration in the logistical system of hospitals.

Lawrence and Lorsch, who made a major contribution to contingency theory, view organizations as open systems in which the behaviors of members are interrelated ${ }^{14}$. They state that not only is integration important, but also that differentiation is essential in order for integration to be effective ${ }^{15}$. They define integration as 'achieving unity of effort among the various subsystems in the accomplishment of the organization's task'. Differentiation refers to 'the state of segmentation of the organizational system into subsystems'. Subsystems execute a part of the organization's task and can develop particular attributes in relation to the requirements posed by the relevant external environment ${ }^{15}$. From this perspective, integration is not an absolute quality or ideal. The necessary degree of integration is determined by 'the felt need for joint decision making', 
which also depends on the organization's specific circumstances. To what degree and in what way integration and differentiation are effective may even depend on the 'unique characteristics of each type of network studied'16.

Research in the field of social network analysis also addresses integration. Several authors mention network metrics to indicate integration in organizations or networks, thereby often referring to coordination between people, groups or organizations ${ }^{16-18}$. Differentiation is also mentioned in literature pertaining to social network analysis, when referring to tasks being differentiated ${ }^{16,19}$, but there are no specific metrics used that refer directly to differentiation. In his book, Kilduff ${ }^{17}$ states in a chapter on social network analysis that 'we await a full-blown contingency theory analysis of how trust-based coordinating mechanisms facilitate differentiation and integration'. The fact that this theory doesn't yet exist could be attributed to the widely reported 'embryonic' stage ${ }^{18}$ of social network analysis, as shown by two literature reviews ${ }^{20,21}$. At the same time, several studies view social network analysis as a promising method. Benham and Clancy ${ }^{22}$ view social network analysis as a new and creative method that is required to meet the complex problems of leaders in modern healthcare organizations. In multiple promising, though mostly exploratory studies, a relation between network structure and the performance of healthcare organizations or networks has been reported, both in terms of quality of care as well as efficiency. For example, Provan and Sebastian ${ }^{16}$ indicate that organizations perform more effectively when integration is established through small groups of highly connected agents, when agents are included in multiple groups. Haythornwaite ${ }^{23}$ points out that groups with strong relationships facilitate information exchange. Several authors mention the utility of 'brokers' or 'integrative devices' that join groups which are disconnected ${ }^{15-17,23}$. Various studies report tentative results in which a link is made between the network structure and performance parameters such as surgery lead time ${ }^{24}$, hospitalization cost ${ }^{19,25}$, process efficiency ${ }^{26}$, readmission rate ${ }^{25}$ and patient quality and safety outcomes ${ }^{27}$. At the same time these studies are said to provide weak evidence, which is attributed to the fact that social network analysis is an upcoming method $^{21}$.

In short, both contingency theory and social network analysis provide useful concepts for addressing the issue of integration in the logistical system of hospitals, but this needs to be explored further. Before we are able to say anything on how integration and differentiation may improve the performance of hospitals, we first need to know how a hospital and in particular its logistical system works. We need to know what the tasks are, who executes these tasks, how all tasks are aligned and whether we see integration and differentiation in the hospital system. Accordingly, the general objective of this research is to understand how a hospital's logistical system works and in particular to what extent 
there is integration and differentiation. Specific objectives for achieving the general objective are:

1. Identify the agents and the interactions between them for organizing logistical processes

2. Describe how the hospital organizes logistical processes

3. Identify integration and differentiation as they exist in the entire hospital network.

We believe that understanding how a hospital's logistical system works is a necessary first step towards improving the functioning of the hospital system. In this study, the hospital logistics are described from a system-wide perspective using social network analysis. To the best of our knowledge, this type of study has not been done before. Therefore this study should be considered exploratory. For this purpose a case study was conducted in a general hospital in the Netherlands, in which a social network analysis of the hospital's logistical system was performed.

In line with our objectives, we focus on the following three questions:

1. What are the tasks executed for hospital logistics and which agents execute these tasks?

2. Which agents interact in executing these tasks?

3. To what extent do we see integration and differentiation in the network?

\section{METHODS}

In this section we explain how and in what setting the study was performed, what data were collected and how they were analyzed through a social network analysis.

\section{Setting}

The study is based on the case study research method devised by Yin ${ }^{28}$. We selected Slingeland Hospital for our study because it is a relatively small Dutch hospital, has wellreported performance and the circumstances were relatively stable, as no large scale transformation projects were taking place. Additional selection criteria were good access to people and data. As a result of the merger with the Queen Beatrix Hospital in Winterswijk in 2017, this hospital became part of the larger Santiz group, but it functions largely as an independent full service hospital. The logistical operations for surgery across facilities were not combined in any way at the time of our research. 
Slingeland Hospital has around 1,600 staff members, including 120 physicians and 426 nurses. It services around 200,000 people in the area, and has 350 beds, which is below the average number of 450 beds for hospitals ${ }^{29}$. Slingeland Hospital performs higher on most logistical indicators than the average Dutch hospital, according to a Dutch OTC benchmark ${ }^{30}$. With an average of $89 \%$ operating room utilization in 2016, Slingeland has higher operating room (OR) utilization than the $82 \%$ average of Dutch hospitals that participate in a national benchmark. For other parameters, such as lateness and average surgery time, Slingeland performs better than the average hospital in the Dutch benchmark.

\section{Study design}

With regard to our first two objectives and research questions on the tasks that are executed for hospital logistics and the agents who interact in executing these tasks, data were collected from multiple sources and then analyzed through data triangulation following a mixed method approach. With regard to our third objective, to establish integration and differentiation, a social network analysis was performed ${ }^{31}$. This analysis reveals the structure of the hospital network; the metrics developed in social network analysis methodologies can indicate the degree of differentiation or integration.

Using a system-wide perspective, ideally we would describe the entire intraorganizational network of a hospital. However, given the exploratory nature of our research and to reduce complexity and increase feasibility, it was decided to focus on the social network that includes all agents of all departments that execute tasks for the benefit of surgery patients. This includes agents of outpatient departments, the preoperative screening department, the nursing departments, the Operating Theatre Complex, the Central Sterilization Unit and the holding and recovery areas. By including all departments that take part in organizing patient flows, material flows and staff flows, a large part of the hospital system was included, which is in line with a system-wide approach. Moreover, the network in place for surgery patients is important, given the fact that more than 60 percent of patients who are admitted to a hospital are treated in the operating theatre complex (OTC) ${ }^{2}$ and the OTC accounts for more than $40 \%$ of a hospital's total revenue, and a similar proportion of its total expenses 33 . We studied the entire intra-organizational network of the hospital, because internal agents are primarily responsible for organizing logistics for patients, thereby focusing on the integration and differentiation within the bounds of the hospital. 


\section{Data collection and analysis}

For establishing the tasks that are executed for hospital logistics (question 1) and which agents interact when executing these tasks (question 2), data were collected from four different sources: the Hospital Information System (HIS), documentation, observations and interviews. The data collection focused on identifying all tasks for surgery patients in 2017, including the interaction between the agents involved in these tasks. The collection and analysis of data from the HIS and documentation took place in January and February of 2018. Following that, observations took place between March and April of 2018. The findings from the data and from the observations resulted in some knowledge gaps, which were further explored in 11 interviews; these took place between May and September 2018.

The HIS data include registrations of surgeries performed in 2017, including date of surgery, staff involved, materials used and timestamps of different stages of the surgery patient's process, as well as of the nursing wards the patients were in before and after surgery. Other data of the HIS include, for example, the number of staff members and the planning schedules.

Documentation includes planning schemes, working procedures and internal presentations on internal processes which were valid at the time these were collected, at the start of 2018.

The daily work of 12 departments was observed on 14 different days. The observations took place in three outpatient departments, at the preoperative screening department, in two nursing departments, in the OTC and the Central Sterilization Unit and in the holding and recovery areas. The departments were selected because they execute tasks that contribute to the overall task of performing surgery. A total of 98 people were observed, including both staff and patients. Observations were conducted using a naturalistic approach, as described by Beuving and De Vries ${ }^{34}$. Each observation day was prepared by studying HIS data and working procedures in that department on the day before the observation took place. These data were used to formulate broad questions for the observer to keep in mind during the observation. In order to avoid creating a formal setting, the observer had casual conversations with the observed staff only when staff initiated this and if the observer felt that this contributed to keeping the situation natural. The observer made field notes of events including timestamps, conversations and observed behaviour, which were reported in an observation report.

For the interviews we selected people of different agent types that we had met during the observations, but with whom we had not spoken comprehensively, and we also selected people who were suggested to us by hospital staff whom we had met during data 
collection and observations. Two surgeons, one anesthesiologist, the cluster manager for the OTC and Services, two OTC team leaders, the OTC capacity planner, a business controller and the application controller were interviewed. For each interview a topic list was prepared; topics include the logistical tasks and interaction with other agents, which demands the agent has to deal with in relation to these other agents and how the network functions as a whole. All interviews were recorded and transcribed ad verbatim.

With these data, the logistical tasks that are executed for patients who have surgery and the order in which they are executed were identified. A task is seen as a 'complete inputtransformation-output cycle'15 for a particular intended result. The focus was on tasks which are triggered directly by the patient and for which interaction between agents was found. Interaction includes face-to-face contact or communication via telephone, email or text messages. Tasks relating to small surgeries that are performed in the outpatient departments were excluded.

Each source was used to identify the interaction relations between the agents involved in each task. For this, the data from the four sources, both quantitative and qualitative, were combined using data triangulation ${ }^{28}$. Interactions were first of all directly derived from HIS data; for example, who was involved in each surgery in 2018 is registered in the system, and it was observed that these agents interact during the surgery. Interactions were also derived from standard working procedures, which were both described and observed; these are interactions as they generally take place between agents with the same function or role. In addition, interviewees were asked specific questions on which agents interact with whom for task execution. In most cases the interactions were derived by combining data from all sources. For example, in the observations we saw that the surgeon visits the nursing ward to see his patients. In the interviews the surgeon explained that this is a daily activity and that he then always interacts with a ward nurse. From the HIS data it was derived how many surgeons and ward nurses there are and on which ward the patients of each surgeon were located. Appendix 3.1 shows which sources provided the input for establishing the interactions for each task.

For each task the working procedures and interactions were first described in text and then the interaction for task $\mathrm{N}$ between agent $\mathrm{A}$ and $\mathrm{B}, \mathrm{B}$ and $\mathrm{C}$ and so on were registered in an Excel database. Each agent was anonymized by using a code that consists of three letters of either the department or the medical discipline the agent works for and an abbreviation of the function of the agent and a number. A Urology surgeon is UROS1 with URO being the medical discipline, $\mathrm{S}$ for surgeon and 1 for the specific agent. This resulted in a structured database of 39,055 rows. Each line in the database represents an undirected communication link - a tie - between agents A and B for a specific task N. 
Each node in the network represents an agent, who is an individual person. Because this study focuses on identifying integration and differentiation by analyzing the social network structure, the interaction frequency was not included in the research and the ties do not have any weight. All interactions described are a result of working procedures and common ways of repetitively executing tasks throughout the year.

Having established the tasks, agents and interaction, a social network analysis was performed in order to elicit integration and differentiation (question 3). The social network was built up from the identified interactions between agents per task, as recorded in the database. The database was inserted in NodeXL, which was used to construct the social network, The Harel Koren Fast Multiscale Algorithm was used for structuring the network. This algorithm was developed specifically for the fast and clear visualization of large social networks ${ }^{36}$. It structures the network in such a way that agents who are linked and have similar links to other agents are positioned close to each other in the network. In addition, agents with a relatively high number of ties in comparison with other agents are positioned in the center of the network.

Specific concepts and measures of the social network that are related to the concepts of integration and differentiation were analyzed. In line with Provan ${ }^{16}$, Kilduff ${ }^{17}$ and Haythornwaite $^{23}$, density, degree, betweenness centrality and clique overlap were used as indications for integration. No metrics were found for differentiation in social network literature, but Kilduff ${ }^{17}$ and Monge ${ }^{18}$ associate differentiation with the existence of groups or cliques that consist of highly connected agents. There is a clique when all agents in a group are connected. These measures are presented in Table 3.1.

On a network level, the entire hospital network was analyzed to identify groups of densely connected agents. A group consists of highly connected agents in which case there is high density. Density is defined as size relative to the number of possible ties and calculated by the ratio of the number of actual links between nodes and the maximum possible edges for the network ${ }^{31}$. A relatively low density for the entire network suggests differentiation or, put the other way around, a lack of integration.

In addition to density we also looked at clique overlap and at multiplexity for integration in the entire network. There is clique overlap when agents are part of more than one clique, thereby connecting different cliques ${ }^{16,17}$. Clique overlap was calculated by dividing the number of agents participating in multiple cliques by the total number of agents. When there is clique overlap across different tasks, there is multiplexity ${ }^{16}$. Multiplexity is the percentage of agents in a clique for a task who are also members of cliques for any other task. 
Table 3.1 Definition of network concepts and metrics

\begin{tabular}{|c|c|}
\hline Concept & Definition \\
\hline Node & An agent \\
\hline Tie & $\begin{array}{l}\text { A communication link between two agents via email, text message, telephone or } \\
\text { face-to-face }\end{array}$ \\
\hline Group & A set of agents who are closely connected to one another \\
\hline Clique & A set of agents who are all connected to one another \\
\hline Subsystem & $\begin{array}{l}\text { A set of agents who are highly connected and execute a part of the organization's } \\
\text { overall task }\end{array}$ \\
\hline Broker & An agent who connects (otherwise) disconnected groups \\
\hline Density & $\begin{array}{l}\text { The number of ties a set of agents have in relation to the number of possible ties } \\
\text { they can have }\end{array}$ \\
\hline Clique overlap & $\begin{array}{l}\text { The percentage of agents who are members of more than one clique for a specific } \\
\text { task }\end{array}$ \\
\hline Degree & The number of ties of one agent \\
\hline $\begin{array}{l}\text { Betweenness } \\
\text { centrality }\end{array}$ & $\begin{array}{l}\text { The number of times a node (agent) lies on the shortest path between other nodes } \\
\text { (agents) }\end{array}$ \\
\hline Multiplexity & $\begin{array}{l}\text { The percentage of agents in a clique for a task who are also members of cliques for } \\
\text { other tasks. }\end{array}$ \\
\hline Centralization & $\begin{array}{l}\text { The extent to which a set of nodes (agents) are organized around a central node } \\
\text { (agent) }\end{array}$ \\
\hline
\end{tabular}

The clique analysis per task was performed in order to see how the organizational system is segmented into subsystems, following Lawrence and Lorsch's definition of subsystems ${ }^{15}$. Breaking down the structure of the overall task of the hospital network into smaller tasks reveals in what way tasks are differentiated. This was done by filtering the database by task and analyzing this part of the network in NodeXL accordingly. Cliques were also identified for each task, revealing possible smaller subsystems.

We looked at betweenness centrality for agents who act as a broker ${ }^{16,17}$ in the network. According to Haythornthwaite ${ }^{23}$ brokers are 'connections between disorganized others' and they carry information from one group to another. Agents with a high betweenness centrality have an intermediary position between others in the network ${ }^{23,31}$. This metric represents the number of times a node lies on the shortest path between two other nodes $^{37}$ and was calculated with the algorithm used in NodeXL ${ }^{38}$.

Further, we looked at centralization, which is defined as 'the extent to which a set of actors are organized around a central point'23. In a centralized network there is a high standard deviation in the degree of agents, i.e., in the number of ties, because some agents have a high degree and most others have a low degree39. Centralization may suggest differentiation, as agents around the central agents could be isolated from the rest of the network, as is the case for nodes $\mathrm{F}$ to $\mathrm{J}$ in the example presented in Figure 3.1. It is important to note that centralization in social network analysis is different from the 
widely accepted definition of Mintzberg, who states that centralization is related to decision- making power ${ }^{40}$.

In Figure 3.1 an example of the social network analysis is presented, including the metrics.

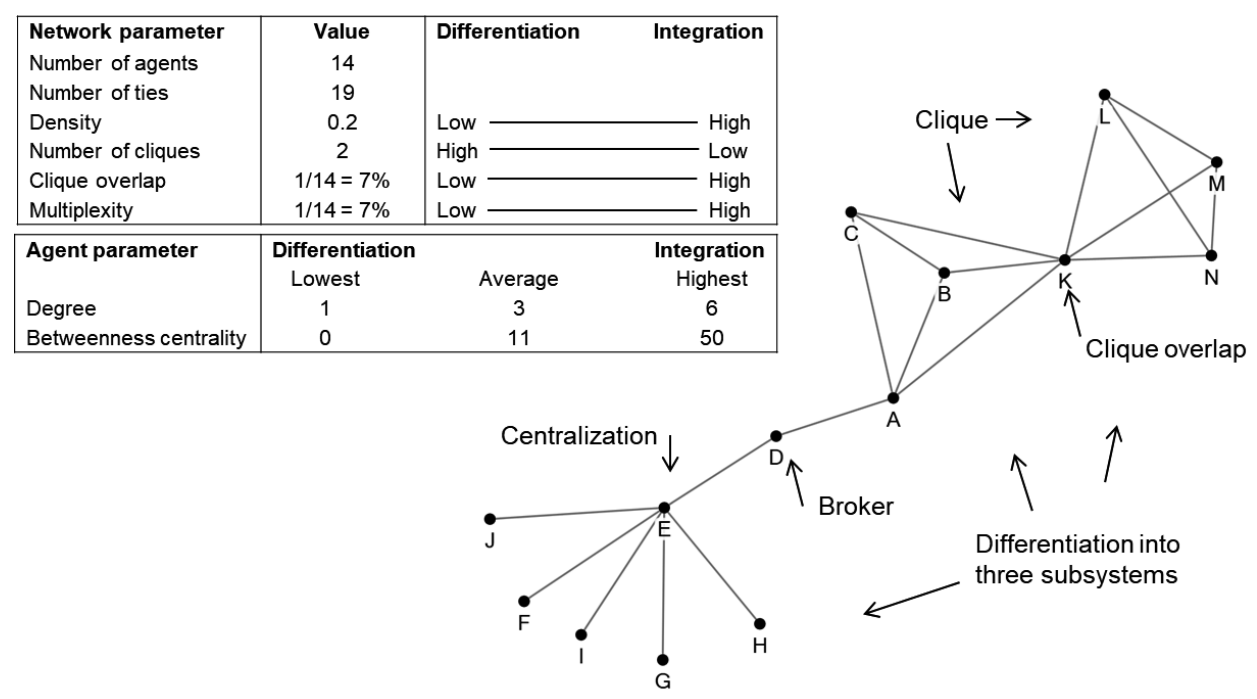

Figure 3.1 Example network with SNA concepts and metrics.

\section{Network validation}

For validation purposes, the social network per task was discussed face-to-face between August 2018 and November 2018 with ten hospital staff members who were also involved in the observations and interviews. Specific details were asked via email to specific members of hospital staff who perform the tasks identified. Remarks from hospital staff were reported in a validation report.

\section{RESULTS}

All tasks and interaction taking place between agents in executing these tasks are described in this section. Further, the entire hospital network, which is built up by these interactions, is presented and integration and differentiation are described. We start this section with some key figures on surgeries in Slingeland Hospital. 


\section{Output of the social network}

In 2017, 10,157 surgeries were performed in Slingeland Hospital. The number of surgeries varies from a minimum of 4 to a maximum of 246 surgeries a week. Of all surgeries, $83 \%$ are planned beforehand, i.e., they are not emergency procedures. Different types of surgeries are performed, which are registered according to 394 treatment codes in the HIS. These treatment codes are divided among nine medical disciplines: general surgery, orthopedics, Ear Nose Throat (ENT) surgery, eye surgery, urology, gynecology, plastic surgery, dental surgery and neurosurgery. Of all 394 treatment codes, on average $66 \%$ are performed once a month or less and 9\% are performed on a weekly basis. More than half of the treatment codes are executed by only one or two specific surgeons. For example, 103 treatment codes are performed by one specific, but not the same, surgeon. For $42 \%$ of all surgeries, there was a unique one time combination of treatment code, surgeon and anesthesiologist. This and the fact that in 2017 a total of 2,881 unique combinations of medical instrument sets were used, suggest that human and material resources are not fit for a large variety of surgeries, but are mostly suitable for specific surgeries.

\section{Agents and tasks performed for surgery}

The main task of the logistical system is to get the right patient, surgeon, anesthesiologist, nurses, materials and infrastructure together at the right time and in the right place. There are 23 tasks that are executed in order to achieve this, as presented in Table 3.2. Figure 3.2 shows the relation between 22 tasks, mostly based on the chronological order in which these are executed. In addition, the arrow between two tasks means that the output of a task is input to the task to which it is connected. Task 23, managing the OTC, is not specifically time dependent, nor is there specific output of this task and therefore it is not mentioned in Figure 3.2. Tasks 1 to 5 are at the tactical level because these concern master scheduling in the medium-term ${ }^{41}$. The other tasks are operational because they are related to short-term allocation of resources and execution. Long-term strategic tasks such as demand forecasting were found, but these do not relate directly to the tasks shown in Figure 3.2. Overall, two main groups of tasks are visible in Figure 3.2: tactical and operational planning 6 months ahead until the day before surgery and the execution of the surgery process. 


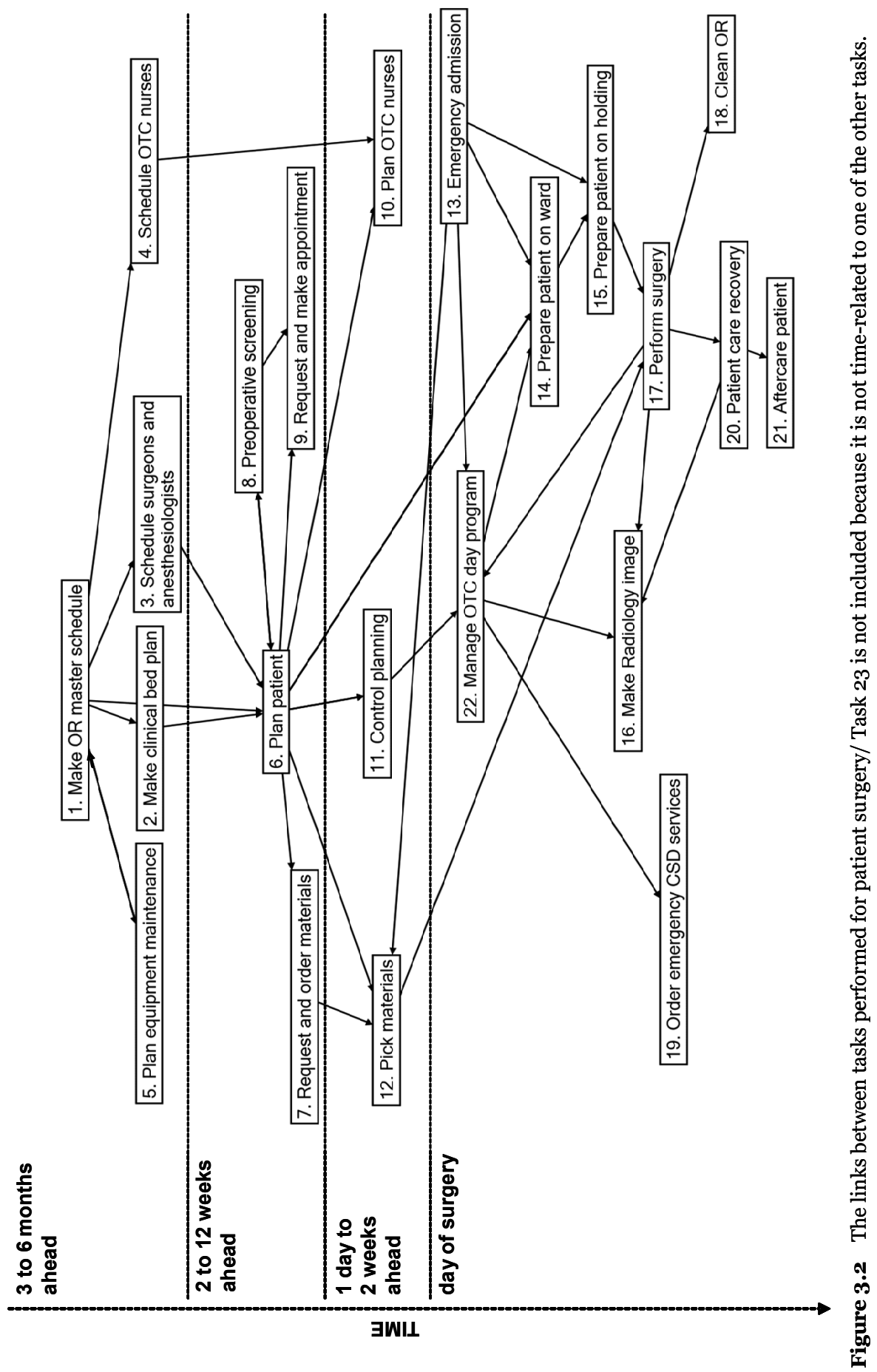




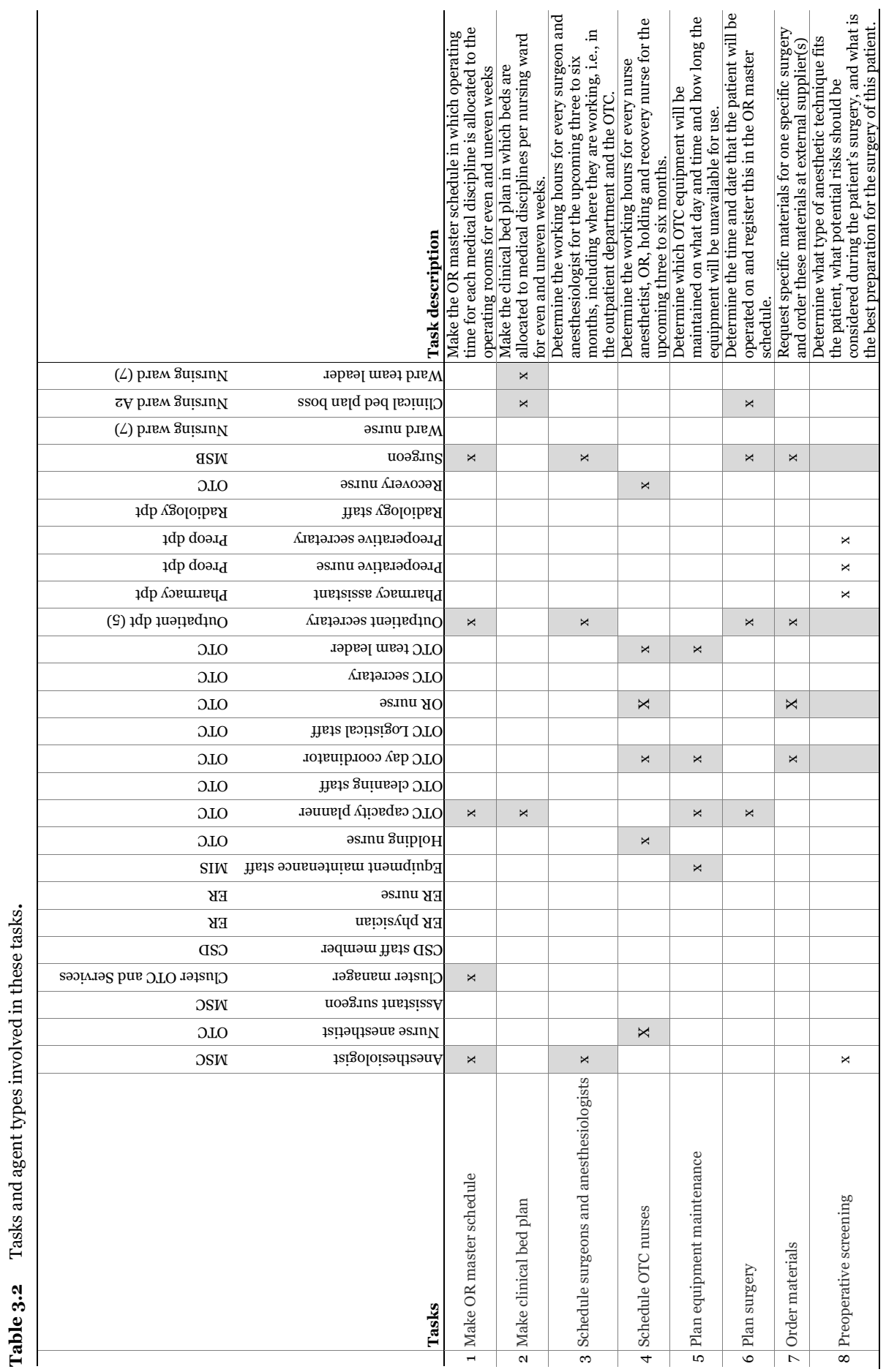




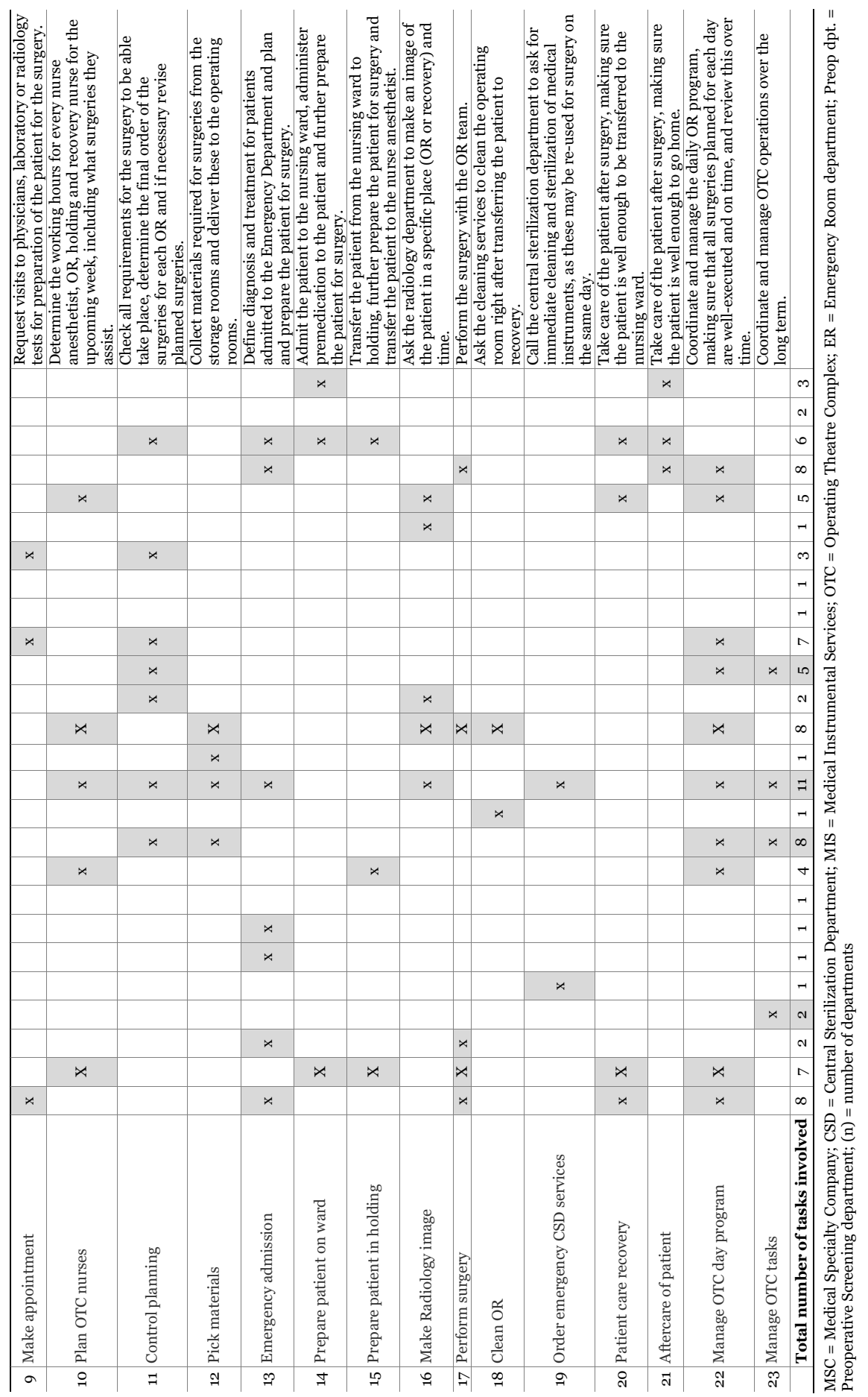


First the OR master schedule is made for a three-month period (task 1), two quarters ahead; the OR master schedule for Q2 of any year is made in Q4 of the previous year. In the OR master schedule, time slots for all ORs are allocated to the nine medical disciplines that operate in the OTC. The clinical bed plan (task 2), equipment maintenance planning (task 5) and staff schedules (tasks 3 and 4) are all derived from the OR master schedule. Around two to twelve weeks before surgery, patients are planned into the OR program (task 6) and preparations start: patients are screened by an anesthesiologist (task 8), materials are ordered (task 7) and patients are seen by other physicians or take radiology or laboratory tests (task 9). In the days before surgery further preparations are made: the OR day program is planned in more detail (task 11), staff is allocated to specific surgeries (task 10) and materials are picked (task 12). On the day of surgery the patient is prepared and held on the ward (task 14) before the actual surgery takes place (task 17) and is afterwards taken care of in the recovery area (task 20) and ward (task 21). In some cases a radiology image is made during or after surgery (task 16). After surgery the OR is cleaned (task 18) and if necessary the medical instruments are immediately cleaned for reuse (task 19). Patients can also be admitted for an emergency surgery (task 13), in which case all tasks are executed within a short period of time. All tasks have been specified in more detail in Appendix 3.2.

Tasks are related to patient, staff and material flows. Tasks 5, 7, 12, 18 and 19 are related to materials and tasks $1,3,4$ and 10 are about staff flows. Tasks 2, 8, 9, 13 and 16 are related to patient flow. The other tasks are related to more than one flow; for example, preparing a patient on the ward before surgery involves both the patient and medication.

For each task a number of agent types is involved, as presented in Table 3.2. The OTC day coordinator participates in 11 of the tasks and has the highest involvement in multiple tasks. The OTC capacity planner, anesthesiologists, surgeons and the OTC nurses all participate in eight different tasks. The other agents participate in fewer tasks, with a minimum of one. The task with the most different agent types involved is managing the OTC day program; ten different agent types play a role in this.

With regard to the flows, most agents are involved in tasks related to patients, staff and materials. The CSD staff members, equipment maintenance staff, OTC cleaning staff and the OTC logistical staff are the only agents who deal with just one flow type, which is materials.

Table 3.2 shows that a number of tasks have an overlap in types of participating agents. This is particularly relevant when tasks are related. For example, tasks 2, 3, 4 and 5 are all 
related to task 1 , and there is overlap in agent participation for the OTC capacity planner for tasks 1 and 2. The outpatient secretary, the anesthesiologist and the surgeon are all involved in both tasks 1 and 3. There are no overlapping agents for related tasks 1 and 4, 6 and 8, 6 and 14, 13 and 14 and 13 and 15. For tasks 4, 8 and 14 relevant information resulting from tasks 1 and 6 are communicated through the HIS, which then is the only information source for agents executing these tasks. For all other related pairs of tasks there are agents who participate in both tasks.

\section{The entire social network}

Figure 3.3 shows the entire social network with all agents and the ties between these agents. The names of all agents were abbreviated in the network figures and are explained in Appendix 3.3. Even though Figure 3.3 does not reveal the details of the network, it clearly shows that all agents are connected in one way or another and that there are no agents or cliques that are completely disconnected from the rest of the network. The relatively low density of 0.16 , as shown in Table 3.3, indicates that there are agents or groups which are less connected, suggesting differentiation. The high number of cliques also indicates the presence of subsystems, demonstrating differentiation. However, $65 \%$ of all agents are part of multiple cliques across two related tasks. This high multiplexity value implies that there is integration as well. The spread between average and highest values for degree and betweenness centrality suggest that a relatively small number agents play an integrative role.

Figure 3.3 also shows groups of agents who are closely connected, which suggests the presence of subsystems. We see groups of agents who share the same task or knowledge, or they deal with a specific patient group depending on age, condition or required length of stay. Examples of agents sharing the same task and patient group are on the top side edges of the network where we see the ER nurses and on the right side the nursing wards, which are all cliques; clockwise the groups of nurses are visible with codes KDVNUR, N2NUR, BoNUR, N1NUR, NoNUR, B2NUR, A2NUR. Each code starts with the name of the nursing department as defined by Slingeland Hospital, e.g., KDVNUR1, KDVNUR2 et cetera are nurses from department KDV. They also form subsystems because these nurses are all involved in the same task. Interestingly, the team leaders (WTEAM) of nursing wards Bo, N1, No, B2, IC have fewer connections to others in the hospital in comparison with the nurses, illustrated by their peripheral position in the network.

The group of intensive care (IC) nurses (ICNUR) form a clique as well, but they are more centrally positioned. This is because IC nurses have connections to all other nursing wards, as IC patients are always transferred to another nursing ward before they are 
discharged. Agents working in the daycare department F2, where patients stay because of their expected one-day length of stay, are also more centrally located because patients are transferred in case they need to stay the night.

All OR nurses (ORAS) also form a group, in three cliques, because they are divided into three clusters which are based on shared knowledge of medical disciplines. The holding and recovery nurses each have a clique as well. The anesthesiologists (AN) are visible as a group as well as the nurse anesthetists (ANNU), who are in the middle of the network. The surgeons do not form one group, but they form nine cliques that each share the knowledge of a specific medical discipline. Here we see separate subsystems according to medical discipline, which essentially all perform the same task. This is also the case for the secretaries of the outpatient departments, who are visible in the bottom left part of Figure 3.3.

The high number of cliques is largely explained by the fact that there are 7,640 unique cliques that perform surgery (task 17). This will be analyzed further in the network analysis of each task.

Table 3.3 Network metrics overall network.

\begin{tabular}{|c|c|c|c|}
\hline Network Parameter & \multicolumn{3}{|c|}{ Value } \\
\hline Number of agents & \multicolumn{3}{|c|}{635} \\
\hline Number of ties & \multicolumn{3}{|c|}{31,499} \\
\hline Density & \multicolumn{3}{|c|}{0.16} \\
\hline Number of cliques & \multicolumn{3}{|c|}{8698} \\
\hline Multiplexity & \multicolumn{3}{|c|}{$413 / 635=65 \%$} \\
\hline Agent parameter & Lowest & Average & Highest \\
\hline Degree & 1 & 99 & 399 \\
\hline Betweenness centrality & $\mathrm{O}$ & 347 & 31,379 \\
\hline
\end{tabular}

The average degree is 99 and standard deviation is 79, which suggests centralization, as there are relatively large differences between the number of ties of agents. The agent with the highest degree is a nurse anesthetist with 399 ties to other agents. The nurse anesthetists all have a high degree, with an average of 387 ties. On the day of surgery they have interaction with all surgery team members, including surgeons, anesthesiologists and OR nurses. Furthermore, they interact with all ward nurses, and with holding and recovery nurses throughout the year. This is also the case for holding and recovery nurses who have an average degree of 300 and 318 , respectively. The agents with relatively low degrees are on the edges of the network in Figure 3.3, e.g., all staff from the Central Sterilization Department (CSD) on the top left. In Appendix 3.3 the degrees of all agents are presented. 


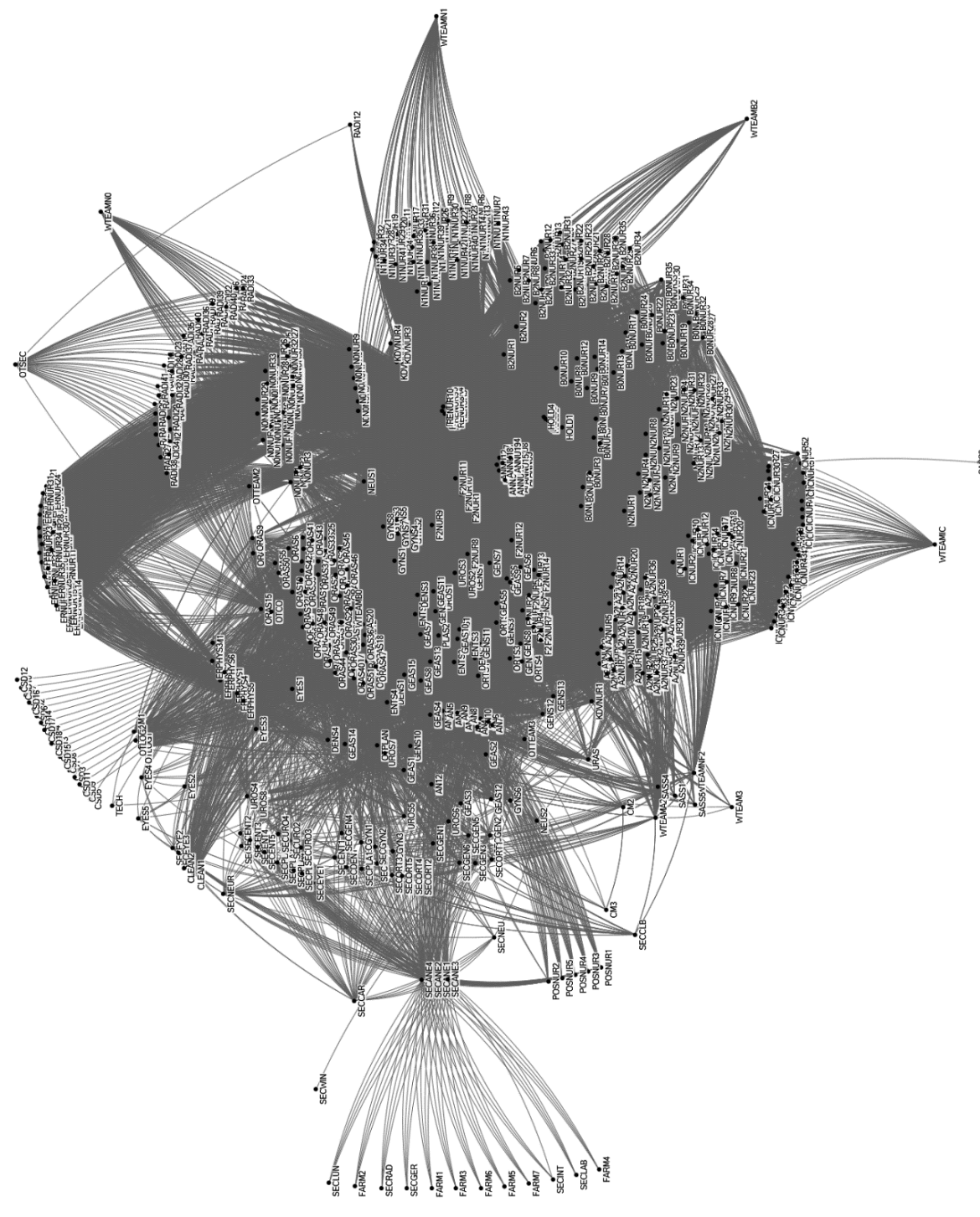

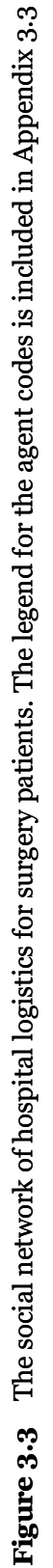


The OTC day coordinator (OTCO) has the highest betweenness centrality, which makes sense given the name of that function, but at the same time it is striking, because he does not contribute to multiplexity. The OTC capacity planner has the second highest centrality, and she has a strong integrative role between related tasks. The nurse anesthetists (ANNU) have high betweenness centrality as well as having a high degree, which also suggests a broker role.

The number of agents and communication links between them are different in the four time horizons which were presented in Figure 3.2. Table 3.4 clearly shows that the number of agents interacting and the density is higher on the day of surgery than before that day. If we look at the planning and execution phase, the density is 0.08 and 0.16 respectively. This suggests that, even though the overall network integration is low, in the months, weeks and days before surgery there is more differentiation and less integration than there is on the day of surgery. Furthermore, the OTC capacity planner plays a more prominent role before the day of surgery, whereas the OTC day coordinator is mainly involved on the day of surgery.

Table 3.4 Network metrics of the network over time.

\begin{tabular}{lcccc}
\hline Time horizon & $\begin{array}{c}\text { Number of } \\
\text { agents }\end{array}$ & $\begin{array}{c}\text { Number of } \\
\text { ties }\end{array}$ & Density & $\begin{array}{c}\text { Highest betweenness } \\
\text { centrality }\end{array}$ \\
\hline 3-6 months & 168 & 1,041 & 0.07 & OTPLAN \\
2-12 weeks & 146 & 695 & 0.07 & OTPLAN \\
1 day to 2 weeks & 144 & 428 & 0.04 & OTPLAN \\
Day of surgery & 605 & 30,135 & 0.16 & OTCO \\
\hline
\end{tabular}

In the next section we will go into more detail of the network for each task.

\section{Network analysis per task}

The social network per task is included in Figures A3.2.1 to A3.2.23 in Appendix 3.2. Table 3.5 shows the differences in network metrics between tasks. The number of participating agents varies from 4 to 391 , the density from a low 0.01 to the maximum of 1 , the number of cliques varies from zero to 7,640 and clique overlap is between zero and $92 \%$.

Tasks with a relatively low density suggest differentiation. In Appendix 3.2 we see two network structures for such tasks: a network with weakly connected or disconnected cliques and a network with centralization. Task 3 (Figure A3.2.3 in Appendix 3.2) is a clear example of a network with ten cliques that are all disconnected. Here we see differentiation according to medical discipline with regard to how surgeons and 
anesthesiologists are scheduled. Each medical discipline represents a subsystem. This is also the case for task 6 , but here the medical disciplines are situated around the OTC capacity planner in a star network.

Other tasks with a centralized network are 7, 9, 10, 12, 15, 18, 19, 20 and 22. The centralization is first explained by the fact that tasks are coordinated by the OTC day coordinator (tasks 7, 10, 19, 22). For the other tasks there is centralization because the central agent in each network interacts with each agent individually, while these agents do not interact with one another for that task. For example, on a regular basis the two logistical staff members ask all OR nurses, the OTC day coordinator and the OTC capacity planner for information on surgeries for which they pick the materials. Based on the definition of subsystems, these star networks do not have subsystems, because the agents are not highly connected.

Table 3.5 Network metrics for each task

\begin{tabular}{|c|c|c|c|c|c|c|c|c|}
\hline \multicolumn{2}{|r|}{ Tasks } & \multirow{2}{*}{$\begin{array}{c}\begin{array}{c}\text { Number } \\
\text { of agents }\end{array} \\
28\end{array}$} & \multirow{2}{*}{$\begin{array}{c}\begin{array}{c}\text { Number } \\
\text { of ties }\end{array} \\
110\end{array}$} & \multirow{2}{*}{$\begin{array}{c}\text { Density } \\
0.3\end{array}$} & \multirow{2}{*}{$\begin{array}{c}\begin{array}{c}\text { Number } \\
\text { of } \\
\text { cliques }\end{array} \\
2\end{array}$} & \multicolumn{2}{|c|}{$\begin{array}{c}\text { Clique } \\
\text { overlap }\end{array}$} & \multirow{2}{*}{$\begin{array}{c}\begin{array}{c}\text { Organization } \\
\text { unit }\end{array} \\
\text { Cross functional }\end{array}$} \\
\hline 1 & Make OR master schedule & & & & & 6 & $21 \%$ & \\
\hline 2 & Make clinical bed plan & 4 & 6 & 1.0 & 1 & $\mathrm{~N} / \mathrm{A}$ & & Cross functional \\
\hline 3 & $\begin{array}{l}\text { Schedule surgeons and } \\
\text { anesthesiologists }\end{array}$ & 70 & 206 & 0.09 & 10 & o & $0 \%$ & Cross functional \\
\hline 4 & Schedule OTC nurses & 88 & 801 & 0.2 & 6 & 1 & $1 \%$ & OTC \\
\hline 5 & Plan equipment maintenance & 4 & 6 & 1.0 & 1 & $\mathrm{~N} / \mathrm{A}$ & & Cross functional \\
\hline 6 & Plan patient & 92 & 315 & 0.08 & 48 & 1 & $1 \%$ & Cross functional \\
\hline 7 & Request and order materials & 61 & 139 & 0.08 & o & N/A & & Cross functional \\
\hline 8 & Pre-operative screening & 27 & 109 & 0.31 & 12 & 9 & $33 \%$ & Cross functional \\
\hline 9 & Request and make appointment & 56 & 140 & 0.09 & o & $\mathrm{N} / \mathrm{A}$ & & Cross functional \\
\hline 10 & Plan OTC nurses & 85 & 84 & 0.02 & o & $\mathrm{N} / \mathrm{A}$ & & OTC \\
\hline 11 & Control planning & 54 & 234 & 0.16 & 2 & 3 & $6 \%$ & Cross functional \\
\hline 12 & Pick materials & 55 & 107 & 0.07 & 53 & 2 & $4 \%$ & OTC \\
\hline 13 & Emergency admission & 139 & 2,840 & 0.30 & 1 & $\mathrm{~N} / \mathrm{A}$ & & Cross functional \\
\hline 14 & Prepare patient on ward & 314 & 11,071 & 0.23 & 171 & 19 & $6 \%$ & Cross functional \\
\hline 15 & Prepare patient on holding & 289 & 1100 & 0.03 & 285 & 4 & $1 \%$ & Cross functional \\
\hline 16 & Make radiology image & 53 & 491 & 0.36 & o & N/A & & Cross functional \\
\hline 17 & Perform surgery & 148 & 5,444 & 0.50 & 7,640 & 136 & $92 \%$ & Cross functional \\
\hline 18 & Clean OR & 53 & 102 & 0.07 & o & $\mathrm{N} / \mathrm{A}$ & & OTC \\
\hline 19 & Order emergency CSD services & 19 & 18 & 0.11 & o & $\mathrm{N} / \mathrm{A}$ & & Cross functional \\
\hline 20 & Patient care recovery & 241 & 2,355 & 0.08 & 285 & 10 & $4 \%$ & Cross functional \\
\hline 21 & Aftercare of patient & 391 & 12,537 & 0.16 & 178 & 266 & $68 \%$ & Cross functional \\
\hline 22 & Manage OTC day program & 184 & 189 & 0.01 & 1 & & & OTC \\
\hline 23 & Manage OTC tasks & 6 & 14 & 0.93 & 2 & 4 & $67 \%$ & OTC \\
\hline
\end{tabular}


Interestingly, the central agents in these star networks do not have a hierarchical position towards the agents around them, because the networks are cross functional (tasks 6, 7, 15, 19, 20). For tasks 4, 10, 12, 18 and 22 the central agents do not have a formal hierarchical position towards the other agents either.

For tasks with a higher density such as tasks 1, 2, 5, 8 and 11 we see integration, either by the presence of one clique (tasks 2 and 5) or multiple cliques (tasks 1, 8, 11). Furthermore, we see a network for task 14 with a highly connected group or subsystem with multiple agents in the center (Figure A3.2.14 in Appendix 3.2). Doing surgery in the OR (task 17) looks like a cloud of connections (Figure A3.2.17 in Appendix 3.2) because surgeons, anesthesiologists, OR nurses and nurse anesthetists work together in 7,640 different cliques.

Besides density, clique overlap is an indication of integration. For tasks 1, 8, 17, 21 and 23 there is a relatively high overlap of $33 \%$ up to $92 \%$, but for the other tasks clique overlap has a maximum of $6 \%$, in which case the integration depends on just a few agents.

Remarkably, almost all tasks in which integration is observed are all organized in a cross functional manner. Managing the OTC tasks is the exception here, as this is done by agents who work only for the OTC department.

With regard to betweenness centrality per task, different agents act as a broker. The OTC capacity planner is most central for making the OR master schedule and planning surgeries. The OTC day coordinator is most central for scheduling and planning OTC nurses, for ordering materials and for responding to emergency orders from the CSD. For other tasks the agents with the highest betweenness centrality are two surgeons (task 3), the preoperative nurses and secretaries (task 8), the Neurology and Cardiology nurses (task 9), OTC logistical staff (task 12), the nurse anesthetists (task 14), holding nurses (task 15), one OR nurse (task 17), cleaning staff (task 18) and recovery nurses (task 20).

If we consider the four time periods of Figure 3.2 we see that the values for numbers of cliques and clique overlap are significantly higher on the day of surgery than for before that. This suggests that there is more differentiation as well as integration on the day of surgery than in the phases before. The high number of cliques is explained mainly by the fact that teams often interact for one specific patient; because these teams change frequently throughout the year, this results in a high clique overlap. In contrast, in the first phase, six to three months before surgery, there is a permanent smaller set of agents who make the OR master schedule, the clinical bed plan and equipment maintenance plan. Here we mainly see integration and no differentiation. At the same time the scheduling of surgeons and anesthesiologists (task 3 ) is executed by disconnected cliques, which shows differentiation. 


\section{DISCUSSION}

This study aims to understand how a hospital's logistical system works and in particular to what extent there is integration and differentiation. The three specific objectives are (1) to identify the tasks that are performed in arranging the logistics for a hospital's surgery patients and (2) to establish which agents involved in these tasks interact with each other. In addition, (3) the degree of integration and differentiation in the entire hospital network is established. In total, 23 logistical tasks that are executed in-hospital for surgery patients have been identified. Twelve tasks are related to planning and eleven tasks are performed in executing surgeries by 635 different agents of 26 different agent types. The social network analysis shows that in the execution of these tasks there are 31,499 ties between these agents representing social interaction.

In the entire social network of the hospital both integration and differentiation are observed. The overall hospital network has a relatively low network integration, according to the low density, and there is differentiation in the execution of tasks per medical discipline, organizational unit and cross functional groups. Despite the overall low network degree, integration is demonstrated in cliques, in high clique overlap for several tasks and in multiplexity.

In contrast to the literature, which states that tasks are performed within functional silos $^{1,4}$, this study shows that most tasks in the case are executed across functional silos. Agents are involved in many different tasks, which are related to patient, material and staff flows. Apart from the way patients are admitted, there is no difference in tasks and involved agents between emergency and planned surgeries. There are several agents who act as a broker, but the OTC day coordinator and the OTC capacity planner are the only two agents whose primary task is to perform typical broker tasks such as network coordination and planning. Their betweenness centrality is substantially higher than for other agents. Besides these two agents, many nurses are brokers, as demonstrated by the relatively high degree and betweenness centrality of the nurse anesthetist, OR, holding, recovery and ward nurses. Other agents who integrate tasks are surgeons and anesthesiologists.

The social network analysis also demonstrates that agents with management roles, such as the cluster manager of the OTC and Services or team leaders, have a relatively low degree and betweenness centrality. Even in networks with centralization, the position of central agents is not based on hierarchy or formalized decision power. Almost all central agents in the networks per task have no hierarchical position with regard to other agents. 
These findings suggest that the hospital's logistical system works differently than what is assumed in logistical and organizational literature with regard to hospitals. The network of Slingeland Hospital does not reflect its formal organizational structure. Nevertheless, interestingly enough, when we look at the hospital's performance, the system as described seems to function.

One explanation might be that in research, informal processes or interaction are not included, even though these take place in practice, due to the high variation in patient demand and uncertainty in the system. We could also argue that the hospital's logistical network is a relatively independent system, in which patient care is exclusively the domain of nurses and physicians, who have to solve issues and deal with situations each day as they present themselves. The social interaction that takes place on the day of surgery may imply that, despite the planning activities in the months and weeks before surgery, there is a continuous real-time adjustment process taking place in the system. This relates to a relevant topic, namely organizational structure versus governance. Provan states that network structures can be very effective in terms of learning ability, efficient resource use and problem solving capacity, but that little is known about how to control and manage these networks ${ }^{42}$. The fact that managing agents seem to have a relatively low integrative role in the network that was studied could be a risk. This is particularly the case because this integration lies mainly with two agents and there is little redundancy of agents performing integrative roles.

The fact that there appears to be so much social interaction also raises questions with regard to the HIS, because the IT system does not seem to replace the interaction needs of agents. This could be because IT systems, which require standardization and uniformity of operational processes ${ }^{9}$, do not fit a reality that is much more varied and uncertain. There could also be a mismatch between the formal and informal organizational memory, in which data and knowledge are stored in both the IT system and in the heads of individuals, as stated by Van Merode et al.9. This mentioned possible shortcoming of an IT system to present data in line with reality is in line with van Merode et al.'s statement that 'processes may fail in unpredictable ways and may be difficult to trouble-shoot and correct'9. In addition, strategic decisions that impact the operational system could also have unexpected outcomes if these decisions are made without knowing how the operational network functions. We believe it is important to link the operational and the strategic systems of hospitals and study how these should be integrated and differentiated.

The findings of this case study raise the important question as to what extent the logistical hospital system generally functions as described here. A clear limitation of this study is 
that this is a first case, both in using a system-wide perspective as well as the application of social network analysis theory to do so. Furthermore, the exclusion of external agents and the patients in our research limits our perspective on the functioning of the system in relation to its environment. A third limitation is the fact that interaction frequency and specific time aspects were excluded; consequently, the importance of one interaction over the other is not identified. Last but not least, based on this research, we do not know how network structure relates to the hospital's performance, which is highly relevant, since improving hospital performance is an important motivation for this type of study. However, in line with Yin, this exploratory study has seized the opportunity 'to shed empirical light on some theoretical concepts or principles'28. Rather than generalizing these findings statistically, this case study should be used for analytic generalization ${ }^{28}$, either by defining new research or by reinterpreting other studies or cases in this field. There are several issues we propose to explore further.

First, an important question to consider is what is the relation between the network structure, in particular integration and differentiation and its performance. In social network theory, several statements have been made regarding the efficiency, effectiveness, flexibility and vulnerability of networks. Kilduff ${ }^{17}$, for example, states that a clique 'represents maximum inefficiency'. Although this statement was put forth in a technical treatise of network structures, the redundant and repetitive interaction between agents in Slingeland Hospital raises questions with regard to the efficient use of resources, in particular concerning the efficient use of physicians and nurses. In relation to efficiency, Provan states that cliques should not be too large nor should the number be too high ${ }^{16}$, and Volland states that relieving medical staff from activities that are not directly patient-related could improve the quality of health care ${ }^{43}$. On the other hand, the high number of cliques and redundancy may be effective in dealing with the complexity of the logistics of surgery. The fact that surgeons, OR nurses and nurse anesthetists collaborate in many different cliques may increase network flexibility. In order to assess hospital performance we believe a new framework is required, which must include multiple parameters relating to the interests of individual agents and the various demands stemming from the hospital's environment, both within parts of the hospital network as well as on a hospital-wide level ${ }^{13}$.

A second topic is how integration is best achieved in hospitals. There are vulnerabilities in the network of Slingeland Hospital, because without the OTC capacity planner and the OTC day coordinator the system would fall into fragmented parts, creating so-called structural holes ${ }^{17}$. In addition, as nurses, surgeons and anesthesiologists perform integrative tasks, it may be a burden for them to perform tasks directly related to patient care. Also, it's important to address the role of management and brokers and whether 
they should coincide or not. Further research is necessary to determine how many brokers are required and how they should be positioned in relation to managers, physicians and nurses.

In addition, given the statements of Lawrence and Lorsch ${ }^{15}$ and Provan ${ }^{16}$ that integration and differentiation should fit the demands of the hospital environment, it is important to examine how the network structure fits the demands that are put on the hospital system, not just by patients but also by policy makers, insurance companies and other stakeholders. Van Merode et al. also state that organizations, 'according to contingency theory should adopt a mechanistic form if their task is simple and stable and their goal is efficiency and they should adopt an organic form if their task is complex and changing and their goal is therefore flexibility'9. From this network analysis no clear distinction between simple or complex tasks emerged. Following van Merode et al's statement that a different control system should be designed if there is no homogeneity in the hospital's services 9 , it is important to study further the distinction between the more 'mechanistic' part of the hospital and tasks requiring more 'organic' flexible structures.

A third research area is how social network theory and the associated metrics relate to the concepts of integration and differentiation. The metrics used here represent a mathematical value for integration and need to be linked to concepts in organization theory. The concepts used in organization theory and social network analysis are not always the same. It is important to note, for example, that "centralization" as defined by Mintzberg 40 is not the same as centralization in social network theory. Mintzberg associates centralization with decision power. For instance, "vertical centralization" entails that decision-making power is centrally located at the strategic apex of an organization. An agent who is in a central position in a social network can be a member of the strategic apex, but this is not necessarily the case. For differentiation the concepts of social network theory are even less clear. In this study we explored these concepts, but we believe this has to be studied further for developing social network theory.

The main strength of this study is that it presents a new perspective on the hospital's logistical system and responds to the statement that most studies fail to address the entire hospital supply chain or network ${ }^{1}$. This study also responds to the fact that hospital-wide studies have not been performed using quantitative techniques, and optimization is often based on 'policy' and 'experience' rather than on data43. Although we have not studied optimization, this study could be a fruitful basis for doing that, thereby developing logistical and organizational theories that are coherent with the hospital's practice. 


\section{CONCLUSIONS}

In conclusion, this social network analysis of a hospital's logistical network, the first as far as we know, sets a basis for further research on integration and differentiation. It identifies a possible gap between existing organizational perspectives on hospitals and the reality. This should be analyzed further in order to be able to increase the effectiveness of hospitals. A first step would be to replicate the methods applied here in other hospitals. More case study research in the future would enable academia to develop new theories on the organization of hospitals. This knowledge is important for healthcare policy makers and for the strategic management of hospitals; it can support the effective integration and differentiation of tasks in both the operational system and the strategic system, within hospitals or even in regional healthcare alliances. 


\section{REFERENCES}

1. Drupsteen J, Van der Vaart T and Van Donk DP. Integrative practices in hospitals and their impact on patient flow. International Journal of Operations \& Production Management 2013;33:912-933.

2. Kodner DL, Spreeuwenberg C. Integrated care: meaning, logic, applications and implications a discussion paper. International Journal of Integrated Care 2002; DOI: http://doi.org/10.5334/ijic.67

3. Lega F, Marsilio $M$ and Villa S. An evaluation framework for measuring supply chain performance in the public healthcare sector: evidence from the Italian NHS. Production Planning \& Control 2013;24:931-947.

4. Aronsson H, Abrahamsson M and Spens K. Developing lean and agile health care supply chains. Supply Chain Management: An International Journal 2011;16:176-183.

5. Przywara B. Projecting future health care expenditure at European level: drivers, methodology and main results. Brussels: European Commission Directorate-General for Economic and Financial Affairs, 2010.

6. Morgan D and Astolfi R. Financial impact of the GFC: health care spending across the OECD. Health Economics, Policy and Law 2015;10:7-19.

7. De Vries J and Huijsman R. Supply Chain Management in health services: an overview. Supply Chain Management: An International Journal 2011;16:159-165.

8. Ludwig M, Van Merode GG and Groot W. Principal agent relationships and the efficiency of hospitals. Eur J Health Econ 2010;11:291-304.

9. Van Merode GG, Groothuis S, Hasman A. Enterprise resource planning for hospitals. International Journal of Medical Informatics 2004;73:493-501.

10. Villa S, Barbieri M and Lega F. Restructuring patient flow logistics around patient care needs: implications and practicalities from three critical cases. Health Care Manag Sci 2009; 12(2): $155-165$.

11. Litvak N, Van Rijsbergen M, Boucherie RJ, et al. Managing the overflow of intensive care patients. European Journal of Operational Research 2008; 185: 998-1010.

12. Borges GA, Tortorella G, Rossini M, Portioli-Staudacher A. Lean implementation in healthcare supply chain: a scoping review. Journal of Healthcare Organization and Management 2019; 33(3):304-322

13. Van der Ham A, Boersma H, Van Raak A, Ruwaard D and Van Merode G.G. Identifying Logistical Parameters in Hospitals: Does literature reflect integration in hospitals? A scoping study. Health Serv Manage Res 2019; 32(3); 158-165.

14. Lawrence PRL, Lorsch JW. Organization and environment: managing differentiation and integration. Boston: Division of Research, Graduate School of Business Administration, Harvard University; 1967.

15. Lawrence PRL, Lorsch JW. Differentiation and Integration in Complex Organizations, Administrative Science Quarterly 1967;12:1-47.

16. Provan KG, Sebastian JG. Networks within Networks: Service Link Overlap, Organizational Cliques, and Network Effectiveness. The Academy of Management Journal 1998;41(4):453-463

17. Kilduff M, Tsai W. Social networks and organizations. London: SAGE Ebook; 2003. Accessed 6 September 2018. 
18. Monge PR, Contractor N. Emergence of Communication Networks. In: Jablin FM, Putman LL, editors. The New Handbook of Organizational Communication. Thousand Oaks: Sage publications, 2011. pp. 440-502.

19. Uddin MS, Hossain L. Social Networks Enabled Coordination Model for Cost Management of Patient Hospital Admissions. Journal for Healthcare Quality 2011;33:37-48.

20. Benton DC, Pérez-Raya F, Fernández- Fernández, MP, González-Jurado MA. A systematic review of nurse-related social network analysis studies. International Nursing Review 2015;62: 321-339.

21. Chambers D, Wilson P, Thompson C, Harden M, Coiera E. Social Network Analysis in Healthcare Settings: A Systematic Scoping Review. PLoS One 2012;7,e41911.

22. Benham-Hutchins M, Clancy TR. Social Networks as Embedded Complex Adaptive Systems. JONA: The Journal of Nursing Administration 2010;40:352-356.

23. Haythornthwaite C. Social Network Analysis: an approach for the study of information exchange LISR 1996;18:323-342.

24. Anderson C, Talsma A. Characterizing the Structure of Operating Room Staffing Using Social Network Analysis. Nursing Research 2011;60:378-385.

25. Uddin S, Hossain L, Alam A, Hamra J. A study of physician collaborations through social network and exponential random graph. BMC Health Services Research [Online] 2013;13.

26. Samarth CN, Gloor PA. Process efficiency. Redesigning social networks to improve surgery patient flow. Journal of healthcare information management 2009;23:20-6.

27. Effken JA, Carley KM, Gephart S, Verran JA, Bianchi D, Reminga J, Brewer BB. Using ORA to explore the relationship of nursing unit communication to patient safety and quality outcomes. International Journal of Medical Informatics 2011; 80: 507-517.

28. Yin RK. Case study research - Design and Methods. 5e edition Thousand Oaks: Sage Publications, 2014.

29. Van Hulst B, Blank J. Nederlandse ziekenhuizen te groot voor verdere schaalvoordelen. Economisch-Statistische Berichten 2017;102(4749):226-228.

30. Benchmark Coppa Consultancy. Online database. Accessed 11 July 2018.

31. O'Malley AJ and Marsden PV. The Analysis of Social Networks. Health Serv Outcomes Res Methodol. 2008;18(4):222-269.

32. Eijkemans MJ, van Houdenhoven M, Nguyen T, Boersma E, Steyerberg EW, Kazemier G. Predicting the unpredictable: a new prediction model for operating room times using individual characteristics and the surgeon's estimate. Anesthesiology. 2010;112:41-9.

33. Peltokorpi A. How do strategic decisions and operative practices affect operating room productivity? Health Care Manag Sci. 2011;14:370-82.

34. Beuving J, De Vries G. Doing Qualitative Research: The Craft of Naturalistic Inquiry. Amsterdam: Amsterdam University Press, 2015.

35. Smith M, Ceni A, Milic-Frayling N, Shneiderman B, Mendes Rodrigues E, Leskovec J, Dunne C, NodeXL: a free and open network overview, discovery and exploration add-in for Excel 2007/2010/2013/2016, from the Social Media Research Foundation: https://www.smrfoundation.org; 2010.

36. Harel D, Koren Y. A Fast Multi-Scale Method for Drawing Large Graphs. Israel: The Weizmann Institute of Science, 2001. 
37. Hansen DL, Smith MA, Shneiderman B. Analyzing Social Media Networks with NodeXL: Insights From a Connected World. San Francisco: Morgan Kaufmann, 2011.

38. Brandes U. A faster algorithm for betweenness centrality. The Journal of Mathematical Sociology 2001; 25(2): 163-177.

39. De Brún A, Mcauliffe E. Social Network Analysis as a Methodological Approach to Explore Health Systems: A Case Study Exploring Support among Senior Managers/Executives in a Hospital Network. International journal of environmental research and public health 2018;15:3.

40. Mintzberg H. Structures in Five: designing effective organizations. Englewood Cliffs: PrenticeHall, 1983.

41. Zhu S, Fan W, Yang S, Pei J, Pardalos PM. Operating room planning and surgical case scheduling: a review of literature. Journal of Combinatorial Optimization 2019;37:757-805.

42. Provan KG, Kenis P. Modes of Network Governance: Structure, Management, and Effectiveness. Journal of Public Administration Research and Theory 2008;18(2):229-252.

43. Volland J, Fugener A, Schoenfelder J, Brunner JO. Material logistics in hospitals: A literature review. Omega 2017;69:82-101. 
APPENDIX 3.1: DATA COLLECTED AND USED FOR SOCIAL NETWORK ANALYSIS PER TASK

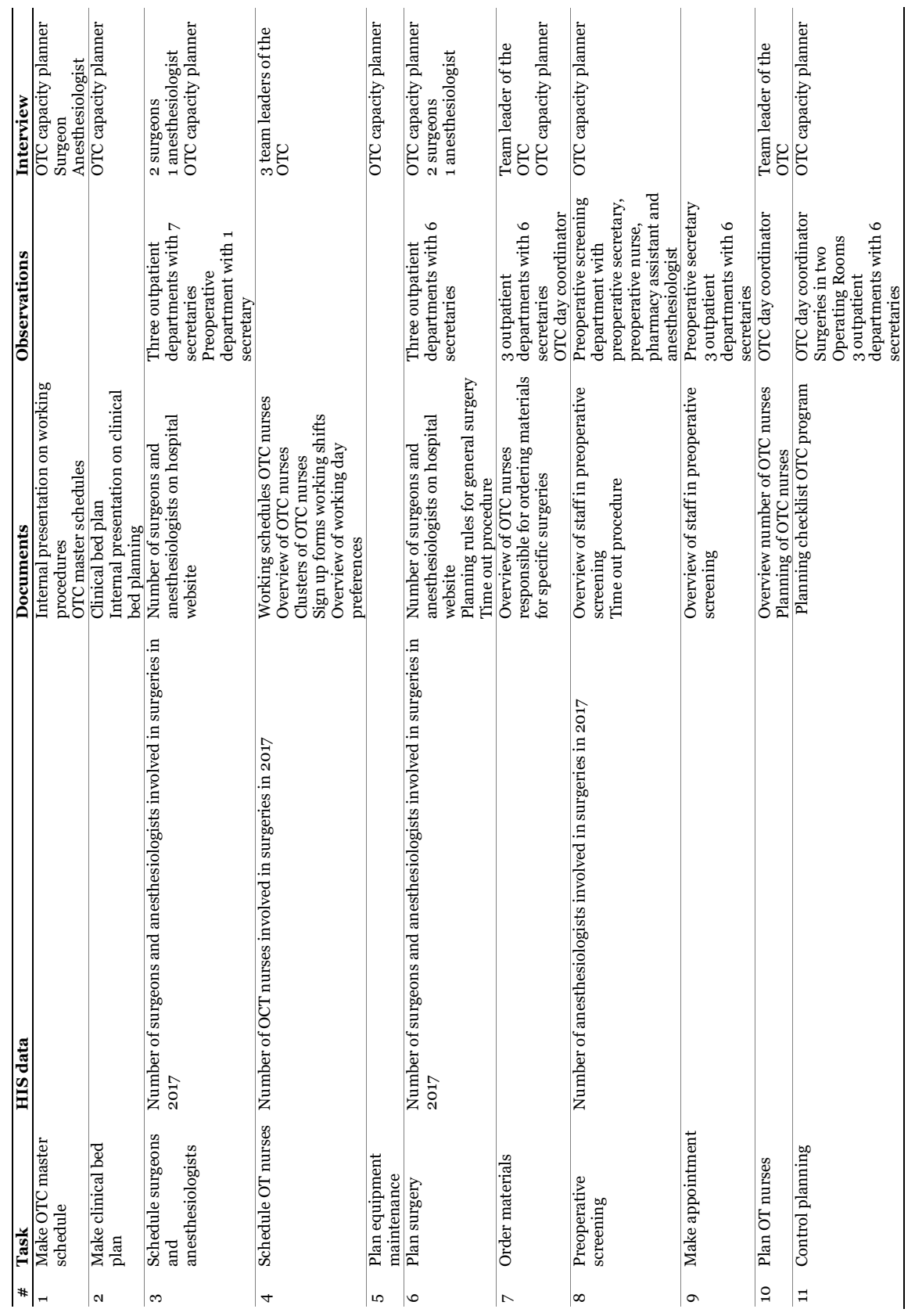




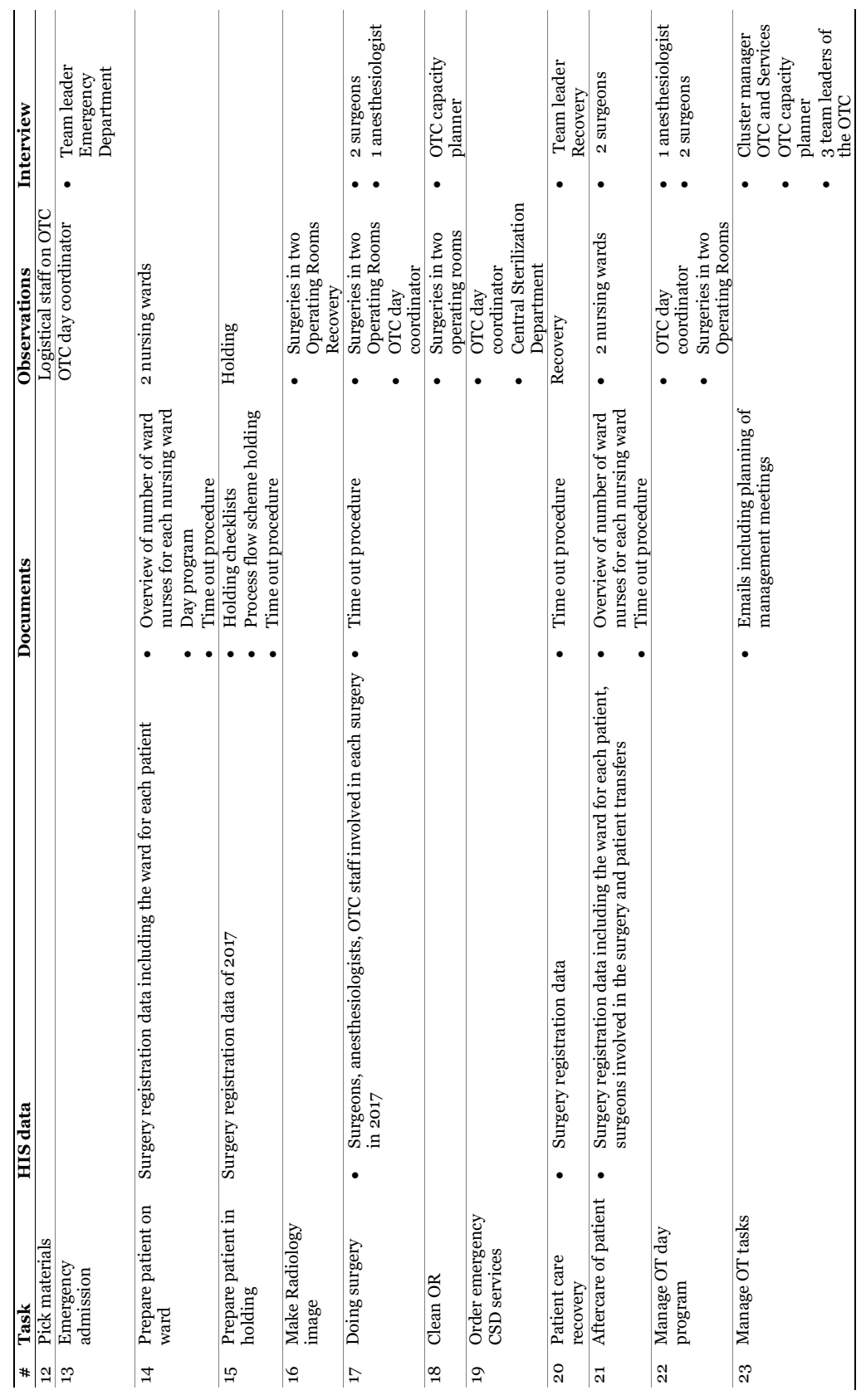




\section{APPENDIX 3.2: SOCIAL NETWORK PER TASK}

\section{Make the OR master schedule}

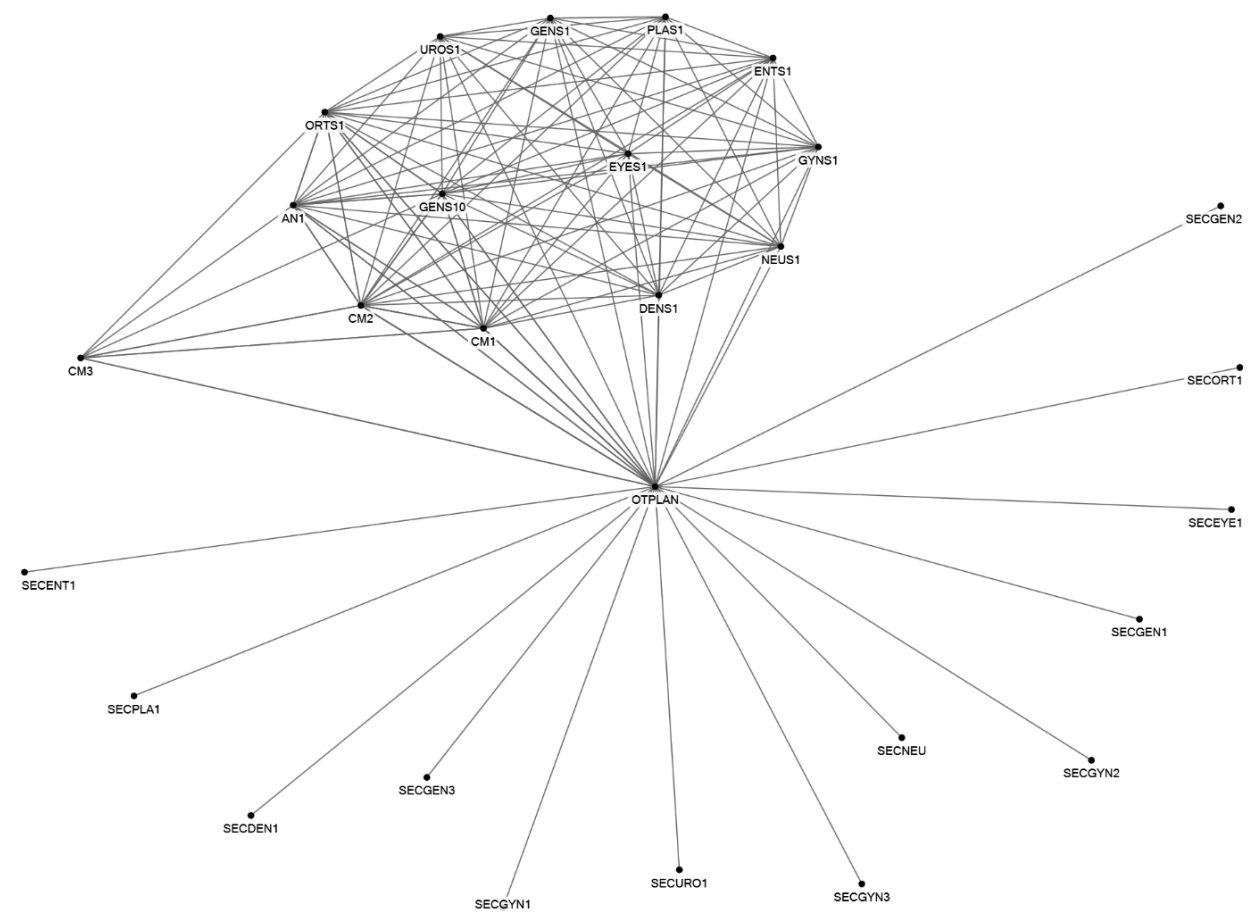

Figure A3.2.1 Social network of Task 1: Making the OR master schedule.

The Operating Room (OR) master schedule is made in the Tactical Planning Meeting (TPM). Three cluster managers who are responsible, respectively, for outpatient, inpatient departments and Operating

\begin{tabular}{lc}
\hline Parameter & Value \\
\hline Number of agents & 28 \\
Number of unique ties & 110 \\
Density & 0.29 \\
Number of cliques & 2 \\
Highest betweenness centrality & OTPLAN \\
\hline
\end{tabular}
Theatre Complex (OTC), three general surgeons, an orthopedic surgeon, an anesthesiologist and the OTC capacity planner participate in this meeting. The OR master schedule is prepared by four participants of the TPM, who then propose the scheme to the entire TPM. The OR master schedule is then presented to the OTC commission. The OTC commission discusses and advises OTC management on planning, staff and budget issues. The OTC commission includes one surgeon from every surgical discipline, the cluster manager responsible for the OTC and the OTC capacity planner. When the session schedule is final, the OTC capacity planner informs all outpatient secretaries of all changes made. 


\section{Make the clinical bed plan}

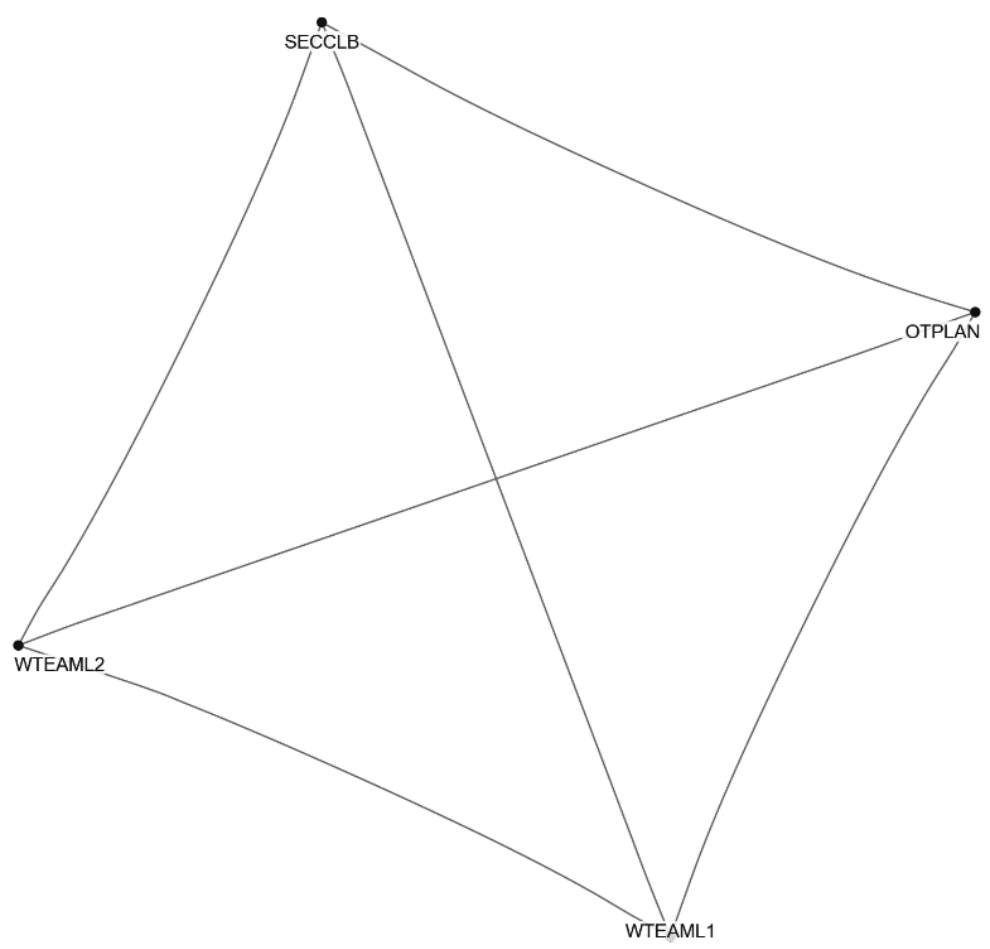

Figure A3.2.2 Social network of Task 2: Making the clinical bed plan.

In the clinical bed plan, beds are assigned to a medical discipline for each nursing department. The clinical bed plan is established in consultation between the OTC capacity planner, one secretary from the nursing

Parameter

Number of agents

Number of unique ties

Density

Number of cliques

Highest betweenness centrality
Value department and the two team leaders of the three nursing wards who host most surgery patients. The team leaders of these nursing wards are also involved in making the clinical bed plan, but one nurse ward secretary has the informal role of 'clinical bed plan boss'. She uses this plan to correct outpatient clinics when they take a bed they cannot claim. 


\section{Schedule surgeons and anesthesiologists}
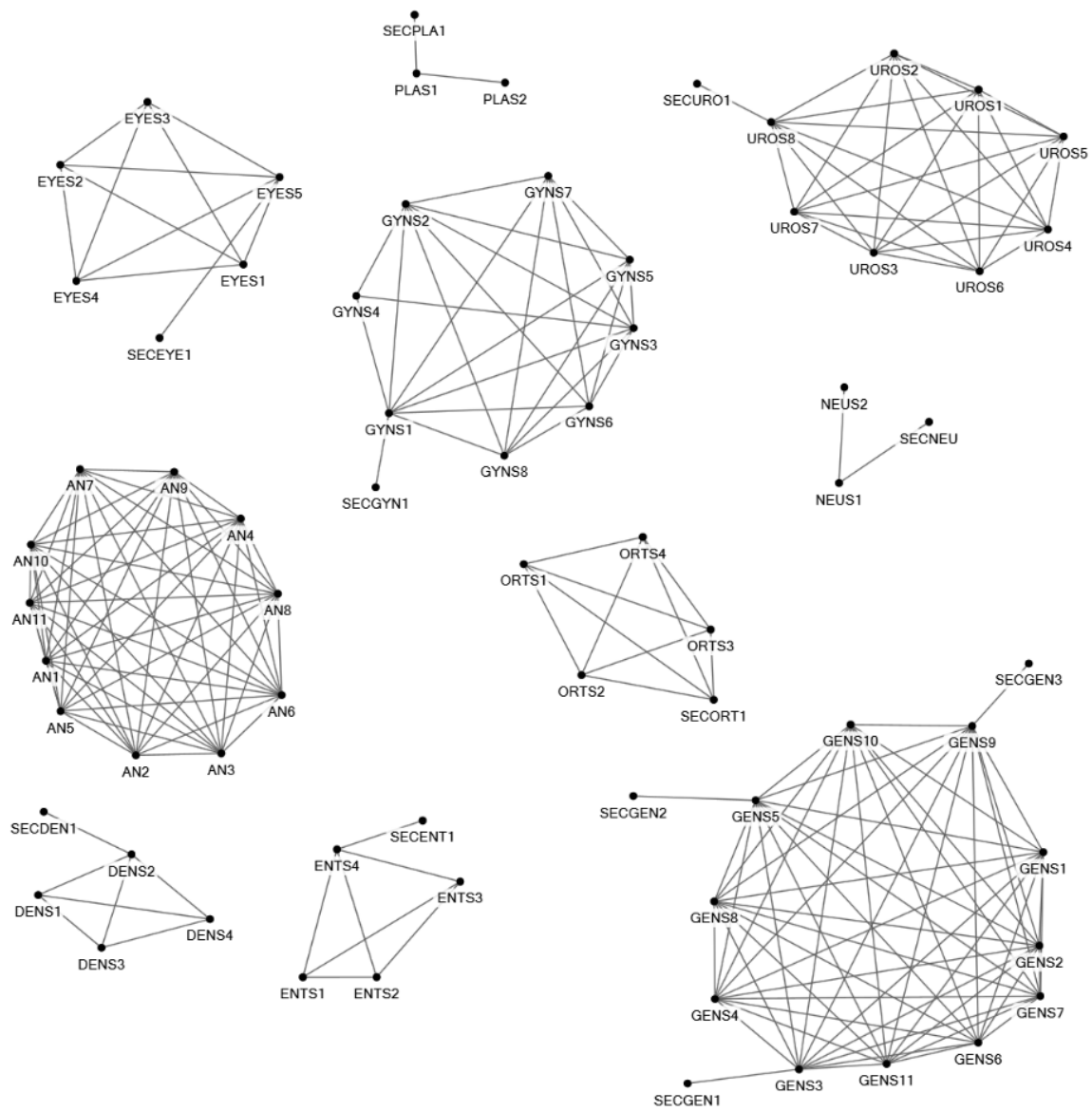

Figure A3.2.3 Social network of Task 3: Scheduling surgeons and anesthesiologists.

The OR master schedule is also used for preparing staff planning schemes. The surgeons of each outpatient department and anesthesiologists make these schedules for themselves and allocate

\begin{tabular}{lc}
\hline Parameter & Value \\
\hline Number of agents & 70 \\
Number of unique ties & 206 \\
Density & 0.09 \\
Number of cliques & 10 \\
Highest betweenness centrality & GENS $_{3} /$ GENS9 \\
\hline
\end{tabular}
surgeons to the time slots in the OR master schedule. One surgeon within each medical discipline group proposes the schedule and discusses it with the other surgeons. In some outpatient departments the secretary of the outpatient department is involved in this. 


\section{Schedule OTC nurses}

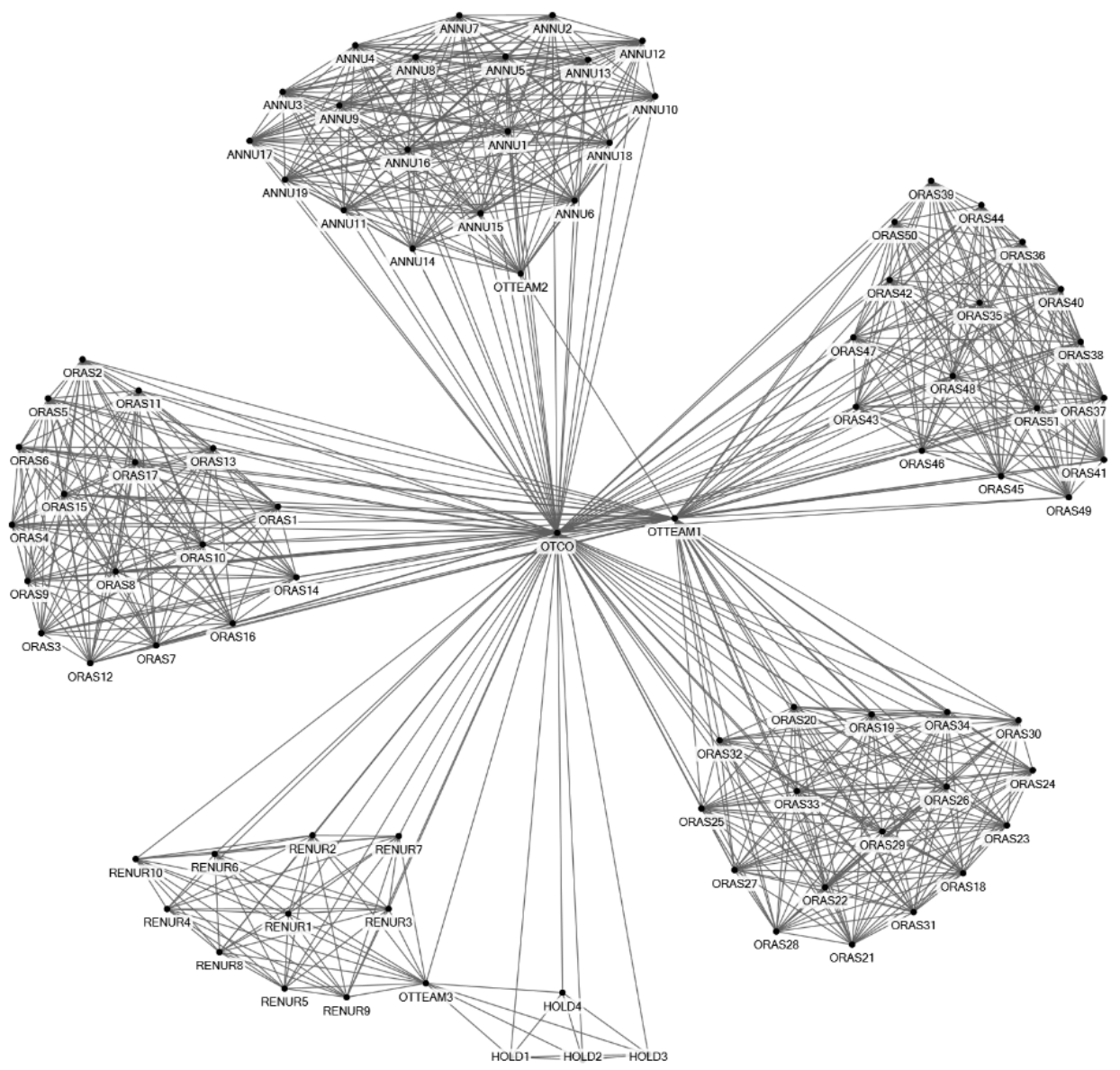

Figure A3.2.4 Social network of Task 4: Scheduling OTC nurses.

The OTC surgery team leader plans the schedule with the OR nurses. He makes a schedule based on the OR master schedule and communicates with OR nurses about it. In this planning process a number of factors which require

\begin{tabular}{lc}
\hline Parameter & Value \\
\hline Number of agents & 88 \\
Number of unique ties & 801 \\
Density & 0.2 \\
Number of cliques & 6 \\
Highest betweenness centrality & OTCO \\
\hline
\end{tabular}
interaction are taken into account. OR nurses sign up for shifts outside regular operating times on nights and weekends. The surgery team leader verifies if the nurses have signed up for the agreed number of shifts and, if necessary, makes changes in this scheme to create a fair division of shifts. When all shifts are filled, the team leader fills in the OR day schedule, taking into account the clusters of medical disciplines to which each OR nurse belongs. He 
also takes into account the employees who want to work on fixed days and after that the shifts for the more flexible nurses are planned. In the event of an expected shortage of OR nurses, the team leader sends an email to the OR nurses, asking them to volunteer for that particular day. If they do not volunteer, the surgery team leader picks someone. The complete OR schedule is then released to all OR nurses via the IT system. At this point OR nurses are allowed to exchange hours among themselves within the three clusters of medical disciplines. If a 'deal' has been concluded between two or more OR assistants and the date at issue is at least two weeks in advance, they make a proposal to the surgery team leader, who assesses this and agrees. If it concerns a date within the next two weeks, the proposal is presented to the OTC day coordinator and he approves or disapproves it. The OTC day coordinator is responsible for the daily operation of the OTC, making sure that all surgeries are performed according to plan.

The OTC anesthesia team leader makes the schedule for the nurse anesthetists and the team leader holding and recovery makes the schedule for the holding and recovery nurses following a similar procedure. 


\section{Plan equipment maintenance}

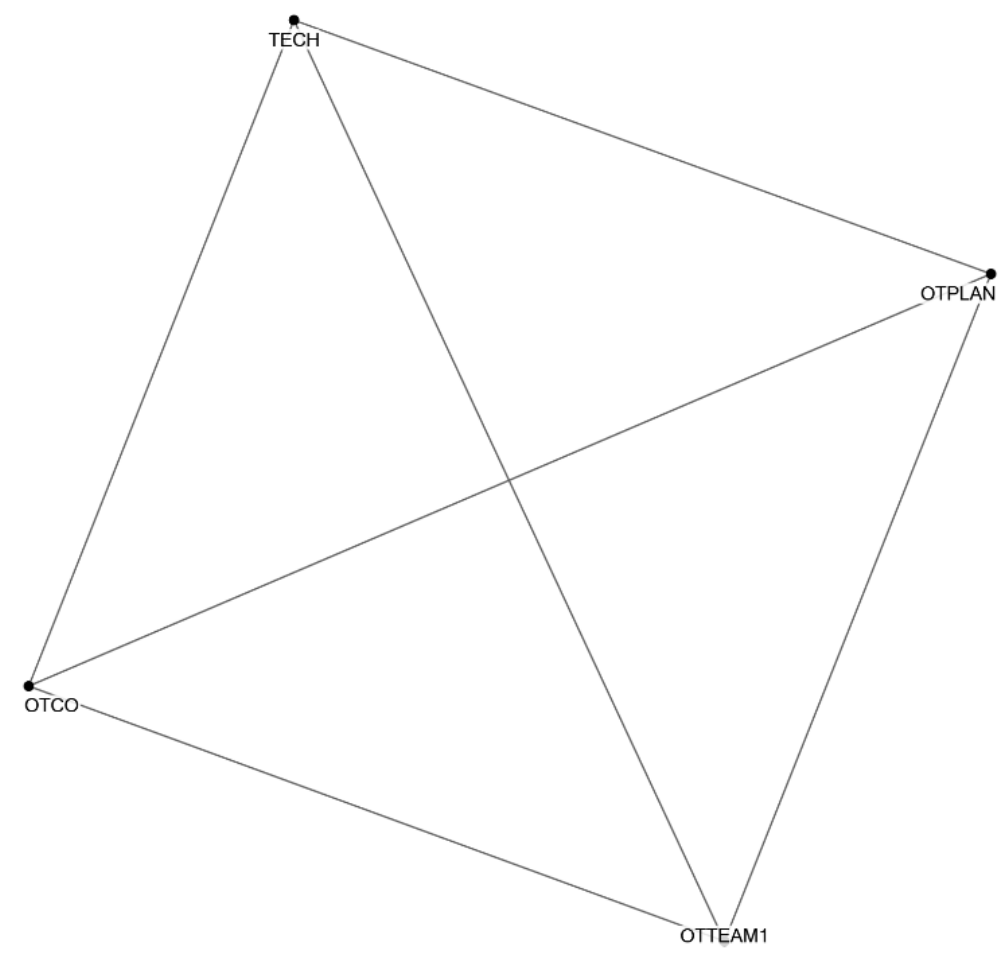

Figure A3.2.5 Social network of Task 5: Planning equipment maintenance.

Planning is also made for OTC equipment maintenance.

Technical staff from the Medical Equipment Department send an email to the OTC capacity planner with a request to perform maintenance on specific equipment. The OTC

Parameter

Number of agents

Number of unique ties

Density

Number of cliques

Highest betweenness centrality
Value

4
6

1

none capacity planner checks with the OTC day coordinator and the surgery team leader whether this is possible, given the OR master schedule and (expected) surgeries in that period of time. 


\section{Plan patient}

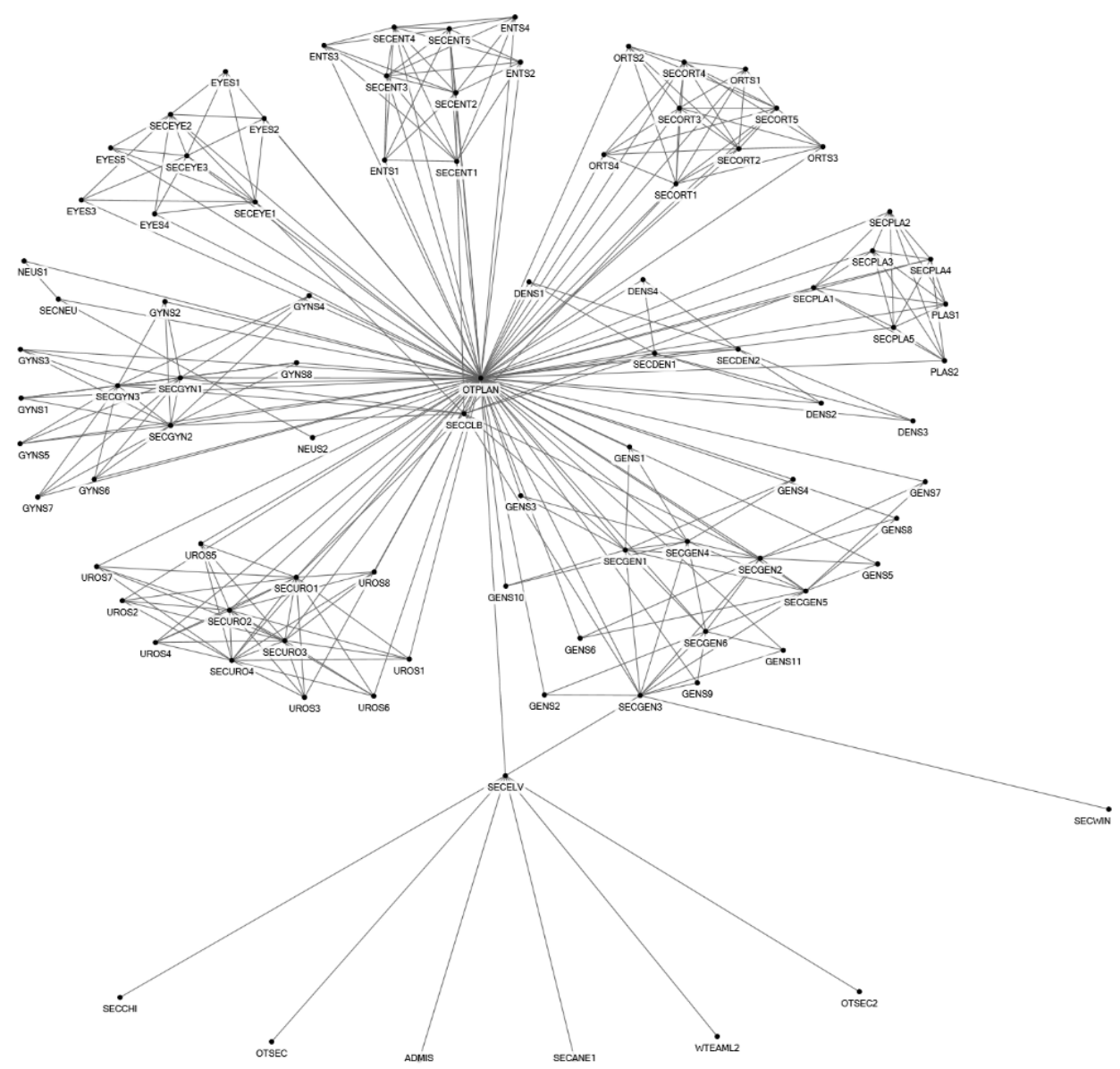

Figure A3.2.6 Social network of Task 6: Planning surgery.

The planning for surgeries takes place at one of the nine outpatient clinics after the diagnosis has been made by the physician. The surgeon agrees with the patient that he or she will be operated in an outpatient

\begin{tabular}{lc}
\hline Parameter & Value \\
\hline Number of agents & 92 \\
Number of unique ties & 315 \\
Density & 0.08 \\
Number of cliques & 48 \\
Highest betweenness centrality & OTPLAN \\
\hline
\end{tabular}
visit and takes the patient to a secretary of the outpatient department, who informs the patient about the surgery, what is to be expected and when and how the patient will be called to set a final surgery date. The secretary puts the patient on the waiting list or a surgery date right away. There can be interaction between secretaries and the OTC capacity planner on specific surgery requirements or in case the OR master schedule is almost filled. 
Also sessions are 'traded' between the secretaries and the OTC capacity planner in case sessions are under or over utilized. Surgeons also email or phone the OTC capacity planner for specific patient cases that require tuning.

Vascular patients of the Queen Beatrix Hospital are operated on in Slingeland Hospital. For these patients the outpatient secretary of the vascular surgery in the Queen Beatrix Hospital emails the vascular surgery outpatient secretary of Slingeland Hospital, who then plans these patients in.

The 'clinical bed plan boss' checks how the secretaries fill in the OR master schedule and how many beds are planned. If the secretaries of the outpatient departments take too many beds, she corrects them. The OTC capacity coordinator and 'clinical bed plan boss' evaluate how the clinical bed plan is followed and provide feedback to the secretaries on their planning activities. 


\section{Request and order materials}

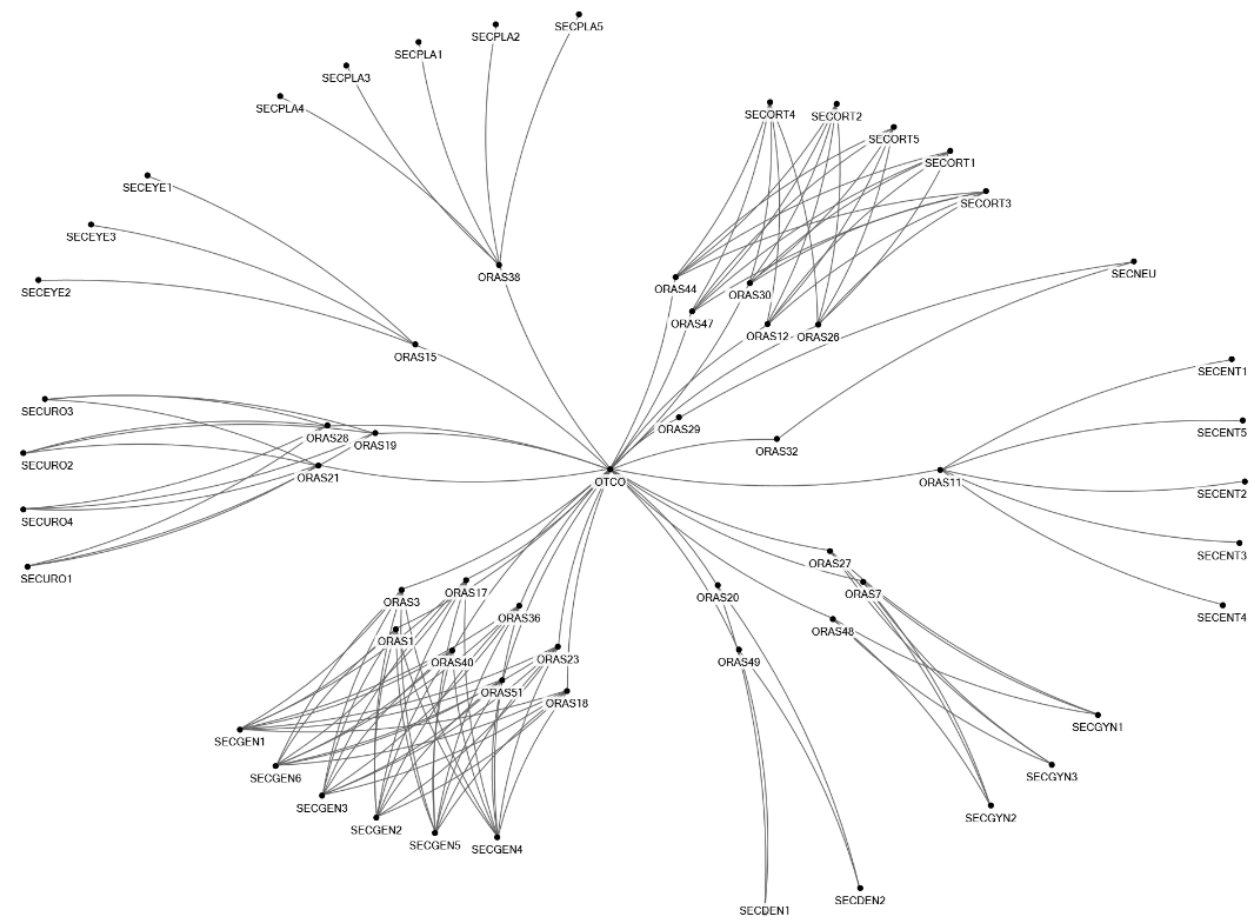

Figure A3.2.7 Social network of Task 7: Order materials.

If specific materials are required for an operation, the secretary of the outpatient clinic informs the OR assistant, who is specialized in the medical discipline it concerns. The OR nurse then orders the required materials via the OTC day coordinator, who then orders

\begin{tabular}{lc}
\hline Parameter & Value \\
\hline Number of agents & 61 \\
Number of unique ties & 139 \\
Density & 0.08 \\
Number of cliques & 0 \\
Highest betweenness centrality & OTCO \\
\hline
\end{tabular}
the materials from external suppliers via the Purchasing Department.

Other material related tasks are the cleaning of medical instruments which are delivered to the OTC by the Central Sterilization Department (CSD) every day. Further, medication, consumables and implants are delivered every day by a variety of external suppliers. One logistical staff member receives these materials and puts these in the right storage room. 


\section{Preoperative screening}

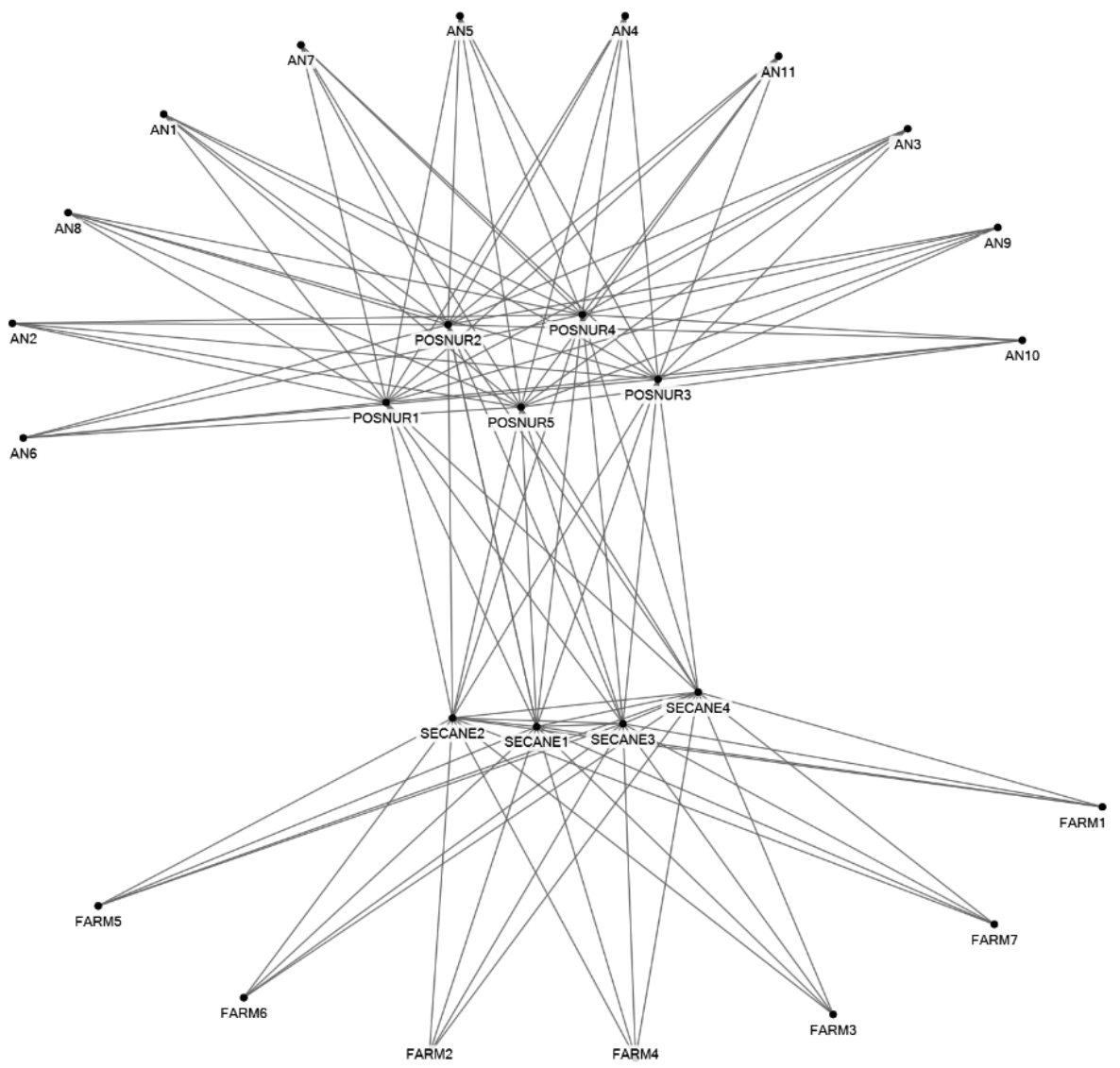

Figure A3.2.8 Social network of Task 8: Preoperative screening.

Before a final date can be set for the surgery, the patient must be screened by the anesthesiologist and prepared accordingly in the preoperative department. In the preoperative visit the patient first visits the pharmacy assistant (FARM), who checks which medication the patient is using. Subsequently, a physical examination is performed, after which the patient

\begin{tabular}{lc}
\hline Parameter & Value \\
\hline Number of agents & 27 \\
Number of unique ties & 109 \\
Density & 0.31 \\
Number of cliques & 12 \\
Highest betweenness centrality & All SECAN/ \\
& POSNUR \\
\hline
\end{tabular}
discusses with the anesthesiologist (AN) which anesthetic technique will be used, which medication he or she may continue to use on the day of the operation and then the anesthesiologist approves the operation. Right after this the patient meets the preoperative nurse (POSNUR), who further prepares the patient for surgery by providing information and discussing the preparations and aftercare the patient requires. 


\section{Request and make appointment}

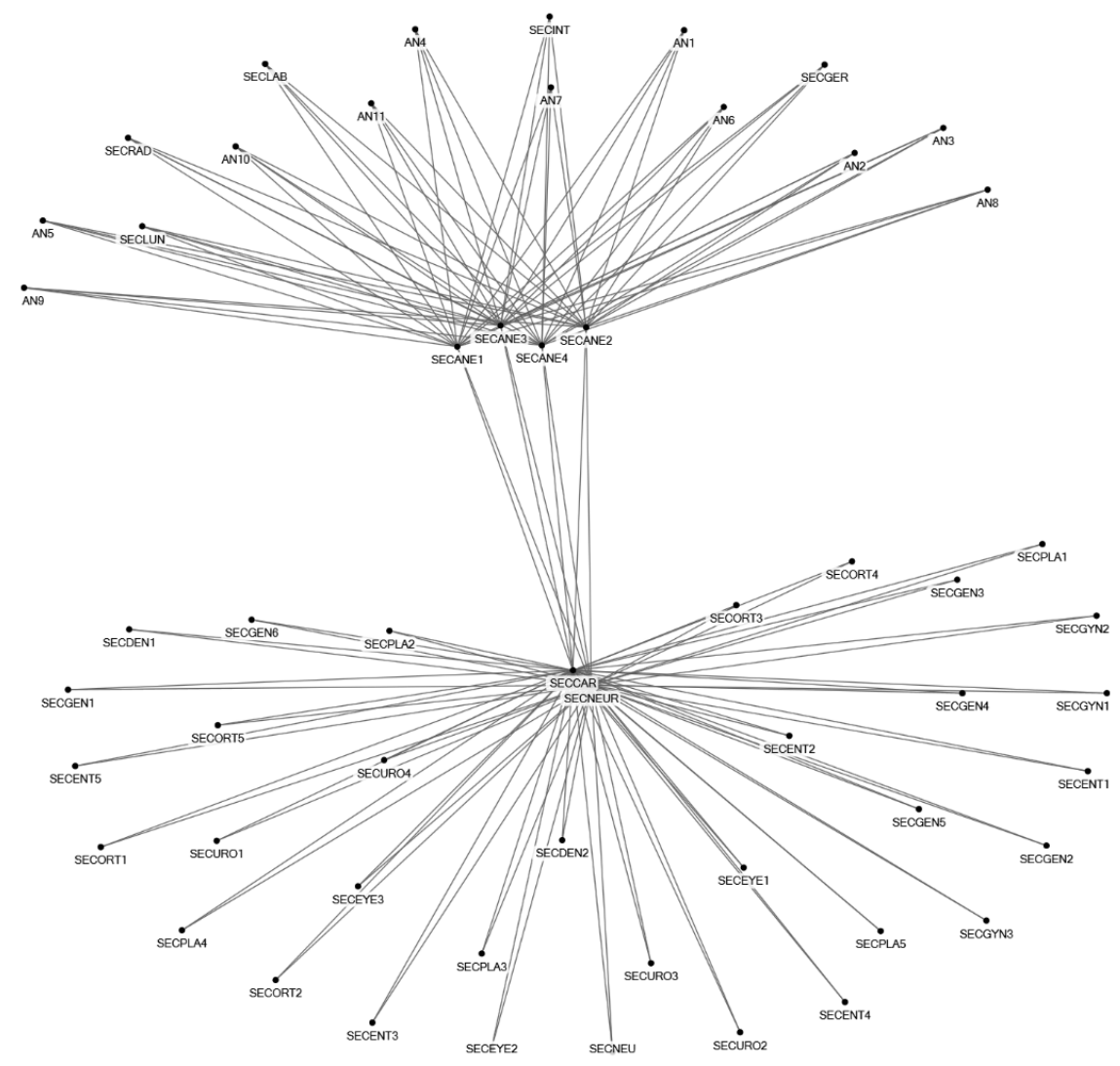

Figure A3.2.9 Social network of Task 9: Make appointment.

The anesthesiologist can decide, based on the patient's health situation, that the patient has to visit other physicians, prior to the operation, such as the cardiologist or the neurologist. The secretary at the

\begin{tabular}{lc}
\hline Parameter & Value \\
\hline Number of agents & 56 \\
Number of unique ties & 140 \\
Density & 0.09 \\
Number of cliques & 0 \\
Highest betweenness centrality & SECNEUR/ \\
& SECCAR \\
\hline
\end{tabular}
pre-operative outpatient clinic arranges this for the patient, as well as any necessary blood tests or making an ECG image. Any appointments that need to be made for this are made by the secretary of the preoperative outpatient department.

After the consultation with the anesthesiologist, the patient goes to a nurse who informs the patient about the operation and prepares him or her more extensively.

In case a patient uses anticoagulants, the outpatient department of the surgeon who will perform the surgery arranges a visit to the neurologist or cardiologist. 


\section{Plan OTC nurses}

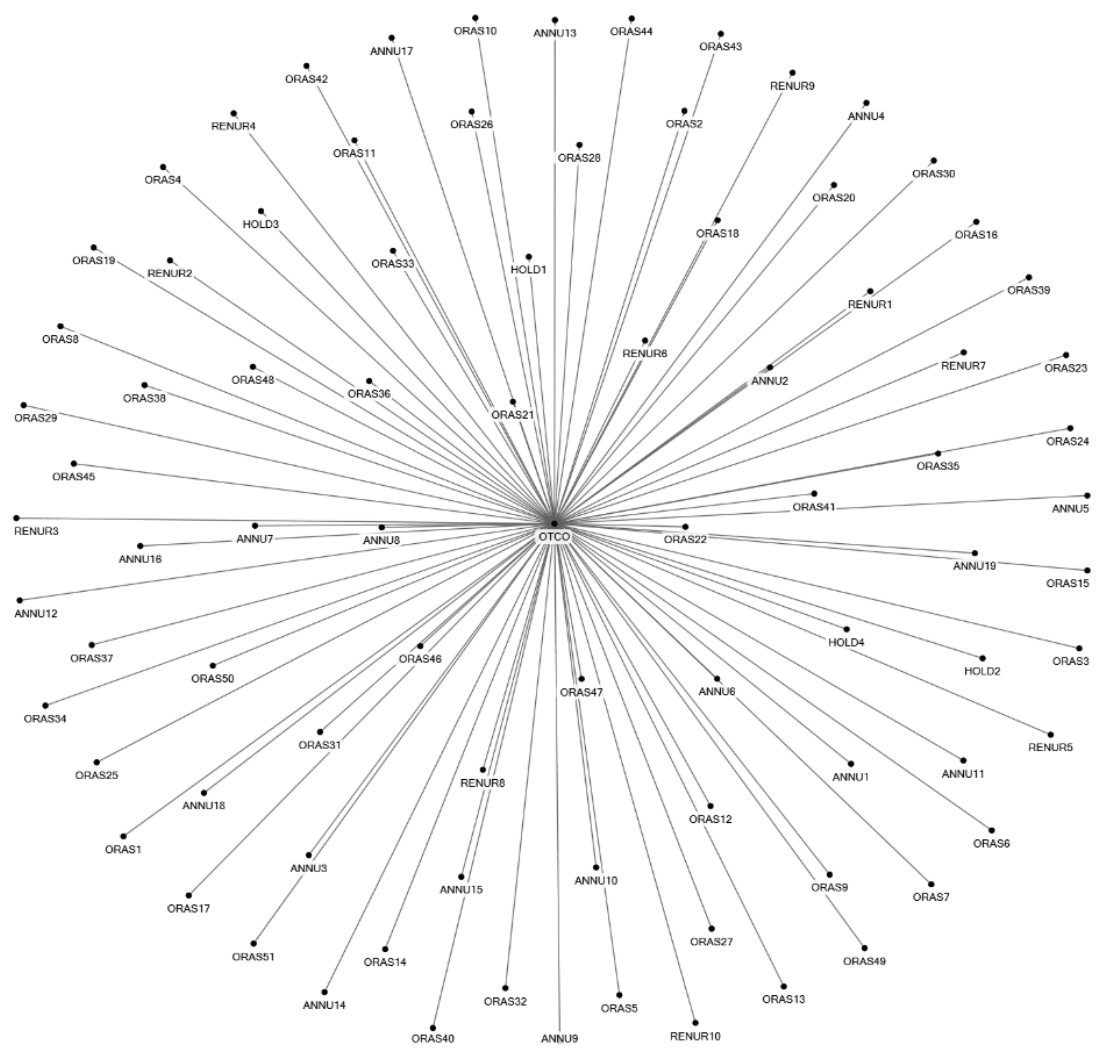

Figure A3.2.10 Social network of Task 10: Plan OTC nurses.

A week before surgeries are performed, the day coordinator allocates the OR nurses to surgeries for the upcoming week and he handles all communication with regard to their availability, illness or other casualties.

\begin{tabular}{ll}
\hline Parameter & Value \\
\hline Number of agents & 85 \\
Number of unique ties & 84 \\
Density & 0.02 \\
Number of cliques & o \\
Highest betweenness centrality & OTCO \\
\hline
\end{tabular}




\section{Control planning}

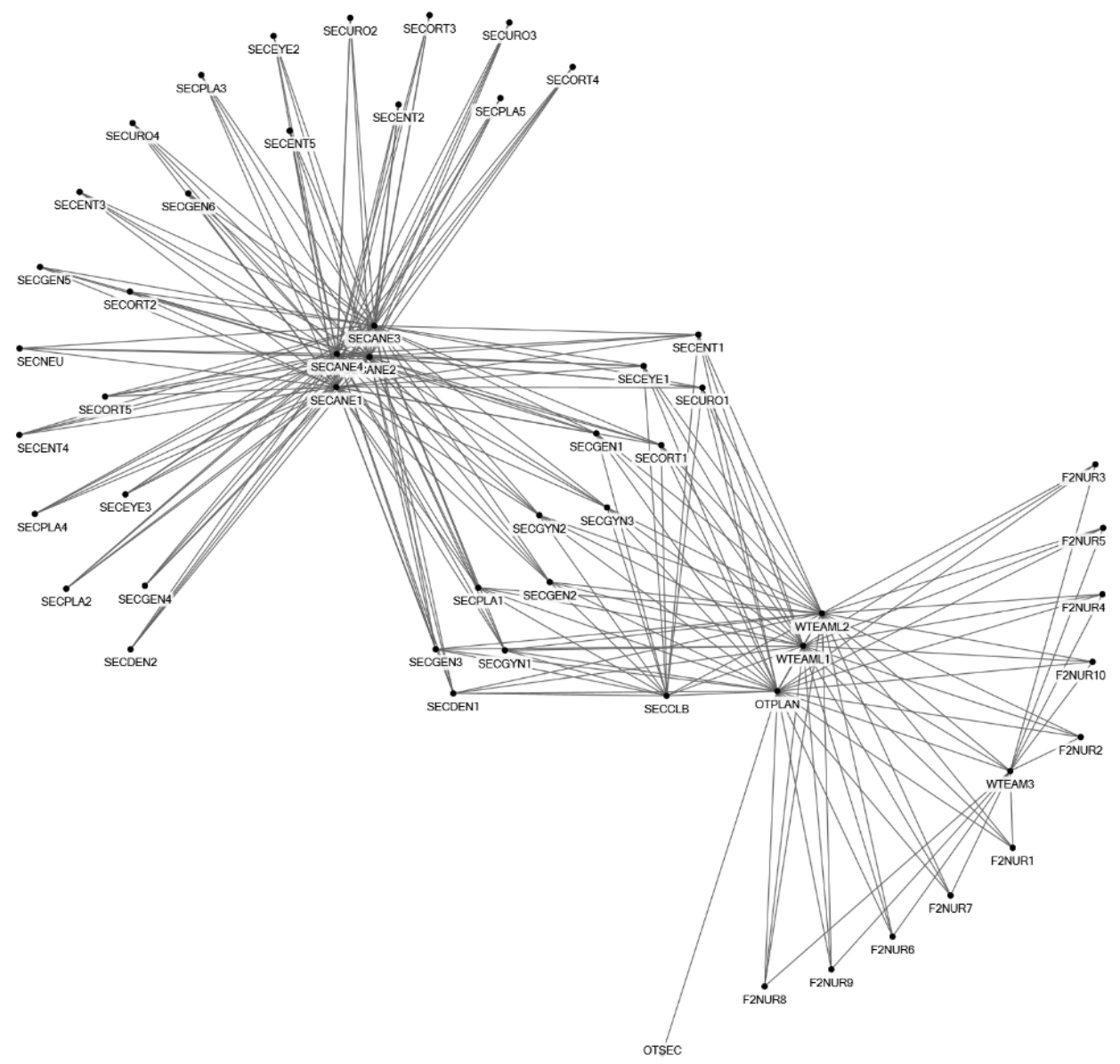

Figure A3.2.11 Social network of Task 11: Control planning.

In the process towards the surgery taking place, the planning is checked and revised. Preoperative screening needs to be performed before the date of surgery is final. The preoperative secretaries interact

\begin{tabular}{ll}
\hline Parameter & Value \\
\hline Number of agents & 54 \\
Number of unique ties & 234 \\
Density & 0.16 \\
Number of cliques & 2 \\
Highest betweenness centrality & All SECANE \\
\hline
\end{tabular}
with all outpatient secretaries on whether everything is arranged for the surgery to take place.

In the weekly 'Tuesday morning' meeting the planning for the upcoming week is discussed between the outpatient secretaries, the ward team leaders and the OTC capacity planner. Also a weekly bed 
meeting takes place between ward team leaders, a nurse and the OTC capacity planner. In this meeting all checks for the next day's OR program are made.

The OTC capacity planner views the daily OTC schedule the day before to determine the exact sequence of the operations. For planning surgeries and determining the sequence of the procedures, a large number of control rules are set and these need to be checked. The OTC capacity planner reviews the electronic patient file of each individual patient, checking if all information has been taken into account. When everything is checked, she informs the OTC day coordinator regarding any specific details in the next day's OTC program. 


\section{Pick materials}

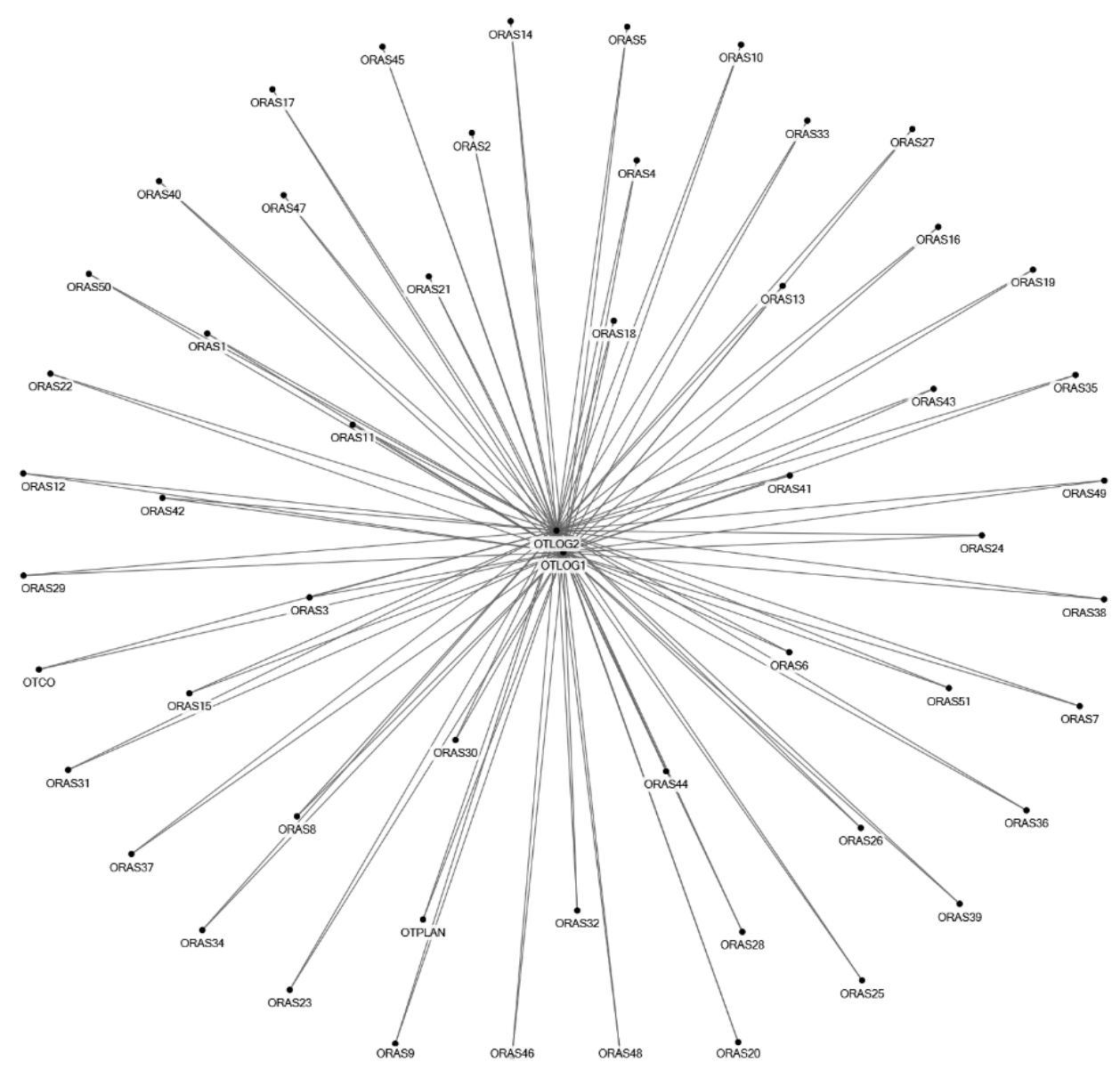

Figure A3.2.12 Social network of Task 12: Picking materials.

Medical instruments, consumables and implants are collected a day in advance by two logistical OTC staff members. Sterile and non-sterile materials stored in three storage rooms at the OTC are picked and placed

\begin{tabular}{lc}
\hline Parameter & Value \\
\hline Number of agents & 55 \\
Number of unique ties & 107 \\
Density & 0.07 \\
Number of cliques & 53 \\
Highest betweenness centrality & All OTLOG \\
\hline
\end{tabular}
in carts, which are then put in the preparation rooms which are located beside each OR. Materials are mainly collected on the basis of bills of material, which are available for every surgery. Logistical staff members consult the OTC capacity planner, OTC day coordinator and OR nurses on what particular surgeries involve, in case the bill of material doesn't provide enough information or in case they are not familiar with a surgery type. 


\section{Emergency admission}

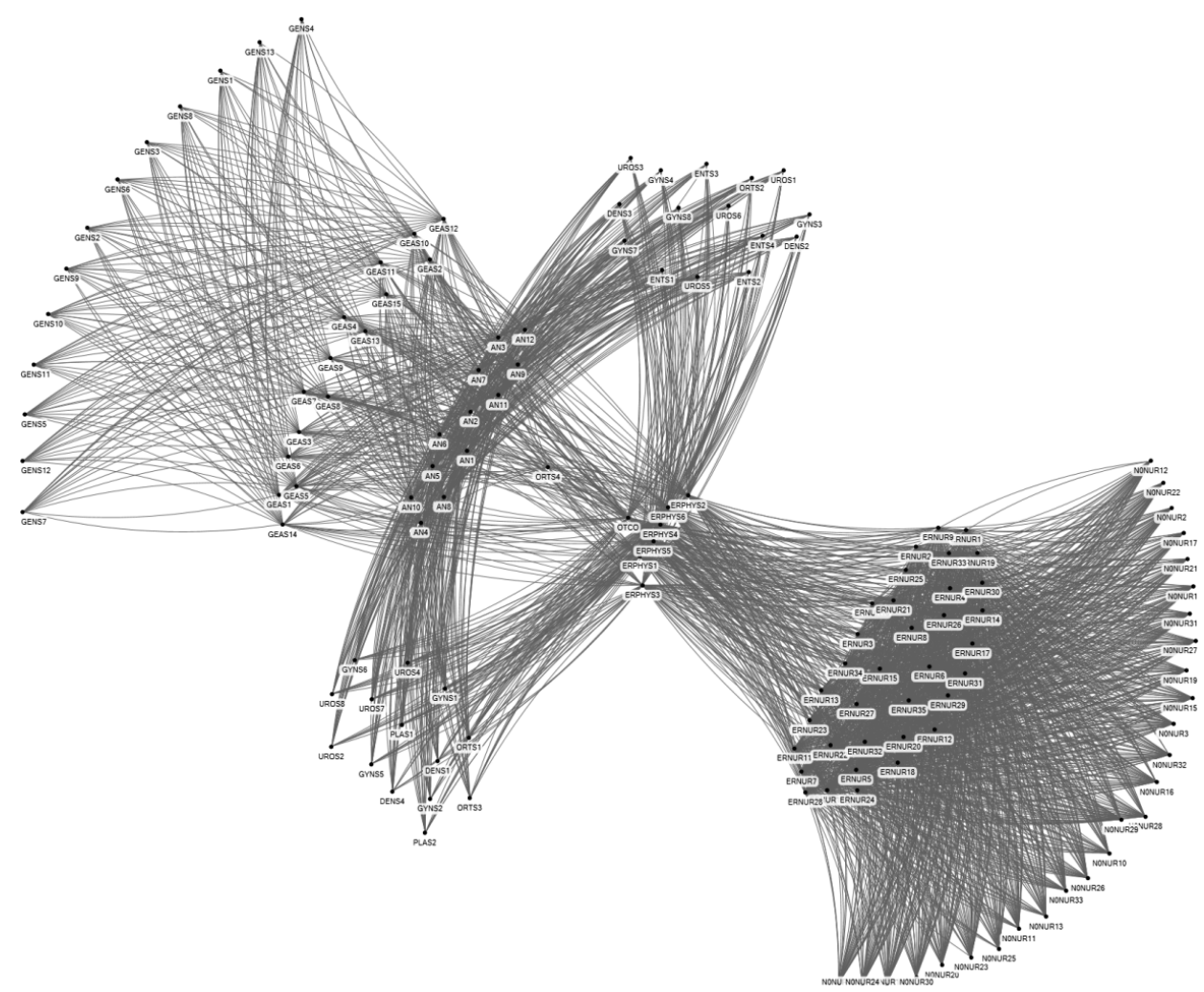

Figure A3.2.13 Social network of Task 13: Emergency admission.

Patients who arrive at the Emergency

Department (ED) are examined by the

ED physician (ERPHYS). He calls the assistant surgeon or a surgeon if he

\begin{tabular}{lc}
\hline Parameter & Value \\
\hline Number of agents & 139 \\
Number of ties & 2840 \\
Density & 0.30 \\
Number of cliques & 1 \\
Highest betweenness centrality & OTC day coordinator (OTCO) \\
\hline
\end{tabular}

thinks that the patient requires

surgery. The assistant surgeon or surgeon comes to the ED and sets the diagnosis. If necessary blood samples or images are made. If they decide to operate, the general surgeon is called, as well as the OTC day coordinator. The ED nurse takes care of the patient and calls the OTC day coordinator as well to see if the patient goes straight to the OTC or to the nursing ward that admits emergency patients. The surgeon orders preoperative screening with the anesthesiologist, who executes this by screening the patient file. Planning the surgery into the OR program is done through communication between the OTC day coordinator, surgeon and anesthesiologist. 


\section{Prepare patient on ward}

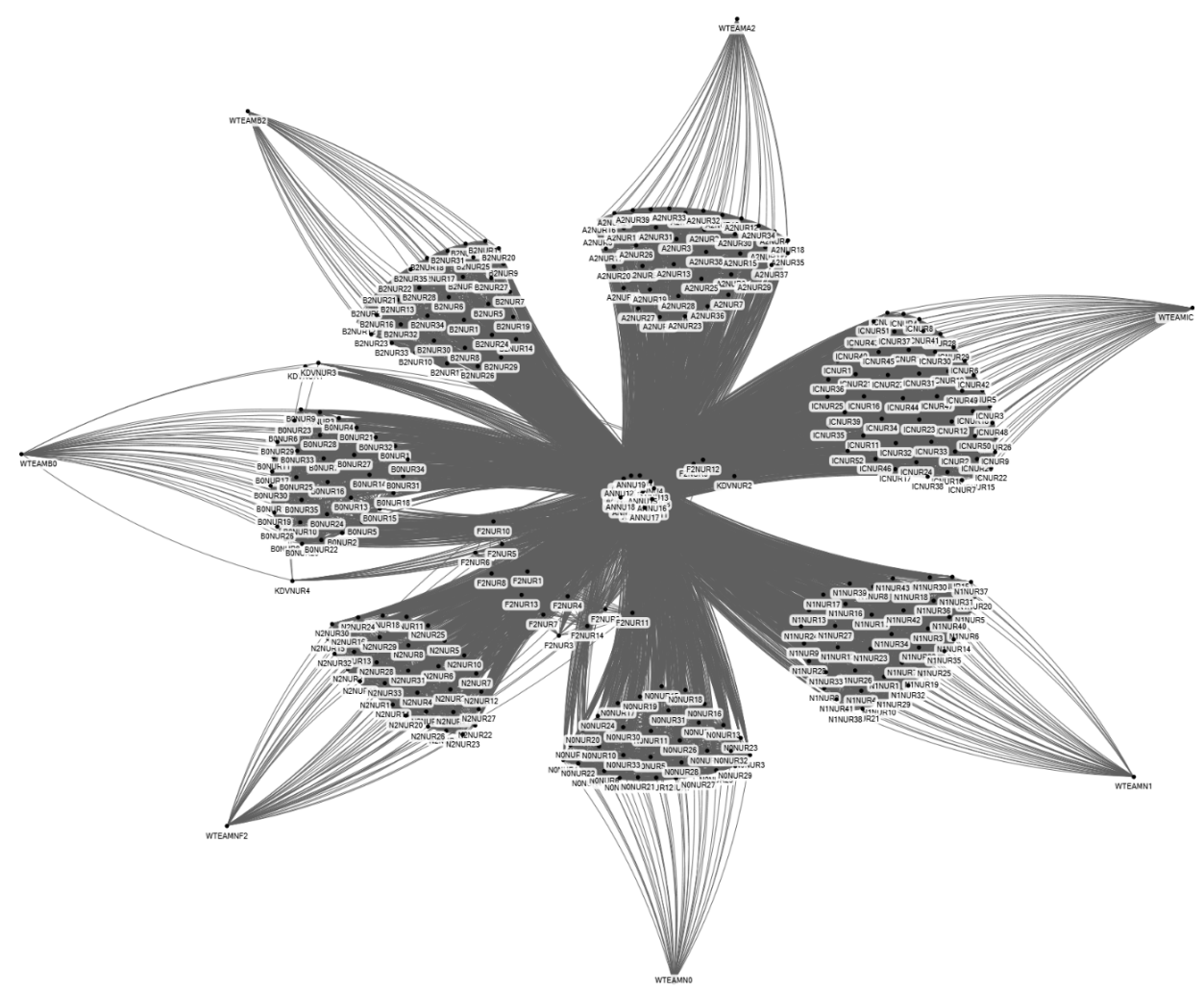

Figure A3.2.14 Social network of Task 14: Prepare patient on nursing ward.

From the moment the patient is admitted to the hospital, a series of tasks including a lot of communication is performed within a short period

\begin{tabular}{lc}
\hline Parameter & Value \\
\hline Number of agents & 314 \\
Number of ties & 11,071 \\
Density & 0.23 \\
Number of cliques & 9 \\
Highest betweenness centrality & All ANNU \\
\hline
\end{tabular}

of time. First the patient is admitted to one of the nursing wards. During the intake interview a number of checks are made to see if the patient is well prepared for the surgery. The nurse anesthetist then calls the nurse to indicate that premedication should be given to the patient, mostly 2 hours before the expected starting time of the surgery. The nurse anesthetist makes a second call to the nurse to say that the patient is to be taken to holding. 


\section{Prepare patient on holding}

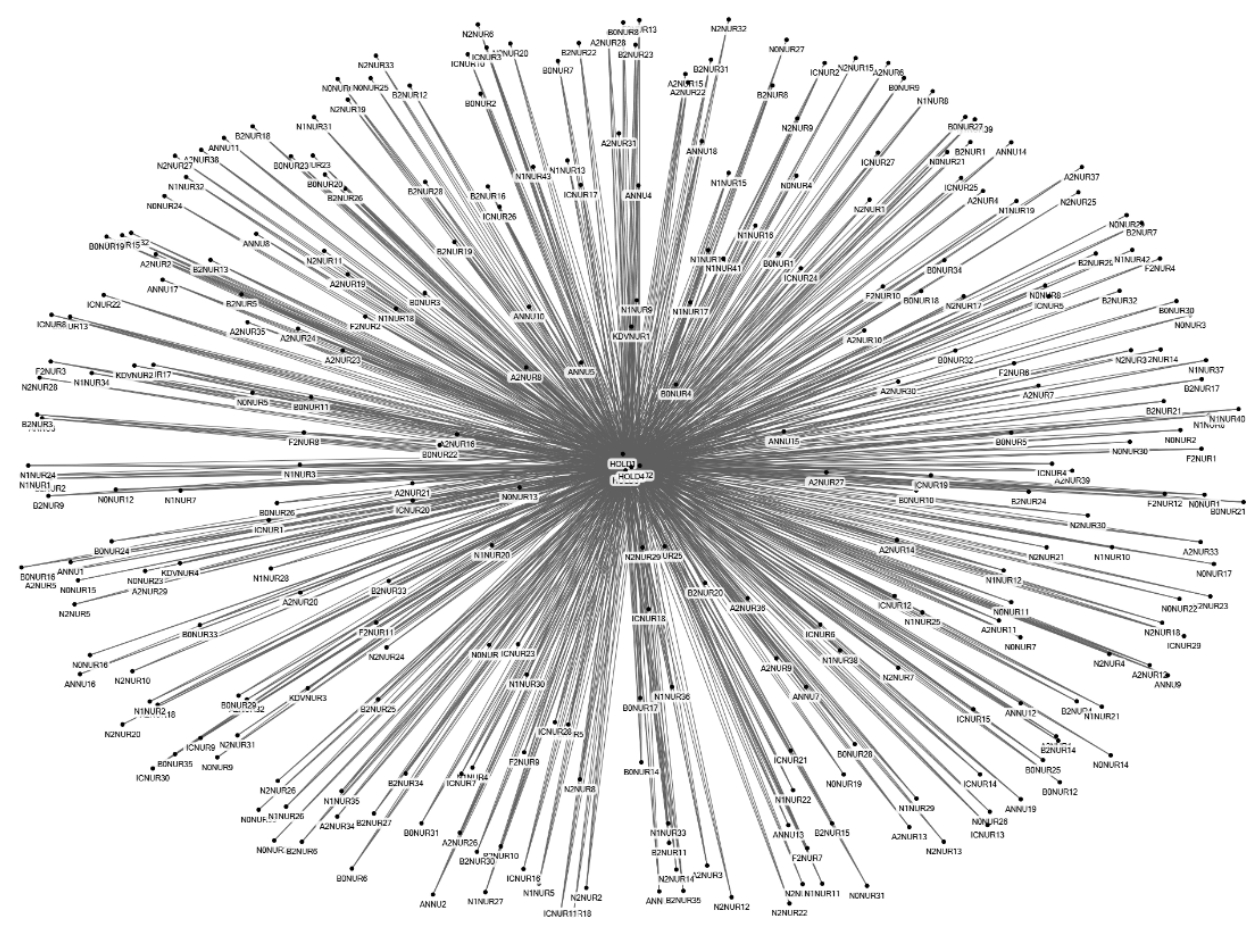

Figure A3.2.15 Social network of Task 15: Prepare patient in holding.

After the nurse hands over the patient to one of the holding nurses, following a standard

\begin{tabular}{lc}
\hline Parameter & Value \\
\hline Number of agents & 289 \\
Number of unique ties & 1100 \\
Density & 0.03 \\
Number of cliques & 65 \\
Highest betweenness centrality & All ANNU \\
\hline
\end{tabular}
transfer protocol, the second stage starts. The holding nurse prepares the patient by, among Highest betweenness centrality All ANNU other things, preparing the infusion devices. When it is time to go to the OR the nurse anesthetist enters holding and has a small chat with the patient. The holding nurse hands the patient over to the nurse anesthetist, using the standard transfer protocol. 


\section{Make Radiology image}

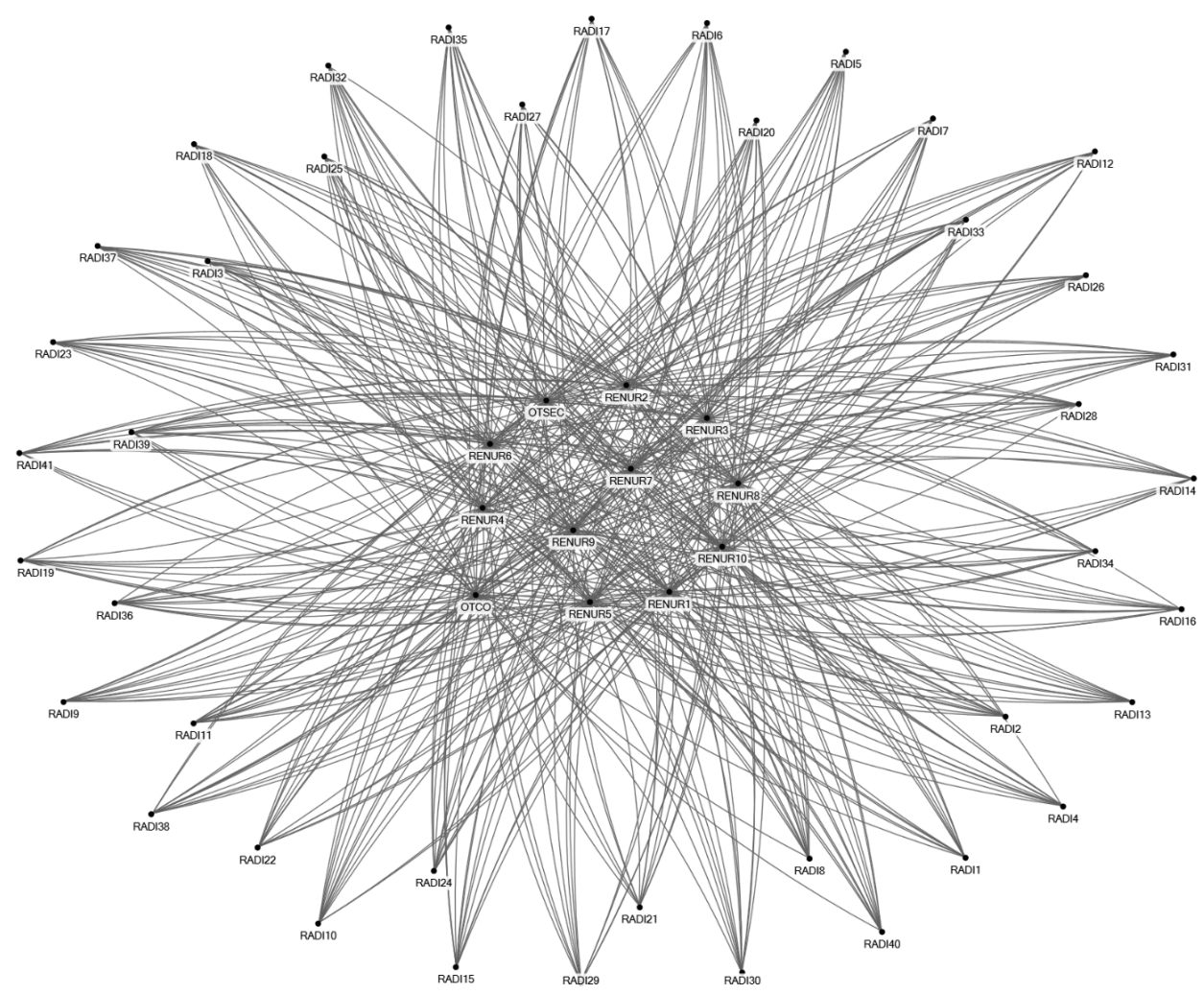

Figure A3.2.16 Social network of Task 16: Making radiology image.

Images can be made before or after surgery. When images are needed before surgery, the OTC day coordinator puts in a request to the radiology department, and they send someone in. When an image is required postsurgery, while the patient is in recovery, the recovery nurse calls the radiology department.

\begin{tabular}{lc}
\hline Parameter & Value \\
\hline Number of agents & 53 \\
Number of unique ties & 491 \\
Density & 0.36 \\
Number of cliques & 0
\end{tabular}

Highest betweenness centrality

All Recovery nurses, OTC day coordinator and OTC secretary 


\section{Perform surgery}

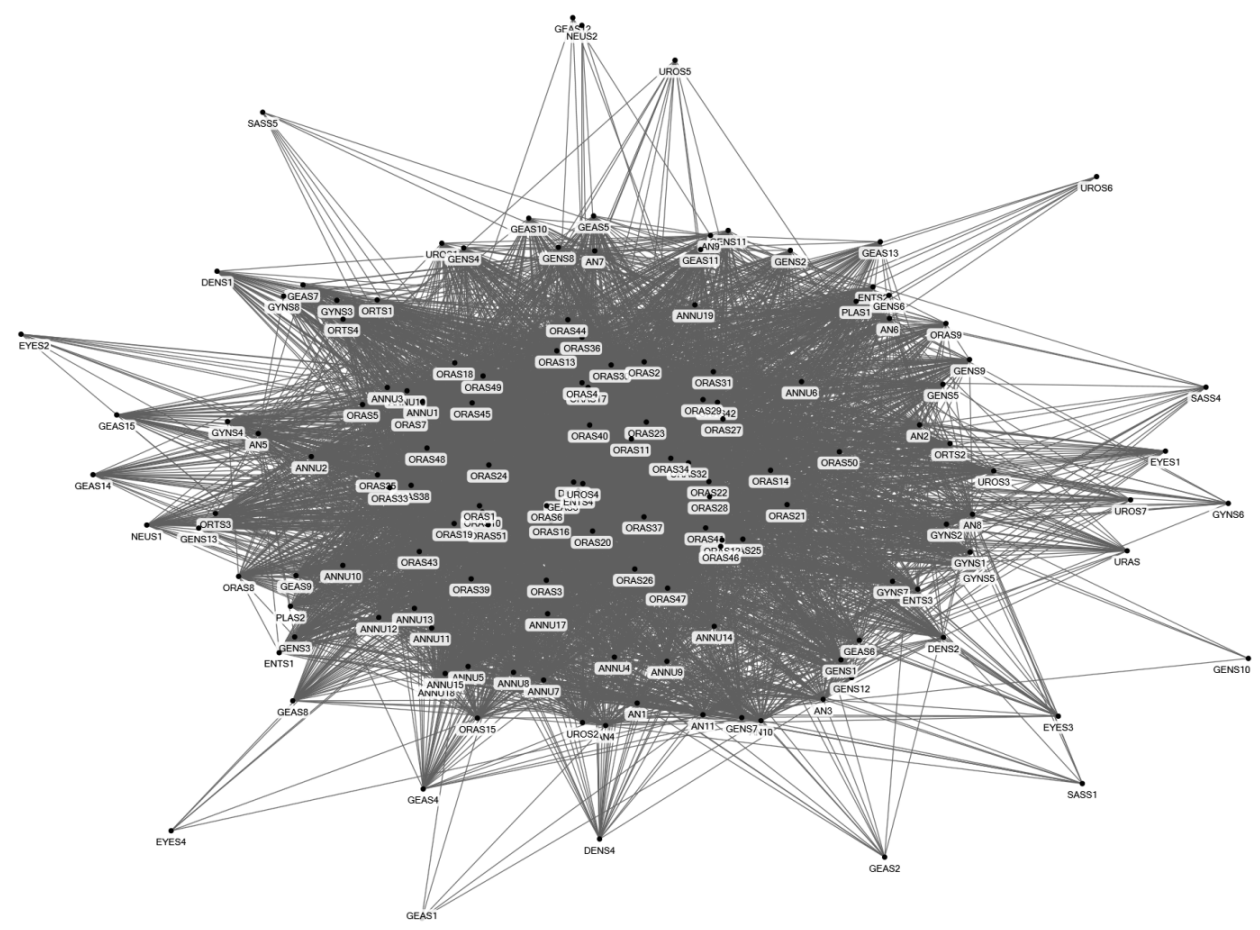

Figure A3.2.17 Social network of Task 17: Collaborating in the OR.

Once the patient is in the OR the nurse anesthetist mentions any relevant details about the patient to the rest of the OR team. The anesthesiologist administers anesthetics prior to the surgery and leaves once the

\section{Parameter}

Number of agents

Number of unique ties

Density

Number of cliques

Highest betweenness centrality

\begin{tabular}{c} 
Value \\
\hline 148 \\
5444 \\
0.5 \\
7640 \\
ORAS17 \\
\hline
\end{tabular}
patient is asleep. The surgery is performed by the surgeon, assisted by the OR nurses. The nurse anesthetist monitors the patient and calls the anesthesiologist if necessary. 


\section{Clean the OR}

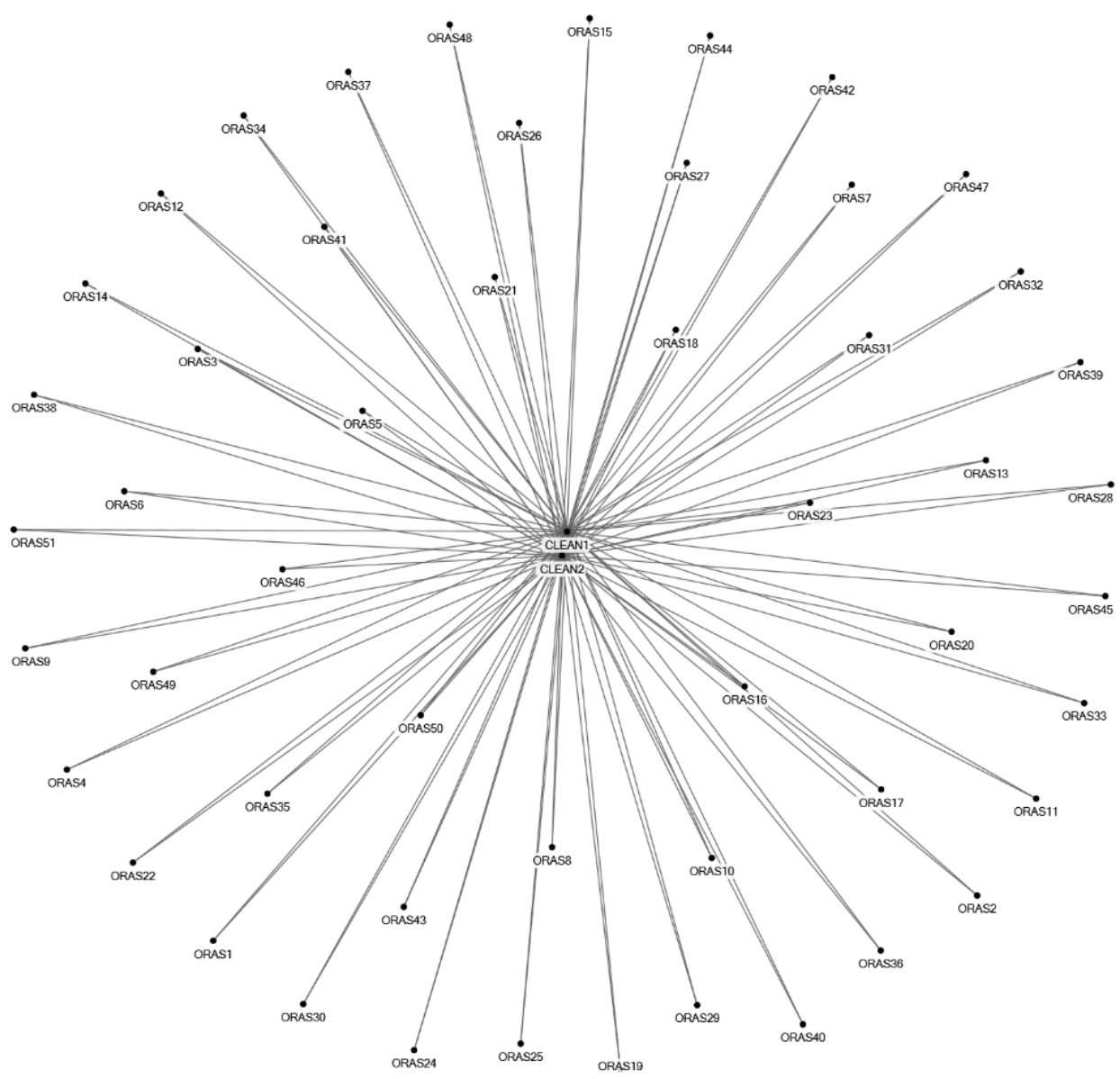

Figure A3.2.18 Social network of task 18: Cleaning the OR.

At the end of the surgery the anesthesiologist wakes the patient and the OR assistant calls the cleaning staff. If body tissue has been removed from the patient, it will be sent to pathology to Parameter investigate abnormalities. 


\section{Order emergency CSD services}

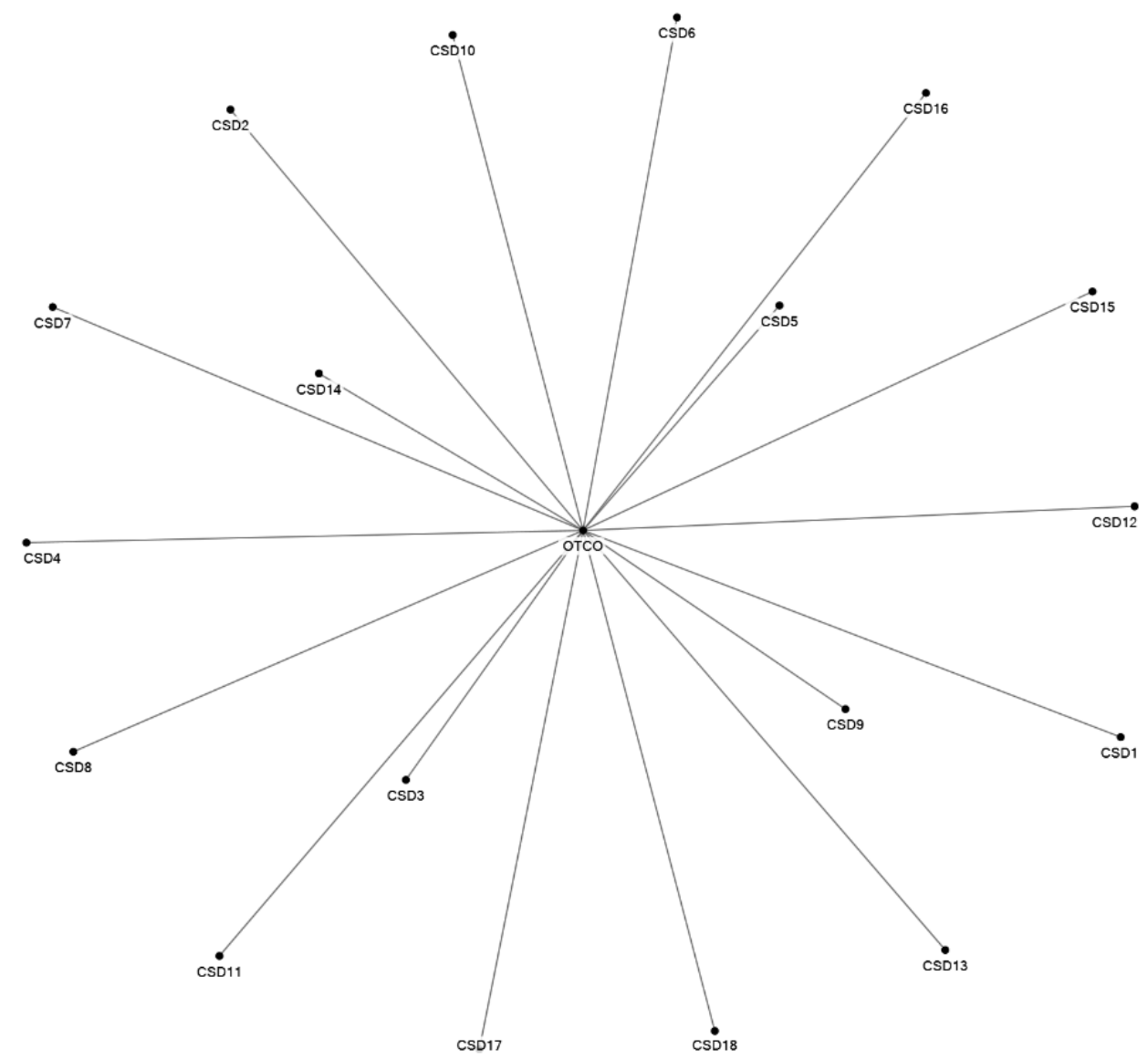

Figure A3.2.19 Social network of task 19: Order emergency CSD services.

After surgery an OR nurse presses a button that switches on a light at the CSD, signaling that the used medical instruments need to be collected Parameter Number of agents

Number of unique ties Density

Number of cliques Highest betweenness centrality interaction for this, so it is not visualized in this figure. If medical instruments need to be cleaned and sterilized immediately, so they can be reused for a surgery on the same day, the OTC day coordinator calls the CSD with an emergency order. 


\section{Patient care in recovery}

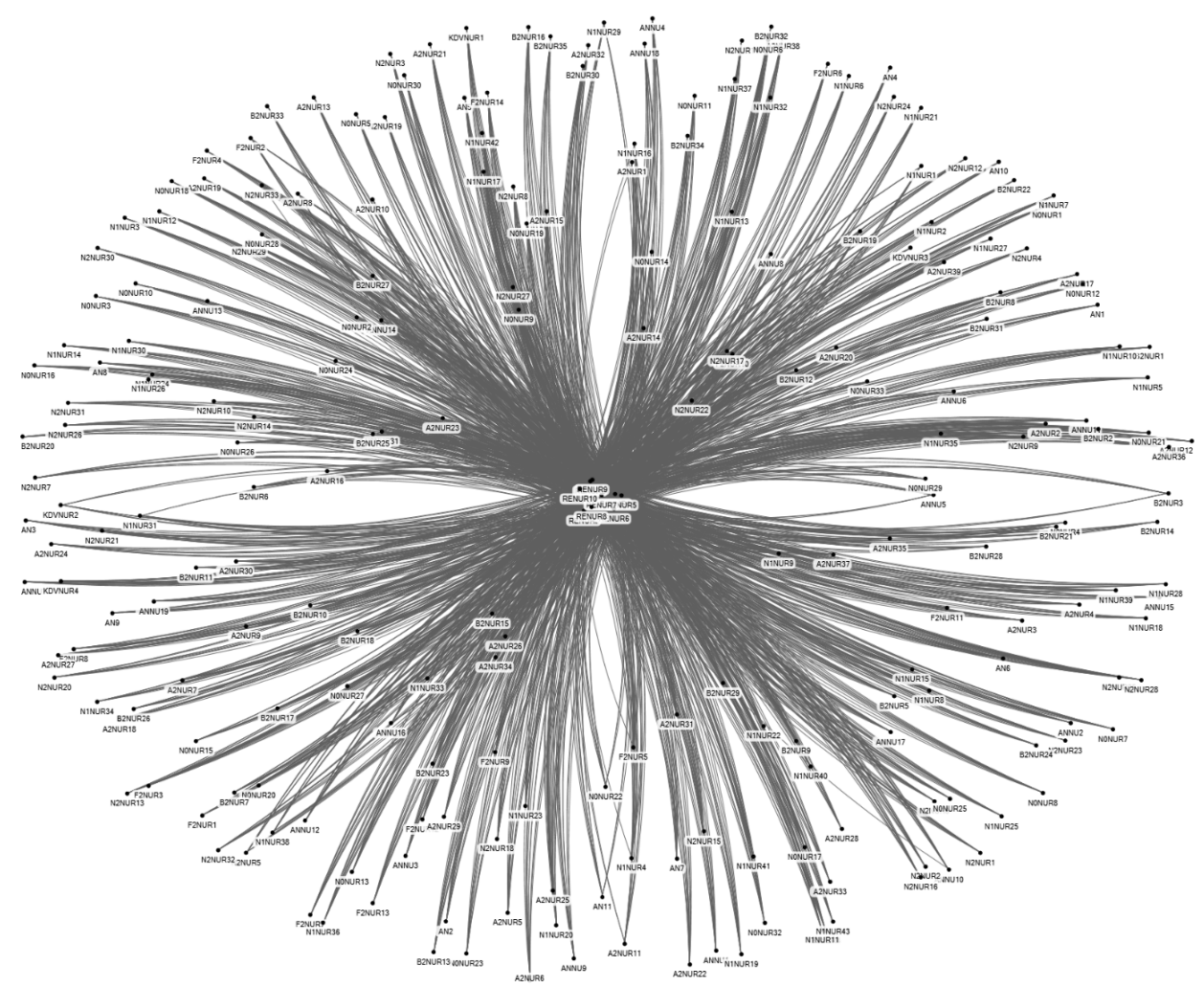

Figure A3.2.20 Social network of task 20: Patient care in recovery.

After surgery the patient is transferred to recovery by the nurse anesthetist. Again the transfer is performed using the standard transfer protocol. In recovery an image might be made of the surgery result, for which a

\begin{tabular}{lc}
\hline Parameter & Value \\
\hline Number of agents & 241 \\
Number of unique ties & 2,355 \\
Density & 0.08 \\
Number of cliques & PM \\
Highest betweenness centrality & PM \\
\hline
\end{tabular}
radiology staff member is called. The recovery nurses interact with anesthesiologists on the medication policy if necessary. 


\section{Aftercare of patient}

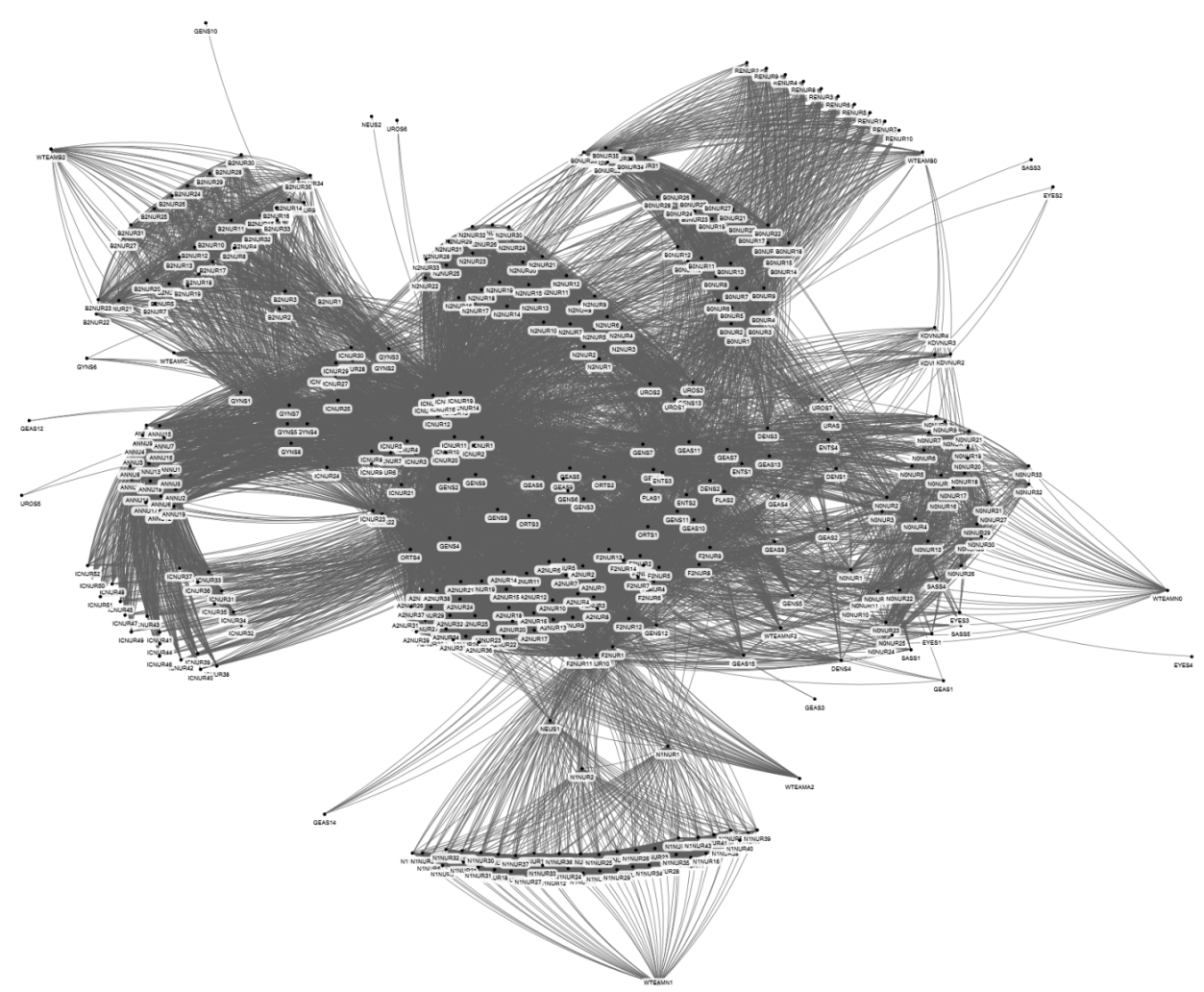

Figure A3.2.21 Social network of task 21: Aftercare of patient.

When the patient is completely awake and is not experiencing too much pain in recovery, he is transferred to the nursing ward. The recovery nurse calls the nursing ward to indicate that the

\begin{tabular}{lc}
\hline Parameter & Value \\
\hline Number of agents & 391 \\
Number of unique ties & 12,537 \\
Density & 0.16 \\
Number of cliques & 178 \\
Highest betweenness centrality & Nurse 1 ward F2 \\
\hline
\end{tabular}
patient is to be picked up. The recovery nurse Highest betweenness centrality Nurse 1 ward F2 then hands the patient over to the ward nurse, using the standard transfer protocol. The patient is taken care of in one of the nursing wards until he or she is recovered well enough to be discharged. Some patients are transferred to another nursing ward and a transfer from nurses from one department to the nurse of the receiving department takes place. Surgeons visit the patients in the nursing ward and discuss their patients with the nurse and physician responsible for the ward on that day. 


\section{Manage the OTC day program}

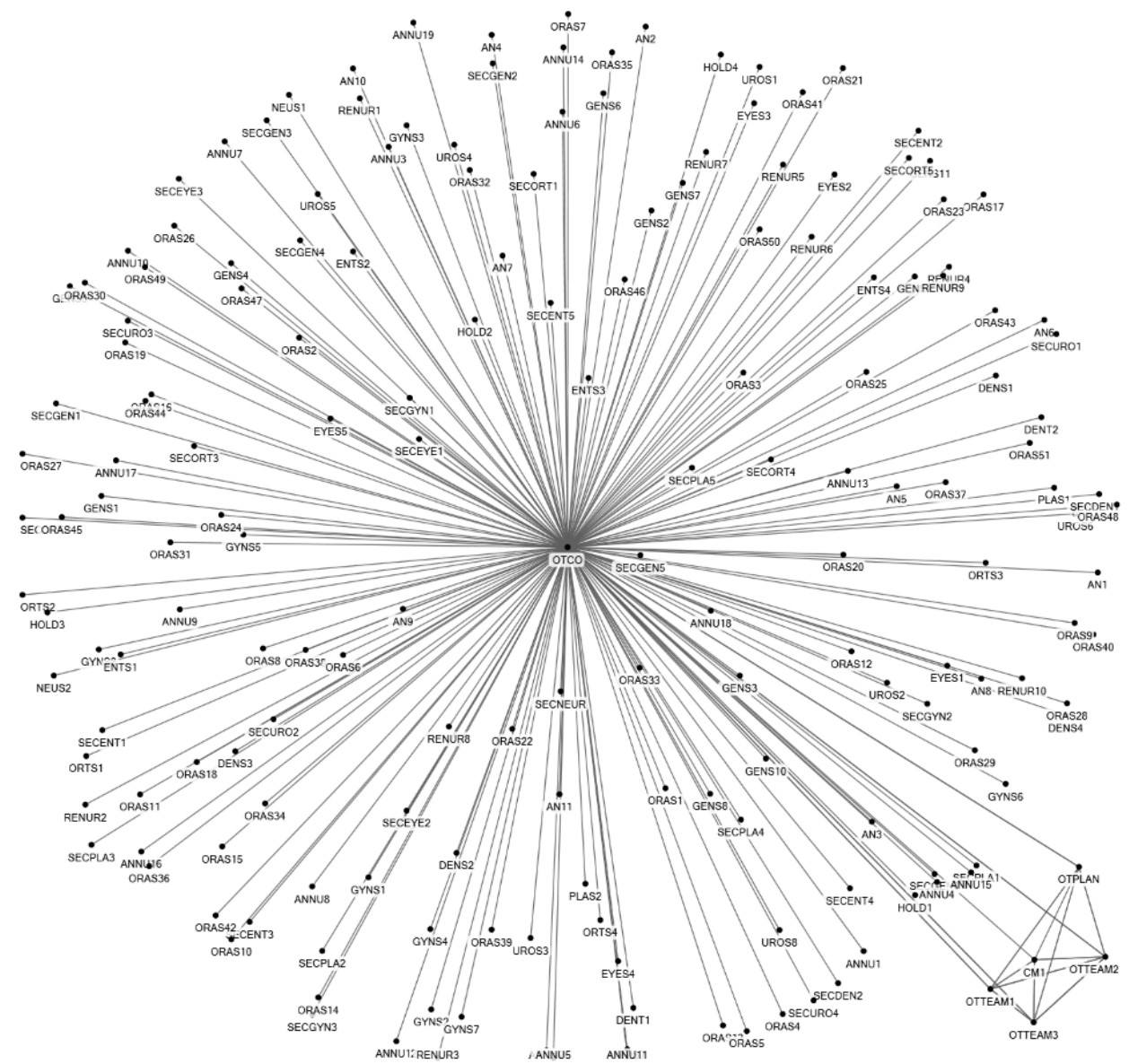

Figure A3.2.22 Social network of task 22: Managing the OTC day program.

There are several tasks, performed at various moments in time, aimed at making sure that the surgeries that are planned for one day are executed well and on time. Every day starts with a start of day

\begin{tabular}{lc}
\hline Parameter & Value \\
\hline Number of agents & 185 \\
Number of unique ties & 181 \\
Density & 0.01 \\
Number of cliques & 2 \\
Highest betweenness centrality & OTCO \\
\hline
\end{tabular}
meeting between the OTC day coordinator and the three OTC team leaders, in which the expectations and special surgeries are discussed.

During the course of the day the day coordinator monitors the progress of each OR, in order to prevent bottlenecks in case surgeries last longer than planned or unexpected events occur, such as 
emergency patients, failing equipment and such. If the day coordinator foresees that more than two ORs will be running late, he communicates with an anesthesiologist or surgeons about any alterations required in the OR scheme. The anesthesiologist plays a role here, because they work across different ORs throughout the day and they have an interest in the OR scheme being executed as planned. They are used as the intermediate between the day coordinator and the surgeons, who take more interest in completing the entire scheme, taking any overtime or reshuffling for granted. This relationship is included in the task Collaborating in the OR. 


\section{Manage OTC tasks}

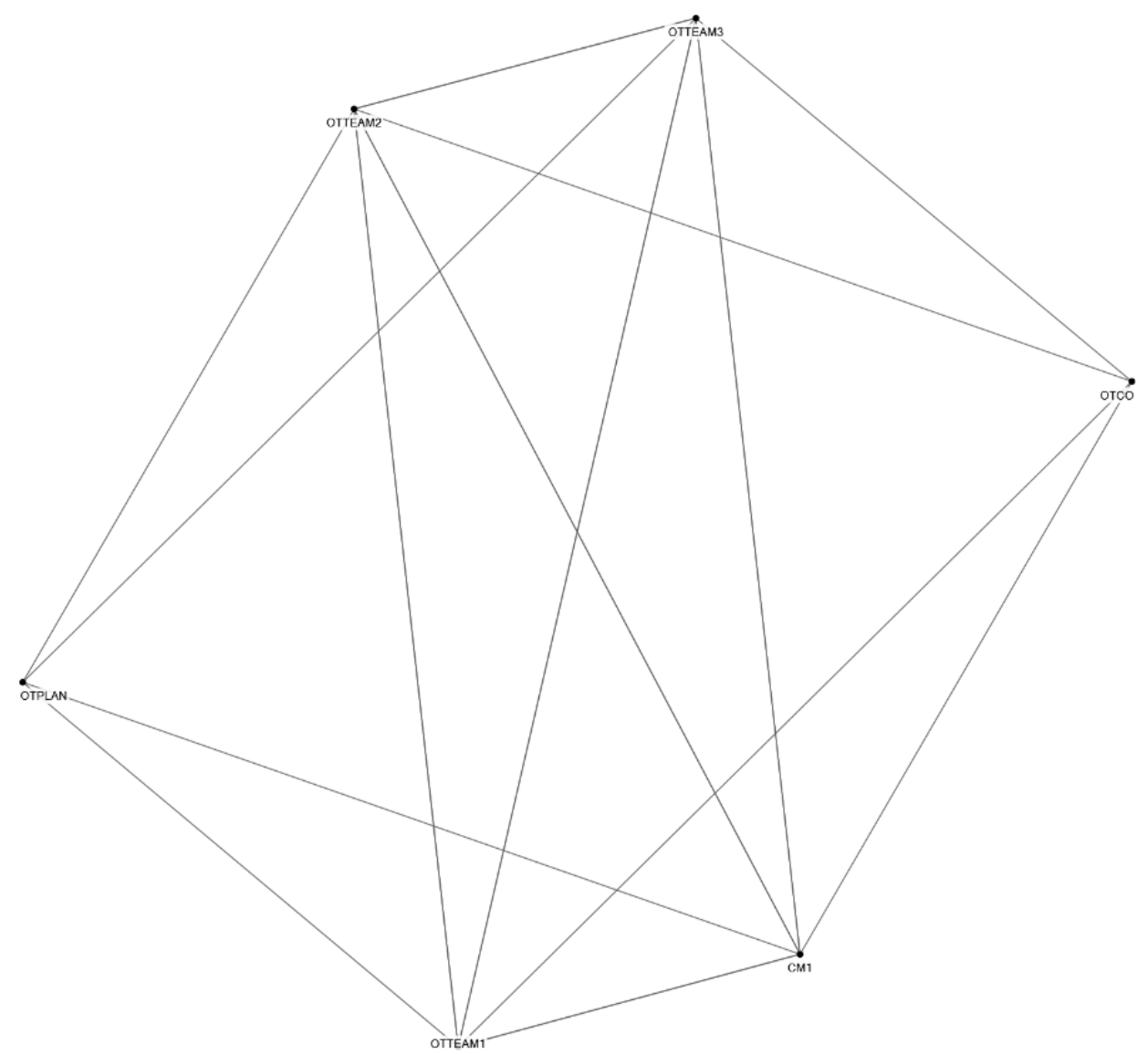

Figure A3.2.23 Social network of task 23: Manage OTC tasks.

There are several regular meetings between the OTC cluster manager, OTC team leaders, the OTC capacity planner and the OTC day coordinator to discuss operations over a longer period of time.

\begin{tabular}{lc}
\hline Parameter & Value \\
\hline Number of agents & 6 \\
Number of unique ties & 14 \\
Density & 0.93 \\
Number of cliques & 2 \\
Highest betweenness centrality & CM1/ OTTEAM1/ \\
& OTTEAM2/ OTTEAM3 \\
\hline
\end{tabular}




\section{APPENDIX 3.3: DESCRIPTION AND DEGREE OF AGENTS IN SOCIAL NETWORKS}

\begin{tabular}{|c|c|c|}
\hline Agent code & Description & Degree \\
\hline ANNU17 & Nurse anesthetist 17 & 399 \\
\hline ANNU16 & Nurse anesthetist 16 & 393 \\
\hline ANNU1 & Nurse anesthetist 1 & 390 \\
\hline ANNU11 & Nurse anesthetist 11 & 390 \\
\hline ANNU5 & Nurse anesthetist 5 & 389 \\
\hline ANNU12 & Nurse anesthetist 12 & 388 \\
\hline ANNU2 & Nurse anesthetist 1 & 388 \\
\hline ANNU2 & Nurse anesthetist 2 & 388 \\
\hline ANNU10 & Nurse anesthetist 10 & 387 \\
\hline ANNU13 & Nurse anesthetist 13 & 387 \\
\hline $\mathrm{ANNU}_{3}$ & Nurse anesthetist 3 & 387 \\
\hline ANNU15 & Nurse anesthetist 15 & 386 \\
\hline ANNU18 & Nurse anesthetist 18 & 386 \\
\hline ANNU6 & Nurse anesthetist 6 & 386 \\
\hline ANNU7 & Nurse anesthetist 7 & 386 \\
\hline ANNU14 & Nurse anesthetist 14 & 385 \\
\hline ANNU19 & Nurse anesthetist19 & 384 \\
\hline ANNU4 & Nurse anesthetist 4 & 384 \\
\hline ANNU9 & Nurse anesthetist 9 & 384 \\
\hline ANNU8 & Nurse anesthetist 8 & 383 \\
\hline RENUR1 & Recovery nurse 1 & 318 \\
\hline RENUR10 & Recovery nurse 10 & 318 \\
\hline RENUR2 & Recovery nurse 2 & 318 \\
\hline RENUR3 & Recovery nurse 3 & 318 \\
\hline RENUR4 & Recovery nurse 4 & 318 \\
\hline RENUR5 & Recovery nurse 5 & 318 \\
\hline RENUR6 & Recovery nurse 6 & 318 \\
\hline RENUR7 & Recovery nurse 7 & 318 \\
\hline RENUR8 & Recovery nurse 8 & 318 \\
\hline RENUR9 & Recovery nurse 9 & 318 \\
\hline HOLD2 & Holding nurse 2 & 312 \\
\hline HOLD3 & Holding nurse 3 & 312 \\
\hline HOLD4 & Holding nurse 4 & 312 \\
\hline OTCO & OTC day coordinator & 294 \\
\hline HOLD1 & Holding nurse 1 & 266 \\
\hline GENS6 & General surgeon 6 & 263 \\
\hline GEAS6 & Assistant surgeon 6 & 260 \\
\hline GENS1 & General surgeon 1 & 251 \\
\hline GEAS9 & Assistant surgeon 9 & 247 \\
\hline GENS7 & General surgeon 7 & 246 \\
\hline ICNUR1 & Intensive care nurse 1 & 220 \\
\hline GENS9 & General surgeon 9 & 218 \\
\hline GENS3 & General surgeon 3 & 213 \\
\hline GENS8 & General surgeon 8 & 211 \\
\hline GENS2 & General surgeon 2 & 209 \\
\hline ICNUR2 & Intensive care nurse 2 & 209 \\
\hline
\end{tabular}




\begin{tabular}{|c|c|c|}
\hline Agent code & Description & Degree \\
\hline GENS4 & General surgeon 4 & 203 \\
\hline ORTS2 & Orthopedic surgeon 2 & 203 \\
\hline GEAS5 & Assistant surgeon 5 & 202 \\
\hline ICNUR10 & Intensive care nurse 10 & 202 \\
\hline ICNUR11 & Intensive care nurse 11 & 201 \\
\hline ICNUR12 & Intensive care nurse 12 & 198 \\
\hline F2NUR1 & Ward F2 nurse 1 & 194 \\
\hline ICNUR13 & Intensive care nurse 13 & 192 \\
\hline ICNUR14 & Intensive care nurse 14 & 192 \\
\hline ORTS4 & Orthopedic surgeon 4 & 192 \\
\hline ICNUR15 & Intensive care nurse 15 & 190 \\
\hline GENS11 & General surgeon 11 & 189 \\
\hline F2NUR10 & Ward F2 nurse 10 & 188 \\
\hline PLAS1 & Plastic surgeon 1 & 188 \\
\hline ICNUR16 & Intensive care nurse 16 & 187 \\
\hline ICNUR17 & Intensive care nurse 17 & 187 \\
\hline ORTS3 & Orthopedic surgeon 3 & 187 \\
\hline ICNUR18 & Intensive care nurse 18 & 184 \\
\hline F2NUR11 & Ward F2 nurse 11 & 183 \\
\hline ICNUR19 & Intensive care nurse 19 & 183 \\
\hline ICNUR20 & Intensive care nurse 20 & 182 \\
\hline UROS2 & Urology surgeon2 & 176 \\
\hline ORTS1 & Orthopedic surgeon 1 & 173 \\
\hline ENTS3 & Ear Nose Throat surgeon 3 & 170 \\
\hline UROS1 & Urology surgeon 1 & 169 \\
\hline UROS3 & Urology surgeon3 & 169 \\
\hline GEAS10 & Assistant surgeon 10 & 164 \\
\hline ENTS1 & Ear Nose Throat surgeon 1 & 163 \\
\hline ICNUR21 & Intensive care nurse 21 & 163 \\
\hline PLAS2 & Plastic surgeon 2 & 161 \\
\hline GEAS11 & Assistant surgeon 11 & 160 \\
\hline ENTS2 & Ear Nose Throat surgeon 2 & 156 \\
\hline F2NUR12 & Ward F2 nurse 12 & 155 \\
\hline F2NUR2 & Ward F2 nurse 2 & 155 \\
\hline $\mathrm{F}_{2 N U R} 3$ & Ward F2 nurse 3 & 155 \\
\hline F2NUR4 & Ward F2 nurse 4 & 153 \\
\hline $\mathrm{GENS}_{5}$ & General surgeon 5 & 153 \\
\hline F2NUR5 & Ward F2 nurse 5 & 151 \\
\hline DENS2 & Dental surgeon 2 & 149 \\
\hline F2NUR6 & Ward F2 nurse 6 & 149 \\
\hline F2NUR7 & Ward F2 nurse 7 & 149 \\
\hline ICNUR22 & Intensive care nurse 22 & 147 \\
\hline GENS12 & General surgeon 12 & 146 \\
\hline ICNUR23 & Intensive care nurse 23 & 144 \\
\hline GYNS7 & Gynecological surgeon 7 & 143 \\
\hline GYNS2 & Gynecological surgeon 2 & 141 \\
\hline NoNUR1 & Ward No nurse 1 & 141 \\
\hline F2NUR13 & Ward F2 nurse 13 & 140 \\
\hline GYNS4 & Gynecological surgeon 4 & 140 \\
\hline A2NUR1 & Ward A2 nurse 1 & 139 \\
\hline
\end{tabular}




\begin{tabular}{|c|c|c|}
\hline Agent code & Description & Degree \\
\hline A2NUR2 & Ward A2 nurse 2 & 139 \\
\hline F2NUR14 & Ward F2 nurse 14 & 139 \\
\hline GYNS3 & Gynecological surgeon 3 & 137 \\
\hline NoNUR2 & Ward No nurse 2 & 137 \\
\hline A2NUR3 & Ward A2 nurse 3 & 136 \\
\hline A2NUR4 & Ward A2 nurse 4 & 136 \\
\hline DENS3 & Dental surgeon 3 & 136 \\
\hline NoNUR3 & Ward No nurse 3 & 136 \\
\hline A2NUR5 & Ward A2 nurse 5 & 135 \\
\hline A2NUR6 & Ward A2 nurse 6 & 135 \\
\hline A2NUR7 & Ward A2 nurse 7 & 135 \\
\hline GENS13 & General surgeon 13 & 135 \\
\hline GYNS5 & Gynecological surgeon 5 & 135 \\
\hline ICNUR3 & Intensive care nurse 3 & 135 \\
\hline ORAS17 & OR nurse 17 & 135 \\
\hline GEAS7 & Assistant surgeon 7 & 134 \\
\hline ORAS1 & OR nurse 1 & 134 \\
\hline ICNUR4 & Intensive care nurse 4 & 133 \\
\hline A2NUR8 & Ward A2 nurse 8 & 132 \\
\hline A2NUR10 & Ward A2 nurse 10 & 131 \\
\hline A2NUR11 & Ward A2 nurse 11 & 131 \\
\hline ORAS11 & OR nurse 11 & 131 \\
\hline ORAS4O & OR nurse 40 & 131 \\
\hline GYNS1 & Gynecological surgeon 1 & 130 \\
\hline ICNUR5 & Intensive care nurse 5 & 130 \\
\hline ORAS23 & OR nurse 23 & 130 \\
\hline A2NUR12 & Ward A2 nurse 12 & 129 \\
\hline A2NUR9 & Ward A2 nurse 9 & 129 \\
\hline GYNS8 & Gynecological surgeon 8 & 129 \\
\hline ICNUR6 & Intensive care nurse 6 & 129 \\
\hline ICNUR7 & Intensive care nurse 7 & 129 \\
\hline ORAS27 & OR nurse 27 & 129 \\
\hline $\mathrm{ORAS}_{3}$ & OR nurse 3 & 129 \\
\hline A2NUR13 & Ward A2 nurse 13 & 128 \\
\hline ORAS13 & OR nurse 13 & 128 \\
\hline ORAS29 & OR nurse 29 & 128 \\
\hline A2NUR14 & Ward A2 nurse 14 & 127 \\
\hline A2NUR15 & Ward A2 nurse 15 & 127 \\
\hline A2NUR16 & Ward A2 nurse 16 & 127 \\
\hline ORAS18 & OR nurse 18 & 127 \\
\hline ORAS19 & OR nurse 19 & 127 \\
\hline ORAS21 & OR nurse 21 & 127 \\
\hline ORAS10 & OR nurse 10 & 126 \\
\hline ORAS16 & OR nurse 16 & 126 \\
\hline A2NUR17 & Ward A2 nurse 17 & 125 \\
\hline A2NUR18 & Ward A2 nurse 18 & 125 \\
\hline ICNUR8 & Intensive care nurse 8 & 125 \\
\hline ICNUR9 & Intensive care nurse 9 & 125 \\
\hline ORAS2 & OR nurse 2 & 125 \\
\hline ORAS2O & OR nurse 20 & 125 \\
\hline ORAS28 & OR nurse 28 & 125 \\
\hline
\end{tabular}




\begin{tabular}{|c|c|c|}
\hline Agent code & Description & Degree \\
\hline ORAS36 & OR nurse 36 & 125 \\
\hline A2NUR19 & Ward A2 nurse 19 & 124 \\
\hline A2NUR2O & Ward A2 nurse 20 & 124 \\
\hline ORAS12 & OR nurse 12 & 124 \\
\hline ORAS14 & OR nurse 14 & 124 \\
\hline ORAS3O & OR nurse 30 & 124 \\
\hline ORAS31 & OR nurse 31 & 124 \\
\hline F2NUR8 & Ward F2 nurse 8 & 123 \\
\hline NEUS1 & Neurosurgeon 1 & 123 \\
\hline ORAS24 & OR nurse 24 & 123 \\
\hline ORAS38 & OR nurse 38 & 123 \\
\hline ORAS47 & OR nurse 47 & 123 \\
\hline A2NUR21 & Ward A2 nurse 21 & 122 \\
\hline BoNUR1 & Ward Bo nurse 1 & 122 \\
\hline A2NUR22 & Ward A2 nurse 22 & 121 \\
\hline GEAS13 & Assistant surgeon 13 & 121 \\
\hline ORAS32 & OR nurse 32 & 121 \\
\hline ORAS34 & OR nurse 34 & 121 \\
\hline A2NUR23 & Ward A2 nurse 23 & 120 \\
\hline A2NUR24 & Ward A2 nurse 24 & 120 \\
\hline A2NUR25 & Ward A2 nurse 25 & 120 \\
\hline ORAS22 & OR nurse 22 & 120 \\
\hline ORAS4 & OR nurse 4 & 120 \\
\hline ORAS42 & OR nurse 42 & 120 \\
\hline A2NUR26 & Ward A2 nurse 26 & 119 \\
\hline A2NUR27 & Ward A2 nurse 27 & 119 \\
\hline A2NUR28 & Ward A2 nurse 28 & 119 \\
\hline A2NUR29 & Ward A2 nurse 29 & 119 \\
\hline A2NUR32 & Ward A2 nurse 32 & 119 \\
\hline A2NUR33 & Ward A2 nurse 33 & 119 \\
\hline A2NUR34 & Ward A2 nurse 34 & 119 \\
\hline A2NUR35 & Ward A2 nurse 35 & 119 \\
\hline A2NUR36 & Ward A2 nurse 36 & 119 \\
\hline A2NUR37 & Ward A2 nurse 37 & 119 \\
\hline $\mathrm{A}_{2} \mathrm{NUR}_{3} 8$ & Ward A2 nurse 38 & 119 \\
\hline ORAS26 & OR nurse 26 & 119 \\
\hline ORAS33 & OR nurse 33 & 119 \\
\hline ORAS37 & OR nurse 37 & 119 \\
\hline ORAS39 & OR nurse 39 & 119 \\
\hline ORAS46 & OR nurse 46 & 119 \\
\hline A2NUR3o & Ward A2 nurse 30 & 118 \\
\hline A2NUR31 & Ward A2 nurse 31 & 118 \\
\hline ORAS51 & OR nurse 51 & 118 \\
\hline A2NUR39 & Ward A2 nurse 39 & 117 \\
\hline NoNUR10 & Ward No nurse 10 & 117 \\
\hline ORAS25 & OR nurse 25 & 117 \\
\hline ORAS35 & OR nurse 35 & 117 \\
\hline ORAS45 & OR nurse 45 & 117 \\
\hline ORAS48 & OR nurse 48 & 117 \\
\hline ORAS49 & OR nurse 49 & 117 \\
\hline ORAS7 & OR nurse 7 & 117 \\
\hline
\end{tabular}




\begin{tabular}{|c|c|c|}
\hline Agent code & Description & Degree \\
\hline AN1 & Anesthesiologist 1 & 116 \\
\hline NoNUR11 & Ward No nurse 11 & 116 \\
\hline AN11 & Anesthesiologist 11 & 115 \\
\hline BoNUR2 & Ward Bo nurse 2 & 115 \\
\hline GEAS15 & Assistant surgeon 15 & 114 \\
\hline NoNUR12 & Ward No nurse 12 & 114 \\
\hline N2NUR1 & Ward N2 nurse 1 & 113 \\
\hline ORAS41 & OR nurse 41 & 113 \\
\hline AN10 & Anesthesiologist 10 & 112 \\
\hline AN2 & Anesthesiologist 2 & 112 \\
\hline AN4 & Anesthesiologist 4 & 112 \\
\hline $\mathrm{AN} 7$ & Anesthesiologist 7 & 112 \\
\hline AN8 & Anesthesiologist 8 & 112 \\
\hline ORAS43 & OR nurse 43 & 112 \\
\hline $\mathrm{AN}_{3}$ & Anesthesiologist 3 & 111 \\
\hline AN6 & Anesthesiologist 6 & 111 \\
\hline GEAS8 & Assistant surgeon 8 & 111 \\
\hline ORAS44 & OR nurse 44 & 111 \\
\hline ORAS6 & OR nurse 6 & 111 \\
\hline AN5 & Anesthesiologist 5 & 110 \\
\hline AN9 & Anesthesiologist 9 & 110 \\
\hline BoNUR3 & Ward Bo nurse 3 & 110 \\
\hline NoNUR13 & Ward No nurse 13 & 110 \\
\hline NoNUR14 & Ward No nurse 14 & 110 \\
\hline NoNUR15 & Ward No nurse 15 & 110 \\
\hline NoNUR16 & Ward No nurse 16 & 109 \\
\hline F2NUR9 & Ward F2 nurse 9 & 108 \\
\hline NoNUR17 & Ward No nurse 17 & 108 \\
\hline OTPLAN & OTC capacity planner & 108 \\
\hline NoNUR18 & Ward No nurse 18 & 107 \\
\hline NoNUR19 & Ward No nurse 19 & 107 \\
\hline NoNUR2O & Ward No nurse 20 & 107 \\
\hline NoNUR21 & Ward No nurse 21 & 107 \\
\hline NoNUR22 & Ward No nurse 22 & 107 \\
\hline ORAS50 & OR nurse 50 & 107 \\
\hline ICNUR24 & Intensive care nurse 24 & 106 \\
\hline ICNUR25 & Intensive care nurse 25 & 106 \\
\hline NoNUR23 & Ward No nurse 23 & 106 \\
\hline N2NUR2 & Ward N2 nurse 2 & 106 \\
\hline ICNUR26 & Intensive care nurse 26 & 105 \\
\hline ICNUR27 & Intensive care nurse 27 & 105 \\
\hline ICNUR28 & Intensive care nurse 28 & 105 \\
\hline ICNUR29 & Intensive care nurse 29 & 105 \\
\hline ICNUR3O & Intensive care nurse 30 & 105 \\
\hline NoNUR24 & Ward No nurse 24 & 105 \\
\hline NoNUR25 & Ward No nurse 25 & 105 \\
\hline NoNUR26 & Ward No nurse 26 & 105 \\
\hline NoNUR27 & Ward No nurse 27 & 105 \\
\hline NoNUR28 & Ward No nurse 28 & 105 \\
\hline NoNUR29 & Ward No nurse 29 & 105 \\
\hline NoNUR30 & Ward No nurse 30 & 105 \\
\hline
\end{tabular}




\begin{tabular}{|c|c|c|}
\hline Agent code & Description & Degree \\
\hline NoNUR31 & Ward No nurse 31 & 105 \\
\hline BoNUR4 & Ward Bo nurse 4 & 104 \\
\hline $\mathrm{N}_{2} \mathrm{NUR}_{3}$ & Ward N2 nurse 3 & 104 \\
\hline BoNUR5 & Ward Bo nurse 5 & 103 \\
\hline NoNUR32 & Ward No nurse 32 & 103 \\
\hline NoNUR33 & Ward No nurse 33 & 103 \\
\hline $\mathrm{ORAS}_{5}$ & OR nurse 5 & 103 \\
\hline N2NUR4 & Ward N2 nurse 4 & 102 \\
\hline N2NUR5 & Ward N2 nurse 5 & 102 \\
\hline BoNUR6 & Ward Bo nurse 6 & 101 \\
\hline N2NUR6 & Ward N2 nurse 6 & 101 \\
\hline N2NUR7 & Ward N2 nurse 7 & 100 \\
\hline B2NUR1 & Ward B2 nurse 1 & 99 \\
\hline DENS1 & Dental surgeon 1 & 98 \\
\hline GEAS4 & Assistant surgeon 4 & 98 \\
\hline N2NUR10 & Ward N2 nurse 10 & 98 \\
\hline N2NUR8 & Ward N2 nurse 8 & 97 \\
\hline N2NUR9 & Ward N2 nurse 9 & 97 \\
\hline BoNUR7 & Ward Bo nurse 7 & 95 \\
\hline NoNUR4 & Ward No nurse 4 & 94 \\
\hline BoNUR8 & Ward Bo nurse 8 & 93 \\
\hline NoNUR5 & Ward No nurse 5 & 93 \\
\hline N2NUR11 & Ward N2 nurse 11 & 93 \\
\hline N2NUR12 & Ward N2 nurse 12 & 93 \\
\hline N2NUR13 & Ward N2 nurse 13 & 93 \\
\hline BoNUR9 & Ward Bo nurse 9 & 92 \\
\hline N2NUR14 & Ward N2 nurse 14 & 92 \\
\hline N2NUR15 & Ward N2 nurse 15 & 92 \\
\hline N2NUR16 & Ward N2 nurse 16 & 91 \\
\hline N2NUR17 & Ward N2 nurse 17 & 91 \\
\hline N2NUR18 & Ward N2 nurse 18 & 91 \\
\hline N2NUR19 & Ward N2 nurse 19 & 91 \\
\hline BoNUR10 & Ward Bo nurse 10 & 89 \\
\hline B2NUR2 & Ward B2 nurse 2 & 89 \\
\hline ENTS4 & Ear Nose Throat surgeon 4 & 89 \\
\hline ICNUR31 & Intensive care nurse 31 & 89 \\
\hline ICNUR32 & Intensive care nurse 32 & 89 \\
\hline ICNUR33 & Intensive care nurse 33 & 89 \\
\hline ICNUR34 & Intensive care nurse 34 & 89 \\
\hline NoNUR6 & Ward No nurse 6 & 89 \\
\hline N2NUR2O & Ward N2 nurse 20 & 89 \\
\hline N2NUR21 & Ward N2 nurse 21 & 89 \\
\hline ICNUR36 & Intensive care nurse 36 & 88 \\
\hline N2NUR22 & Ward N2 nurse 22 & 88 \\
\hline BoNUR11 & Ward Bo nurse 11 & 87 \\
\hline BoNUR12 & Ward Bo nurse 12 & 87 \\
\hline DENS4 & Dental surgeon 4 & 87 \\
\hline ICNUR35 & Intensive care nurse 35 & 87 \\
\hline ICNUR37 & Intensive care nurse 37 & 87 \\
\hline NoNUR7 & Ward No nurse 7 & 87 \\
\hline N2NUR23 & Ward N2 nurse 23 & 87 \\
\hline
\end{tabular}




\begin{tabular}{|c|c|c|}
\hline Agent code & Description & Degree \\
\hline N2NUR24 & Ward N2 nurse 24 & 87 \\
\hline N2NUR25 & Ward N2 nurse 25 & 87 \\
\hline BoNUR13 & Ward Bo nurse 13 & 86 \\
\hline ICNUR38 & Intensive care nurse 38 & 86 \\
\hline N2NUR26 & Ward N2 nurse 26 & 86 \\
\hline N2NUR27 & Ward N2 nurse 27 & 86 \\
\hline N2NUR28 & Ward N2 nurse 28 & 86 \\
\hline N2NUR29 & Ward N2 nurse 29 & 86 \\
\hline N2NUR3O & Ward N2 nurse 30 & 86 \\
\hline N2NUR31 & Ward N2 nurse 31 & 86 \\
\hline N2NUR32 & Ward N2 nurse 32 & 86 \\
\hline N2NUR33 & Ward N2 nurse 33 & 86 \\
\hline ICNUR39 & Intensive care nurse 39 & 85 \\
\hline N1NUR1 & Ward N1 nurse 1 & 85 \\
\hline ORAS15 & OR nurse 15 & 85 \\
\hline $\mathrm{B}_{2 N U R} 3$ & Ward B2 nurse 3 & 84 \\
\hline ICNUR40 & Intensive care nurse 40 & 84 \\
\hline NoNUR8 & Ward No nurse 8 & 84 \\
\hline BoNUR14 & Ward Bo nurse 14 & 83 \\
\hline ICNUR41 & Intensive care nurse 41 & 83 \\
\hline ICNUR42 & Intensive care nurse 42 & 83 \\
\hline ICNUR43 & Intensive care nurse 43 & 83 \\
\hline NoNUR9 & Ward No nurse 9 & 83 \\
\hline B2NUR10 & Ward B2 nurse 10 & 82 \\
\hline B2NUR11 & Ward B2 nurse 11 & 82 \\
\hline B2NUR12 & Ward B2 nurse 12 & 82 \\
\hline B2NUR13 & Ward B2 nurse 13 & 82 \\
\hline B2NUR14 & Ward B2 nurse 14 & 82 \\
\hline B2NUR15 & Ward B2 nurse 15 & 82 \\
\hline B2NUR16 & Ward B2 nurse 16 & 82 \\
\hline B2NUR17 & Ward B2 nurse 17 & 82 \\
\hline B2NUR18 & Ward B2 nurse 18 & 82 \\
\hline B2NUR19 & Ward B2 nurse 19 & 82 \\
\hline B2NUR2O & Ward B2 nurse 20 & 82 \\
\hline B2NUR21 & Ward B2 nurse 21 & 82 \\
\hline B2NUR22 & Ward B2 nurse 22 & 82 \\
\hline B2NUR23 & Ward B2 nurse 23 & 82 \\
\hline B2NUR24 & Ward B2 nurse 24 & 82 \\
\hline B2NUR25 & Ward B2 nurse 25 & 82 \\
\hline B2NUR26 & Ward B2 nurse 26 & 82 \\
\hline B2NUR27 & Ward B2 nurse 27 & 82 \\
\hline ICNUR44 & Intensive care nurse 44 & 82 \\
\hline N1NUR2 & Ward N1 nurse 2 & 82 \\
\hline BoNUR15 & Ward Bo nurse 15 & 81 \\
\hline B2NUR28 & Ward B2 nurse 28 & 81 \\
\hline B2NUR29 & Ward B2 nurse 29 & 81 \\
\hline B2NUR9 & Ward B2 nurse 9 & 81 \\
\hline ICNUR45 & Intensive care nurse 45 & 81 \\
\hline ICNUR46 & Intensive care nurse 46 & 81 \\
\hline ICNUR47 & Intensive care nurse 47 & 81 \\
\hline ICNUR48 & Intensive care nurse 48 & 81 \\
\hline
\end{tabular}




\begin{tabular}{|c|c|c|}
\hline Agent code & Description & Degree \\
\hline B2NUR3o & Ward B2 nurse 30 & 80 \\
\hline B2NUR31 & Ward B2 nurse 31 & 80 \\
\hline B2NUR32 & Ward B2 nurse 32 & 80 \\
\hline B2NUR33 & Ward B2 nurse 33 & 80 \\
\hline B2NUR4 & Ward B2 nurse 4 & 80 \\
\hline B2NUR8 & Ward B2 nurse 8 & 80 \\
\hline ERPHYS1 & ER physician 1 & 80 \\
\hline ERPHYS4 & ER physician 4 & 80 \\
\hline ERPHYS5 & ER physician 5 & 80 \\
\hline ERPHYS6 & ER physician 6 & 80 \\
\hline ICNUR49 & Intensive care nurse 49 & 80 \\
\hline N1NUR10 & Ward N1 nurse 10 & 80 \\
\hline N1NUR11 & Ward N1 nurse 11 & 80 \\
\hline N1NUR12 & Ward N1 nurse 12 & 80 \\
\hline N1NUR13 & Ward N1 nurse 13 & 80 \\
\hline N1NUR14 & Ward N1 nurse 14 & 80 \\
\hline N1NUR15 & Ward N1 nurse 15 & 80 \\
\hline N1NUR16 & Ward N1 nurse 16 & 80 \\
\hline N1NUR17 & Ward N1 nurse 17 & 80 \\
\hline N1NUR18 & Ward N1 nurse 18 & 80 \\
\hline N1NUR19 & Ward N1 nurse 19 & 80 \\
\hline N1NUR2O & Ward N1 nurse 20 & 80 \\
\hline N1NUR21 & Ward N1 nurse 21 & 80 \\
\hline N1NUR22 & Ward N1 nurse 22 & 80 \\
\hline N1NUR23 & Ward N1 nurse 23 & 80 \\
\hline N1NUR24 & Ward N1 nurse 24 & 80 \\
\hline N1NUR25 & Ward N1 nurse 25 & 80 \\
\hline N1NUR26 & Ward N1 nurse 26 & 80 \\
\hline N1NUR27 & Ward N1 nurse 27 & 80 \\
\hline N1NUR28 & Ward N1 nurse 28 & 80 \\
\hline N1NUR29 & Ward N1 nurse 29 & 80 \\
\hline N1NUR3 & Ward N1 nurse 3 & 80 \\
\hline N1NUR3O & Ward N1 nurse 30 & 80 \\
\hline N1NUR31 & Ward N1 nurse 31 & 80 \\
\hline N1NUR32 & Ward N1 nurse 32 & 80 \\
\hline N1NUR33 & Ward N1 nurse 33 & 80 \\
\hline N1NUR34 & Ward N1 nurse 34 & 80 \\
\hline N1NUR35 & Ward N1 nurse 35 & 80 \\
\hline N1NUR36 & Ward N1 nurse 36 & 80 \\
\hline N1NUR37 & Ward N1 nurse 37 & 80 \\
\hline N1NUR38 & Ward N1 nurse 38 & 80 \\
\hline N1NUR39 & Ward N1 nurse 39 & 80 \\
\hline N1NUR4 & Ward N1 nurse 4 & 80 \\
\hline N1NUR4O & Ward N1 nurse 40 & 80 \\
\hline N1NUR41 & Ward N1 nurse 41 & 80 \\
\hline N1NUR42 & Ward N1 nurse 42 & 80 \\
\hline N1NUR43 & Ward N1 nurse 43 & 80 \\
\hline N1NUR5 & Ward N1 nurse 5 & 80 \\
\hline N1NUR6 & Ward N1 nurse 6 & 80 \\
\hline N1NUR7 & Ward N1 nurse 7 & 80 \\
\hline N1NUR8 & Ward N1 nurse 8 & 80 \\
\hline
\end{tabular}




\begin{tabular}{|c|c|c|}
\hline Agent code & Description & Degree \\
\hline N1NUR9 & Ward N1 nurse 9 & 80 \\
\hline BoNUR16 & Ward Bo nurse 16 & 79 \\
\hline BoNUR17 & Ward Bo nurse 17 & 79 \\
\hline B2NUR5 & Ward B2 nurse 5 & 79 \\
\hline B2NUR6 & Ward B2 nurse 6 & 79 \\
\hline B2NUR7 & Ward B2 nurse 7 & 79 \\
\hline ICNUR50 & Intensive care nurse 50 & 79 \\
\hline ICNUR51 & Intensive care nurse 51 & 79 \\
\hline BoNUR18 & Ward Bo nurse 18 & 78 \\
\hline ICNUR52 & Intensive care nurse 52 & 78 \\
\hline BoNUR19 & Ward Bo nurse 19 & 77 \\
\hline BoNUR2O & Ward Bo nurse 20 & 77 \\
\hline ERPHYS3 & ER physician 3 & 77 \\
\hline BoNUR21 & Ward Bo nurse 21 & 76 \\
\hline BoNUR22 & Ward Bo nurse 22 & 76 \\
\hline BoNUR23 & Ward Bo nurse 23 & 76 \\
\hline BoNUR24 & Ward Bo nurse 24 & 76 \\
\hline ERPHYS2 & ER physician 2 & 76 \\
\hline BoNUR25 & Ward Bo nurse 25 & 75 \\
\hline BoNUR26 & Ward Bo nurse 26 & 75 \\
\hline BoNUR27 & Ward Bo nurse 27 & 75 \\
\hline BoNUR28 & Ward Bo nurse 28 & 75 \\
\hline BoNUR29 & Ward Bo nurse 29 & 74 \\
\hline BoNUR3o & Ward Bo nurse 30 & 74 \\
\hline BoNUR31 & Ward Bo nurse 31 & 74 \\
\hline BoNUR32 & Ward Bo nurse 32 & 74 \\
\hline BoNUR33 & Ward Bo nurse 33 & 74 \\
\hline BoNUR34 & Ward Bo nurse 34 & 74 \\
\hline BoNUR35 & Ward Bo nurse 35 & 74 \\
\hline B2NUR34 & Ward B2 nurse 34 & 74 \\
\hline B2NUR35 & Ward B2 nurse 35 & 74 \\
\hline ORAS8 & OR nurse 8 & 74 \\
\hline ERNUR1 & ER nurse 1 & 68 \\
\hline ERNUR10 & ER nurse 10 & 68 \\
\hline ERNUR11 & ER nurse 11 & 68 \\
\hline ERNUR12 & ER nurse 12 & 68 \\
\hline ERNUR13 & ER nurse 13 & 68 \\
\hline ERNUR14 & ER nurse 14 & 68 \\
\hline ERNUR15 & ER nurse 15 & 68 \\
\hline ERNUR16 & ER nurse 16 & 68 \\
\hline ERNUR17 & ER nurse 17 & 68 \\
\hline ERNUR18 & ER nurse 18 & 68 \\
\hline ERNUR19 & ER nurse 19 & 68 \\
\hline ERNUR2 & ER nurse 2 & 68 \\
\hline ERNUR2O & ER nurse 20 & 68 \\
\hline ERNUR21 & ER nurse 21 & 68 \\
\hline ERNUR22 & ER nurse 22 & 68 \\
\hline ERNUR23 & ER nurse 23 & 68 \\
\hline ERNUR24 & ER nurse 24 & 68 \\
\hline ERNUR25 & ER nurse 25 & 68 \\
\hline ERNUR26 & ER nurse 26 & 68 \\
\hline
\end{tabular}




\begin{tabular}{|c|c|c|}
\hline Agent code & Description & Degree \\
\hline ERNUR27 & ER nurse 27 & 68 \\
\hline ERNUR28 & ER nurse 28 & 68 \\
\hline ERNUR29 & ER nurse 29 & 68 \\
\hline ERNUR3 & ER nurse 3 & 68 \\
\hline ERNUR3O & ER nurse 30 & 68 \\
\hline ERNUR31 & ER nurse 31 & 68 \\
\hline ERNUR32 & ER nurse 32 & 68 \\
\hline ERNUR33 & ER nurse 33 & 68 \\
\hline ERNUR34 & ER nurse 34 & 68 \\
\hline ERNUR35 & ER nurse 35 & 68 \\
\hline ERNUR4 & ER nurse 4 & 68 \\
\hline ERNUR5 & ER nurse 5 & 68 \\
\hline ERNUR6 & ER nurse 6 & 68 \\
\hline ERNUR7 & ER nurse 7 & 68 \\
\hline ERNUR8 & ER nurse 8 & 68 \\
\hline ERNUR9 & ER nurse 9 & 68 \\
\hline EYES1 & Eye surgeon1 & 68 \\
\hline ORAS9 & OR nurse 9 & 67 \\
\hline SECANE1 & Secretary1 Anesthesia & 67 \\
\hline SECANE2 & Secretary2 Anesthesia & 67 \\
\hline SECANE3 & Secretary3 Anesthesia & 67 \\
\hline SECANE4 & Secretary4 Anesthesia & 67 \\
\hline GEAS14 & Assistant surgeon 14 & 65 \\
\hline WTEAMA2 & Ward team leader A2 & 65 \\
\hline UROS7 & Urology surgeon7 & 63 \\
\hline WTEAMNF2 & Ward team leader F2 & 63 \\
\hline KDVNUR1 & Pediatric ward nurse 1 & 60 \\
\hline URAS & Urology assistant surgeon & 60 \\
\hline GEAS2 & Assistant surgeon 2 & 59 \\
\hline KDVNUR2 & Pediatric ward nurse 2 & 57 \\
\hline OTTEAM1 & Team leader Surgery & 57 \\
\hline KDVNUR3 & Pediatric ward nurse 3 & 54 \\
\hline KDVNUR4 & Pediatric ward nurse 4 & 54 \\
\hline OTLOG1 & OTC logistical staff member 1 & 54 \\
\hline OTLOG2 & OTC logistical staff member 1 & 54 \\
\hline CLEAN1 & Cleaning staff member 1 & 51 \\
\hline CLEAN2 & Cleaning staff member 2 & 51 \\
\hline WTEAMIC & Ward team leader Intensive Care & 50 \\
\hline EYES3 & Eye surgeon 3 & 49 \\
\hline GYNS6 & Gynecology surgeon 6 & 47 \\
\hline AN12 & Anesthesiologist 12 & 46 \\
\hline GENS10 & General surgeon 10 & 46 \\
\hline SASS4 & Physician assistant 4 & 44 \\
\hline $\mathrm{UROS}_{5}$ & Urology surgeon 5 & 44 \\
\hline WTEAMN1 & Ward team leader N1 & 43 \\
\hline OTSEC & OTC secretary & 42 \\
\hline GEAS1 & Assistant surgeon 1 & 39 \\
\hline SECNEUR & Secretary of Neurology outpatient department & 39 \\
\hline UROS6 & Urology surgeon 6 & 39 \\
\hline WTEAMBo & Ward team leader Bo & 39 \\
\hline SECCAR & Secretary of Cardiology outpatient department & 38 \\
\hline
\end{tabular}




\begin{tabular}{|c|c|c|}
\hline Agent code & Description & Degree \\
\hline GEAS12 & Assistant surgeon 12 & 37 \\
\hline GEAS3 & Assistant surgeon 3 & 36 \\
\hline WTEAMB2 & Ward team leader B2 & 35 \\
\hline UROS4 & Urology surgeon 4 & 34 \\
\hline WTEAMNo & Ward team leader No & 33 \\
\hline SASS1 & Physician assistant 1 & 32 \\
\hline UROS8 & Urology surgeon 8 & 31 \\
\hline SECGEN1 & Secretary 1 General surgery & 28 \\
\hline SECGEN2 & Secretary 2 General surgery & 28 \\
\hline SECGEN3 & Secretary 3 General surgery & 28 \\
\hline SECGEN4 & Secretary 4 General surgery & 25 \\
\hline SECGEN5 & Secretary 5 General surgery & 25 \\
\hline SECURO1 & Secretary 1 Urology outpatient department & 25 \\
\hline EYES2 & Eye surgeon 2 & 24 \\
\hline OTTEAM2 & Team leader Anesthesia & 24 \\
\hline SECGEN6 & Secretary 6 General surgery & 24 \\
\hline SECGYN1 & Secretary 1 Gynecology & 24 \\
\hline SECGYN2 & Secretary 2 Gynecology & 24 \\
\hline $\mathrm{SECGYN}_{3}$ & Secretary 3 Gynecology & 24 \\
\hline SECORT1 & Secretary 1 Orthopedics outpatient department & 24 \\
\hline SASS$_{5}$ & Physician assistant 5 & 22 \\
\hline SECURO2 & Secretary 2 Urology outpatient department & 22 \\
\hline SECURO3 & Secretary 3 Urology outpatient department & 22 \\
\hline $\mathrm{SECURO}_{4}$ & Secretary 4 Urology outpatient department & 22 \\
\hline SECORT2 & Secretary 2 Orthopedics outpatient department & 21 \\
\hline SECORT3 & Secretary 3 Orthopedics outpatient department & 21 \\
\hline SECORT4 & Secretary 4 Orthopedics outpatient department & 21 \\
\hline SECORT5 & Secretary 5 Orthopedics outpatient department & 21 \\
\hline SECENT1 & Secretary1 ENT & 20 \\
\hline OTTEAM3 & Team leader Recovery/holding & 19 \\
\hline SECEYE1 & Secretary 1 Ophthalmology & 19 \\
\hline CM1 & Cluster manager OTC and Services & 18 \\
\hline SECDEN1 & Secretary1 Dental Surgery & 18 \\
\hline SECPLA1 & Secretary1 Plastic surgery outpatient department & 18 \\
\hline SECENT2 & Secretary2 ENT & 17 \\
\hline SECENT3 & Secretary3 ENT & 17 \\
\hline SECENT4 & Secretary4 ENT & 17 \\
\hline SECENT 5 & Secretary5 ENT & 17 \\
\hline EYES4 & Eye surgeon 4 & 16 \\
\hline SECEYE2 & Secretary2 Ophthalmology & 16 \\
\hline SECEYE3 & Secretary3 Ophthalmology & 16 \\
\hline POSNUR1 & Preoperative nurse 1 & 15 \\
\hline POSNUR2 & Preoperative nurse 2 & 15 \\
\hline POSNUR2 & Preoperative nurse 3 & 15 \\
\hline POSNUR3 & Preoperative nurse 4 & 15 \\
\hline POSNUR4 & Preoperative nurse 5 & 15 \\
\hline POSNUR5 & Preoperative nurse 6 & 15 \\
\hline SECCLB & Clinical plan boss & 15 \\
\hline SECDEN2 & Secretary2 Dental Surgery & 15 \\
\hline SECPLA2 & Secretary2 Plastic surgery outpatient department & 15 \\
\hline SECPLA3 & Secretary3 Plastic surgery outpatient department & 15 \\
\hline
\end{tabular}




\begin{tabular}{|c|c|c|}
\hline Agent code & Description & Degree \\
\hline SECPLA4 & Secretary4 Plastic surgery outpatient department & 15 \\
\hline SECPLA5 & Secretary5 Plastic surgery outpatient department & 15 \\
\hline $\mathrm{CM} 2$ & Cluster manager Surgery & 14 \\
\hline WTEAM3 & Team leader in training & 13 \\
\hline RADI1 & Radiology staff member 1 & 12 \\
\hline RADI10 & Radiology staff member 10 & 12 \\
\hline RADI11 & Radiology staff member 11 & 12 \\
\hline RADI13 & Radiology staff member 13 & 12 \\
\hline RADI14 & Radiology staff member 14 & 12 \\
\hline RADI15 & Radiology staff member 15 & 12 \\
\hline RADI16 & Radiology staff member 16 & 12 \\
\hline RADI17 & Radiology staff member 17 & 12 \\
\hline RADI18 & Radiology staff member 18 & 12 \\
\hline RADI19 & Radiology staff member 19 & 12 \\
\hline RADI2 & Radiology staff member 2 & 12 \\
\hline RADI2O & Radiology staff member 20 & 12 \\
\hline RADI21 & Radiology staff member 21 & 12 \\
\hline RADI22 & Radiology staff member 22 & 12 \\
\hline RADI23 & Radiology staff member 23 & 12 \\
\hline RADI24 & Radiology staff member 24 & 12 \\
\hline RADI25 & Radiology staff member 25 & 12 \\
\hline RADI26 & Radiology staff member 26 & 12 \\
\hline RADI27 & Radiology staff member 27 & 12 \\
\hline RADI28 & Radiology staff member 28 & 12 \\
\hline RADI29 & Radiology staff member 29 & 12 \\
\hline RADI3 & Radiology staff member 3 & 12 \\
\hline RADI30 & Radiology staff member 30 & 12 \\
\hline RADI31 & Radiology staff member 31 & 12 \\
\hline RADI32 & Radiology staff member 32 & 12 \\
\hline RADI33 & Radiology staff member 33 & 12 \\
\hline RADI34 & Radiology staff member 34 & 12 \\
\hline RADI35 & Radiology staff member 35 & 12 \\
\hline RADI36 & Radiology staff member 36 & 12 \\
\hline RADI37 & Radiology staff member 37 & 12 \\
\hline RADI38 & Radiology staff member 38 & 12 \\
\hline RADI39 & Radiology staff member 39 & 12 \\
\hline RADI4 & Radiology staff member 4 & 12 \\
\hline RADI40 & Radiology staff member 40 & 12 \\
\hline RADI41 & Radiology staff member 41 & 12 \\
\hline RADI5 & Radiology staff member 5 & 12 \\
\hline RADI6 & Radiology staff member 6 & 12 \\
\hline RADI7 & Radiology staff member 7 & 12 \\
\hline RADI8 & Radiology staff member 8 & 12 \\
\hline RADI9 & Radiology staff member 9 & 12 \\
\hline RADI12 & Radiology staff member 12 & 11 \\
\hline SECNEU & Secretary Neurosurgery & 11 \\
\hline EYES5 & Eye surgeon 5 & 9 \\
\hline NEUS2 & Neuro surgeon 2 & 9 \\
\hline $\mathrm{CM}_{3}$ & Cluster manager Women and Child & 6 \\
\hline FARM1 & Pharmacy assistant 1 & 4 \\
\hline FARM2 & Pharmacy assistant 2 & 4 \\
\hline
\end{tabular}




\begin{tabular}{lll}
\hline Agent code & Description & Degree \\
\hline FARM3 & Pharmacy assistant 3 & 4 \\
\hline FARM4 & Pharmacy assistant 4 & 4 \\
\hline FARM5 & Pharmacy assistant 5 & 4 \\
\hline FARM6 & Pharmacy assistant 6 & 4 \\
\hline FARM7 & Pharmacy assistant 7 & 4 \\
\hline SECGER & Secretary of Geriatric outpatient department & 4 \\
\hline SECINT & Secretary of Internal medicine department & 4 \\
\hline SECLAB & Secretary of Laboratory & 4 \\
\hline SECLUN & Secretary of Lung disease outpatient department & 4 \\
\hline SECRAD & Secretary of Radiology & 4 \\
\hline TECH & Technical staff member & 3 \\
\hline CSD1 & Central Sterilization Department staff member 1 & 1 \\
\hline CSD10 & Central Sterilization Department staff member 10 & 1 \\
\hline CSD11 & Central Sterilization Department staff member 11 & $\mathbf{1}$ \\
\hline CSD12 & Central Sterilization Department staff member 12 & 1 \\
\hline CSD13 & Central Sterilization Department staff member 13 & $\mathbf{1}$ \\
\hline CSD14 & Central Sterilization Department staff member 14 & $\mathbf{1}$ \\
\hline CSD15 & Central Sterilization Department staff member 15 & 1 \\
\hline CSD16 & Central Sterilization Department staff member 16 & $\mathbf{1}$ \\
\hline CSD17 & Central Sterilization Department staff member 17 & 1 \\
\hline CSD18 & Central Sterilization Department staff member 18 & 1 \\
\hline CSD2 & Central Sterilization Department staff member 2 & $\mathbf{1}$ \\
\hline CSD3 & Central Sterilization Department staff member 3 & 1 \\
\hline CSD4 & Central Sterilization Department staff member 4 & 1 \\
\hline CSD5 & Central Sterilization Department staff member 5 & 1 \\
\hline CSD6 & Central Sterilization Department staff member 6 & 1 \\
\hline CSD7 & Central Sterilization Department staff member 7 & 1 \\
\hline CSD8 & Central Sterilization Department staff member 8 & 1 \\
\hline CSD9 & Central Sterilization Department staff member 9 & $\mathbf{1}$ \\
\hline SASS3 & Physician assistant 3 & $\mathbf{1}$ \\
\hline SECWIN & Secretary Winterswijk Surgery outpatient department & $\mathbf{1}$ \\
\hline & &
\end{tabular}






\section{CHAPTER 4}

EXPLAINING INTEGRATION AND DIFFERENTIATION BYIDENTIFYING THE RULES AND COORDINATIONMECHANISMS IN AHOSPITAL'S LOGISTICAL SYSTEM

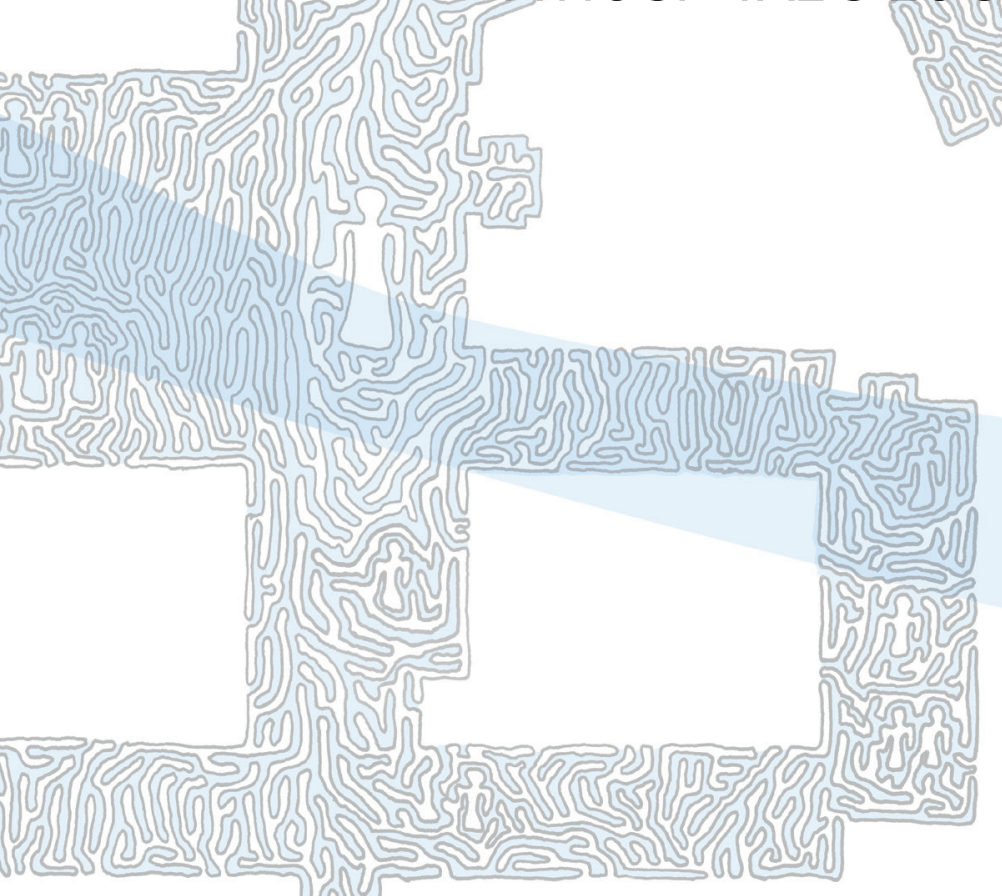

Annelies van der Ham, Arno van Raak, Dirk Ruwaard, Frits van Merode J Health Organ Manag 2021;35(9):66-84 


\section{ABSTRACT}

\section{Purpose}

Integration, i.e. the coordination and alignment of tasks, is widely promoted as a means to improve hospital performance. A previous study examined integration and differentiation, i.e. the extent to which tasks are segmented into subsystems, in a hospital's social network. The current study carries this research further, aiming to explain integration and differentiation by studying the rules and coordination mechanisms that agents in a hospital network use.

\section{Design/methodology/approach}

The current case study deepens the analysis of the social network in a hospital. All planning tasks and tasks for surgery performance were studied, using a naturalistic inquiry approach and a mixed method.

\section{Findings}

Of the 314 rules found, $85 \%$ predominantly exist in people's minds, $31 \%$ are in documents and $7 \%$ are in the information system. In the early planning stages for a surgery procedure, mutual adjustment based on hospital-wide rules is dominant. Closer to the day of surgery, local rules are used and open loops are closed through mutual adjustment, thus achieving integration. On the day of surgery, there is mainly standardization of work and output, based on hospital-wide rules. We propose topics for future research, focusing on increasing the hospital's robustness and stability.

\section{Originality}

This exploratory case study provides an overview of the rules and coordination mechanisms that are used for organizing hospital-wide logistics for surgery patients. The findings are important for future research on how integration and differentiation are effectively achieved in hospitals. 


\section{INTRODUCTION}

Literature in the field of health care calls for a more integrative approach to the logistical or operational system of hospitals ${ }^{1-3}$. There is wide consensus that an integrated perspective in hospitals, which is a central concept in supply chain management, lean strategies and in other operations management theories, can contribute to the improvement of hospital performance ${ }^{4-10}$. This approach includes aligning activities and planning resources from the perspective of the total system, taking hospital-wide processes and resources into account 4 . This is considered important in addressing the widely felt need to improve the quality, accessibility and affordability of healthcare systems ${ }^{5}$ and of hospitals in particular, given the fact that hospitals are a major cost item in the healthcare system ${ }^{11}$.

There are few studies that focus on the impact of adapting integrative practices with regard to improving system-wide performance 5 . In a previous scoping study ${ }^{12}$ we found that research on logistics in hospitals typically focuses on one specific logistical flow (patients, material or staff) or on specific departments, but not on the system as a whole. Furthermore, De Vries and Huijsman ${ }^{6}$ point out that little is known on how integration can be achieved in healthcare settings.

Ludwig et al. ${ }^{8}$ found evidence that more efficient hospitals score high on cooperation, while efficient departments within a hospital do not necessarily contribute to the hospital's overall efficiency. Lawrence and Lorsch ${ }^{13}$ state that not only is integration important, but also that differentiation is essential in order for integration to be effective. They define integration as 'achieving unity of effort among the various subsystems in the accomplishment of the organization's task'13. Differentiation refers to 'the state of segmentation of the organizational system into subsystems'13. Based on these definitions, hospitals that perform well and in which departments cooperate well may have the right degree of integration as well as differentiation in place.

Research in the field of social network analysis (SNA) also addresses integration ${ }^{14-16}$. In a previous SNA case study of Slingeland Hospital in the Netherlands, we described the network structure of the logistical system, which includes both integration and differentiation ${ }^{17}$. This SNA showed that the hospital's network structure differs from its formal organizational structure, with tasks being performed mainly across functional silos, and that nurses, physicians and coordinators perform integrative tasks.

However, we agree with Beuving and De $\operatorname{Vries}^{18}$, that by reducing human action to structural positions in the network, little is revealed about what actually happens between 
the agents in the network. We should look specifically at what rules and mechanisms agents use, in order to understand the social network structure, i.e. the integration and differentiation observed in the SNA.

Literature pertaining to social networks and integration often refers to coordination between people, groups or organizations as a core activity in organizations ${ }^{14-16}$. According to Mintzberg ${ }^{19}$, there are different types of coordination that connect differentiated activities, which themselves result from the division of labor. Each type of coordination mechanism requires different interactions between agents. Coordination mechanisms are based on rules. Beuving and De Vries ${ }^{18}$ use the metaphor of dancing to explain that dancers follow the rules of dancing that have been set by previous dancers, while at the same time dancers still respond to each other, thereby varying within these rules. Accordingly, the structure of the hospital's social network may be explained by describing the rules that the agents use, and by studying the coordination mechanisms that determine the interactions between these agents.

This study deepens the previous SNA study; it aims to explain the integration and differentiation in a hospital by studying the rules and coordination mechanisms that agents use. This topic is important because, despite the fact that there are several promising SNA studies that address the issue of integration ${ }^{14-16,20-22}$, Kilduff \& Tsai ${ }^{15}$ state that little is known on how coordinating mechanisms facilitate differentiation and integration.

The main research questions are: what are the rules and coordination mechanisms that are used in the hospital's operational system and how do these explain the social network structure, i.e. the integration and differentiation?

\section{METHODS}

\section{Setting}

The study design is based on the case study research method devised by Yin ${ }^{23}$. Slingeland Hospital was selected for this case study because it is a relatively small Dutch hospital with a highly rated performance and no large transformations took place during the time of research. Additional selection criteria were good access to people and data. Slingeland Hospital has around 1,600 staff members and 120 physicians. It services around 200,000 people in the area, and has 350 beds, which is below the average number of 450 beds for Dutch hospitals ${ }^{24}$. Slingeland Hospital performs higher on most logistical indicators than 
the average Dutch hospital, according to a Dutch benchmark ${ }^{25}$. With an average of $89 \%$ operating room (OR) utilization in 2016, Slingeland has higher OR utilization than the 82\% average of Dutch hospitals that participate in the national benchmark. For other parameters such as lateness and average surgery time, Slingeland performs better than the average hospital that participates in the Dutch benchmark.

\section{Study design}

This study was designed to determine what rules and coordination mechanisms are used for the coordination of tasks and why and how this takes place. A naturalistic inquiry approach was followed, aiming to develop a deeper understanding of how the hospital's network functions ${ }^{18}$. Data were collected from multiple sources and then analyzed through data triangulation, following a mixed method approach.

The study includes all departments that contribute to either the intake, diagnosis, preparations for or performance of the surgery or the aftercare of surgery patients. Figure 4.1 shows all the tasks performed which relate either to the planning or performing of surgeries, including all activities that take place between patient intake and discharge. In this study we focus on planning tasks $1,2,3,6$, and 11, and tasks directly related to performing surgery, including preparations and aftercare, being tasks 14, 15, 17, 20, 21 and 22. The main reason for this selection is that these tasks involve coordination, as illustrated by the central position of these tasks in Figure 4.1. These tasks are performed by agents of outpatient departments, the nursing departments, the Operating Theatre Complex (OTC) and the holding and recovery areas.

The Ethics Committee of Maastricht University reviewed the study design and the data protection aspects of the work that was undertaken. The Committee stated that according to Dutch law this study did not need a full review of the Ethics Committee, because no humans, i.e. patients were involved. Nevertheless, the Committee stated that the work was undertaken in a manner that conformed to the ethics and data protections standards of Maastricht University.

\section{Collected data}

Data were collected from four different sources: the Hospital Information System (HIS), documentation, observations and interviews. The collection and analysis of data from the HIS and documentation took place in January 2018 and March 2019. Observations and interviews took place between March 2018 and June 2019. 


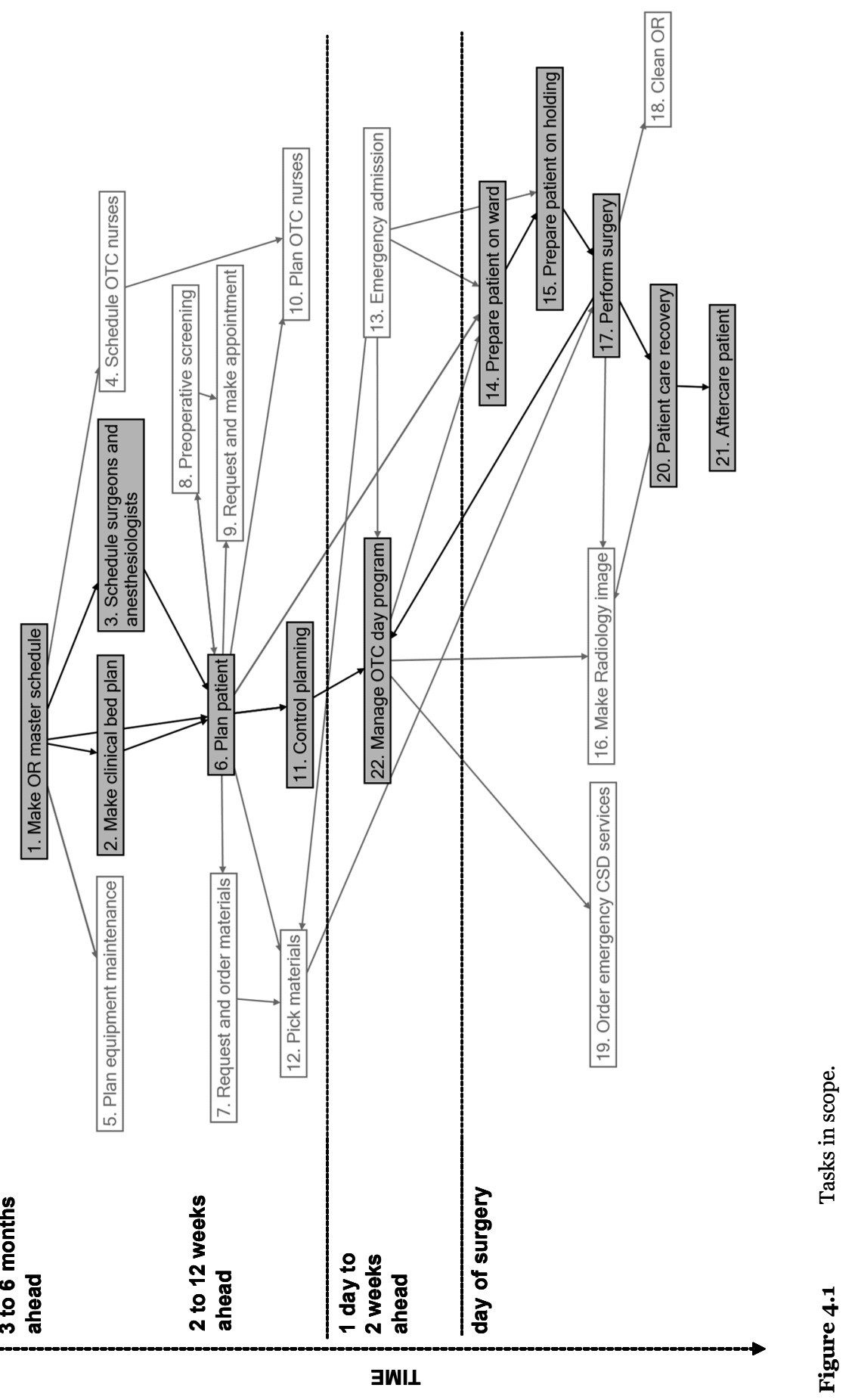


HIS data were collected in order to determine the system's output, to observe the system's rhythm and what resources were used for surgery patients. The HIS data include registrations of surgeries performed in 2018, including date of surgery, resources involved, and timestamps of different stages in the surgery patient's process, and in which nursing wards patients stayed before and after surgery.

Documentation was collected in order to find rules that are written down. In total 55 documents were collected, including management reports, planning schemes, working procedures, emails and internal presentations. In addition, planning rules were listed between February and May 2019 by one outpatient secretary and the clinical bed planner. This activity was part of the preparations for the implementation of a central planning department in which surgeries are planned, as of June 2019, by central planners.

Planning and controlling activities were observed over 18 observation days in order to find additional local documents on working procedures and any unwritten rules. The 18 observations took place at three outpatient departments, three nursing departments, the holding area, three surgeries in the OR, the recovery area, with the OTC day coordinator, at the preoperative screening department, two planning meetings and twice at the workplace of the clinical bed planner. During each observation the activities of the hospital staff were observed and several unplanned informal conversations with staff took place, as they explained what tasks they performed. The sequence of events for each observation, together with relevant parts of the conversations, were reported in an observation report.

All collected data were then further explored in 25 interviews, looking specifically for unwritten rules. For the interviews we selected people who are involved in planning activities, including the application controller of the OR, the OTC capacity planner, eleven secretaries of the various outpatient departments, the OTC day coordinator and one cluster manager. For each interview a topic list was prepared, including questions on rules, rhythm, interaction and performance. In addition, a data dashboard was prepared for the interviews with the outpatient secretaries. The dashboard includes HIS data on the number of surgeries and surgeons, planned and emergency surgery percentages, the yearly and weekly pattern of sessions and surgeries, the waiting list development, the percentage of types of surgeries that are performed by one or multiple surgeons and variations in surgery time. In addition, a table was prepared including the average age of patients, utilization rates of OR sessions, the deviation percentage between planned surgery time and actual surgery time, the number of surgeries with particular planning rules, how many patients stayed on each nursing ward and which anesthesiology techniques were used. These data were used in the interviews in order to find unwritten 
rules and deeper explanations for how agents act. All interviews were recorded and transcribed ad verbatim.

\section{Data analysis}

All 94 qualitative data sources, i.e. documents, observations and interviews were structured in five data matrices that include the three main topics of rules, rhythm and interaction. One data matrix was constructed for each of tasks 1, 2 and 3. One data matrix was made for tasks 6 and 11 and another for tasks 14, 15, 17, 20, 21 and 22, because with regard to coordination activities, these tasks are strongly connected.

The rules that are used for each task, i.e. from each data matrix, were then listed. First of all, for each rule the sources in which the rule was found were registered. Rules were then labelled as hospital-wide or local. A hospital-wide rule is used throughout the entire hospital system and a local rule exists for one particular department, group of people or person. In order to assess whether rules are written or unwritten, we indicated whether the rule itself is registered (R) or the output of applying the rule is registered $(\mathrm{O})$ in a document or in the HIS, or if it exists in the mind of hospital staff.

Furthermore, one or multiple coordination mechanisms through which each rule in the hospital is applied was registered. Coordination mechanisms include (1) mutual adjustment, (2) direct supervision, and standardization of (3) work processes, (4) output, (5) skills and (6) norms ${ }^{19}$. A rule is applied through 'mutual adjustment' if an agent interacts with other agents regarding what a rule entails or if the rule is applied through communication in a specific situation. There is 'direct supervision' if a rule is set and monitored by people with formal authority. Rules are the result of 'standardization of work' when they result from specified or programmed working processes. They are related to 'standardization of output' when rules include specified output in terms of predetermined standards for services or performance. When coordination results from rules regarding specified skills and knowledge, this is labelled as 'standardization of skills'. Finally, when rules result from a common culture or ideology, they relate to standardization of norms, in which case rules related to behaviour are set.

The classification of the rules and coordination mechanisms were validated by a second researcher. He reviewed all rules and the associated coordination mechanisms, based on Mintzberg ${ }^{26}$ and an agreed set of criteria for operationalization of those mechanisms. Rules that were classified differently by the reviewer were then discussed by the prime researcher and the reviewer. During the discussion the differences in interpretations of Mintzberg's definitions of coordination mechanisms were corrected or the classification 
was substantiated with the collected data. Consensus was reached on all rules with regard to the coordination mechanism that is used for a rule.

\section{RESULTS}

\section{Output of the network}

In 2018, a total of 9,846 patients who required surgery were diagnosed in one of nine outpatient departments. In total 344 different types of surgery procedures were performed, by 48 different surgeons and 14 assistant surgeons in nine different operating rooms. Patients were cared for in 12 different nursing departments. Of all surgeries, 82\% were planned beforehand, i.e. they were not emergency surgeries. Patients flowed through a series of locations, as shown in Figure 4.2.

There is a variable rhythm in the system, as shown by Figures A4.1.1 and A4.1.2 in Appendix 4.1. In 2018, the number of surgeries varied from a minimum of 20 to a maximum of 242 surgeries a week, as shown in Figure A4.1.1 in Appendix 4.1. The number of surgeries per week varies by $25 \%$ on average. Per medical discipline, variability is larger with an average relative standard deviation of $41 \%$ (parameter 12 in Table 4.1). Types of surgery procedures were performed between 1 and 729 times per year in 2018, with an average of 23 times. Of all types of surgeries, $5 \%$ were performed once a week or more on average.

\section{Tasks and flows}

The main task of the logistical system is to get the right patient, surgeon, anesthesiologist, nurses, materials and infrastructure together at the right time and in the right place. In order to succeed in this, planning and scheduling of resources in relation to patient demand takes place, as presented by tasks 1, 2, 3, 6 and 11. Everything that has been planned is performed on the day of surgery through tasks 14, 15, 17, 20, 21 and 22. All tasks are described in more detail in Appendix 4.2.

In the OR master schedule (task 1) and clinical bed plan (task 2) operating time, space and beds are allocated to medical disciplines. After the OR master schedule is set, surgeons and anesthesiologists schedule when they will work in the outpatient department and in the OR (task 3). The patient is planned for in task 6, along with the surgeon who will perform the surgery. In task 11 the final OTC planning is checked and revised. After that, the patient enters the hospital for the surgery, and a series of tasks are performed from the intake of the patient (task 14) until aftercare (task 21). 


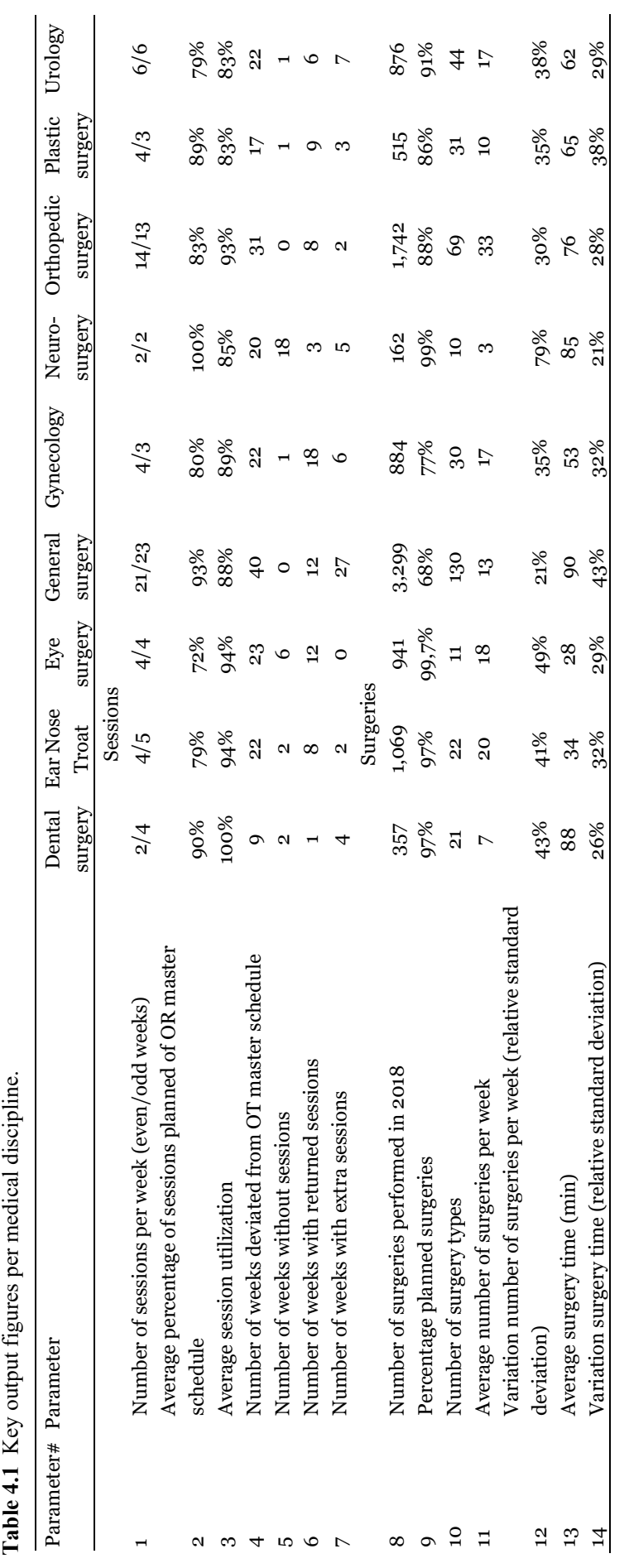


Tasks are differentiated on the basis of multiple rules. First of all, tasks throughout the patient process are allocated to different departments. In outpatient departments the patient is diagnosed and planned for. The intake, preparations and aftercare take place in nursing wards, and actual surgeries are performed in the OTC. Second, the care for patients is differentiated according to medical disciplines. This is most visible at the start of the process, when the patient enters the hospital in one of the outpatient departments, each of which is associated with a medical discipline. For nursing wards, the medical discipline, the expected the length of stay (e.g., the Daycare Department), the age (e.g., the Pediatric Department) and the acuity (e.g., the Intensive Care Unit) of the patients are differentiation criteria.

As a result of differentiation, in 2018 patients flowed past the locations shown in Figure 4.2, using 122 different routes. Each route is a unique combination of either an outpatient department or the Emergency Department to a ward, the OTC, and a ward for aftercare. Table A4.1.1 in Appendix 4.1 shows how many patients from each medical discipline flowed past each location.

Figure 4.2 shows that planning tasks 1, 2, 3, 6 and 11 are performed in parallel. The OR master schedule provides input to the planning for beds (task 2), to the schedule for surgeons and anesthesiologists (task 3) and to the planning of patients (task 6). Patients enter the hospital an unknown number of weeks before the surgery takes place and are registered in the surgery planning between two to twelve weeks ahead of the surgery day, with an average of 45 days. So, the OR master schedule, the clinical bed plan and surgeon's schedules are set before the patient demand is known. In addition, because surgeon's schedules are not shared with agents outside the medical disciplines, information on when surgeons operate emerges from task 6. As a result the OR master schedule and clinical bed plan are adapted and there is feedback between tasks 1, 2 and 6, as illustrated by the dotted lines in Figure 4.2. On the day of surgery tasks are performed in a fixed order, which is based on how patients flow from one location to the other, as shown in Figure 4.2. Controlling this chain of events is done largely in the OTC (task 22) by the OTC day coordinator, who receives feedback from tasks 14, 15, 17 and 20. 


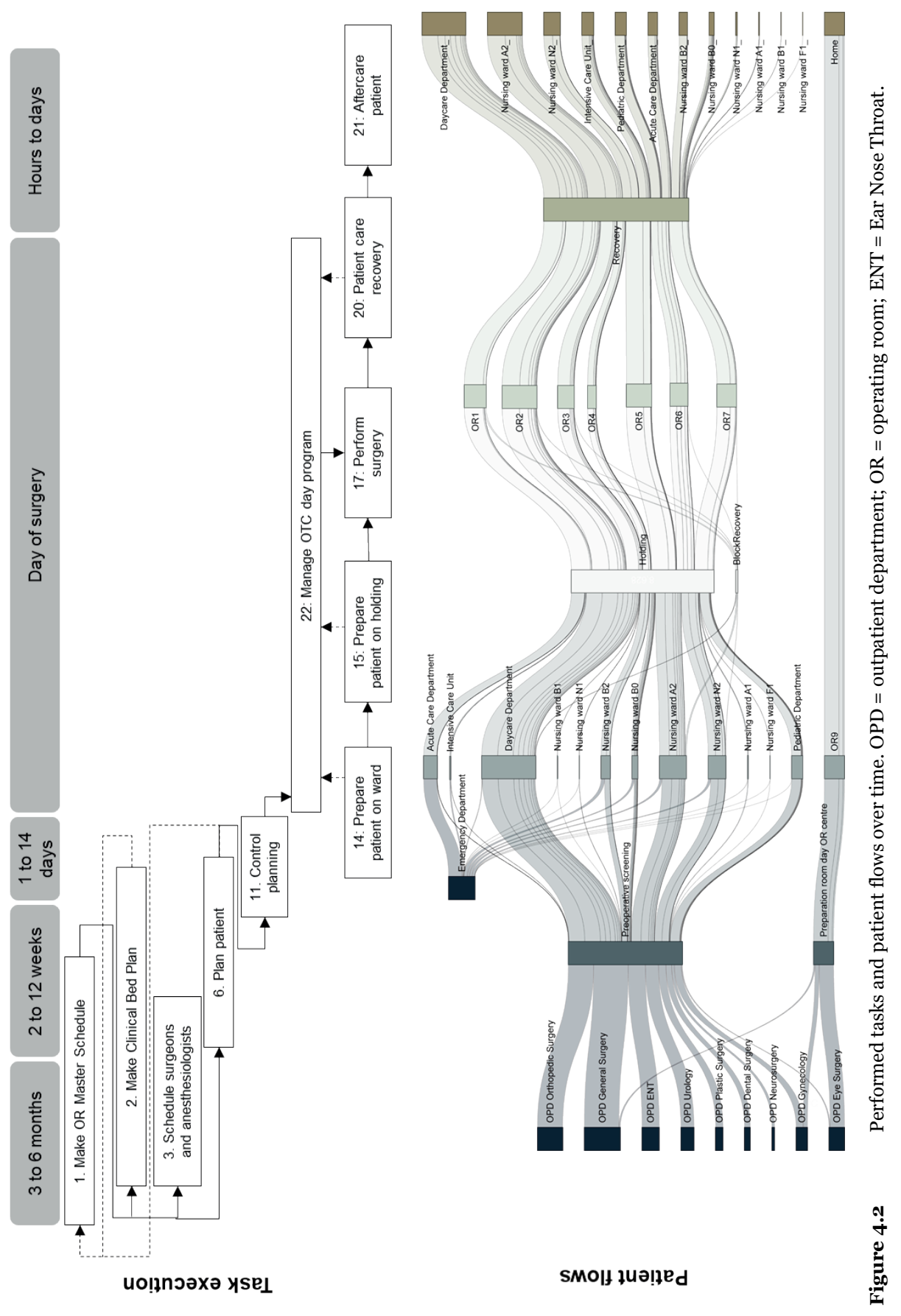




\section{Rules and coordination mechanisms}

In Appendix 4.2 the rules, coordination mechanisms and interactions that are used for performing the tasks are listed. Table 4.2 shows that $31 \%$ of the total 314 rules are captured in documents; $7 \%$ are in the HIS, but most rules (85\%) predominantly exist in the minds of the agents in the network. Rules can be both written down and reside in people's minds, in which case they are written down in an often local document, and shared throughout the hospital through social interaction. In total $82 \%$ of the documents are not generally known, as these are local or personal documents such as checklists, emails, memos or delivered in internal presentations. Besides being in documents, $16 \%$ of all rules are more or less written down because the consequence of applying a rule is registered in the HIS, as for example the OR master schedule.

Table 4.2 Rules and coordination mechanisms per task.

\begin{tabular}{|c|c|c|c|c|c|c|c|c|c|c|c|c|c|c|}
\hline \multirow[t]{2}{*}{ Task } & \multirow[t]{2}{*}{ Task description } & \multirow[t]{2}{*}{$\begin{array}{l}\text { Number } \\
\text { of rules }\end{array}$} & \multicolumn{2}{|c|}{$\begin{array}{c}\text { Hospital } \\
\text {-wide or } \\
\text { local } \\
\end{array}$} & \multicolumn{4}{|c|}{$\begin{array}{c}\text { Number of rules } \\
\text { per information } \\
\text { carrier }\end{array}$} & \multicolumn{6}{|c|}{ Coordination mechanism } \\
\hline & & & 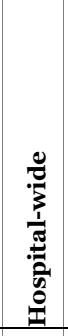 & 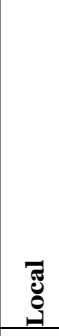 & 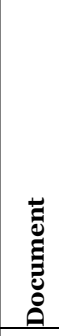 & $\underset{\Xi}{0}$ & 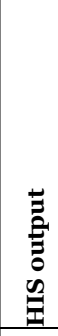 & 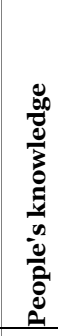 & 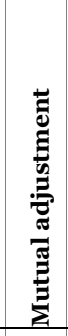 & 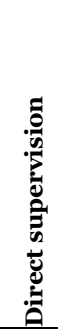 & 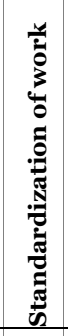 & 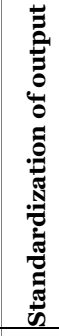 & 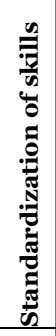 & שี \\
\hline 1 & Make OR Master Schedule & 53 & 48 & 5 & 26 & 0 & 16 & 48 & 36 & o & 26 & 3 & 0 & 2 \\
\hline 2 & Make clinical bed plan & 51 & 51 & o & 12 & o & 10 & 46 & 35 & o & 35 & o & 1 & 3 \\
\hline 3 & $\begin{array}{l}\text { Schedule surgeons and } \\
\text { anesthesiologists }\end{array}$ & 34 & 5 & 29 & 15 & o & o & 38 & 20 & o & 31 & o & o & o \\
\hline $\begin{array}{l}6 \text { and } \\
11\end{array}$ & $\begin{array}{l}\text { Plan patient and control } \\
\text { planning }\end{array}$ & 106 & 64 & 42 & 39 & 4 & 20 & 87 & 37 & o & 72 & 18 & 8 & 1 \\
\hline 14-22 & $\begin{array}{l}\text { Prepare patient on ward, } \\
\text { prepare patient on holding, } \\
\text { perform surgery, aftercare } \\
\text { on recovery, aftercare on } \\
\text { nursing ward, control OTC } \\
\text { program }\end{array}$ & 70 & 51 & 19 & 5 & 19 & 3 & 47 & 26 & o & 45 & 35 & 4 & o \\
\hline $\begin{array}{l}\text { Total } \\
\% \\
\end{array}$ & & 314 & \begin{tabular}{|c|}
219 \\
$70 \%$ \\
\end{tabular} & $\begin{array}{c}95 \\
30 \% \\
\end{array}$ & $\begin{array}{c}97 \\
31 \% \\
\end{array}$ & $\begin{array}{l}23 \\
7 \% \\
\end{array}$ & $\begin{array}{c}49 \\
16 \% \\
\end{array}$ & $\begin{array}{l}266 \\
85 \% \\
\end{array}$ & \begin{tabular}{|c|}
154 \\
$49 \%$ \\
\end{tabular} & $\begin{array}{c}0 \\
0 \% \\
\end{array}$ & \begin{tabular}{|l|}
209 \\
$67 \%$ \\
\end{tabular} & $\begin{array}{c}56 \\
18 \% \\
\end{array}$ & $\begin{array}{l}13 \\
4 \% \\
\end{array}$ & $\begin{array}{c}6 \\
2 \% \\
\end{array}$ \\
\hline
\end{tabular}

Tasks are mainly coordinated through standardization of work (67\%) and mutual adjustment (49\%) as shown by Table 4.2 . Other rules refer to output (18\%), and a minority of rules relate to skills (4\%) or norms (2\%). There is no direct supervision. For $38 \%$ of rules, more than one coordination mechanism is used and this explains why the 
total percentages do not add up to $100 \%$. In particular, on the day of surgery (tasks 14 to 22), standardization of both working procedures and output go hand in hand with mutual adjustment. For example, rule 285 states that the nurse anesthetist takes the patient to the recovery area and executes the Time Out Procedure (TOP) with a recovery nurse. The TOP is coordinated by standardization of work and output, because both the process as well as required output are specified. The TOP has to be performed through mutual adjustment between the nurse anesthetist and the recovery nurse, because they perform the TOP together, thereby responding to each other.

In the early stages of planning (tasks 1 and 2), mutual adjustment using hospital-wide rules is the dominant coordination mechanism, whereas closer to the day of surgery there is more standardization of work, based on both hospital-wide and local rules. On the day of surgery, there is also standardization of output, which includes hospital-wide rules that need to be met in order for the patient to be operated on.

\section{Coordination and interaction per task}

Tasks 1 and 2 are performed using mainly hospital-wide rules in a highly connected social network structure in which almost all agents interact with one another, as shown by the interaction matrices in Appendix 4.2. Hospital-wide rules are largely based on space and time structures that are largely taken for granted by all agents in the hospital. The time structures relate to universal and national time structures, such as the distinction between weekdays and weekends, public holidays and annual national conferences for physicians. In addition, time is structured by defining working hours and by allocating operating time on the basis of historically acquired rights to operating time by medical disciplines. Space structures result from the infrastructure, i.e. the physical building and the presence or absence of specific equipment in operating rooms. As a result the OR master schedule remained largely unchanged throughout 2017 and 2018; 82\% of the allocated OR sessions in the first quarter of 2017 are identical to those in the last quarter of 2018.

In addition, hospital-wide rules define how to negotiate through mutual adjustment on allocated operating time, which is defined in OR sessions, and on beds. Both of these have to be requested or returned via the OTC capacity planner and the clinical bed planner. There are norms and output measures as to how and how often a medical discipline may or may not request or return OR sessions or beds, but these are discussed or put aside under certain circumstances, through mutual adjustment. Table 4.1 shows that most medical disciplines request and return OR sessions. As a result, in 50 weeks in 2018 the OR master schedule was different from the initial schedule. The initial OR master 
schedule and clinical bed plan, which are recorded in Excel and printed on paper, deviate from the allocated OR sessions and beds that are registered in the HIS.

Surgeons and anesthesiologists are scheduled within each medical discipline (task 3), thereby predominantly following local rules. These rules are not set in the HIS, but in local documents, computer systems or through oral agreements between agents. Documents or systems are not shared hospital-wide nor are they easily accessible to agents outside the outpatient department. There is a multitude of locally defined scheduling methods, e.g. surgeons are either scheduled on fixed days or not, perform surgery part of the day or all day, distribute shifts in different ways et cetera. These rules are set and applied within each medical discipline through mutual adjustment.

When surgeries for patients are actually scheduled (task 6), the overview of the inflow of patients and what resources are needed starts to build up. Hospital-wide rules state that medical disciplines plan patients using their own methods (e.g. rules 158 and 165), using standard surgery coding and surgery times set in the HIS. Within the outpatient departments the secretaries match the patient's wishes and the surgeon's orders, thereby following a multitude of local rules with regard to demand management, resource allocation to surgeries and national regulations and norms. For 80\% of the 344 types of surgery procedures one or more specific rules are used; this includes $52 \%$ of all performed surgeries. Rules relate to individual patients as well as individual surgeons, as illustrated by rules 147 to 157 in Appendix 4.2. Secretaries often use a preliminary planning schedule, which is mostly kept in personal paper notebooks, on whiteboards or in the secretaries' minds, before registering the surgery in the HIS. By looking at the HIS and by interacting with the outpatient secretaries and surgeons, the OTC capacity planner and the clinical bed planner monitor the planned patients and try to control the overall planning in order to prevent any possible instability, e.g. shortages of beds, cancellations of surgeries or lateness in the OTC. In the two weeks before the surgery date, the preoperative secretaries, the outpatient secretaries and the OTC capacity planner and ward team leaders meet up to check whether all rules have been met in order to proceed with the surgeries as planned (task 11).

Tasks that are performed on the day of surgery include mainly hospital-wide rules that result from the Time Out Procedure (TOP), which is a series of standard checklists that is used in every step of the patient process, from intake until discharge, and which is laid down in the HIS. What needs to be done for patient transfer is standardized and registered in the HIS, but exactly when and by whom activities are performed is determined during task performance, through mutual adjustment. In order to maintain stability, the OTC day 
coordinator monitors the progress of surgeries, both by looking at the HIS and by observing the holding area, the recovery area and ORs. He uses several local rules for detecting any potential factors that may endanger a smooth patient flow in the OTC.

\section{Rules, coordination and interaction over time}

In the planning process, initially drafted hospital-wide schedules are adjusted as time passes and reality unfolds. Table 4.3 shows that three to six months ahead, coordination is mainly based on hospital-wide rules (75\%), through standardization of work (67\%) and mutual adjustment (66\%). Then, from three months to one week before surgery, $40 \%$ of the rules applied are local rules and $68 \%$ are part of standard working procedures. In this phase the OTC capacity planner and the clinical bed planner coordinate local planning through mutual adjustment. On the day itself there is predominantly hospital-wide standardization of work and output (see Table 4.3).

Table 4.3 Rules and coordination mechanisms over time.

\begin{tabular}{|c|c|c|c|c|c|c|c|c|c|}
\hline \multirow[t]{2}{*}{ Time horizon } & \multirow[t]{2}{*}{ Tasks } & \multicolumn{4}{|c|}{$\%$ of rules } & \multicolumn{4}{|c|}{ Coordination mechanism } \\
\hline & & 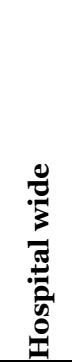 & త్త & 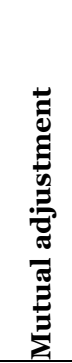 & 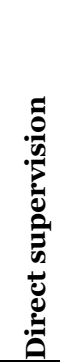 & 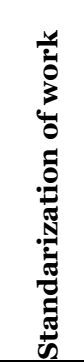 & 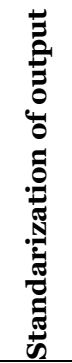 & 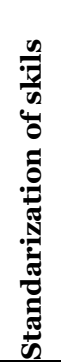 & 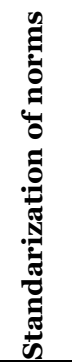 \\
\hline $3-6$ months & $1,2,3$ & $75 \%$ & $25 \%$ & $66 \%$ & O\% & $67 \%$ & $2 \%$ & $1 \%$ & $4 \%$ \\
\hline 1 day to 12 weeks & 6,11 & $60 \%$ & $40 \%$ & $35 \%$ & $0 \%$ & $68 \%$ & $17 \%$ & $8 \%$ & $1 \%$ \\
\hline Day of surgery & $14,15,17,20,21,22$ & $73 \%$ & $27 \%$ & $37 \%$ & $0 \%$ & $64 \%$ & $50 \%$ & $6 \%$ & $0 \%$ \\
\hline
\end{tabular}

Figure 4.3 shows that more agents become involved in the interaction as the surgery date approaches. Twelve agents are involved from the start (tasks 1 and 2), six months ahead, and 373 agents interact only on, or about, the day of surgery. Besides a time horizon of one day, these 373 agents have a space horizon of one department or they go one step upor downstream, like for example a ward nurse who takes the patient to the holding area. Surgeons and one anesthesiologist are involved from months before until the day of surgery and they work in multiple locations in the hospital. As shown in Figure 4.3, over the long term (task 1) nine surgeons and one anesthesiologist are involved in coordination. In the short term, they coordinate on the day of surgery (tasks 14, 15, 17, 20, 21,22 ). In between those two time horizons (tasks 3 and 6) surgeons and anesthesiologists coordinate locally. 


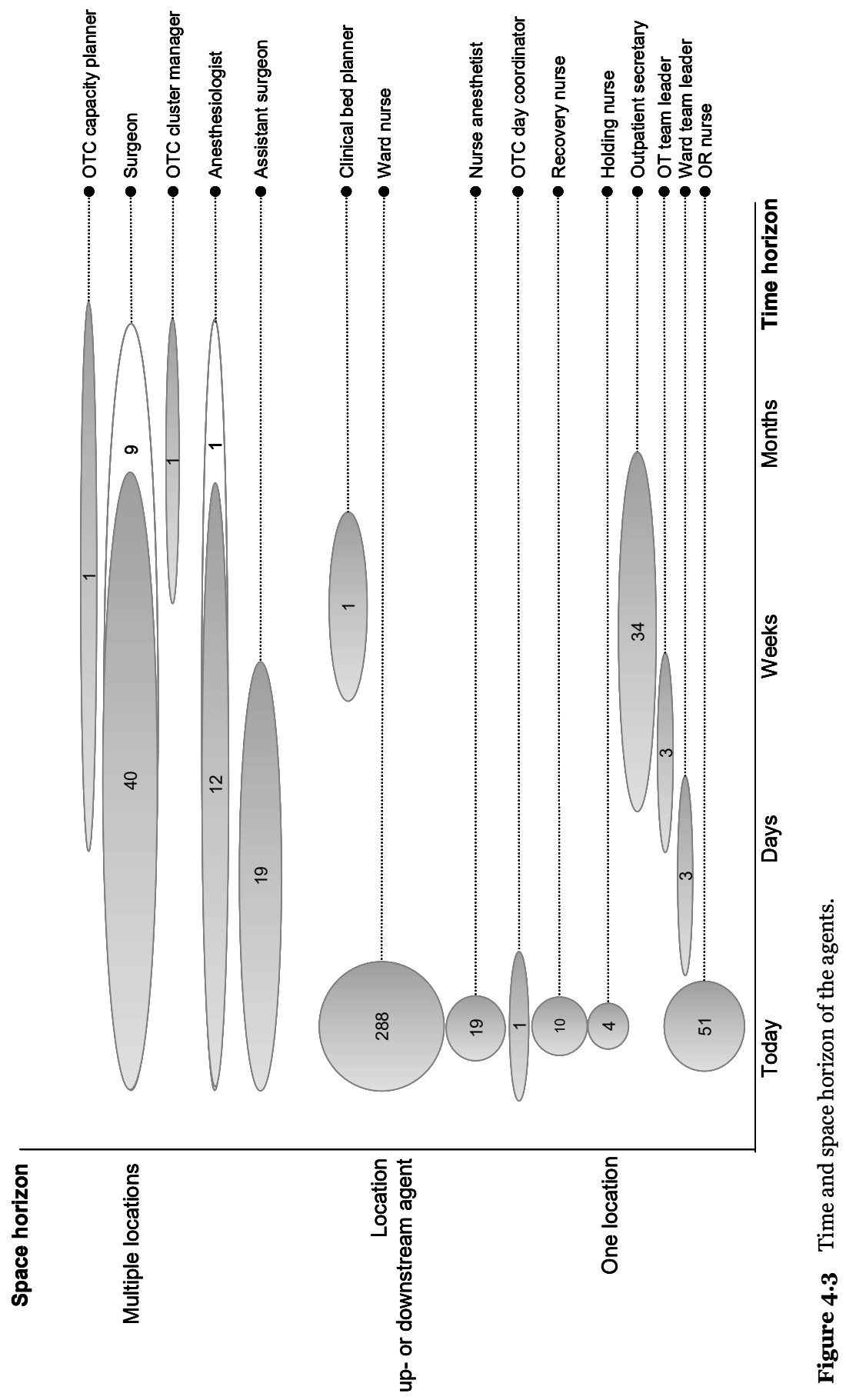




\section{DISCUSSION}

In a previous SNA study ${ }^{17}$ we described the Slingeland Hospital's social network structure, i.e. the integration and differentiation that shape the network. In the current study the social network structure of Slingeland Hospital was further explored by studying the rules and coordination mechanisms that explain the interactions observed in the social network analysis.

In order to coordinate the patients' process from hospital admission to discharge, and to schedule the use of all necessary resources, 314 rules were found. Long-term schedules and plans are the result of applying hospital-wide rules, which were set in the past and by time and space structures. In the shorter term, these schedules are subsequently adapted to the circumstances through negotiation by agents in the social network. Circumstances unfold when the local schedules for surgeons are made and when patients are planned for surgery in the OTC. Standardized ways of working are adapted to the circumstances as they present themselves, thus requiring mutual adjustment. There is continuous interaction between agents to observe the expected future and current state of the system, which often changes given the variable rhythm of the system. In addition there is no reliable central view of all local rules and schedules, as these reside mostly in people's minds. Most agents interact shortly before or on the day of surgery.

The OR master schedule, the clinical bed plan and the surgeon's schedules create open loops, because they are not based on future patient demand. As time passes the loops are closed through mutual adjustment, by adapting these schedules to the reality of the actual demand and availability of resources. The OTC capacity planner and the clinical bed planner continuously monitor the current situation and raise issues that may endanger the stability of the system with other agents, i.e. outpatient secretaries and surgeons. Any remaining open loops on the day of surgery are closed by the OTC day coordinator, nurses, nurse anesthetists, surgeons and anesthesiologists.

Central to literature pertaining to surgery planning is the idea of being able to structure time, space, demand, resource availability and uncertainty ${ }^{27-29}$. Many studies use formal and mathematical methods to create a controllable future state of the system. In contrast, in this case agents work in a negotiated order ${ }^{30}$, in particular for planning tasks. Copp et al. ${ }^{31}$ state that in negotiated orders there are 'ongoing processes of negotiation' and agents 'alternately create, maintain, transform, and are constrained by social structures'. There is coordination between autonomously acting parts, and people coordinate themselves and 
each other in their social network rather than through 'managers' who coordinate from the top, or by a fixed and formalized set of rules.

In this study, Mintzberg's ${ }^{26}$ notion that standardization of skills is the dominant coordination mechanism for professional organizations such as hospitals, is much less observed for organizing hospital-wide logistics. Interestingly, in his later work Mintzberg19 advocates for more coordination through mutual adjustment and standardization of norms. Following Mintzberg's line of thinking, this raises the question of on what idea, belief or to what ends mutual adjustment is based. Perhaps there is expansive learning, a concept introduced by Engeström ${ }^{32}$, in which engaged agents with differentiated tasks produce new patterns of activity, driven by their shared responsibility for patients. In addition, stabilizing the system appears to be an important motive for integration, especially because this is mainly done by agents with no formal responsibility for (large parts of) the system as a whole. This apparent need for stabilization may have to do with the absence of the concept of Takt time as a coordination mechanism. Takt time is the desired time between units of output, to be synchronized to the customers' demand, as described by Munavalli et al.33. Takt time is considered important for the synchronization and integration of activities and for stabilizing the system ${ }^{33}$. From this perspective, interactions in the social network could be there to respond to patient demand in the second instance, because the initial hospital-wide schedules are not based on patient demand. When surgeons plan patients, the open loop character of the system emerges and agents who observe this try to close these loops.

Perhaps this self-organizing, adaptive and learning organization is a good thing, as stated both in literature and given the highly rated performance of Slingeland Hospital. There could, however, be a downside. The hospital's performance may be vulnerable and potentially unstable, leading to critical events, as mentioned by Ren et al. ${ }^{34}$. The multitude of very detailed, conflicting or specific rules may hinder the overview of the system and hide possible open loops. In the SNA ${ }^{17}$ it was observed that the OTC capacity planner and the OTC day coordinator have a very central position in the network. This study shows that, together with the clinical bed planner, their integrative actions result from mutual adjustment and not from direct supervision. This can be a very challenging task for which extraordinary skills or even a certain personality are required. When these agents are absent or leave the hospital, the network may not only fall apart, but their knowledge of hospital-wide and local rules may disappear from the hospital, as most of those rules are unwritten. In addition, the lack of direct supervision by management may lead to a disconnection between the strategic and operational parts of the hospital. Relevant bottom-up feedback could be missed by top management, and operational agents may not 
respond to top-down management input, thus creating more open loops. This may hinder, for example, effective cost control of the hospital.

This exploratory case study provides an overview of the rules, coordination mechanisms and variables that are used for organizing the hospital-wide logistics for surgery patients. The main contribution of this study is that it reveals the rules and the coordination mechanisms that are used in a hospital, and it shows that the combination of these create open loops, for which integration is achieved. In line with $\mathrm{Yin}^{23}$, the findings should be used for 'analytic generalization'23 and the lessons learned provide input to working hypotheses for future research. Clearly, the limitations of this study should be taken into account when drawing up hypotheses. The rules as described here may be temporary, and not universal, both in time as well as given the environment of this particular hospital. Furthermore, from this study we cannot conclude how the coordination mechanisms relate to the hospital's performance.

Given the findings of this exploratory study, there are several issues we propose to explore further. First of all, we observe that the variability and uncertainty which are inextricably characteristic of hospital logistics3,4,9,10,27-29,33 are managed through local rules and standards and by mutual adjustment processes. Integration is the result of actions of agents who try to stabilize the hospital system through mutual adjustment. We should further explore how integration and differentiation can be organized in hospitals in a more structural way. It is the question of what degree of integration and differentiation works and accordingly, how a closed loop system can be achieved within a certain network structure.

Further, we have to learn more about whether variability is the cause or the effect of the current way of working, or both. We need to understand how and when to close the loops - in other words, how to use and facilitate mutual adjustment in these uncertain circumstances. In relation to this it would be interesting to further explore which network structure and what rules and coordination mechanisms could facilitate Takt time management and thus facilitate stabilizing the hospital system. In addition, we need to explore how all this contributes to the hospital's performance.

We believe it is important to further develop Slingeland Hospital's logistical system in order to make it more robust, for example by creating redundancy in the network, and possibly even improve its stability and performance. We should not leave the logistical organization of hospitals entirely up to the personal initiatives of some individuals nor 
discard informal mutual adjustment processes as a whole, for their apparent chaotic character. We propose three different approaches for future research.

First of all, if mutual adjustment is to be combined with standardization of norms ${ }^{19}$, we need to understand what the norms of agents in hospitals are with regard to logistics. Mintzberg's norms ${ }^{19}$ refer to engagement in health care as a calling, but what this means for hospital logistics has to be specified further. A second approach is to study how the interplay between rules, coordination mechanisms, social network structures and hospital performance evolve over time. When circumstances change, both externally and internally, new rules may emerge and old ones be abolished, possibly as the result of a learning process. A third approach is to develop a multi-agent system model in which the role of the OTC capacity planner is supported or even performed by an intelligent realtime scheduler, as proposed for outpatient clinics by Munavalli et al.35. In this approach the relation between coordination and performance is explored by developing formal negotiation processes and studying the effects of Takt time management in computer simulation models. 


\section{REFERENCES}

1. Drupsteen J, Van der Vaart $\mathrm{T}$ and Van Donk DP. Integrative practices in hospitals and their impact on patient flow. International Journal of Operations \& Production Management 2013; 33:912-933.

2. Kodner DL and Spreeuwenberg C. Integrated care: meaning, logic, applications and implications - a discussion paper. International Journal of Integrated Care 2002; 2(4). http://doi.org/10.5334/ijic.67.

3. Lega F, Marsilio $M$ and Villa S. An evaluation framework for measuring supply chain performance in the public healthcare sector: evidence from the Italian NHS. Production Planning \& Control 2013; 24: 931-947.

4. Aronsson H, Abrahamsson M and Spens K. Developing lean and agile health care supply chains. Supply Chain Management: An International Journal 2011; 16: 176-183.

5. Borges GA, Tortorella G, Rossini M and Portioli-Staudacher A. Lean implementation in healthcare supply chain: a scoping review. Journal of Healthcare Organization and Management. 2019; 33(3): 304-322.

6. De Vries J and Huijsman R. Supply Chain Management in health services: an overview. Supply Chain Management: An International Journal 2011; 16: 159-165.

7. Litvak N, Van Rijsbergen M, Boucherie RJ et al. Managing the overflow of intensive care patients. European Journal of Operational Research 2008; 185: 998-1010.

8. Ludwig M, Van Merode GG and Groot W. Principal agent relationships and the efficiency of hospitals. Eur J Health Econ 2010; 11: 291-304.

9. Van Merode GG, Groothuis S and Hasman A. Enterprise resource planning for hospitals. International Journal of Medical Informatics 2004; 73(6): 493-501.

10. Villa S, Barbieri M and Lega F. Restructuring patient flow logistics around patient care needs: implications and practicalities from three critical cases. Health Care Manag Sci 2009; 12(2): 155-165.

11. Morgan D and Astolfi R. Financial impact of the GFC: health care spending across the OECD. Health Economics, Policy and Law 2015; 10: 7-19.

12. Van der Ham A, Boersma H, Van Raak A, Ruwaard D and Van Merode G.G. Identifying Logistical Parameters in Hospitals: Does literature reflect integration in hospitals? A scoping study. Health Serv Manage Res 2019; 32(3); 158-165.

13. Lawrence PRL, Lorsch JW, Differentiation and Integration in Complex Organizations, Administrative Science Quarterly 1967; 12: 1-47.

14. Provan KG and Sebastian JG. Networks within Networks: Service Link Overlap, Organizational Cliques, and Network Effectiveness. The Academy of Management Journal 1998; 41(4): 453463 .

15. Kilduff M, Tsai W. Social networks and organizations. London: SAGE Ebook; 2003. Accessed 6 September 2018.

16. Monge PR, Contractor N. Emergence of Communication Networks. In: Jablin FM, Putman LL, editors. The New Handbook of Organizational Communication. Thousand Oaks: Sage publications, 2011. pp. 440-502. 
17. Van der Ham A, Van Merode F, Ruwaard D and Van Raak A. Identifying Integration and Differentiation in a Hospital's Logistical System: A social network analysis of a case study. BMC Health Serv Res 2020; 20: 857. DOI: 10.1186/s12913-020-05514-w.

18. Beuving J, De Vries G. Doing Qualitative Research: The Craft of Naturalistic Inquiry. Amsterdam: Amsterdam University Press, 2015.

19. Mintzberg H. Managing the myths of health care. Oakland: Berrett-Koehler Publishers, 2012.

20. Uddin MS, Hossain L. Social Networks Enabled Coordination Model for Cost Management of Patient Hospital Admissions. Journal for Healthcare Quality 2011;33:37-48.

21. Benham-Hutchins M, Clancy TR. Social Networks as Embedded Complex Adaptive Systems. JONA: The Journal of Nursing Administration 2010;40:352-356.

22. Haythornthwaite C. Social Network Analysis: an approach for the study of information exchange. LISR 1996 18:323-342.

23. Yin RK. Case study research - Design and Methods. 5e edition. Thousand Oaks: Sage Publications, 2014.

24. Van Hulst, B, Blank J Nederlandse ziekenhuizen te groot voor verdere schaalvoordelen. Economisch-Statistische Berichten 2017;102(4749):226-228.

25. Benchmark Coppa Consultancy. Online database. Accessed 11 July 2018.

26. Mintzberg H. Structures in Five: designing effective organizations. Englewood Cliffs: PrenticeHall, 1983.

27. Demeulemeester E, Belien J, Cardoen B and Samundra M. Operating Room Planning and Scheduling. In: B.T. Denton (Ed. Handbook of Operations Management: Methods and Applications. International series in Operations Research \& Management Science New York, NY: Springer Science + Business Media, 2013.

28. Hulshof JH, Kortbeek N, Boucherie RJ, Hans EW and Bakker PJM. Taxonomic classification of planning decisions in healthcare: a structured review of the state of art in OR/MS. Health Systems 2012;1:129-175.

29. Zhu S, Fan W, Yang S, Pei J, Pardalos PM. Operating room planning and surgical case scheduling: a review of literature. Journal of Combinatorial Optimization 2019;37:757-805.

30. Parhankangas A, Ing D, Hawk DL, Dane G and Kosits M. Negotiated Order and Network Form Organizations. Systems Research and Behavioral Science 2005; 22: 431-452.

31. Copp M. Negotiated Order. In: G. Ritzer (Ed.) Encyclopedia of Social Theory. Thousand Oaks: Sage Publications, 2005.

32. Engeström Y. Expansive Learning at Work: toward an activity theoretical reconceptualization. Journal of Education and Work 2001;14: 133-156.

33. Munavalli JR, Rao SV, Srinivasan A, Manjunath U and Van Merode GG. A Robust Predictive Resource Planning under Demand Uncertainty to Improve Waiting Times in Outpatient Clinics. Journal of Health Management 2017;19:563-583.

34. Ren Y, Kiesler S and Fussell SR. Multiple Group Coordination in Complex and Dynamic Task Environments: Interruptions, Coping Mechanisms, and Technology Recommendations. Journal of Management Information Systems 2008;25:105-130.

35. Munavalli, J.R., Rao. S.V., Srinivasan A and Van Merode G.G. An Intelligent real-time scheduler for outpatient clinics: A multi-agent system model. Health Informatics Journal 2020; 26(4): 2383-2406. doi: 10.1177/1460458220905380. 


\section{APPENDIX 4.1}

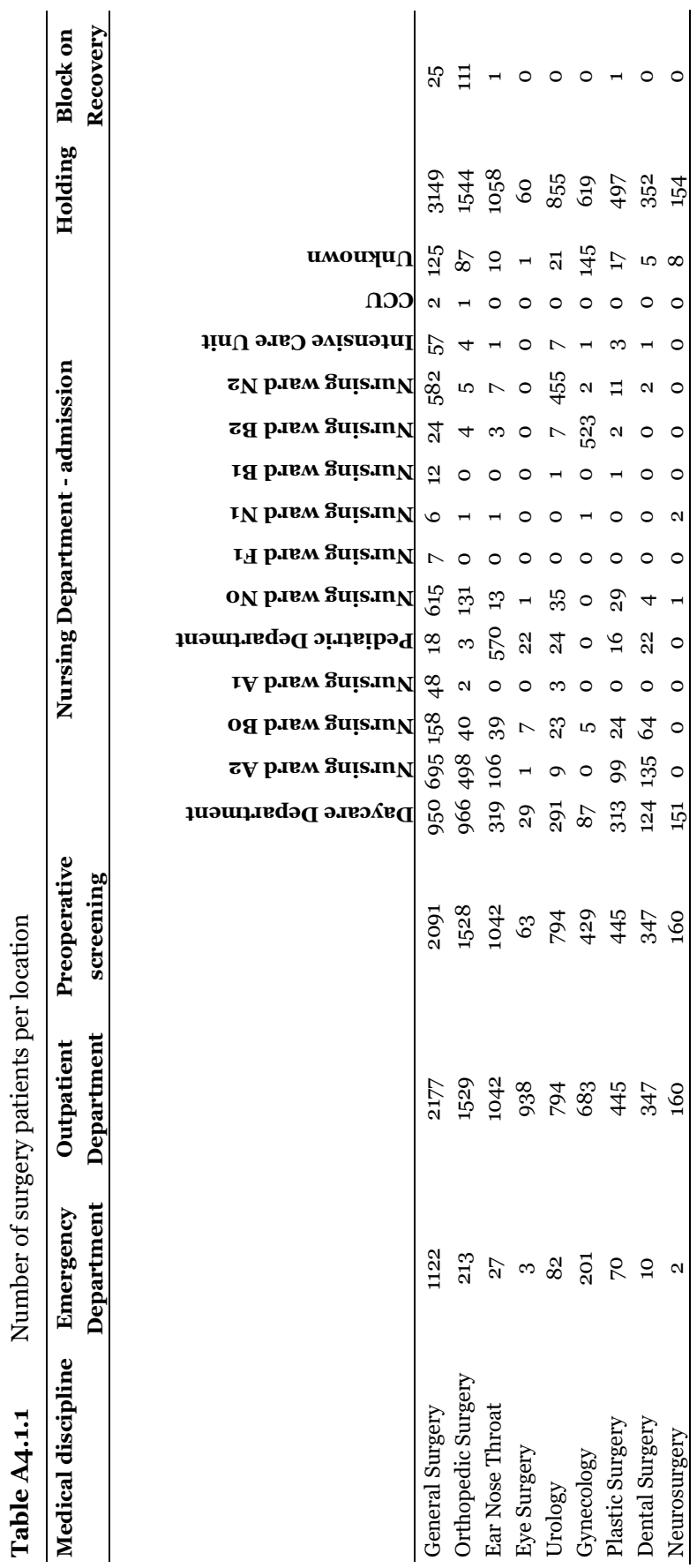




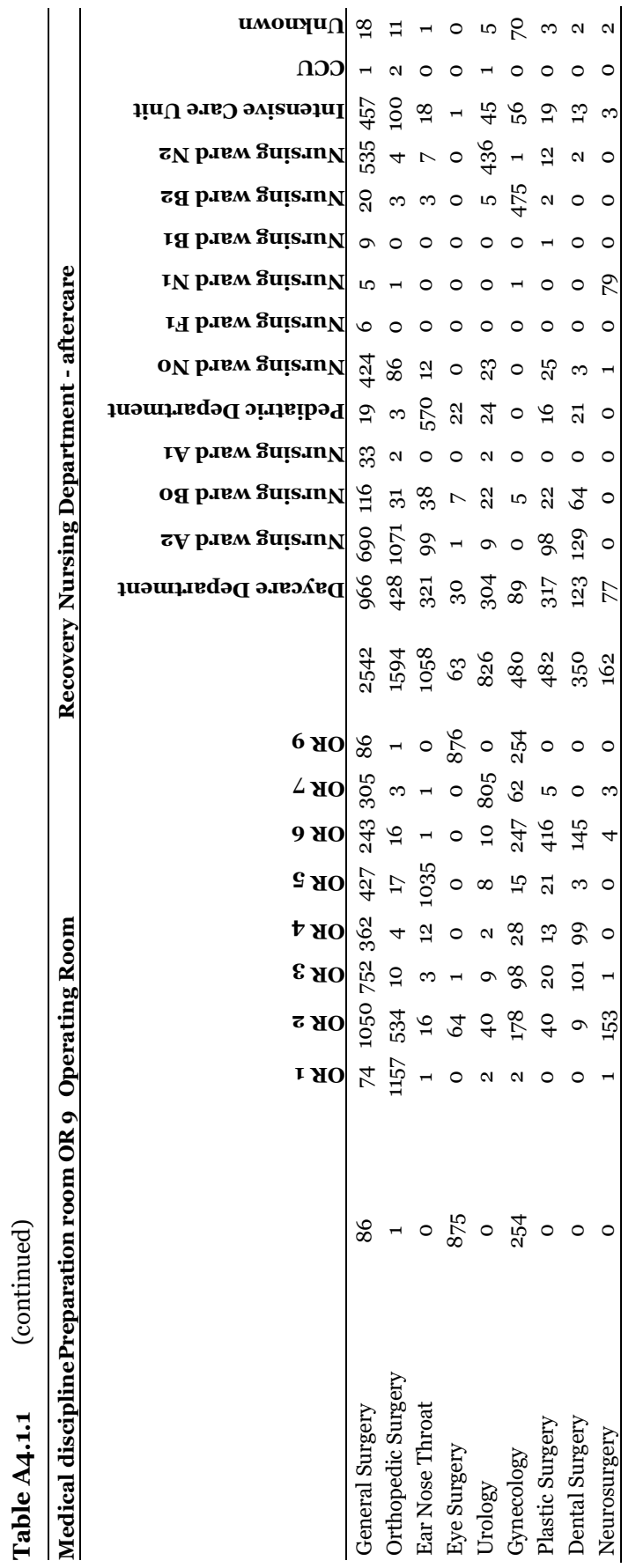



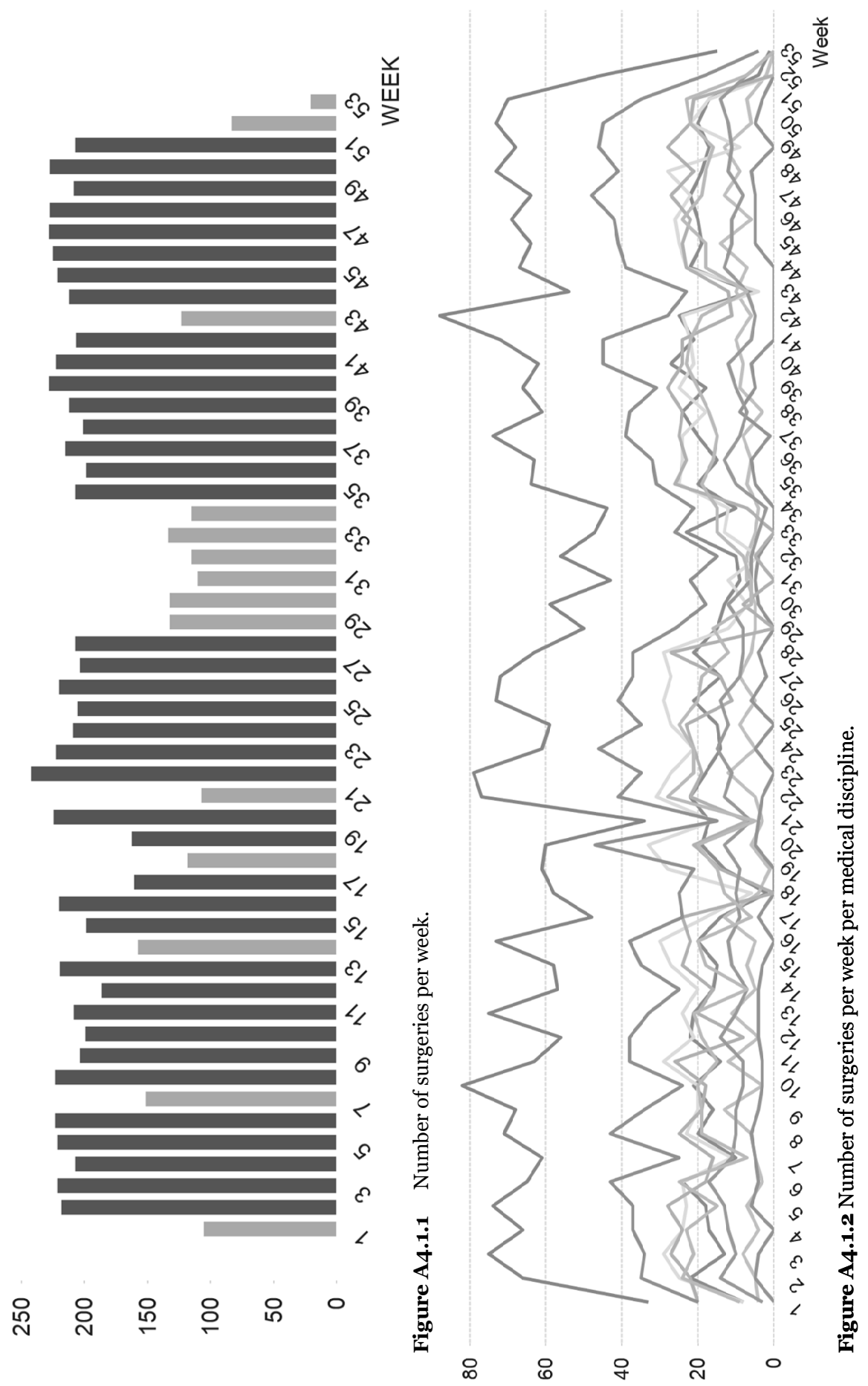


\section{APPENDIX 4.2}

\section{The tasks, agents, interactions and coordination mechanisms in the social network}

\section{Task 1: Make OR Master Schedule}

Task

description

Time horizon

Frequency

Interactions
The Operating Room (OR) master schedule is made in the Tactical Planning Meeting (TPM). Three cluster managers, who are responsible, respectively, for outpatient, inpatient departments and the Operating Theatre Complex (OTC), nine surgeons, one anesthesiologist and the OTC capacity planner participate in this meeting. The OR master schedule is prepared by four participants of the TPM, who then propose the scheme to the entire TPM. The OR master schedule is then presented to the OTC commission. The OTC commission discusses and advises OTC management on planning, staff and budget issues. The OTC commission includes one surgeon from every surgical discipline, the cluster manager responsible for the OTC and the OTC capacity planner. When the OR master schedule is final, the OTC capacity planner informs all outpatient secretaries on the changes made.

12 to 20 weeks ahead

4 times a year

\begin{tabular}{|c|c|c|c|c|c|c|}
\hline & $\begin{array}{c}\text { Number } \\
\text { of agents }\end{array}$ & 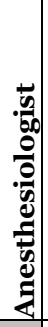 & 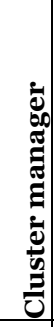 & 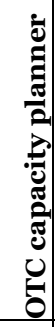 & 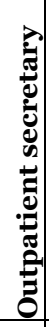 & $\begin{array}{l}5 \\
0 \\
0 \\
\vdots \\
\vdots \\
0 \\
0\end{array}$ \\
\hline Anesthesiologist & 1 & & $\mathrm{X}$ & $\mathrm{X}$ & & $\mathrm{X}$ \\
\hline Cluster manager & 3 & & $\mathrm{X}$ & $\mathrm{X}$ & & $\mathrm{X}$ \\
\hline OTC capacity planner & 1 & & & & $\mathrm{X}$ & \\
\hline Outpatient secretary & 13 & & & & & \\
\hline Surgeon & 9 & & & & & $\mathrm{X}$ \\
\hline
\end{tabular}


Rules for task performance

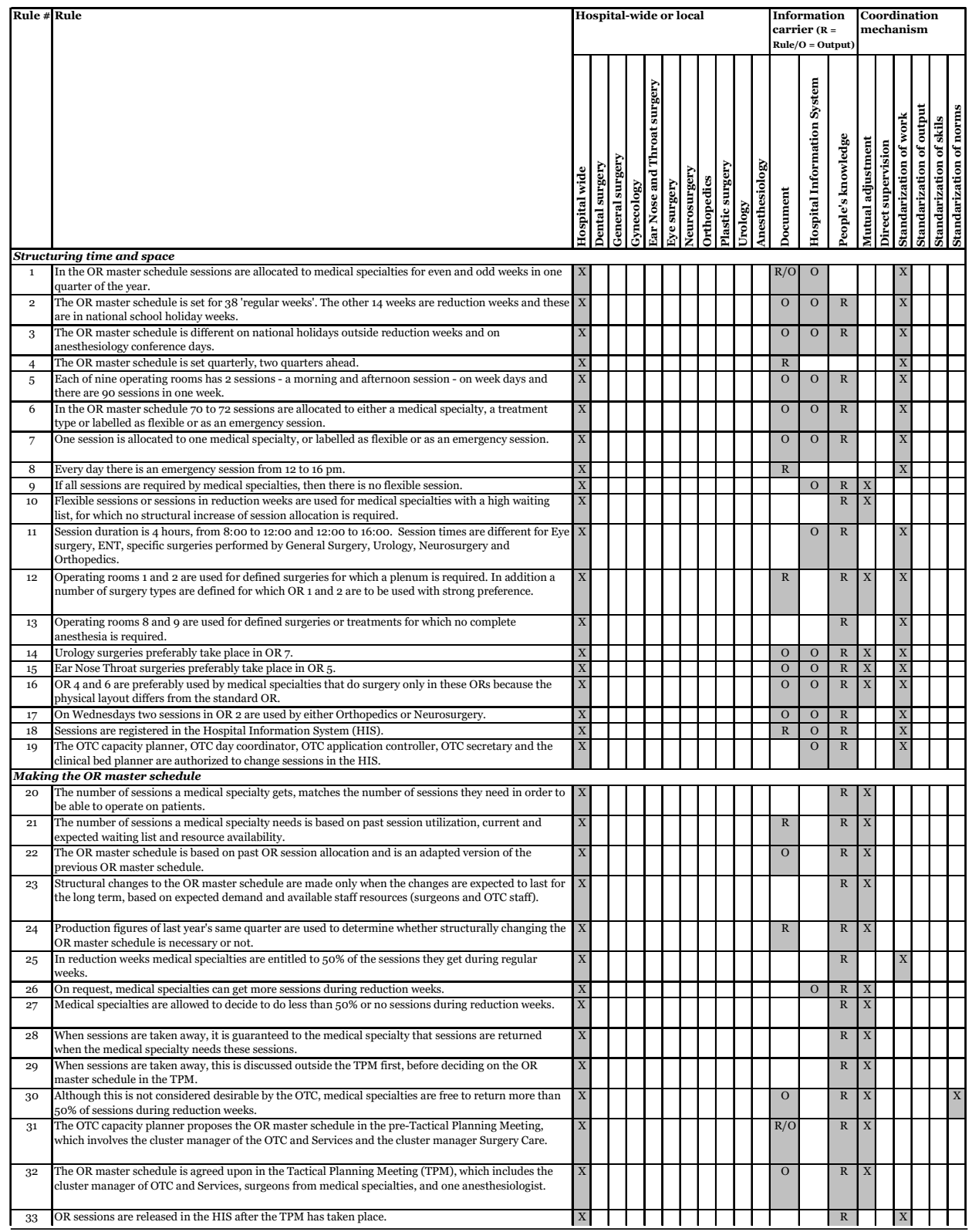




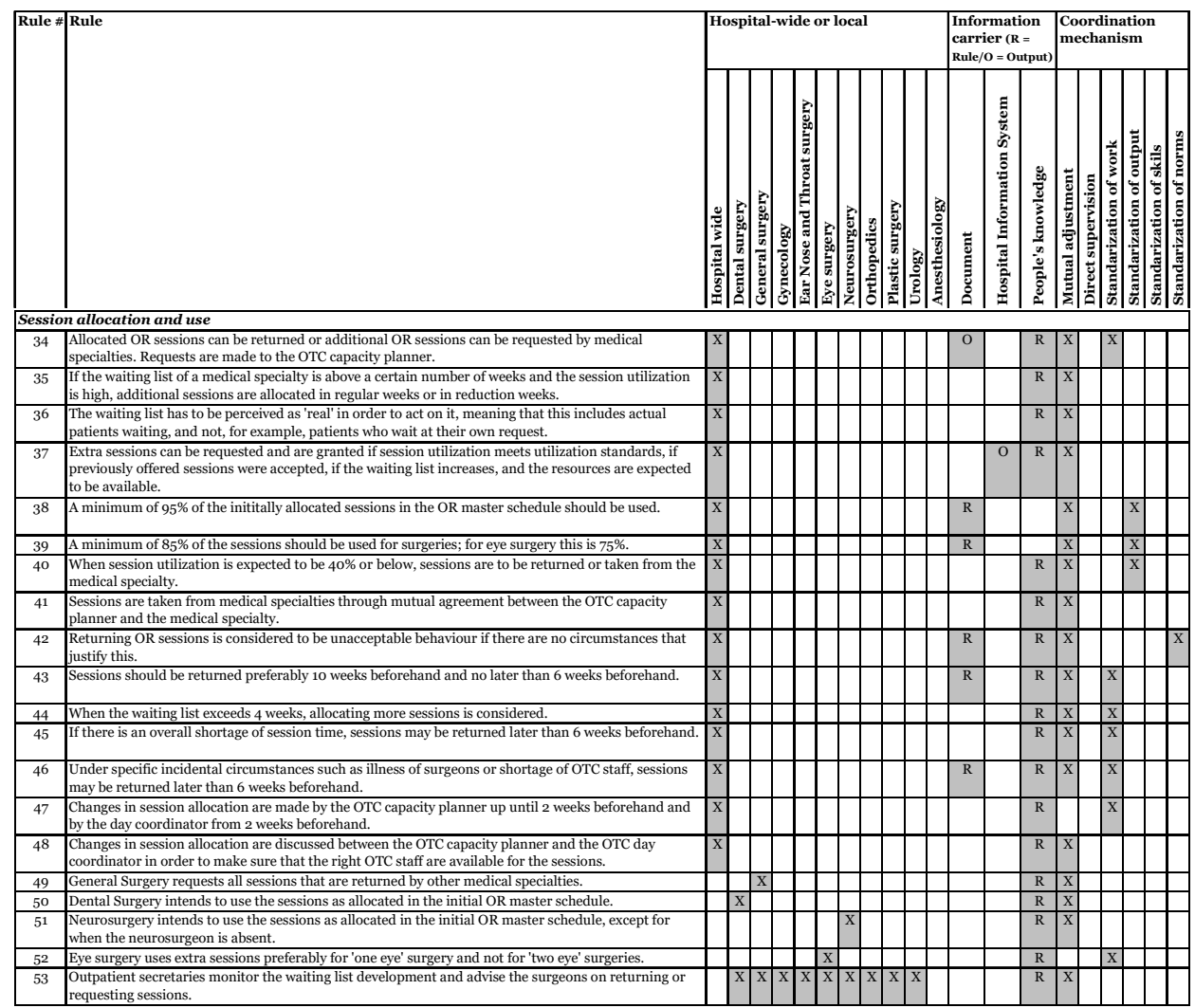




\section{Task 2: Make Clinical Bed Plan}

Task description

In the clinical bed plan, beds are assigned to a medical discipline for each nursing department. The clinical bed plan is established in consultation between the OTC capacity planner, one secretary from the nursing department and the two team leaders of the three nursing wards who host most surgery patients. The team leaders of these nursing wards are also involved in making the clinical bed plan, but one nurse ward secretary has the informal role of 'clinical bed plan boss'.

Time horizon 12 to 20 weeks ahead

Frequency 4 times a year

Interactions 


\section{Rules for task performance}

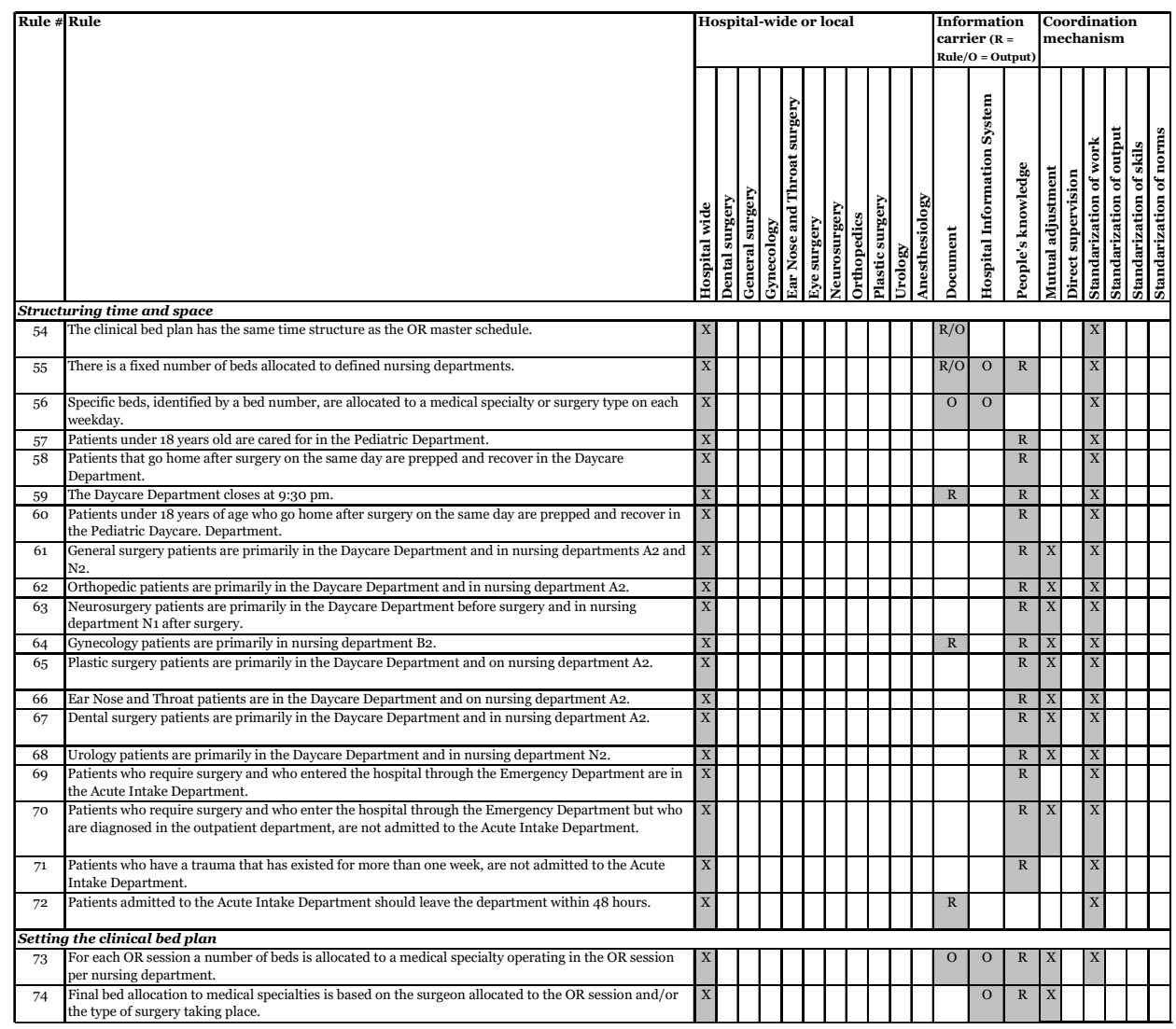




\begin{tabular}{|c|c|c|c|c|c|c|c|c|c|c|c|c|c|c|c|}
\hline \multirow[t]{2}{*}{ Rule $\# \mathbf{R}$} & \multirow[t]{2}{*}{ Rule } & \multicolumn{6}{|c|}{ Hospital-wide or local } & \multicolumn{3}{|c|}{$\begin{array}{l}\begin{array}{l}\text { Information } \\
\text { carrier (R = } \\
\text { Rule// = Output) }\end{array} \\
\end{array}$} & \multicolumn{5}{|c|}{$\begin{array}{l}\text { Coordination } \\
\text { mechanism }\end{array}$} \\
\hline & & \multicolumn{7}{|c|}{ 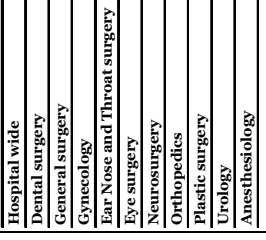 } & 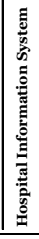 & 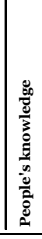 & & & & & $\ddot{n}$ \\
\hline \multicolumn{16}{|c|}{ Bed allocation and use } \\
\hline 75 & $\begin{array}{l}\text { In principle medical specialties are only allowed to reserve beds that have been allocated to them } \\
\text { according to the clinical bed plan. }\end{array}$ & $\mathrm{x}$ & & & & & & $\mathrm{R}$ & & & $\mathrm{x}$ & & $\mathrm{x}$ & & \\
\hline 76 & Bed allocation is tailored as much as possible to each medical specialty's demand for beds. & $\mathrm{x}$ & & & & & & & & $\mathrm{R}$ & $\mathrm{x}$ & & & & \\
\hline 77 & Outpatient secretaries can request additional beds from the clinical bed planner. & $\mathrm{x}$ & & & & & & & & $\mathrm{R}$ & $\mathrm{x}$ & & & & \\
\hline 78 & $\begin{array}{l}\text { Based on the final OTC program and how many patients require a bed specific beds are allocated to } \\
\text { specific patients, on the basis of practical experience and knowledge. }\end{array}$ & $\mathrm{x}$ & & & & & & & $\mathrm{O}$ & $\mathrm{R}$ & $\mathrm{x}$ & & & & \\
\hline 79 & $\begin{array}{l}\text { The medical specialty, as represented by the outpatient department, is responsible for reserving beds } \\
\text { for patients six weeks ahead. }\end{array}$ & $\mathrm{x}$ & & & & & & & & $\bar{R}$ & & & $\bar{x}$ & & \\
\hline 80 & $\begin{array}{l}\text { The medical specialty, as represented by the outpatient department, is responsible for a good ratio } \\
\text { between day care and clinical bed patients. }\end{array}$ & $\mathrm{x}$ & & & & & & & & $\mathrm{R}$ & $\mathrm{x}$ & & & & \\
\hline 81 & $\begin{array}{l}\text { The allocated beds in the clinical bed plan can be reserved for patients by outpatient secretaries } \\
\text { without consultation with the clinical bed planner. }\end{array}$ & $\mathrm{x}$ & & & & & & & & $\mathrm{R}$ & & & $\mathrm{x}$ & & \\
\hline 82 & $\begin{array}{l}\text { Beds may be exchanged between sub-specialties within General Surgery (Vascular Surgery, Oncology } \\
\text { and Trauma surgery) without consulting the clinical bed planner. }\end{array}$ & $\mathrm{x}$ & & & & & & & & $\mathrm{R}$ & $\mathrm{x}$ & & & & \\
\hline 83 & $\begin{array}{l}\text { A standard number of beds are reserved for as yet unknown emergency patients in nursing } \\
\text { departments. }\end{array}$ & $\mathrm{x}$ & & & & & & & $\mathrm{O}$ & $\mathrm{R}$ & & & $\bar{x}$ & & \\
\hline 84 & A bed that is required for a small number of hours per day is not reserved for one patient. & $\mathrm{x}$ & & & & & & & $\mathrm{O}$ & $\mathrm{R}$ & & & $\bar{x}$ & & \\
\hline 85 & $\begin{array}{l}\text { Deviations from the allocated number of beds in the clinical bed plan have to be discussed with the } \\
\text { clinical bed planner. }\end{array}$ & $\mathrm{x}$ & & & & & & & & $\mathrm{R}$ & $\mathrm{x}$ & & & & \\
\hline 86 & $\begin{array}{l}\text { The clinical bed planner monitors the planning of OR sessions and bed reservations and takes } \\
\text { proactive action if there is a risk of a possible mismatch between the number of patients and the } \\
\text { number of available beds on specific days. }\end{array}$ & $\mathrm{x}$ & & & & & & & & $\mathrm{R}$ & $\mathrm{x}$ & & & & \\
\hline 87 & The clinical bed planner takes action two weeks ahead of planned surgeries. & $\mathrm{x}$ & & & & & & & & $\mathrm{R}$ & $\mathrm{x}$ & & $\mathrm{x}$ & & \\
\hline 88 & $\begin{array}{l}\text { Requesting beds on short notice or reserving beds that are not allocated to your department according } \\
\text { to the clinical bed plan, is not considered as be acceptable behaviour. }\end{array}$ & $\mathrm{x}$ & & & & & & & & $\mathrm{R}$ & $\mathrm{x}$ & & & & \\
\hline 89 & $\begin{array}{l}\text { The more outpatient secretaries share the need for beds on time and consult with the clinical bed } \\
\text { planner on bed requirements the more she is willing to find a solution for any bed shortages. This is a } \\
\text { give and take process. }\end{array}$ & $\mathrm{x}$ & & & & & & & & $\mathrm{R}$ & $\mathrm{x}$ & & & & \\
\hline 90 & $\begin{array}{l}\text { If a medical specialty does not behave as expected, the clinical bed planner waits with communication } \\
\text { on a possible solution, in order to enforce improved planning behaviour for the future. }\end{array}$ & $\mathrm{x}$ & & & & & & & & $\mathrm{R}$ & $\bar{x}$ & & & & \\
\hline 91 & $\begin{array}{l}\text { If no beds are available in the nursing department where a patient of a medical specialty should be, } \\
\text { then the patient is allocated to another nursing department. }\end{array}$ & $\mathrm{x}$ & & & & & & $\mathrm{R}$ & $\mathrm{O}$ & $\mathrm{R}$ & $\mathrm{x}$ & & & & \\
\hline 92 & $\begin{array}{l}\text { Shifting patients to a different nursing department is possible when the required level of care of the } \\
\text { patient and the knowledge and skills of nurses, which are acquired in training, in the other nursing } \\
\text { department matches. }\end{array}$ & $\mathrm{x}$ & & & & & & $\mathrm{R}$ & & $\mathrm{R}$ & $\mathrm{x}$ & & & & \\
\hline 93 & $\begin{array}{l}\text { If OR sessions are planned } 100 \% \text { for a specific medical specialty, then the allocation of beds in the } \\
\text { clinical bed plan for that day is not applicable. }\end{array}$ & $\mathrm{x}$ & & & & & & & & $\mathrm{R}$ & $\mathrm{x}$ & & $\overline{\mathrm{x}}$ & & \\
\hline 94 & $\begin{array}{l}\text { If beds are not reserved two weeks ahead, the allocated beds in the clinical bed plan for that week are } \\
\text { cancelled. }\end{array}$ & $\mathrm{x}$ & & & & & & $\mathrm{R}$ & & & $\mathrm{x}$ & & $\bar{x}$ & & \\
\hline 95 & $\begin{array}{l}\text { If all allocated beds are reserved for a specific medical specialty, but the OR session is not, then the } \\
\text { clinical bed planner contacts the outpatient department in order to discuss a possible need for }\end{array}$ & $\mathrm{x}$ & & & & & & & & $\mathrm{R}$ & $\mathrm{x}$ & & & & \\
\hline 96 & $\begin{array}{l}\text { Patients for whom no bed is available yet or for which no allocated bed is yet required, are placed in the } \\
\text { 'ball box'. This is a registry of all patients in the HIS, which includes all patients who are planned for } \\
\text { surgery and allocated to a nursing department, but who do not yet have a reserved bed. }\end{array}$ & $\mathrm{x}$ & & & & & & & 0 & $\mathrm{R}$ & $\mathrm{x}$ & & $\bar{x}$ & & \\
\hline 97 & $\begin{array}{l}\text { The final bed allocation is made by the team leader of the nursing department, on the day before } \\
\text { patient admission. }\end{array}$ & $\mathrm{x}$ & & & & & & & 0 & $\mathrm{R}$ & & & $\bar{x}$ & & \\
\hline 98 & $\begin{array}{l}\text { In case of conflicts between the clinical bed planner and a medical specialty on bed requests, the } \\
\text { clinical bed planner consults with the nursing departments team leaders and/or the OTC capacity } \\
\text { planner in order to determine a common policy. }\end{array}$ & $\mathrm{x}$ & & & & & & & & $\mathrm{R}$ & $\mathrm{x}$ & & & & \\
\hline 99 & $\begin{array}{l}\text { Patients with sleeping apnea or lung surgery are cared for in the Intensive Care Department after } \\
\text { surgery. }\end{array}$ & $\mathrm{x}$ & & & & & & $\mathrm{R}$ & & $\mathrm{R}$ & & & $\bar{x}$ & & \\
\hline 100 & $\begin{array}{l}\text { If there are only daycare patients on the waiting list of a medical specialty, it is allowed to request } \\
\text { additional beds two weeks beforehand. }\end{array}$ & $\mathrm{x}$ & & & & & & & & $\mathrm{R}$ & $\mathrm{x}$ & & $\mathrm{x}$ & & \\
\hline 101 & $\begin{array}{l}\begin{array}{l}\text { Specific requests of patients, e.g. to stay in a single room, are taken into account and granted if } \\
\text { possible. }\end{array} \\
\text {. }\end{array}$ & $\mathrm{x}$ & & & & & & & & $\mathrm{R}$ & $\mathrm{x}$ & & & & \\
\hline 102 & $\begin{array}{l}\text { If the expected length of stay of a patient is expected to be high or the patient is infected with MRSA, } \\
\text { the outpatient secretary discusses the bed reservation with the clinical bed planner. }\end{array}$ & $\mathrm{x}$ & & & & & & & & $\mathrm{R}$ & $\bar{x}$ & & $\mathrm{x}$ & & \\
\hline 103 & Oncology patients have priority over all other patients when allocating beds to specific patients. & $\mathrm{x}$ & & & & & & & & $\mathrm{R}$ & $\mathrm{x}$ & & $\mathrm{x}$ & & \\
\hline 104 & $\begin{array}{l}\text { Specific combinations of patients that are being cared for in nursing departments are averted, based on } \\
\text { past experience. For example, one rule is that when a bed is required for a patient in nursing } \\
\text { department No, no vascular surgeries, which can have a heavy impact on the patient, should be } \\
\text { planned for at the same time. }\end{array}$ & $\mathrm{x}$ & & & & & & & & $\mathrm{R}$ & $\mathrm{x}$ & & $\bar{x}$ & & \\
\hline
\end{tabular}




\section{Task 3: Schedule surgeons and anesthesiologists}

Task description

Time horizon Frequency

Interactions
The surgeons of each outpatient department and anesthesiologists make schedules for themselves and allocate surgeons to the time slots in the OR master schedule. The scheduler of each medical discipline group proposes the schedule and discusses it with the surgeons. In some outpatient departments the secretary of the outpatient department is involved in this.

10 weeks ahead

Variable

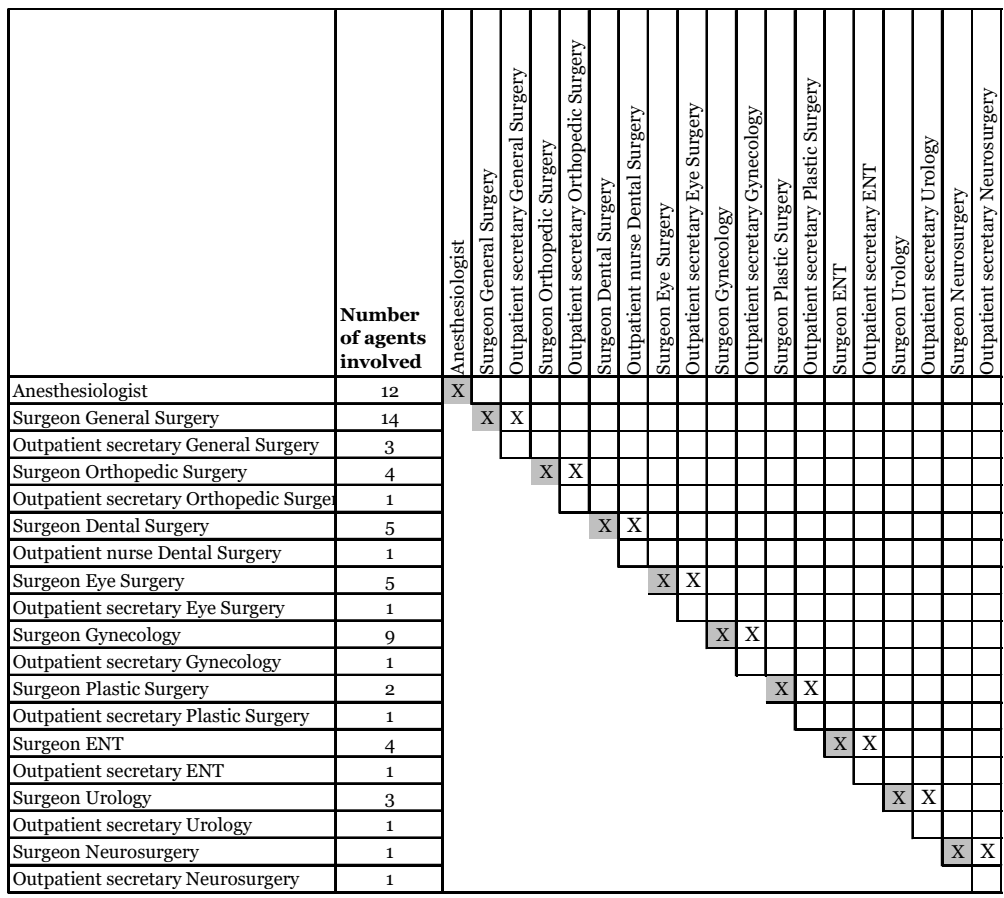




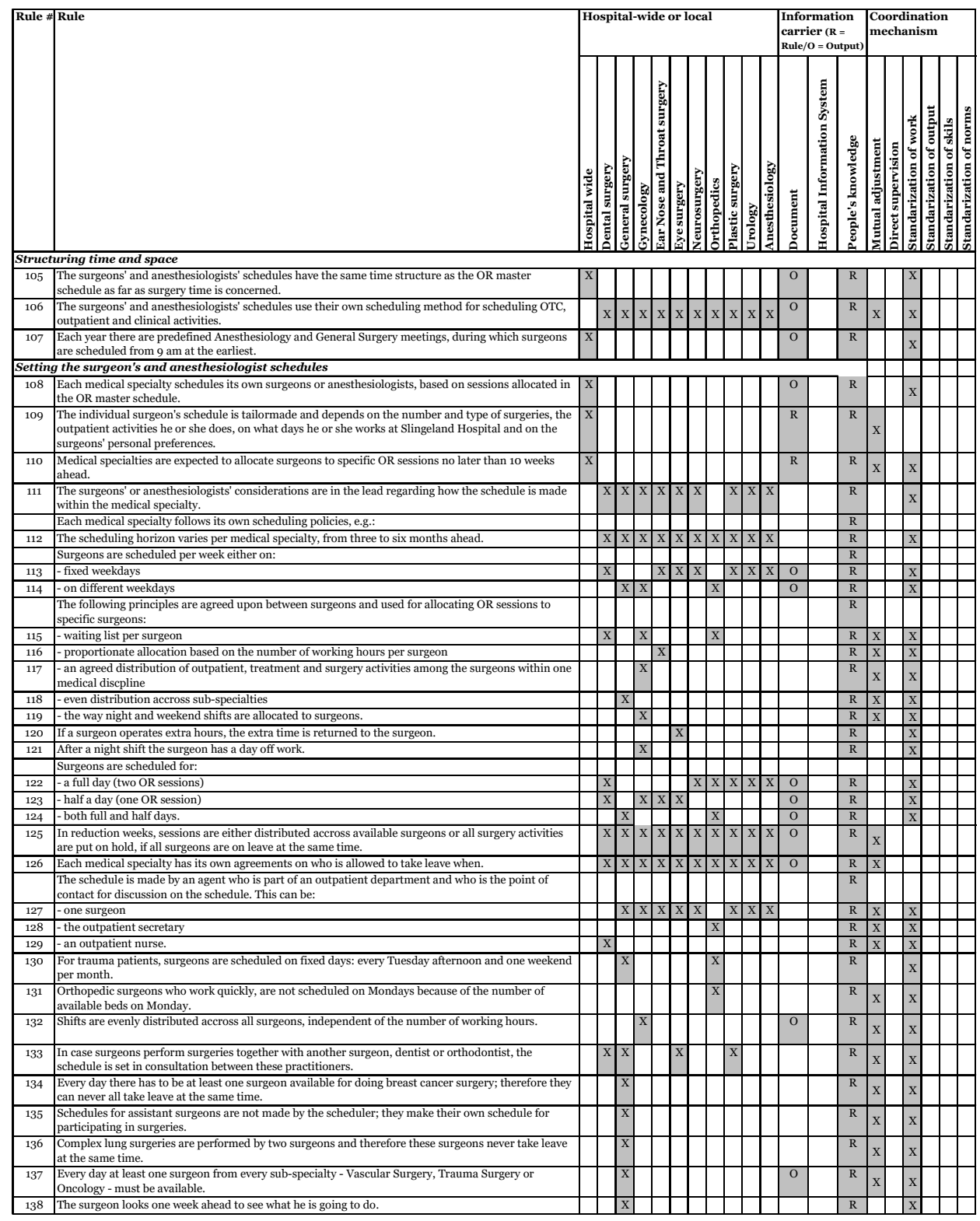




\section{Tasks 6 and 11: Plan patient and control planning}

Task description

Time

horizon

Frequency

\section{1) Daily}

6) Daily

\section{Interactions}

6) The planning for surgeries takes place at one of the nine outpatient clinics. The secretary puts the patient on the waiting list or sets a surgery date right away. There can be interaction between secretaries and the OTC capacity planner on specific surgery requirements or when the OR master schedule is almost filled. Surgeons also email or phone the OTC capacity planner for specific patient cases that require tuning.

11) The planning is checked and revised in the process leading to surgery. The preoperative secretaries interact with all outpatient secretaries on whether everything is arranged for the surgery. In the weekly 'Tuesday morning' meeting, the planning for the upcoming week is discussed among the outpatient secretaries, the ward team leaders and the OTC capacity planner. Also, a weekly bed meeting takes place between ward team leaders, a nurse and the OTC capacity planner. All checks for the next day's OR program are made in this meeting. The OTC capacity planner views the daily OTC schedule the day before to determine the exact sequence of the operations. When everything is checked, she informs the OTC day coordinator regarding any specific details in the next day's OTC program.

6) 6 days to 20 weeks ahead

11) 1 day to 2 weeks ahead

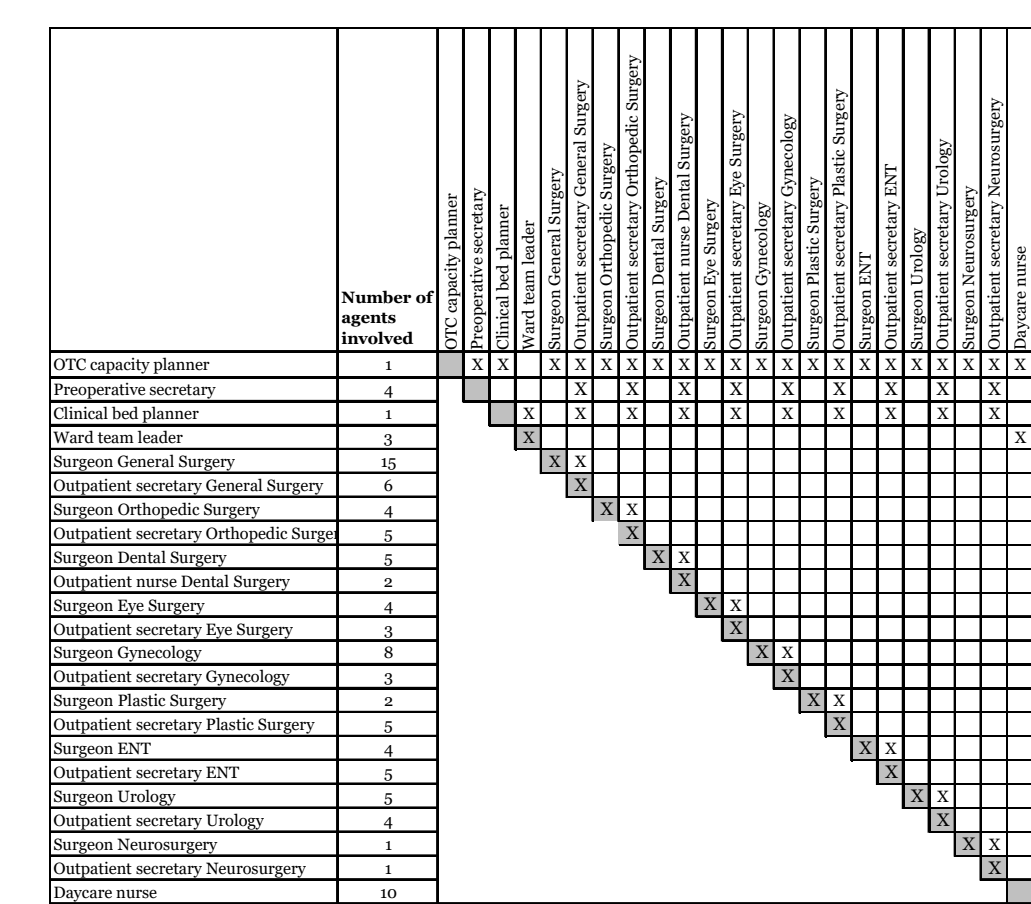




\section{Rules for task performance}

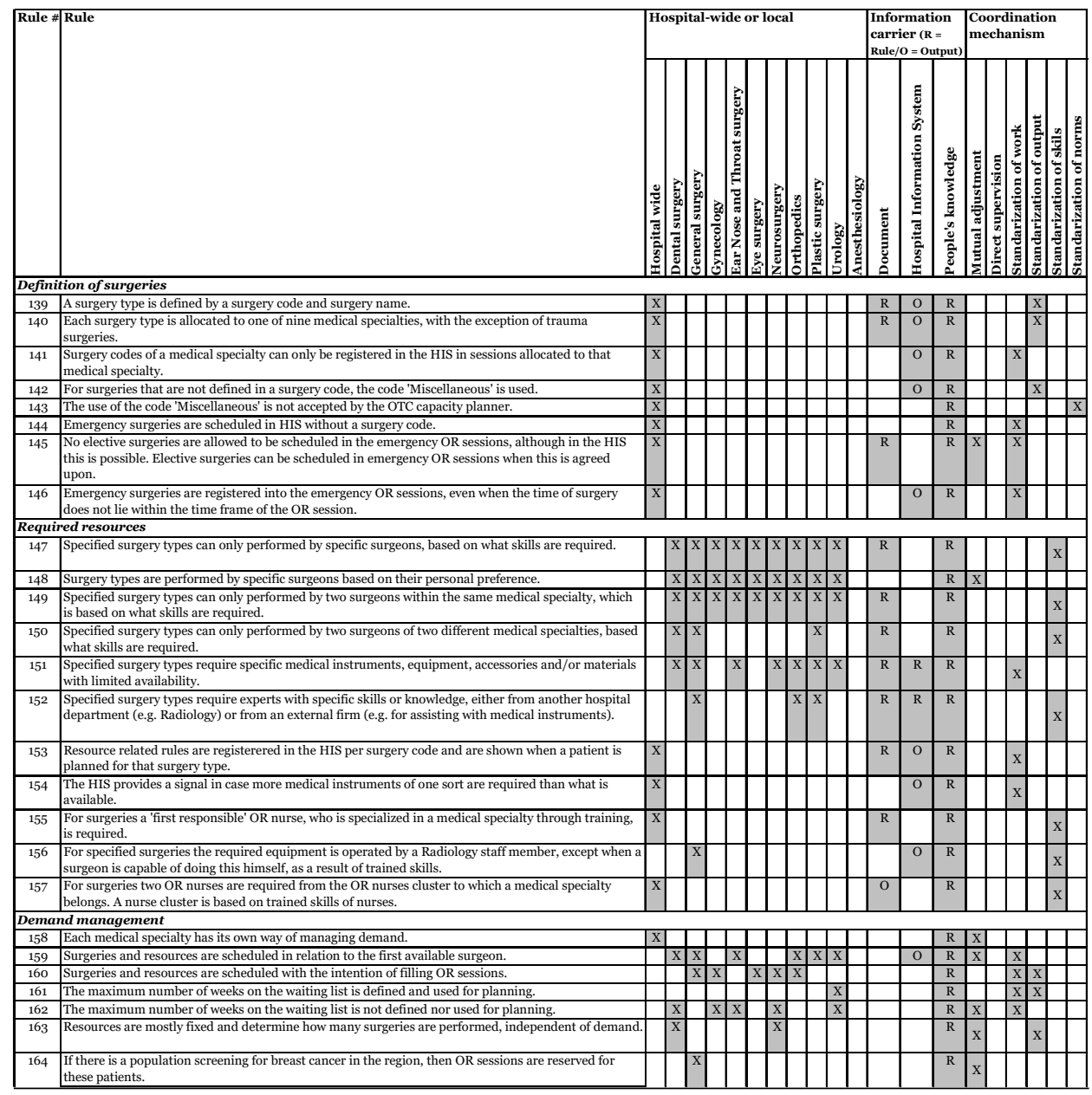




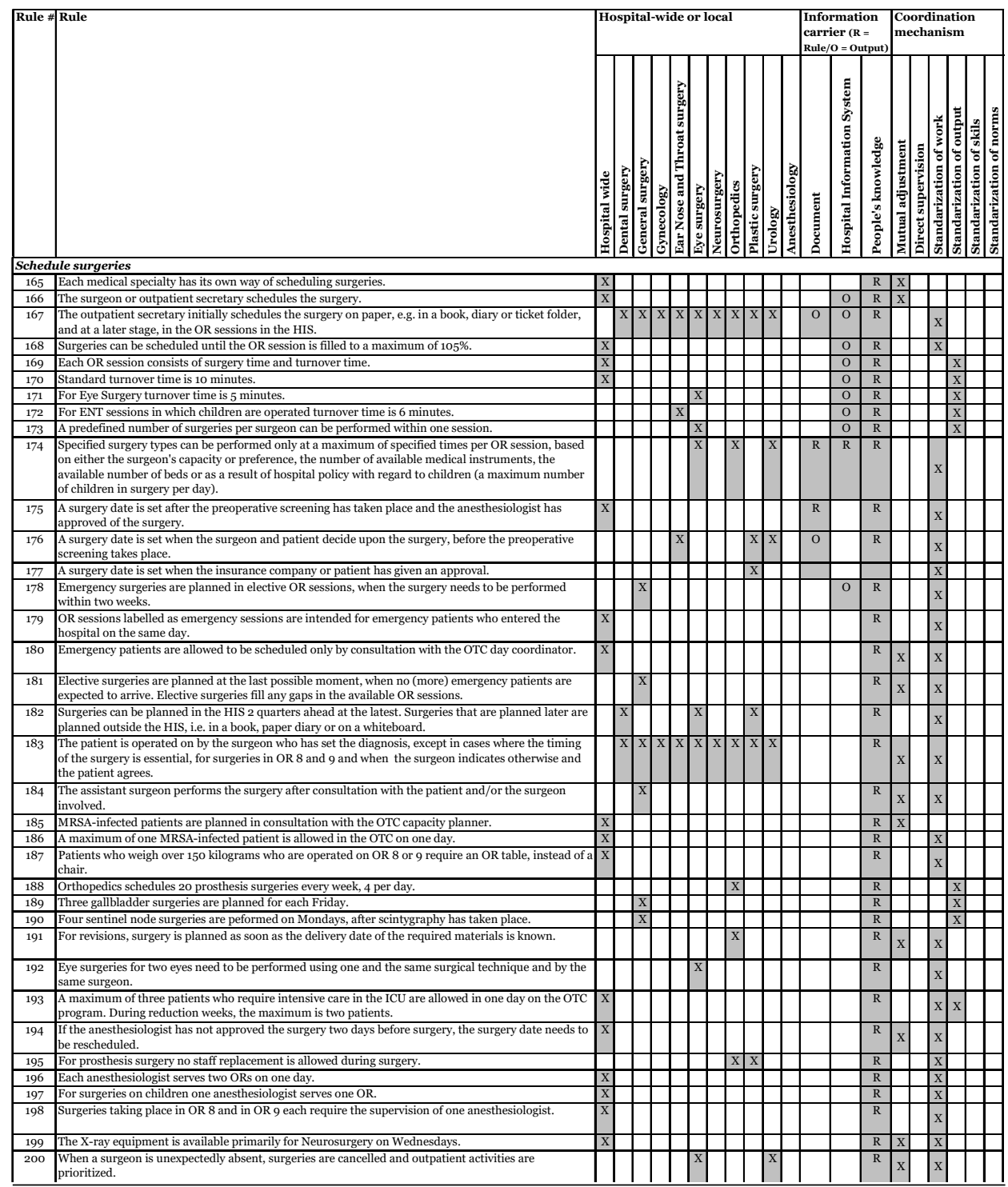




\begin{tabular}{|c|c|c|c|c|c|c|c|c|c|c|c|c|c|c|c|c|c|}
\hline \multirow[t]{2}{*}{ Rule \# 1} & \multirow[t]{2}{*}{ Rule } & \multicolumn{8}{|c|}{ Hospital-wide or local } & \multicolumn{3}{|c|}{\begin{tabular}{|l|}
$\begin{array}{l}\text { Information } \\
\text { carrier (R = } \\
\text { Rule/O = Output) }\end{array}$ \\
\end{tabular}} & \multicolumn{5}{|c|}{\begin{tabular}{|l} 
Coordination \\
mechanism
\end{tabular}} \\
\hline & & $\mid$ & & & 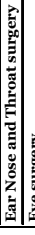 & & & & 泾 & & 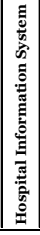 & & & & & 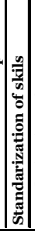 & 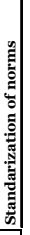 \\
\hline \multirow{2}{*}{\multicolumn{18}{|c|}{$\begin{array}{l}\text { Surgery timing } \\
201 \mid \text { The surgery date is planned in accordance with the patient's preference. }\end{array}$}} \\
\hline & $\begin{array}{l}\text { The surgery date is planned in accordance with the patient's preference. } \\
\text { Patients who use blood thinners have to be planned for a specific day at least five days ahead. }\end{array}$ & $|x|$ & & & & & & & & & & \begin{tabular}{|l|l}
$R$ \\
$R$
\end{tabular} & & X & & & \\
\hline \begin{tabular}{|l|l|l|l|l}
202 \\
203
\end{tabular} & $\begin{array}{l}\text { Patients who use blood thinners have to be planned for a specific day at least five days ahead. } \\
\text { Specified surgery types need to be performed within days after the diagnosis is set, according to guidelin }\end{array}$ & nes. & & & $\mathrm{x}$ & & & & & $\mathrm{R}$ & & $\mathrm{R}$ & & & $|x|$ & & \\
\hline \begin{tabular}{|c|c|c|}
204 \\
\end{tabular} & A patient surgery is planned on the first date that any surgeon is available. & & $x$ & & $\mathrm{x}$ & $\underline{x}$ & & $x+3$ & & & & \begin{tabular}{|l|l|l}
$R$ \\
\end{tabular} & $\mathrm{x}$ & $\mathrm{x}$ & & & \\
\hline 205 & The patient's surgery is planned for the first date that the surgeon who made the diagnosis is available. & & $\bar{x}$ & & $\mathrm{x}$ & & & $\mathrm{x} \mathbf{3}^{3}$ & & & & 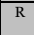 & $\mathrm{x}$ & $\mathrm{x}$ & & & \\
\hline 206 & $\begin{array}{l}\text { Surgeries are performed as soon as possible in one of three hospitals within a regional network } \\
\text { collaborative. }\end{array}$ & & $\mathrm{x}$ & & & & & & & & & \begin{tabular}{|l}
$\mathrm{R}$ \\
\end{tabular} & $\mathrm{x}$ & $\mathrm{x}$ & & & \\
\hline 207 & The timing of specified surgery types depends on the menstrual cycle of the patient. & & & & & & & & & $\mathrm{R}$ & & $\mathrm{R}$ & $\bar{x}$ & $\mathrm{X}$ & & & \\
\hline 208 & $\begin{array}{l}\text { Surgeries, for which specific equipment with limited availability is required (e.g. gammaprobe, } \\
\text { lonestar, saw, drill ) cannot be performed at the same time and/or at a specified maximum number of } \\
\text { times a day. }\end{array}$ & $\mathrm{x}$ & & & & & & & & $\mathrm{R}$ & & $\mathrm{R}$ & & & $\mathrm{x}$ & & \\
\hline 209 & The surgery for patients who have had a miscarriage are planned as soon as possible. & & & & & & & & & & & $R$ & 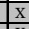 & $\frac{x}{x}$ & & & \\
\hline 210 & Patients in a dental treatment process are operated as soon as the braces are removed. & 1 & & & & & & & & & & $\mathrm{R}$ & $\mathrm{x}$ & $\mathrm{x}$ & & & \\
\hline 211 & $\begin{array}{l}\text { When surgery on two eyes must be performed at different times, there must be four weeks between the } \\
\text { first and the second surgery. }\end{array}$ & & & & 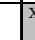 & $\bar{x}$ & & & & $\mathrm{R}$ & & $\mathrm{R}$ & & $\mathrm{x}$ & & & \\
\hline 212 & $\begin{array}{l}\text { Surgeries for which Radiology is required are not planned before 8:30 am because the Radiology } \\
\text { Department starts working at 8:30 am. }\end{array}$ & $\mathrm{x}$ & & & & & & & & $\mathrm{R}$ & & $\mathrm{R}$ & & $\mathrm{x}$ & & & \\
\hline 213 & $\begin{array}{l}\text { When a different medical specialty uses the afternoon OR session, the medical specialty using the } \\
\text { morning session has to be finished strictly at 12:30 pm. }\end{array}$ & $\mathrm{x}$ & & & & & & & & & & $\mathrm{R}$ & & $\mathrm{x}$ & & & \\
\hline 214 & $\begin{array}{l}\text { Patients undergoing specified surgery types need be researched or prepared before surgery can take } \\
\text { place (e.g. dental imprints, scintigraphy, urine or blood tests etc.). This has to be accounted for when } \\
\text { scheduling the surgery. }\end{array}$ & & $\mathrm{x} \mid \mathrm{x}$ & & s & $\mathrm{x}$ & & & $\mathrm{x}$ & $\mathrm{R}$ & & $\mathrm{R}$ & & $\mathrm{x}$ & & & \\
\hline 215 & Patients should be admitted to the hospital at least two hours before surgery. & $\mathrm{x}$ & & & & & & & & $\mathrm{R}$ & & $\mathrm{R}$ & & $\mathrm{x}$ & & & \\
\hline 216 & $\begin{array}{l}\text { Patients receiving a block should be admitted to the hospital at least two and a half hours before } \\
\text { surgery. }\end{array}$ & $\mathrm{x}$ & & & & & & & & & & $\mathrm{R}$ & & $\mathrm{x}$ & & & \\
\hline 217 & Children should be admitted to the hospital at least 1 hour before surgery. & $|\mathrm{x}|$ & & & & & & & & & & $\mathrm{R}$ & & $\mathrm{X}$ & & & \\
\hline \multicolumn{18}{|c|}{ Surgery time } \\
\hline 218 & $\begin{array}{l}\text { The surgery time is proposed by the HIS and is based on the last } 25 \text { times that the specific surgeon has } \\
\text { performed this surgery type. }\end{array}$ & $\mathrm{x}$ & & & & & & & & & $\mathrm{R}$ & & & & $\mathrm{x}$ & & \\
\hline 219 & The proposed surgery time may be changed by the surgeon or outpatient secretary. & $\mathrm{x}$ & & & & & & & & & $\mathrm{O}$ & $\mathrm{R}$ & & & & & \\
\hline 220 & $\begin{array}{l}\text { The surgery time depends on the surgical technique, anesthesia method, what is to be done in the } \\
\text { surgery (e.g. one eye/two eyes, one finger/multiple fingers etc.) and the condition of the patient, the } \\
\text { work pace of the surgeon. }\end{array}$ & $\mathrm{x}$ & & & & & & & & & & $\mathrm{R}$ & $\mathrm{x}$ & & & & \\
\hline 221 & $\begin{array}{l}\text { The surgical technique of individual surgeons may vary for one surgery type and this has to be } \\
\text { accounted for when registering the surgery time. }\end{array}$ & $\mathrm{x}$ & & & & & & & & & & $\mathrm{R}$ & $\mathrm{x}$ & & & $\mathrm{x}$ & \\
\hline 222 & The anesthesia method impacts the surgery time. & $\mathrm{x}$ & & & & & & & & & & $\mathrm{R}$ & $\mathrm{x}$ & & & & \\
\hline 223 & $\begin{array}{l}\text { Anesthesia method depends on the surgeon who performs the surgery, the patient's preference and/or } \\
\text { the anesthesiologist's orders. }\end{array}$ & $\mathrm{x}$ & & & & & & & & & & $\mathrm{R}$ & & & & & \\
\hline \multirow{2}{*}{\multicolumn{18}{|c|}{\begin{tabular}{|l} 
Order of surgeries \\
224 The order in which surgeries are planned is determined by the OTC capacity planner.
\end{tabular}}} \\
\hline & The order in which surgeries are planned is determined by the OTC capacity planner. & $\mathrm{x}$ & & & & & & & & & & $\mathrm{R}$ & & $\mathrm{x}$ & & & \\
\hline 225 & For children, the order in which surgeries are planned is determined by the Pediatric Daycare. & $\mathrm{x}$ & & & & & & & & & & $\mathrm{R}$ & & $\mathrm{x}$ & & & \\
\hline 226 & Surge & $\mathrm{x}$ & & & & & & & & $\mathrm{R}$ & & & & $\mathrm{x}$ & & & \\
\hline 227 & Patients who receive a block as anesthesia, are scheduled preferably after 9:30 am. & $\mathrm{x}$ & & & & & & & & $\mathrm{R}$ & & & $\mathrm{x}$ & $\mathrm{x}$ & & & \\
\hline 228 & Surgeries of children are scheduled for early in the day. & $\mathrm{x}$ & & & & & & & & $\mathrm{R}$ & & & & $\mathrm{x}$ & & & \\
\hline 229 & MRSA-infected patients are scheduled for the end of the day. & $\mathrm{x}$ & & & & & & & & $\mathrm{R}$ & & & & $\mathrm{x}$ & & & \\
\hline 230 & Lengthy surgeries are preferably scheduled for the start of the day and shorter surgeries at the end. & $\mathrm{x}$ & & & & & & & & $\mathrm{R}$ & & & $\mathrm{x}$ & $\mathrm{x}$ & & & \\
\hline 231 & Surgeries for which the patient's body is marked are not scheduled for early in the day. & $\mathrm{x}$ & & & & & & & & $\mathrm{R}$ & & & & $\mathrm{x}$ & & & \\
\hline 232 & Patients who require intensive care are not scheduled as the first patients in the OTC program. & $\mathrm{x}$ & & & & & & & & $\mathrm{R}$ & & & & $\mathrm{x}$ & & & \\
\hline 233 & Patients with a latex allergy are preferable scheduled for early in the day. & $\mathrm{x}$ & & & & & & & & $\mathrm{R}$ & & & & $\mathrm{x}$ & & & \\
\hline $\begin{array}{lll}234 & \end{array}$ & Patients who require an INR value test are preferably not scheduled for early in the day. & $|x|$ & & & & & & & & R & & & $\bar{x}$ & $\mathrm{x}$ & & & \\
\hline 235 & Oral diabetes patients are preferably scheduled for early in the day. & $\mathrm{x}$ & & & & & & & & $\mathrm{R}$ & & & $\mathrm{x}$ & $\mathrm{x}$ & & & \\
\hline 236 & $\begin{array}{l}\text { Insuline diabetes patients have to be admitted before 8:30 am, not scheduled as a first patient, but } \\
\text { later in the morning. }\end{array}$ & $\mathrm{x}$ & & & & & & & & $\mathrm{R}$ & & & & $\mathrm{x}$ & & & \\
\hline 237 & Ureterorenoscopy surgeries should be scheduled from 9:30 am, in case an X-ray has to be made. & $\mathrm{x}$ & & & & & & & & $\mathrm{R}$ & & & & $\mathrm{x}$ & & & \\
\hline 238 & $\begin{array}{l}\text { Sentinel node procedures are scheduled in the morning, apart from the sentinel node surgeries in OR } 8 \\
\text { and } 9 \text {. }\end{array}$ & $\mathrm{x}$ & & & & & & & & $\mathrm{R}$ & & & & $\mathrm{x}$ & & & \\
\hline 239 & Patients with contact isolation are preferably scheduled for the end of the day. & $\mathrm{x}$ & & & & & & & & $\mathrm{R}$ & & & $\mathrm{x}$ & $\mathrm{x}$ & & & \\
\hline 240 & Carotis procedures are not scheduled for the start of the day. & $\mathrm{x}$ & & & & & & & & $\mathrm{R}$ & & & & $\mathrm{x}$ & & & \\
\hline 241 & $\begin{array}{l}\text { Small standard surgeries are scheduled between the morning and afternoon session in order to control } \\
\text { variation for the entire day program. }\end{array}$ & $\mathrm{x}$ & & & & & & & & & & $\mathrm{R}$ & & $\mathrm{x}$ & & & \\
\hline
\end{tabular}




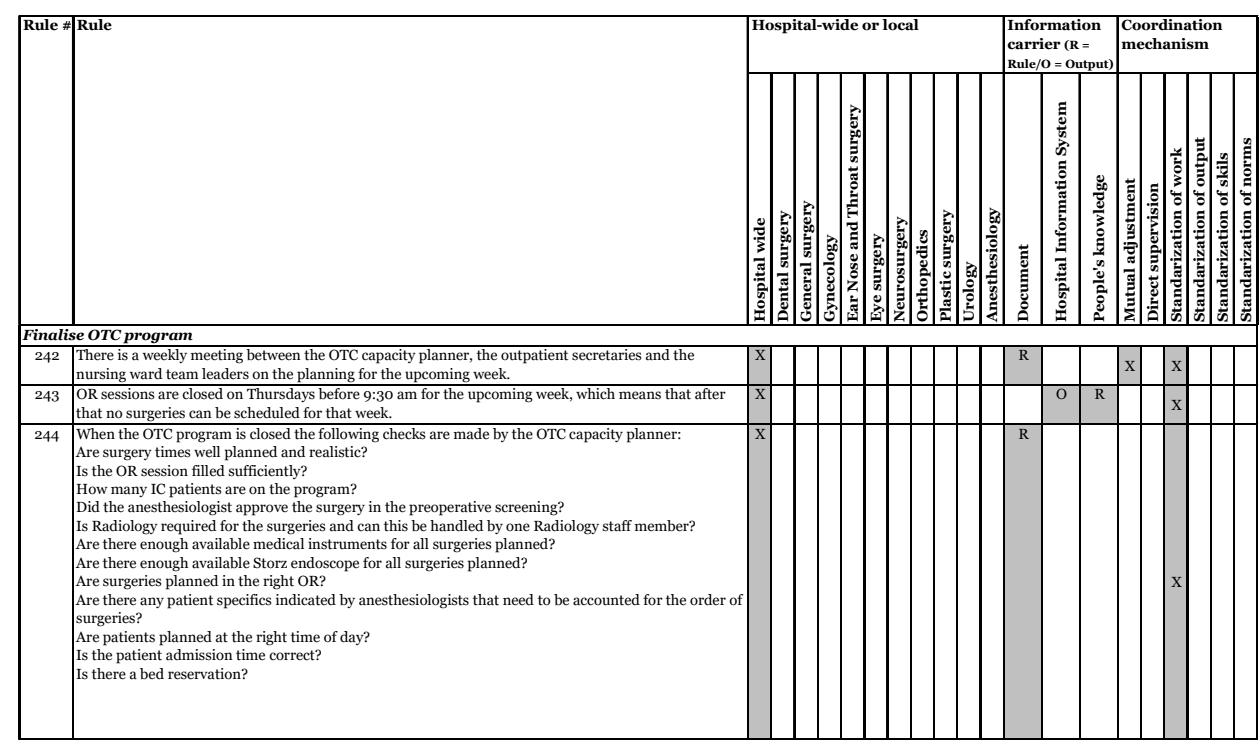




\section{Tasks 14,15,17,20,21 and 22: Prepare patient on ward, holding, perform surgery and aftercare on recovery and nursing ward, control OTC program}

Task description

\author{
14)
}

The patient is admitted to one of the nursing wards. The nurse anesthetist then calls the nurse to indicate that premedication should be given to the patient, mostly two hours before the expected starting time of the surgery. The nurse anesthetist makes a second call to the nurse to say that the patient is to be taken to holding area.

15) The ward nurse hands the patient over to one of the holding nurses. The holding nurse prepares the patient for surgery. When it is time to go to the OR, the nurse anesthetist enters the holding area and the holding nurse hands the patient over to the nurse anesthetist.

17) The nurse anesthetist mentions any relevant details about the patient to the rest of the OR team. The anesthesiologist administers anesthetics prior to the surgery and leaves once the patient is asleep. The surgery is performed by the surgeon, assisted by the OR nurses. The nurse anesthetist monitors the patient and calls the anesthesiologist if necessary.

20) After surgery the patient is transferred to recovery by the nurse anesthetist. The transfer is performed between the nurse anesthetist and the recovery nurse. The recovery nurses interact with the anesthesiologists regarding the medication policy if necessary.

22) There are several tasks, performed at various moments in time, making sure that the surgeries that are scheduled for one day are performed well and on time. There is daily start of day meeting between the OTC day coordinator and the three OTC team leaders, in which expectations and special surgeries are discussed. During the course of the day the OTC day coordinator monitors the progress of each OR. The OTC day coordinator communicates with the anesthesiologist or surgeons about any alterations required in the OR scheme.

$\begin{array}{lll}\text { Time } & \text { All } & \text { Day of surgery } \\ \text { horizon } & \text { tasks) }\end{array}$

Frequency All Daily tasks) 
Interactions

\begin{tabular}{|c|c|c|c|c|c|c|c|c|c|c|c|c|c|c|c|}
\hline & $\begin{array}{l}\text { Number of } \\
\text { agents } \\
\text { involved }\end{array}$ & 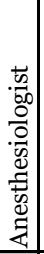 & 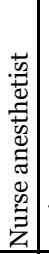 & 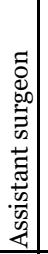 & 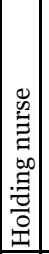 & 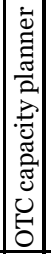 & 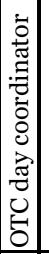 & 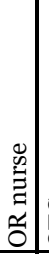 & 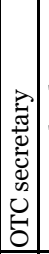 & 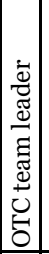 & 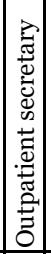 & 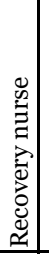 & \begin{tabular}{|c|} 
\\
\\
0 \\
0 \\
0 \\
0 \\
$\vdots$ \\
0 \\
0 \\
\end{tabular} & 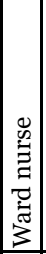 & 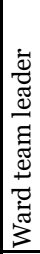 \\
\hline Anesthesiologist & 12 & $\mathrm{X}$ & \begin{tabular}{|l|l}
$\mathrm{X}$ & \\
\end{tabular} & $\mathrm{X}$ & & & $\mathrm{X}$ & $\mathrm{X}$ & & & & $\mathrm{X}$ & $\mathrm{X}$ & & \\
\hline Nurse anesthetist & 19 & & \begin{tabular}{l|l}
$\mathrm{X}$ \\
\end{tabular} & \begin{tabular}{|l|l}
$\mathrm{X}$ & \\
\end{tabular} & $\mathrm{X}$ & & \begin{tabular}{|l|}
$\mathrm{X}$ \\
\end{tabular} & $\mathrm{X}$ & & & & $\mathrm{X}$ & $\mathrm{X}$ & $\mathrm{X}$ & \\
\hline Assistant surgeon & 14 & & & & & & & $\mathrm{X}$ & & & & & $\mathrm{X}$ & & \\
\hline Holding nurse & 4 & & & & $\mathrm{X}$ & & & & & & & & & $\mathrm{X}$ & \\
\hline OTC capacity planner & 1 & & & & & & $\mathrm{X}$ & & & & & & & & $\mathrm{X}$ \\
\hline OTC day coordinator & 1 & & & & & & & $\mathrm{X}$ & $\mathrm{X}$ & $\mathrm{X}$ & $\mathrm{X}$ & $\mathrm{X}$ & $\mathrm{X}$ & & \\
\hline OR nurse & 51 & & & & & & & $\mathrm{X}$ & & & & & $\mathrm{X}$ & & \\
\hline OTC secretary & 1 & & & & & & & & & & & & & & \\
\hline OTC team leader & 3 & & & & & & & & & $\mathrm{X}$ & & & & & \\
\hline Outpatient secretary & 34 & & & & & & & & & & & & & & \\
\hline Recovery nurse & 10 & & & & & & & & & & & $\mathrm{X}$ & & $\mathrm{X}$ & \\
\hline Surgeon & 48 & & & & & & & & & & & & & $\mathrm{X}$ & \\
\hline Ward nurse & 288 & & & & & & & & & & & & & $\mathrm{X}$ & $\mathrm{X}$ \\
\hline Ward team leader & 3 & & & & & & & & & & & & & & $\mathrm{X}$ \\
\hline
\end{tabular}




\section{Rules for task performance}

\begin{tabular}{|c|c|c|c|c|c|c|c|c|c|c|c|c|c|c|c|c|c|c|c|}
\hline \multirow[t]{2}{*}{ Rule \# } & \multirow[t]{2}{*}{ Rule } & \multicolumn{9}{|c|}{ Hospital-wide or local } & \multicolumn{3}{|c|}{\begin{tabular}{|l|} 
Information \\
carrier ( $=$ \\
Rule/O= Output)
\end{tabular}} & \multicolumn{6}{|c|}{$\begin{array}{l}\text { Coordination } \\
\text { mechanism }\end{array}$} \\
\hline & & 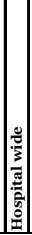 & 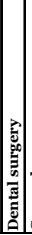 & 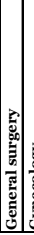 & 递 & 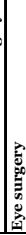 & & 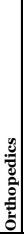 & 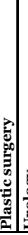 & 要 & : & 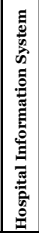 & 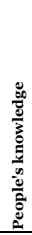 & & 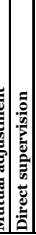 & 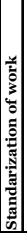 & 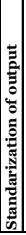 & 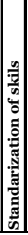 & क्ञّ \\
\hline \multicolumn{20}{|c|}{\begin{tabular}{|l|} 
Time Out Procedure \\
\end{tabular}} \\
\hline 245 & $\begin{array}{l}\text { Each step in the patient process is performed according to the Time Out Procedure (TOP). In the TOP } \\
\text { standard procedures and required outcomes are specified in order for the patient to proceed to the } \\
\text { next (sub)process. }\end{array}$ & $\mathrm{x}$ & & & & & & & & & & $\mathrm{R}$ & & & & $\mathrm{x}$ & $\mathrm{X}$ & & \\
\hline 246 & Approval of surgeon & $\mathrm{x}$ & & & & & & & & & & $\mathrm{R}$ & & & & $\mathrm{x}$ & $\mathrm{X}$ & & \\
\hline 247 & Nurse intake & $\mathrm{x}$ & & & & & & & & & & $\mathrm{R}$ & & & & $\mathrm{x}$ & $\mathrm{x}$ & & \\
\hline 248 & Approval of anesthesiologist & $\mathrm{x}$ & & & & & & & & & & $\mathrm{R}$ & & & & $\mathrm{x}$ & $\mathrm{x}$ & & \\
\hline 249 & Release OTC planning & $\mathrm{x}$ & & & & & & & & & & $\mathrm{R}$ & & & & $\mathrm{x}$ & $\mathrm{x}$ & & \\
\hline 250 & Admission to nursing department & $\mathrm{x}$ & & & & & & & & & & $\mathrm{R}$ & & & & $\mathrm{x}$ & $\mathrm{x}$ & & \\
\hline 251 & Sign in part 1 & $\mathrm{x}$ & & & & & & & & & & $\mathrm{R}$ & & & & $\mathrm{x}$ & $\mathrm{x}$ & & \\
\hline 252 & Sign in part 2 & $\mathrm{x}$ & & & & & & & & & & $\mathrm{R}$ & & & & $\mathrm{x}$ & $\mathrm{x}$ & & \\
\hline 253 & Pre-time out procedure in recovery & $\mathrm{x}$ & & & & & & & & & & $\mathrm{R}$ & & & & $\mathrm{x}$ & 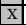 & & \\
\hline 254 & Time out in the Operating Room & $\mathrm{x}$ & & & & & & & & & & $\mathrm{R}$ & & & & $\mathrm{x}$ & $\mathrm{x}$ & & \\
\hline 255 & Sign out in the Operating Room & $\mathrm{x}$ & & & & & & & & & & $\mathrm{R}$ & & & & $\mathrm{x}$ & $\mathrm{x}$ & & \\
\hline 256 & Sign in at recovery & $\mathrm{x}$ & & & & & & & & & & $\mathrm{R}$ & & & & $\mathrm{x}$ & $\mathrm{x}$ & & \\
\hline 257 & Check out of recovery & $\mathrm{x}$ & & & & & & & & & & $\mathrm{R}$ & & & & $\mathrm{x}$ & $\mathrm{x}$ & & \\
\hline 258 & Checklist in nursing department by surgeon & $\mathrm{x}$ & & & & & & & & & & $\mathrm{R}$ & & & & $\mathrm{x}$ & $\mathrm{x}$ & & \\
\hline 259 & Checklist in nursing department by nurse. & $\mathrm{x}$ & & & & & & & & & & $\mathrm{R}$ & & & & $\mathrm{x}$ & $\mathrm{x}$ & & \\
\hline 260 & $\begin{array}{l}\text { In the TOP for each step, all requirements that need to be met and checks that need to be performed } \\
\text { are specified. }\end{array}$ & $\mathrm{x}$ & & & & & & & & & & $\mathrm{R}$ & & & & $\mathrm{x}$ & $\mathrm{x}$ & & \\
\hline \multicolumn{20}{|c|}{ Prepare the patient on the ward } \\
\hline 261 & $\begin{array}{l}\text { The ward nurse prepares the patient for the holding area and makes sure that the patient is ready on } \\
\text { time. }\end{array}$ & $\mathrm{x}$ & & & & & & & & & & & $\mathrm{R}$ & & & $\mathrm{x}$ & $\mathrm{X}$ & & \\
\hline 262 & Ward nurses are allocated to specific rooms of patients. & & $\mathrm{x}$ & & & & & & & & & & $\mathrm{R}$ & & & $\mathrm{x}$ & & & \\
\hline 263 & Patients who receive a block go to the recovery area and not to holding. & $\mathrm{x}$ & & & & & & & & & $\mathrm{R}$ & & & & & $\mathrm{x}$ & & & \\
\hline 264 & The ward nurse who takes the patient to the holding performs the TOP procedure with a holding nurse. & $\mathrm{x}$ & & & & & & & & & & $\mathrm{O}$ & $\mathrm{R}$ & & & $\mathrm{x}$ & & & \\
\hline 265 & Emergency patients are admitted to the Acute Admissions Department. & $\mathrm{x}$ & & & & & & & & & & & $\mathrm{R}$ & & & $\mathrm{x}$ & & & \\
\hline 266 & $\begin{array}{l}\text { If a patient in the Emergency Department is operated on within half an hour, then the patient goes } \\
\text { directly from the Emergency Department to the OTC. }\end{array}$ & $\mathrm{x}$ & & & & & & & & & & & $\mathrm{R}$ & $\mathrm{X}$ & & $\mathrm{x}$ & & & \\
\hline 267 & The nurse anesthetist tells the ward nurse when to administer premedication with the patient. & $\mathrm{x}$ & & & & & & & & & & & $\bar{R}$ & $\mathrm{x}$ & & $\mathrm{x}$ & & & \\
\hline 268 & The nurse anesthetist tells the ward nurse when to take the patient to the OTC. & $\mathrm{x}$ & & & & & & & & & & & $\mathrm{R}$ & $\mathrm{x}$ & & $\mathrm{x}$ & & & \\
\hline 269 & Ward nurses serve each other's patients when this supports the flow of patients. & 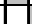 & $\mathrm{x}$ & & & & & & & & & & $\mathrm{R}$ & $\mathrm{x}$ & & & & & \\
\hline 270 & Ward nurses ask another ward nurse to check the medication that they administer to the patient. & $\mathrm{x}$ & & & & & & & & & & & $\mathrm{R}$ & $\mathrm{x}$ & & $\mathrm{x}$ & & & \\
\hline 271 & $\begin{array}{l}\text { If blood needs to be taken from the patient before surgery, the patient is sent to the lab. When the } \\
\text { patient is not in a well enough state, the lab technician is asked to come to the nursing ward. }\end{array}$ & & $\mathrm{x}$ & & & & & & & & & & $\bar{R}$ & $\mathrm{x}$ & & $x \mid$ & & & \\
\hline \multicolumn{19}{|c|}{\begin{tabular}{|l|} 
Prepare the patient in the holding \\
\end{tabular}} & \\
\hline 272 & The holding nurse prepares the patient for surgery and makes sure that the patient is ready on time. & $\mathrm{x}$ & & & & & & & & & & & $\bar{R}$ & & & & $\mathrm{x}$ & & \\
\hline 273 & $\begin{array}{l}\text { Holding nurses insert patients with puncture drips, except when it is busy. Then this is done by the } \\
\text { nurse anesthetist. }\end{array}$ & & & $\mathrm{x}$ & & & & & & & & & $\mathrm{R}$ & $\mathrm{x}$ & & & $\mathrm{x}$ & & \\
\hline 274 & Nursing staff from outside the holding assist holding nurses at the start of the day, when it is busy. & & & $\mathrm{x}$ & & & & & & & & & $\mathrm{R}$ & $\mathrm{x}$ & & & & & \\
\hline 275 & There are standard procedures for preparing equipment, materials and medication. & & & $\mathrm{x}$ & & & & & & & $\mathrm{R}$ & & & & & $\mathrm{x}$ & & & \\
\hline 276 & $\begin{array}{l}\text { There are standard procedures per anesthesia method on what patients are allowed to wear, e.g. } \\
\text { glasses, make-up etc. }\end{array}$ & $\mathrm{x}$ & & & & & & & & & $\mathrm{R}$ & & & & & & $\mathrm{x}$ & & \\
\hline 277 & $\begin{array}{l}\text { The nurse anesthetist who takes the patient from the holding area to the OR performs the TOP } \\
\text { procedure with a holding nurse. }\end{array}$ & $\mathrm{x}$ & & & & & & & & & & & $\mathrm{R}$ & & & $\mathrm{x}$ & & & \\
\hline 278 & The nurse anesthetist stays with the patient from holding to recovery. & $\mathrm{x}$ & & & & & & & & & & & $\mathrm{R}$ & & & $\mathrm{x}$ & & & \\
\hline \multicolumn{19}{|c|}{\begin{tabular}{|l|} 
Perform surgery \\
\end{tabular}} & \\
\hline 279 & The surgeon is responsible for the surgery and determines when to start and end with the surgery. & $\mathrm{x}$ & & & & & & & & & & & $\mathrm{R}$ & & & & & $\mathrm{x}$ & \\
\hline 280 & $\begin{array}{l}\text { The anesthesiologist is responsible for the anesthesia and determines when to start and end anesthesia } \\
\text { and any medication during the surgery. }\end{array}$ & $\mathrm{x}$ & & & & & & & & & & & $\bar{R}$ & & & & & $\mathrm{x}$ & \\
\hline 281 & The OR nurse assists the surgeon. & $\mathrm{x}$ & & & & & & & & & & & $\mathrm{R}$ & & & & & $\mathrm{x}$ & \\
\hline 282 & $\begin{array}{l}\text { The nurse anesthetist assists the anesthesiologist and is responsible for monitoring the patient during } \\
\text { surgery, informing the anesthesiologist on this. }\end{array}$ & $\mathrm{x}$ & & & & & & & & & & & $\mathrm{R}$ & $\mathrm{x}$ & & & & $\mathrm{x}$ & \\
\hline 283 & All checks of the TOP are performed with all members of the operating team and the patient. & $\mathrm{x}$ & & & & & & & & & & $\mathrm{R}$ & & $\mathrm{x}$ & & $\mathrm{x}$ & $\mathrm{x}$ & & \\
\hline 284 & $\begin{array}{l}\text { In case x-ray photos are taken during surgery, the OTC day coordinator or OTC secretary asks the } \\
\text { Radiology Department to send someone to the OTC. }\end{array}$ & & & & $\bar{x}$ & & & & & & & & $\mathrm{R}$ & $\mathrm{x}$ & & & & & \\
\hline
\end{tabular}




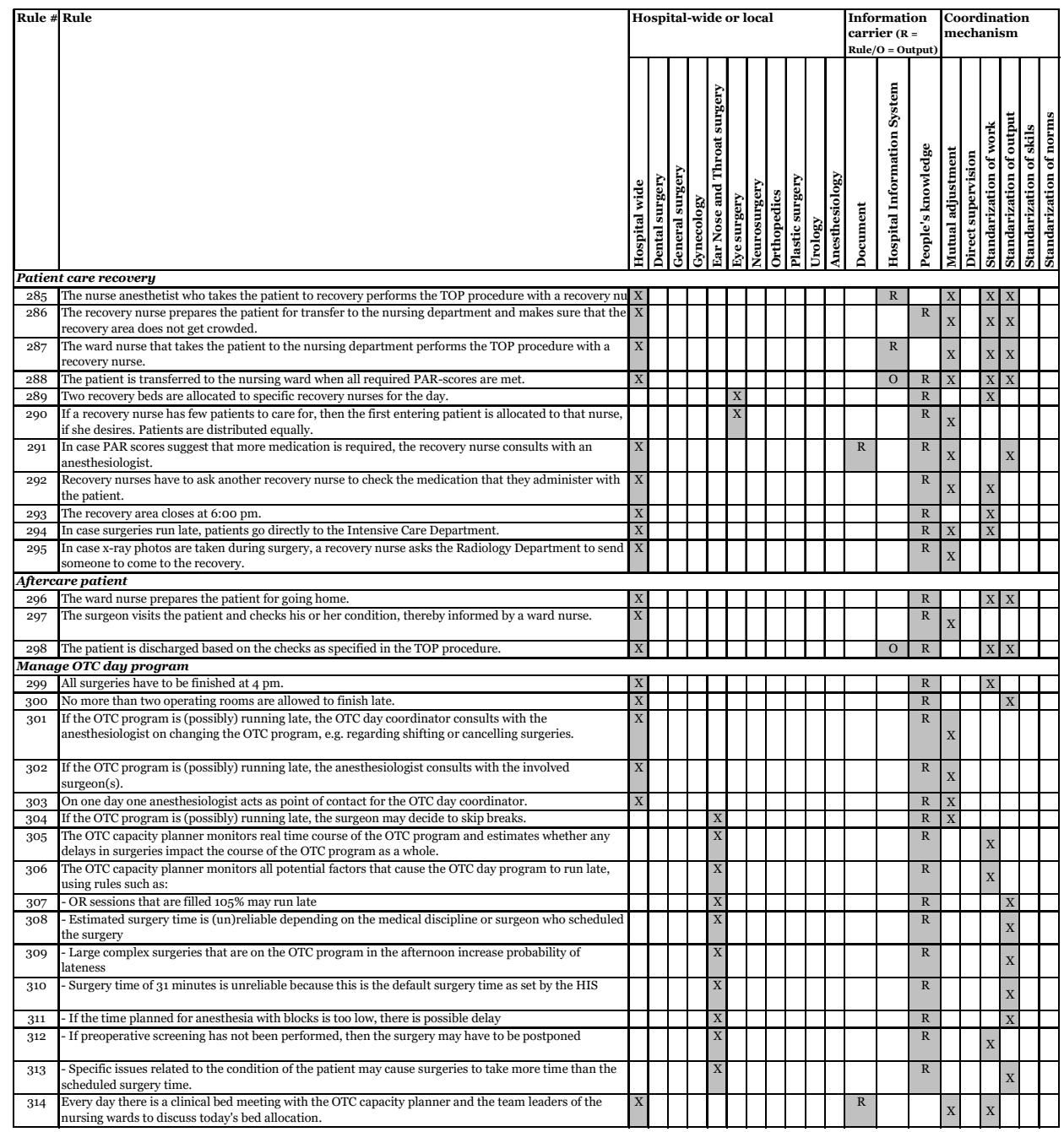





\section{CHAPTER 5}

EVALUATING CHANGES IN INTEGRATION, DIFFERENTIATION, RULES, COORDINATION AND PERFORMANCE FOLLOWING THE INTRODUCTION OF AHOSPITAL PLANNING CENTRE: A CASE STUDY

Annelies van der Ham, Arno van Raak, Dirk Ruwaard, Frits van Merode Submitted 


\section{ABSTRACT}

\section{Purpose}

This study evaluates changes in a hospital with regard to integration, i.e. the coordination and alignment of tasks - and differentiation, i.e. the extent to which tasks are segmented into subsystems, rules and coordination mechanisms - and hospital performance following the introduction of a Hospital Planning Centre (HPC).

\section{Design/methodology/approach}

A case study was conducted in which a hospital's social network, rules, coordination mechanisms and performance were studied both before and after the HPC was introduced. All planning and execution tasks for surgery patients were studied, using a naturalistic inquiry and mixed method approach.

\section{Findings}

Following the introduction of the HPC, bed utilization increased with peak utilization of beds and operating rooms decreasing, increases in the waiting list, in cancellations and in variability. More integration was observed for specific planning tasks, but not for the hospital network as a whole. Differentiation based on medical discipline remained. More hospital-wide and fewer local rules exist and these have remained largely undocumented, i.e. in people's minds. Coordination mechanisms both before and after the introduction of the HPC are mainly mutual adjustment and standardization of work. For performance enhancement, the authors propose system-wide horizontal coordination that includes collective learning and information sharing.

\section{Originality}

This exploratory study describes how a hospital network's structure, rules, coordination mechanisms and performance change following the introduction of a HPC. The findings are important for future research on enhancing hospital performance. 


\section{INTRODUCTION}

Integration in organizations, i.e. the coordination and alignment of tasks, is widely promoted in order to improve hospital performance ${ }^{1-3}$. There is consensus that concepts such as supply chain management, lean strategies and other operations management theories can contribute to the improvement of hospital performance ${ }^{4-10}$. This is considered important to meet a broadly felt need to improve the quality, accessibility and affordability of healthcare systems ${ }^{5}$ and of hospitals in particular, given the fact that hospitals are a major cost item in the healthcare system ${ }^{11}$.

A previous scoping study ${ }^{12}$ showed that research on logistics and operations in hospitals is fragmented. Studies typically focus on one or two logistical parameters, specific logistical flows (patients, material or staff) or on specific departments, but not on the hospital as a whole. This may be problematic, as Ludwig et al. ${ }^{8}$ found evidence that in well-performing hospitals, departments cooperate for the benefit of the hospital's efficiency, while efficient departments by themselves do not necessarily contribute to the overall efficiency of the hospital.

Lawrence and Lorsch ${ }^{13}$ state that not only is integration important, but also that differentiation is essential in order for integration to be effective. They define integration as 'achieving unity of effort among the various subsystems in the accomplishment of the organization's task'13. Differentiation refers to 'the state of segmentation of the organizational system into subsystems' ${ }^{13}$. From this perspective, well-performing hospitals in which departments cooperate well are likely to have the right degree of integration as well as differentiation in place.

In previous case studies integration and differentiation were investigated in a hospital 14-15. These case studies showed that tasks are performed mainly across functional silos and that nurses, physicians and coordinators perform integrative tasks. In addition, rules that are used by agents exist predominantly in people's minds. Coordination mainly takes place through mutual adjustment and local standardization of work, as defined by Mintzberg ${ }^{16}$. Long-term schedules for surgeries create open loops ${ }^{17}$, as resources and patients are not scheduled based on actual or future patient demand, potentially causing the system to become unstable. As the surgery date approaches, several agents in the hospital try to close these loops through mutual adjustment, thereby stabilizing the hospital system. 
In our case studies, the observed ways of working seem to have emerged as a result of an individual agent's action rather than from an explicit organizational design. Central agents coordinate tasks without having a formal hierarchical position towards others and their actions are based mostly on undocumented working procedures. In line with Ren et al. ${ }^{18}$, the way of working observed may result in vulnerability and potential instability in the hospital's performance, leading to critical events. The hospital where our case studies took place, Slingeland Hospital in the Netherlands, had similar concerns, and decided in 2019 to change the way in which surgeries are planned. Since 1 June 2019 a Hospital Planning Centre (HPC) has been responsible for planning surgeries and beds for surgery patients. Before 1 June 2019 surgeries were planned by secretaries in outpatient departments, which are differentiated according to medical disciplines.

Understanding how a hospital's logistical system works in practice is a first and necessary step towards improving the way hospitals function. This organizational change provides us with the opportunity to explore further how integration, differentiation and coordination mechanisms relate to hospital performance. A most obvious and highly relevant question is whether the introduction of the HPC improved the hospital's performance. As suggested by Van der Ham et al. ${ }^{15}$, creating redundancy in the network may increase the robustness of the hospital, in which case interaction patterns and the related information processing will have changed. In line with Galbraith ${ }^{19}$, who relates integration to the information processing capacity of an organization, the introduction of the HPC may have changed the degree of integration, differentiation, and the performance of the hospital. On the other hand, as stated by Van der Ham et al. ${ }^{15}$, any intervention may also destabilize the hospital, in which case the performance also changes, but not for the better.

Accordingly, our aim is to evaluate whether the hospital's social network structure, coordination mechanisms and performance have changed following introduction of the HPC. There are three research questions:

1. Did the hospital's network structure, i.e. integration and differentiation, change following the introduction of the HPC and if so, in what way?

2. Did the rules and coordination mechanisms that explain the network structure change following the introduction of the HPC and if so, in what way?

3. Can changes in the system's performance be observed following the introduction of the HPC? 


\section{METHODS}

\section{Setting}

This study is the third case study in Slingeland Hospital, which is situated in Doetinchem in the Netherlands. Slingeland Hospital was selected for the previous two case studies because of its relatively small size, highly rated performance ${ }^{20}$ and stable environment. Slingeland Hospital has around 1,600 staff members and 120 physicians. It services around 200,000 people in the area and has 350 beds, which is below the average number of 450 beds for Dutch hospitals ${ }^{21}$.

In 2018 Slingeland Hospital set up the 'Integral Capacity Management' (ICM) program. This program envisages the integral design, planning, management and safeguarding of all care-related critical capacities, i.e. time, people, space, and resources, in order to achieve the desired quality, efficiency and service levels ${ }^{22}$. In accord with this program the HPC started on 1 June 2019, and is ongoing. The HPC was a new department, with six central planners who are responsible for planning surgeries and beds for surgery patients. Five planners were former outpatient secretaries and one planner who had not previously worked for Slingeland Hospital was hired. Since July 2020 the ICM program has been converted to a more permanent form, the ICM department. The HPC is part of this department.

Not all surgeries are planned by the HPC. The HPC plans all elective and semi-urgent surgeries that are performed under general anesthesia. This excludes all eye surgeries and a part of the gynaecology surgeries, because these are often performed under local anesthesia. Urgent surgeries, which take place the same day, are planned by surgeons and secretaries of the outpatient departments, in direct contact with the Operating Theatre Complex (OTC).

\section{Design}

This study was designed to compare the network structure, the rules, coordination mechanisms and performance before and after the HPC was introduced. The before period was defined from 1 June 2018 to 13 March 2019 and the after period from 1 June 2019 to 13 March 2020. The date of 13 March was selected because from 13 March 2020 all but the most urgent surgeries were cancelled due to the Covid-19 pandemic. By choosing that date we exclude any potential impact of the pandemic from this study. In this paper we will refer to the two periods as the before period and the after period. 
In order to be able to compare the before period with the after period, the study design for the third case study is largely the same as for the previous two case studies. The main methods and concepts of the two previous case studies ${ }^{14-15}$ are summarized below.

The study design for both previous case studies was based on the case study research method devised by Yin $^{23}$ and a naturalistic inquiry approach as described by Beuving and De Vries ${ }^{24}$ was followed. Data were collected from multiple sources and then analysed through data triangulation following a mixed method approach. The study included all departments that contribute to either the intake, diagnosis, preparations, the surgery or the aftercare of surgery patients. In the second case study ${ }^{15}$ there was a particular focus on planning tasks $1,2,3,6$, and 11, and tasks related to coordinating the execution of surgery and the preparations and aftercare that surgery involves, these being tasks 14, 15, 17, 20, 21 and 22 (Figure 5.1).

Integration and differentiation were described using social network analysis to analyse the network structure in the first case study ${ }^{14}$. All interactions that agents have for performing tasks (Figure 5.1) were identified, registered in an Excel database per task and then inserted in NodeXL ${ }^{25}$. Specific measures of the social network that are related to integration and differentiation were analysed, both for the entire network and per task. Density, degree, betweenness centrality and clique overlap were used as indications for integration. A clique exists when all agents in a group are connected. There is clique overlap when agents are part of more than one clique, thereby connecting different cliques. Cliques were looked at for identifying differentiation, as groups of highly connected agents may indicate a division of labour. These measures are presented in Table 5.1.

The coordination mechanisms and rules that were studied in the second case study ${ }^{15}$ refer to the before period. The after period was analysed to determine whether a rule still exists or if any new rules were added, and abolished rules were registered. Coordination mechanisms were registered for each rule, based on Mintzberg ${ }^{26}$, as presented in Table 5.1 .

In addition the performance of the hospital was analysed for both the before and the after period. In summary, in this third case study all concepts as defined in Table 5.1 were studied for both the before and the after period, in order to evaluate changes following the introduction of the HPC. 


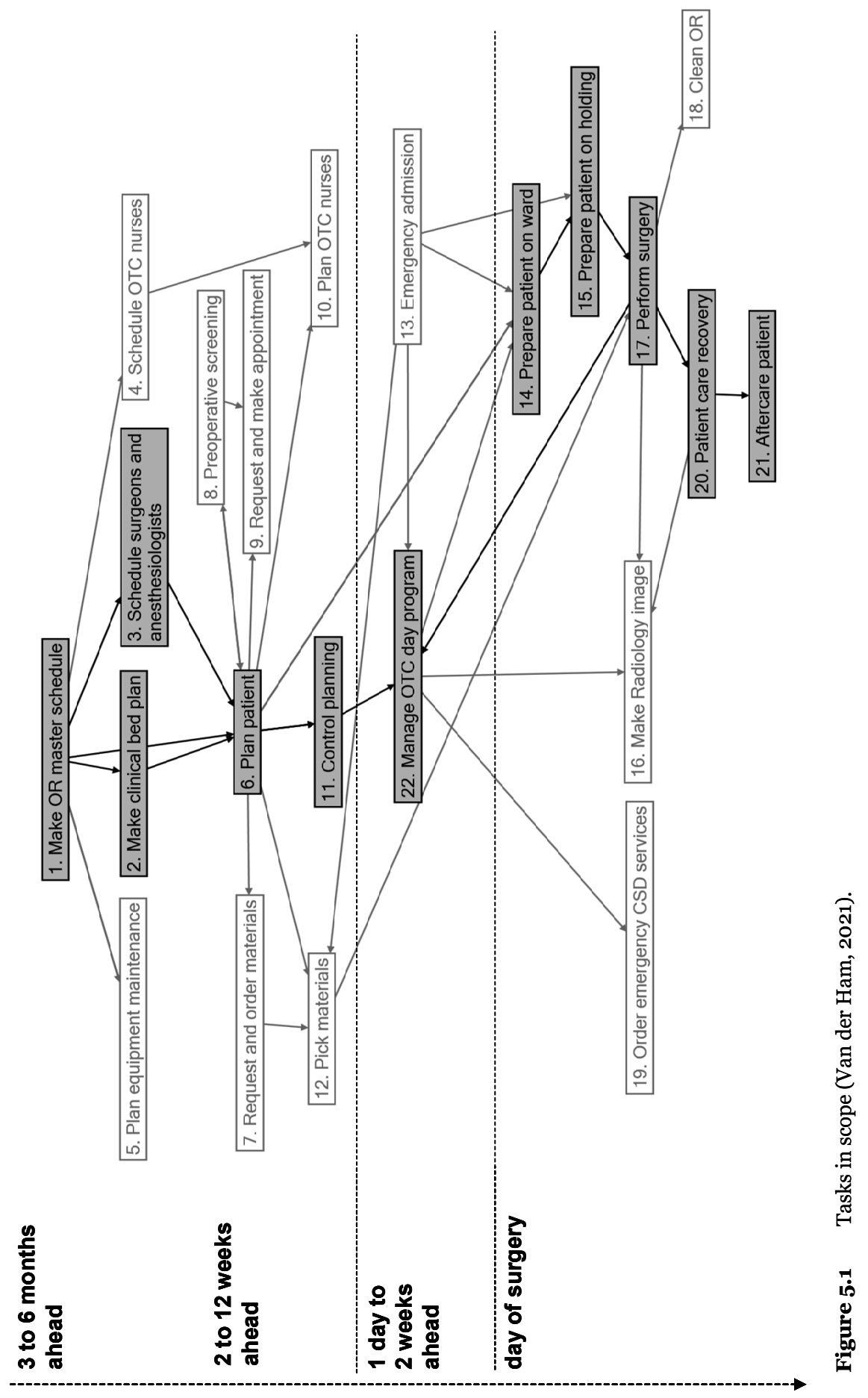


Table 5.1 Definition of concepts.

\begin{tabular}{|c|c|}
\hline Concept & Definition \\
\hline Integration & $\begin{array}{l}\text { The coordination and alignment of tasks, thus achieving 'unity } \\
\text { of effort among the various subsystems in the accomplishment } \\
\text { of the organization's task'13 }\end{array}$ \\
\hline Differentiation & $\begin{array}{l}\text { The 'state of segmentation of the organizational system into } \\
\text { subsystems'13 }\end{array}$ \\
\hline \multicolumn{2}{|l|}{ Social network analysis } \\
\hline Node & An agent \\
\hline Tie & $\begin{array}{l}\text { A communication link between two agents via email, text } \\
\text { message, telephone or face-to-face. }\end{array}$ \\
\hline Clique & A set of agents who are all connected to one another. \\
\hline Density & $\begin{array}{l}\text { The number of ties a set of agents has in relation to the } \\
\text { number of possible ties they can have. }\end{array}$ \\
\hline Clique overlap & $\begin{array}{l}\text { The percentage of agents who are members of more than one } \\
\text { clique for a specific task. }\end{array}$ \\
\hline Degree & The number of ties of one agent. \\
\hline Betweenness centrality & $\begin{array}{l}\text { The number of times a node (agent) lies on the shortest path } \\
\text { between other nodes (agents). }\end{array}$ \\
\hline \multicolumn{2}{|c|}{ Rules and coordination mechanisms } \\
\hline Rule & $\begin{array}{l}\text { A defined, accepted or agreed way of performing tasks, which } \\
\text { includes what is done, how it is done and what is allowed and } \\
\text { what is not allowed. }\end{array}$ \\
\hline Mutual adjustment & $\begin{array}{l}\text { An agent interacts with other agents about a rule, i.e. what it } \\
\text { entails or how to apply it in a specific situation or the } \\
\text { application of the rule requires interaction. }\end{array}$ \\
\hline Direct supervision & A rule is set and monitored by people with formal authority. \\
\hline Standardization of work processes & Rules result from specified or programmed working processes. \\
\hline Standardization of output & $\begin{array}{l}\text { Rules include specified output in terms of predetermined } \\
\text { standards for services or performance. }\end{array}$ \\
\hline Standardization of skills & Rules include specified skills and knowledge. \\
\hline Standardization of norms & $\begin{array}{l}\text { Rules result from a common culture or ideology and specify } \\
\text { norms for behaviour. }\end{array}$ \\
\hline \multicolumn{2}{|l|}{ Performance indicators } \\
\hline Patient inflow & The number of surgery orders within a specified period. \\
\hline Number of surgeries & The number of surgical cases performed. \\
\hline $\begin{array}{l}\text { Number of elective/non-elective } \\
\text { surgeries }\end{array}$ & The number of planned/(semi-)urgent surgeries. \\
\hline Surgery time & $\begin{array}{l}\text { The time between starting a surgery, i.e. when patient } \\
\text { positioning and/or skin preparation starts, to when the surgery } \\
\text { is completed. }\end{array}$ \\
\hline $\begin{array}{l}\text { Planned versus realized surgery } \\
\text { time }\end{array}$ & The difference between realized and planned surgery time. \\
\hline $\begin{array}{l}\text { Overutilization operating room } \\
\text { (OR) }\end{array}$ & $\begin{array}{l}\text { The total number of operating room days that finished after } 4 \\
\text { pm divided by the total number of regular operating room days } \\
\text { on which elective surgeries took place. }\end{array}$ \\
\hline Number of late operating rooms & The number of operating rooms that finish after $4 \mathrm{pm}$. \\
\hline Cancellations & The number of cancelled surgeries. \\
\hline Waiting list length & $\begin{array}{l}\text { Average number of weeks necessary for operating on all } \\
\text { patients on the waiting list, given the number of OR sessions } \\
\text { allocated to a medical discipline. }\end{array}$ \\
\hline
\end{tabular}


Table 5.1 (continued)

\begin{tabular}{ll}
\hline Concept & Definition \\
\hline OR session utilization & The total amount of time surgical patients are present in the \\
& OR, divided by the amount of allocated OR session time. An \\
& OR session is a time slot that is allocated to a specific medical \\
discipline on a specific weekday and OR. & The total amount of time surgical patients are present in the \\
& OR during regular working hours between 8 am - 4 pm, \\
OR utilization & divided by the total amount of OR time during these working \\
& hours (8 hours). \\
& The average number of beds used for a patient in a nursing \\
& department divided by the number of available beds. \\
Bed utilization & The number of beds in the nursing departments. \\
& The degree to which OR utilization deviates from the average \\
Number of beds & OR utilization. \\
Variability OR utilization & The degree to which OR session utilization deviates from the \\
Variability OR session utilization & average OR session utilization. \\
& The degree to which bed utilization deviates from the average \\
Variability bed utilization & bed utilization. \\
The degree to which waiting list length deviates from the
\end{tabular}

\section{Data collection}

Data were collected from four different sources: the Hospital Information System (HIS), documentation, observations and interviews. For the before period data were collected as described in the previous two case studies ${ }^{14-15}$. For the after period between June 2020 and October 2020 HIS data and documentation were collected specifically for this study. Observations and interviews took place between August 2020 and October 2020. Staff who were interviewed in the before period were also interviewed in the after period, as far as possible.

For the total study period between 1 June 2018 and 13 March 2020, HIS data include registrations of surgeries performed in 2018, 2019 and 2020, including date of surgery, resources involved, timestamps of different stages in the surgery patient's process, and in which nursing wards patients stayed before and after surgery. In total 72 documents were collected between 2018 and 2020, including project plans, management reports, planning schemes, working procedures, emails and internal presentations. Of 72 documents, 64 are dated in the before period and eight documents were made in the after period.

Planning and controlling activities were observed between 2018 and 2020 over 19 observation days. One observation day was in the after period and 18 in the before period, which includes four observation days between March 2019 and June 2019, when 
preparations for the HPC were made. The 19 observations took place, variously, in three outpatient departments, three nursing departments, the holding area, during three surgeries in the operating room (OR), in the recovery area, with the OTC day coordinator, in the preoperative screening department, during two planning meetings and twice at the workplace of two, at that moment in time, future central planners and at the HPC. During each observation, the activities of the hospital staff were observed and several unplanned informal conversations with staff took place, as they explained what tasks they performed. The sequence of events for each observation, together with relevant parts of the conversations, was reported in an observation report.

In the before period, between March 2018 and June 2019, 25 interviews were held with 23 different people. In the after period, between August 2020 and January 2021, 19 interviews were held with 19 different people. In total 14 people were interviewed in both the before and after periods. Two people were observed in the before period and interviewed in the after period. People who were interviewed only in the before period, were involved in tasks that are outside the scope of this study, but who were relevant to our earlier case study (Figure 5.1). People who were interviewed only in the after period were new to a function that was performed by another person in the before period. For each interview, a topic list was prepared, including questions on agents, interactions, rules, coordination and performance. All interviews were recorded and transcribed ad verbatim with the consent of the respondents.

\section{Data analysis}

The network structure, i.e. the agents and interactions between them, was constructed per task (Figure 5.1) in the same way as in the first case study ${ }^{14}$. The social network analysis that was based on data from 2017 and $2018^{14}$ was updated to reflect the entire before period. For example, the number of agents involved in the tasks was updated. Then the social network was constructed for the after period. Measures for integration and differentiation were analysed for both the before and after period.

All 44 data sources for rules and coordination mechanisms for the after period, that is all documents, observations and interviews, were structured in five data matrices. One data matrix was constructed for each of tasks 1, 2 and 3; one data matrix was made for tasks 6 and 11, and another for tasks 14, 15, 17, 20, 21 and 22. For the before period, these five data matrices were constructed in the second case study, based on 94 qualitative sources. We then analysed whether a rule still exists in the after period, whether it is applied hospital-wide or locally, i.e. within one particular department, group of people or by one person. Any new rules were added and abolished rules were registered. In addition, we 
analysed whether rules are registered (R) or the output of applying the rule is registered (O) in a document or in the HIS, and/or if this exists only in the mind of hospital staff. The coordination mechanisms ${ }^{26}$ were registered for all rules in the after period, based on the definition of the coordination mechanisms as presented in Table 5.1.

The performance indicators that are mentioned in the 138 data sources of the before and after periods were then listed. Performance indicators that could be calculated on the basis of available HIS data were included in this study, as presented in Table 5.1. It was registered in which and how many sources each performance indicator was mentioned before the introduction of the HPC. In addition it was registered whether the indicator or desired changes were mentioned qualitatively or quantitatively. The value of these performance indicators was calculated for the before and after period.

A focus group session was held for validating the quantified performance indicators. The manager of the ICM Department, who was the OTC capacity planner in the before and the after period, and one central planner participated. In this session all performance indicators were validated, i.e. it was discussed whether the performance indicators reflect the performance in reality. The manager and central planner considered all performance indicators to be valid.

\section{RESULTS}

\section{Network structure}

The evaluation of the network structure following the introduction of the HPC shows that there is a decrease in the number of agents who are involved in the network. The number of agents went down from 526 to 514 , as shown in Table 5.2. Table 5.3 shows that in the after period fewer OR nurses, secretaries and ward nurses participate in the network, and there is one less manager involved. On the other hand, the number of surgeons and/or surgeon assistants increased and six central planners were added.

Table 5.2 Network parameters overall network in the before and after period

\begin{tabular}{|c|c|c|c|c|c|c|c|c|c|}
\hline Network Parameter & \multicolumn{3}{|c|}{ Before 1 June 2019} & \multicolumn{3}{|c|}{ After 1 June 2019} & \multicolumn{3}{|c|}{ Change } \\
\hline Number of agents & & 526 & & & 514 & & & $-2 \%$ & \\
\hline Number of ties & & 32,002 & & & 31,703 & & & $-1 \%$ & \\
\hline Density & & 0.23 & & & 0.24 & & & $4 \%$ & \\
\hline Number of cliques & & 7,692 & & & 6,909 & & & $-10 \%$ & \\
\hline Agent parameter & Lowest & Average & Highest & Lowest & Average & Highest & Lowest & Average & Highest \\
\hline Degree & 1 & 122 & 411 & 2 & 124 & 402 & $100 \%$ & $2 \%$ & $-2 \%$ \\
\hline Betweenness centrality & o & 240 & 5,611 & o & 233 & 4,728 & $\mathrm{~N} / \mathrm{A}$ & $-3 \%$ & $-16 \%$ \\
\hline
\end{tabular}


Further, the number of cliques went down from 7,692 to 6,909 , a decrease of $10 \%$. This change is attributed mainly to the fact that in the after period surgeries were performed more frequently by the same OR team. In the after period there were 5,881 unique OR teams, i.e. cliques, while in the before period there were 6,660, as shown in Table 5.4. Network parameters associated with integration, i.e. density, degree and betweenness centrality barely changed, as shown by Table 5.2 .

Table 5.3 shows that there has been a change in the network position of managers. In the before period one cluster manager was also manager of the OTC and this latter position was taken over by an OTC team leader. The new OTC manager has a higher degree (25) and betweenness centrality (311) in the after period than the average degree (11) and centrality (4) for the cluster managers in the before period. Table A5.1.1 in Appendix 5.1 shows that the OTC manager has become involved with planning surgeries (task 6) whereas in the before period the cluster manager was not involved.

The position of the OTC capacity planner changed as well. In the after period her degree and centrality decreased by $78 \%$ and $88 \%$ respectively. Her formal position was OTC capacity planner until July 2020, but her network position and tasks changed earlier, i.e. during the after period. After the HPC was introduced, the OTC capacity planners' tasks shifted to the OTC manager and central planners. In addition, the centrality of the outpatient secretaries, surgeons, OTC team leaders and OTC day coordinator decreased substantially as a result of the HPC.

Central planners have taken a central position in the network with the fourth highest betweenness centrality. The OTC day coordinator is most central, followed by nurse anesthetists and recovery nurses. Their central position is explained mainly by the fact that on the day of surgery they interact with all agents who are involved in performing surgeries, i.e. OR nurses, nurse anesthetists, surgeons, anesthesiologists and ward nurses, who transfer patients from and to the OTC. In addition, the OTC day coordinator interacts with the central planners and outpatient secretaries for planning tasks on the day before a surgery takes place.

The neurosurgeon has the highest betweenness centrality both in the before and in the after period. This is explained by the fact that the neurosurgeon is the only surgeon who visits patients in nursing ward N1, because all other surgery patients stay in other nursing wards. Thus he is the only agent in the entire network who interacts with the nurses of nursing ward N1. As a result his network position is relatively central, as shown by Figure A5.2.1 in Appendix 5.2. 

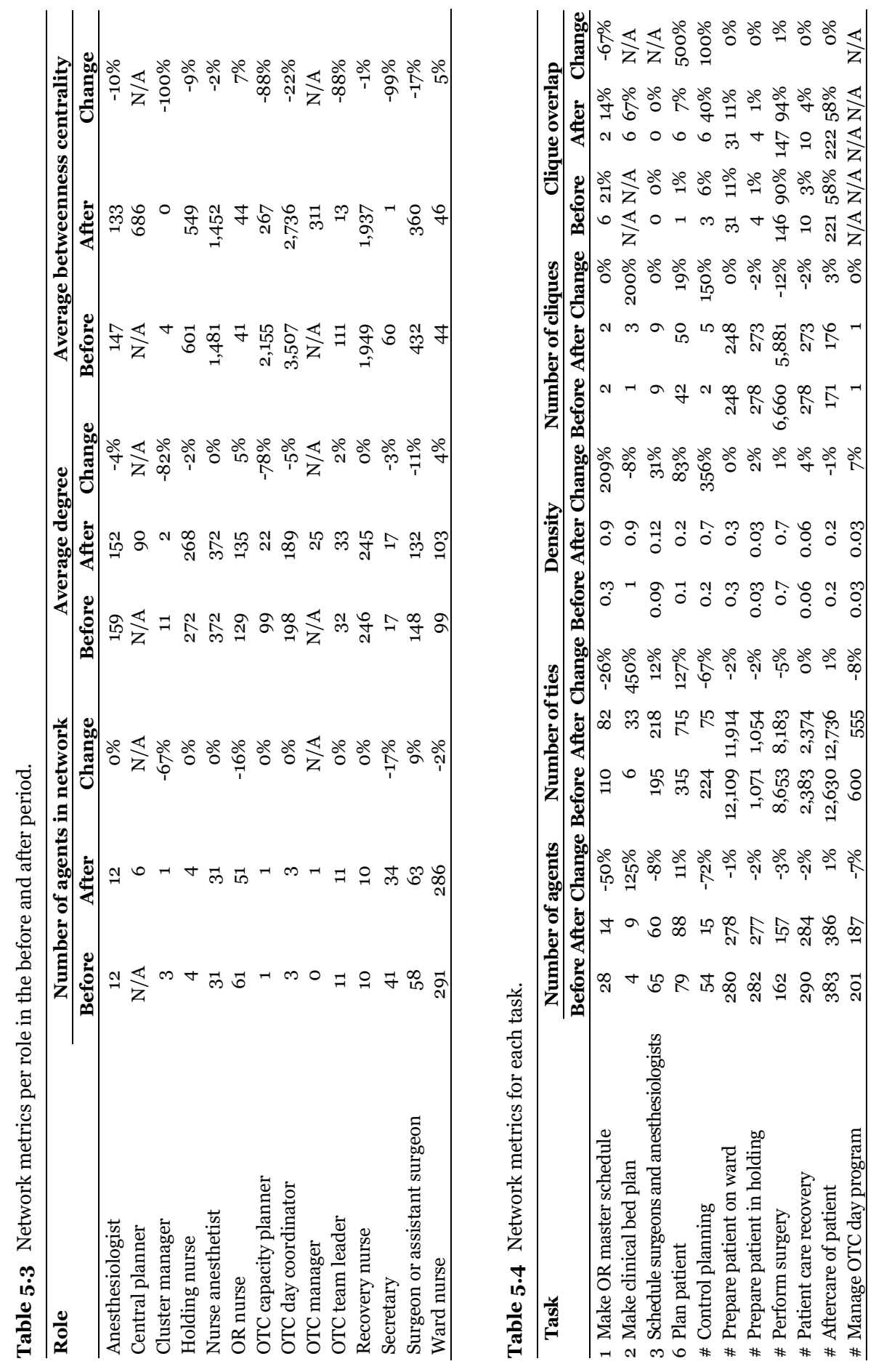


\section{Network structure per task}

From the social networks per task (Appendix 5.2) and Table 5.4 one can see that the network structure for tasks 1, 2, 6 and 11 changed in the after period, with task 1 being performed by a denser network, with a density that increased from 0.3 to 0.9. Fewer agents (50\%) are involved in the after period (Figure A5.2.2) because outpatient secretaries and two cluster managers are no longer involved in this task. Clique overlap decreased by $67 \%$, which is explained by the fact that in the after period only two agents participate in multiple cliques instead of six, as in the before period.

For the clinical bed plan (task 2), the central planners take the lead in the after period, and they interact with nursing ward team leaders (Figure A5.2.3) Density decreases by 8\% in the after period, as there are now three cliques instead of one.

For patient planning (task 6), density has increased by $83 \%$ and clique overlap has increased by 500\%. Figure A5.2.5 in Appendix 5.2 shows that now six planners have connections with all surgeons and outpatient secretaries, instead of with one OTC capacity planner who coordinated planned surgeries. In addition, $72 \%$ fewer agents are involved in controlling the planning (task 11) in the after period, i.e. 15 instead of 54 , increasing the density of the network from 0.2 to 0.7 . In addition, the clique overlap increased from $6 \%$ to $40 \%$ for task 11 .

For scheduling surgeons and anesthesiologists (task 3), there are ten networks that are not connected both in the before and in the after period, as shown by Figure A5.2.4 in Appendix 5.2. The density for task 3 increased by $31 \%$ because there are more surgeons than in the before period. All tasks performed on the day of surgery barely changed in terms of density and the number of cliques. Any changes were explained by changes in the number of involved agents. The number of cliques for performing surgeries (task 17) decreased by $12 \%$, which means that there are fewer unique OR teams than in the before period.

\section{Rules and coordination}

Table 5.5 shows that after the introduction of the HPC the total number of rules decreased by $7 \%$. Although there are $8 \%$ more rules that are applied hospital-wide, there are $38 \%$ less local rules. The decrease of local rules is largely attributed to tasks 6 and 11, for which local rules have gone down by $83 \%$. Of 314 rules from the before period in total 63 rules (20\%) changed in the after period. 


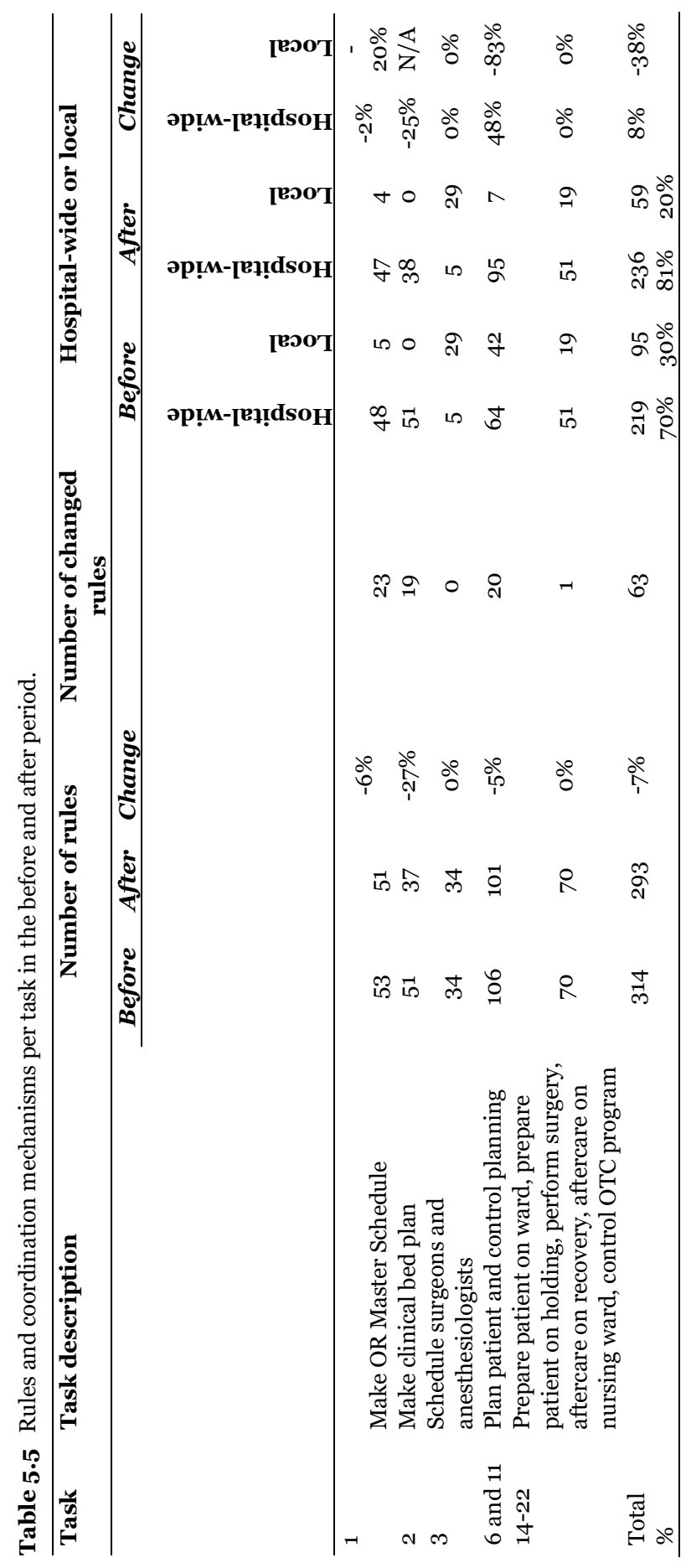




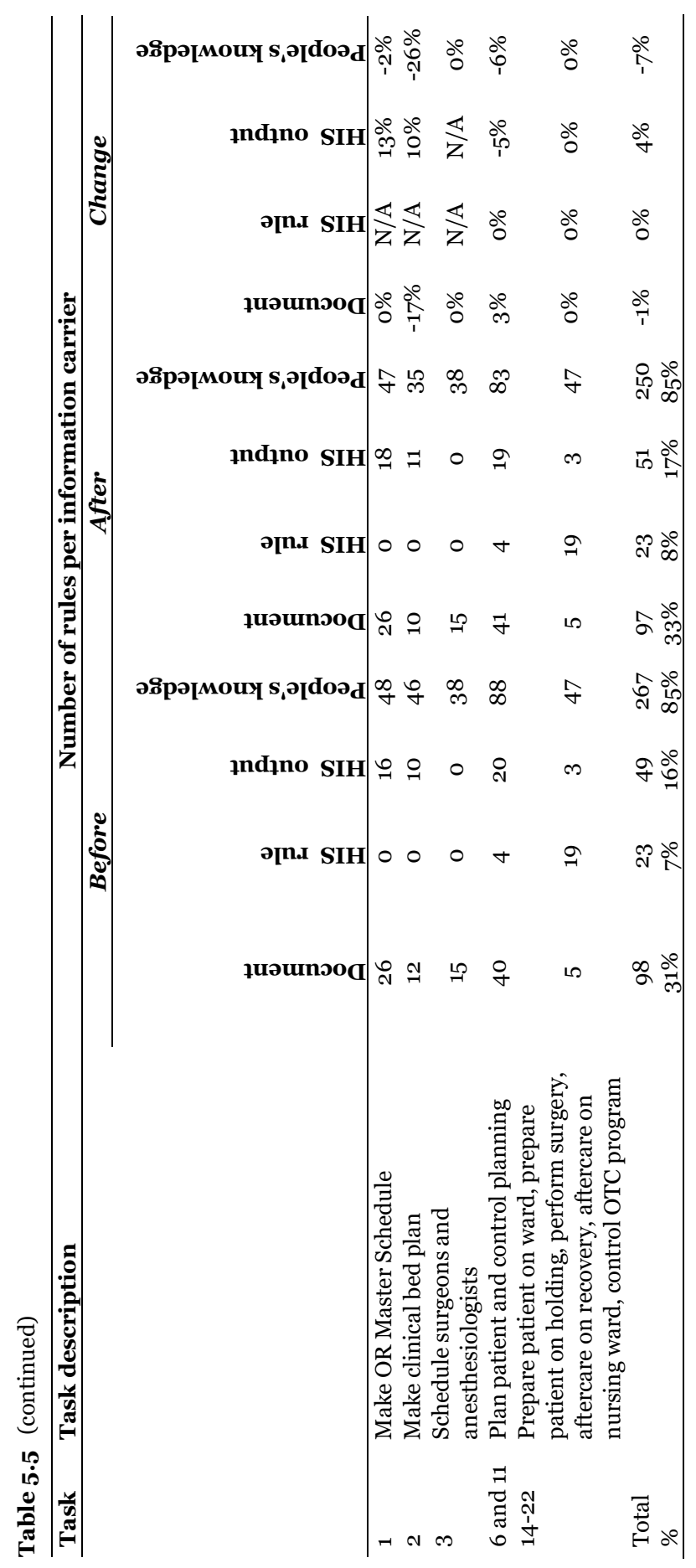




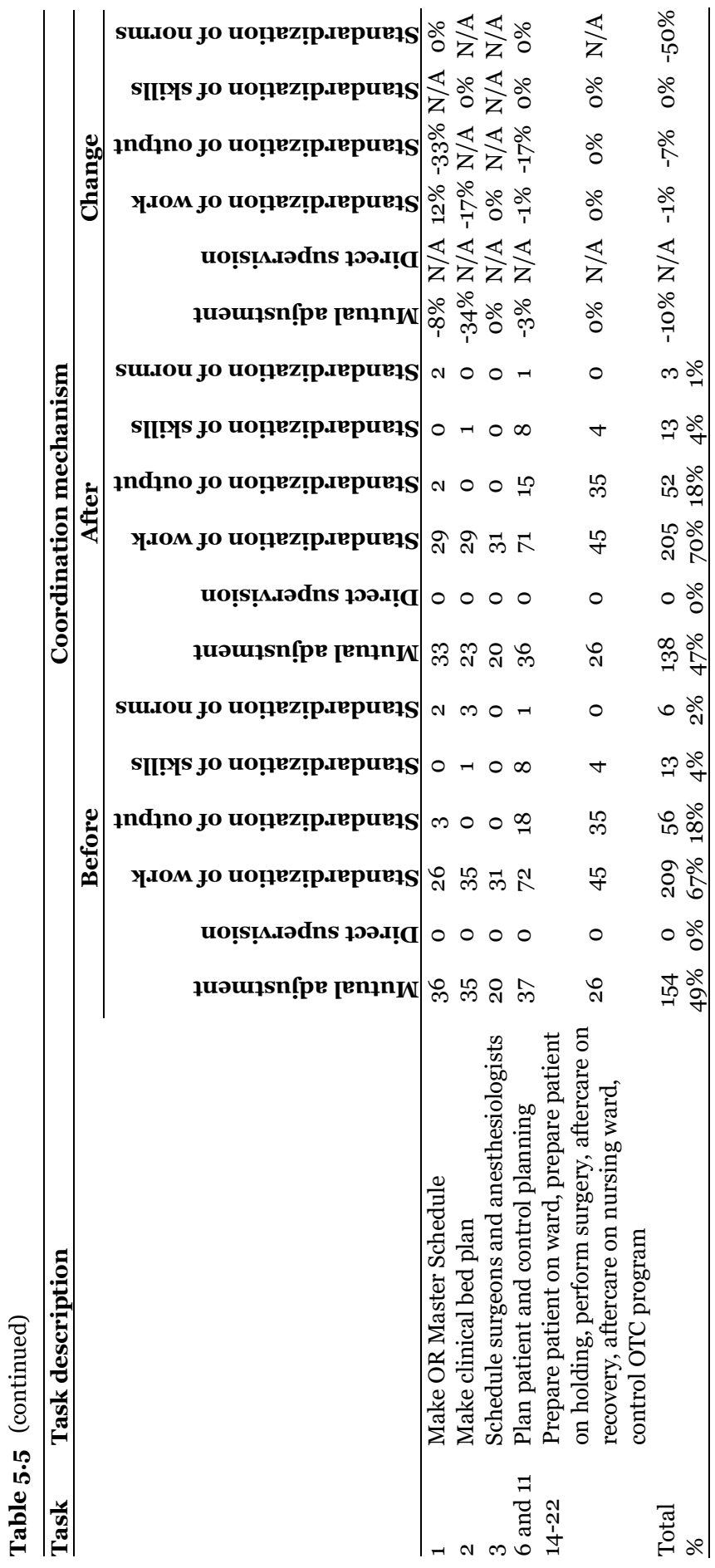


For task 1 the number of rules changed by $6 \%$ and 23 of 53 rules were changed. During the after period, as of 1 January 2020, the OR master schedule was restructured, taking bed availability in the nursing wards into account. In addition, the HPC has taken more initiative and control over the process of returning or granting extra sessions, and rules related to this were changed accordingly.

A similar change is observed for task 2, as the number of rules decreased by $27 \%$ and 19 of the 51 rules were changed. In the before period the clinical bed plan was informally controlled by the clinical bed planner, who was a nursing ward secretary with no formal position for this task. In the after period the HPC was given planning and control over the beds for nursing wards A2, N2 and for the Short Stay Department.

Nine new rules were introduced and 20 rules changed for patient planning (task 6) and controlling the planning (task 11). A number of local rules that were applied in the before period were standardized into one hospital-wide rule, which has to be applied by the HPC. For example, the HPC does not set a surgery date for the patient at the time of visiting the outpatient department. The HPC sets a date approximately two weeks ahead of surgery, whereas in the before period some outpatient departments set this in an earlier stage while other outpatient departments did not. In addition, semi-urgent surgeries are treated by the HPC as 'regular' surgeries, i.e. these are not put in between planned surgeries, but planned as though they are elective surgeries, even though they have to take place on shorter notice. Also the maximum planned utilization of an OR session was decreased from $105 \%$ to $100 \%$ and is strictly applied by the HPC. Further, the HPC has to plan all patients in the HIS instead of in paper planning documents.

Rules did not change for scheduling surgeons and anesthesiologists (task 3), i.e. the majority of rules have remained local. For tasks 14 to 22 the rules did not change either, with the exception of one, and these remained mostly hospital-wide rules. Both in the before and after period rules are mostly in people's minds (85\%) and to a lesser extent in documents (31\% before and $33 \%$ after) or in the HIS.

Looking at coordination mechanisms, standardization of work and mutual adjustment have remained the most used mechanisms, whereas direct supervision is absent and standardization of output and standardization of norms are low. For task 1, standardization of output decreased by $33 \%$, mutual adjustment by $8 \%$ and there is more standardization of work (12\%). This is explained by the restructuring of the OR master schedule, which was done by the OTC manager and OTC capacity planner during the after period. The clinical bed plan was restructured in line with the OR master schedule, and central control of the HPC led to $34 \%$ less mutual adjustment and $17 \%$ less standardization of work. For planning and control tasks 6 and 11, no large changes were 
observed with regard to coordination mechanisms. For tasks 3 and 14 to 22, coordination mechanisms and all tasks on the day of surgery remained largely unchanged.

\section{Performance indicators}

Before introducing the HPC, Slingeland hospital envisaged changes for 17 performance indicators, as presented in Table 5.1. Table 5.6 shows that before the HPC was introduced, the expected change of the associated performance indicators for each performance area were mostly specified qualitatively. The value of waiting list length and resource utilization are the only performance indicators that are reported quantitively both in the before and the after period. However, for these two indicators the desired or expected change was not specified beforehand. Several improvements were envisaged for performance indicators, related to how well processes were planned. Improved planning of surgery time, less overutilization of ORs, lateness and cancellations, were most frequently mentioned beforehand, in six documents and four interviews. The second most mentioned indicator was a reduction of variability, which was mentioned in six documents and three interviews.

While the number of surgeries performed stayed roughly the same, the average waiting list length increased by $21 \%$, from 5.8 to 7 weeks on average. Figure 5.4.1 in Appendix 5.4 shows that the increase of the waiting list started in week 37 in 2019 (9 September), which is three months after the HPC was introduced. The waiting list length stabilizes at the start of 2020.

The ORs and OR sessions were utilized slightly $3 \%$ less and beds were utilized $11 \%$ more. Higher bed utilization is related to the fact that the number of beds was reduced by $14 \%$ in the after period.

The main change with regard to the area of process quality and control is the increase of 88\% in cancellations. Figure 5.4.2 in Appendix 5.4 shows the number cancellations per registered reason. The increase of cancellations is largely attributed to administrative reasons. Surgeries were 'entered incorrectly in the system' $172 \%$ times more in the after period and surgeries for which 'the surgery date is unknown' increased by $5250 \%$. This was attributed to the fact that, based on rule 167, planners should plan all surgeries in the HIS, including those for which the surgery date is not final and the patient has not yet been informed of the date. Leaving out these two administrative factors, the number of cancellations has increased by $15 \%$. 


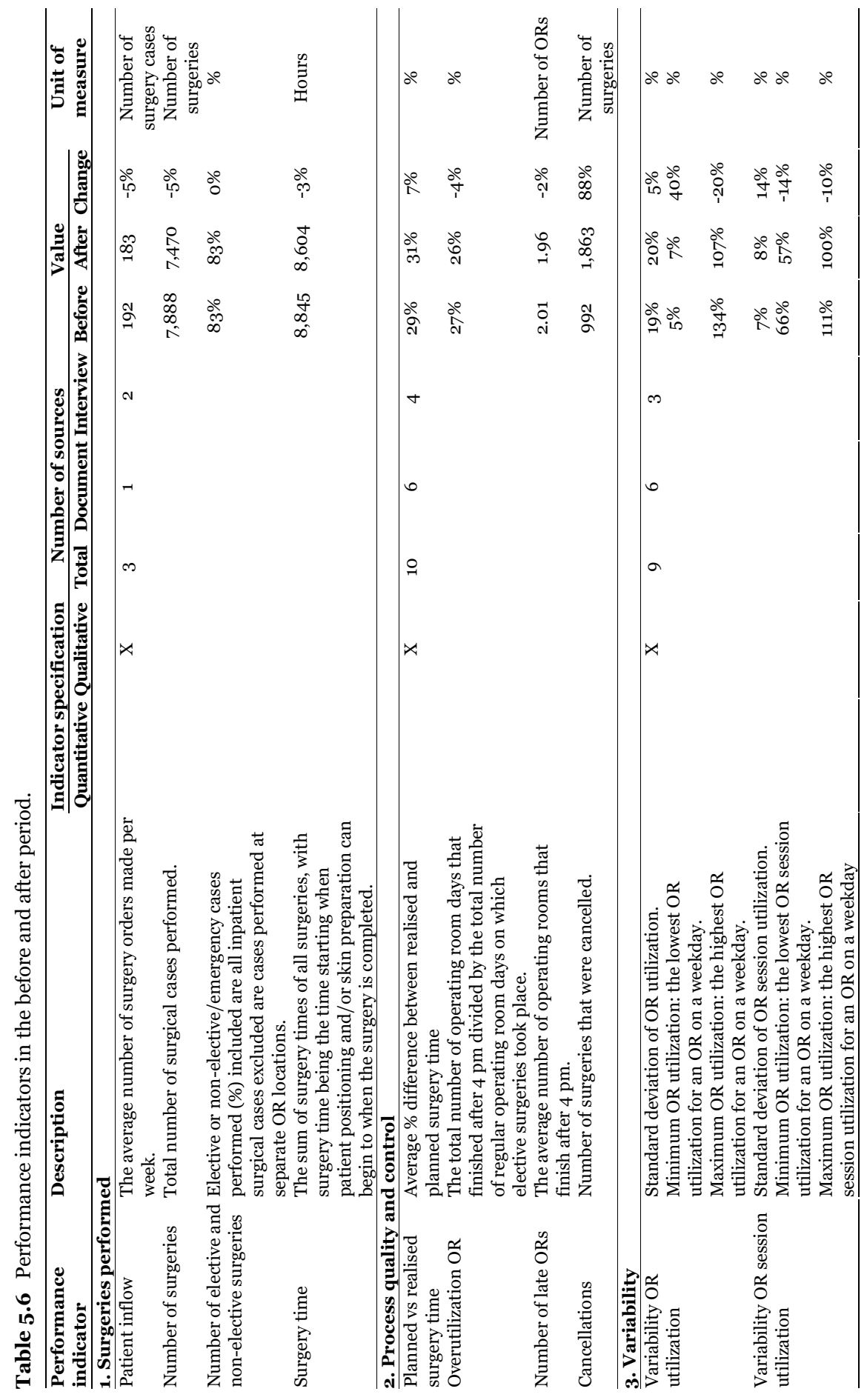




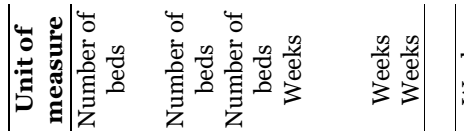
|

ดัด

.
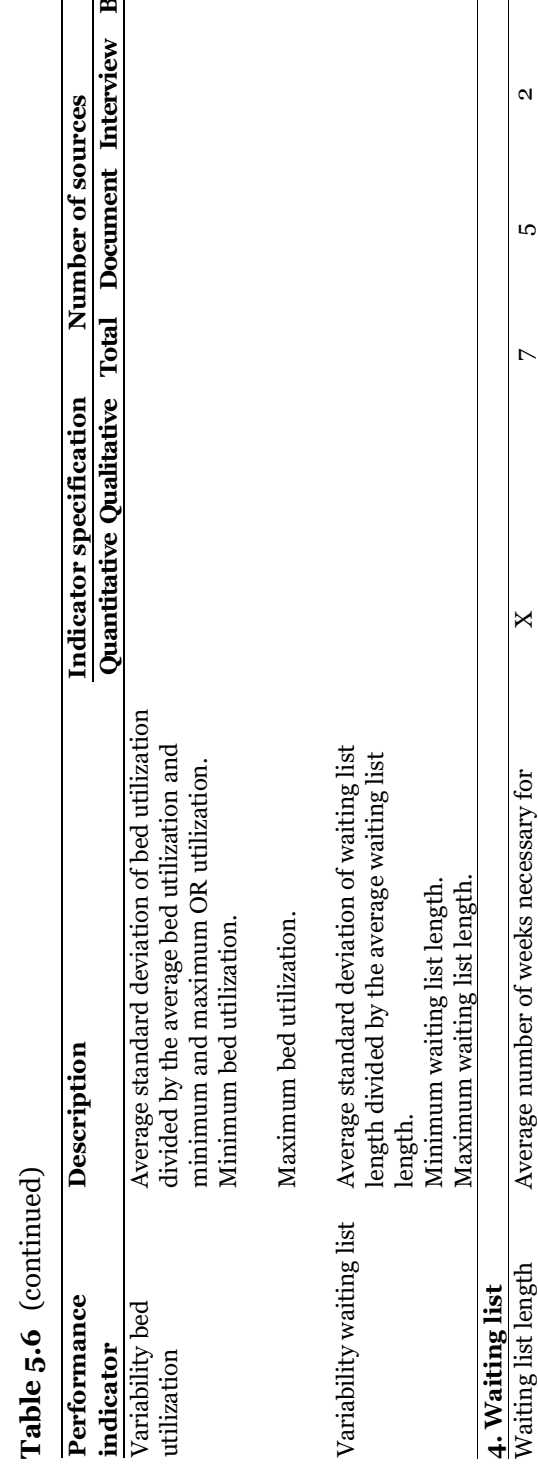

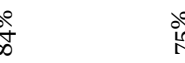

文

$\stackrel{\circ}{\hat{N}}$

ஷे ㅇํำ

ํำ के

$\infty$

\&

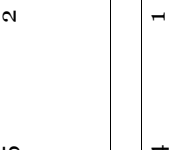

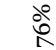
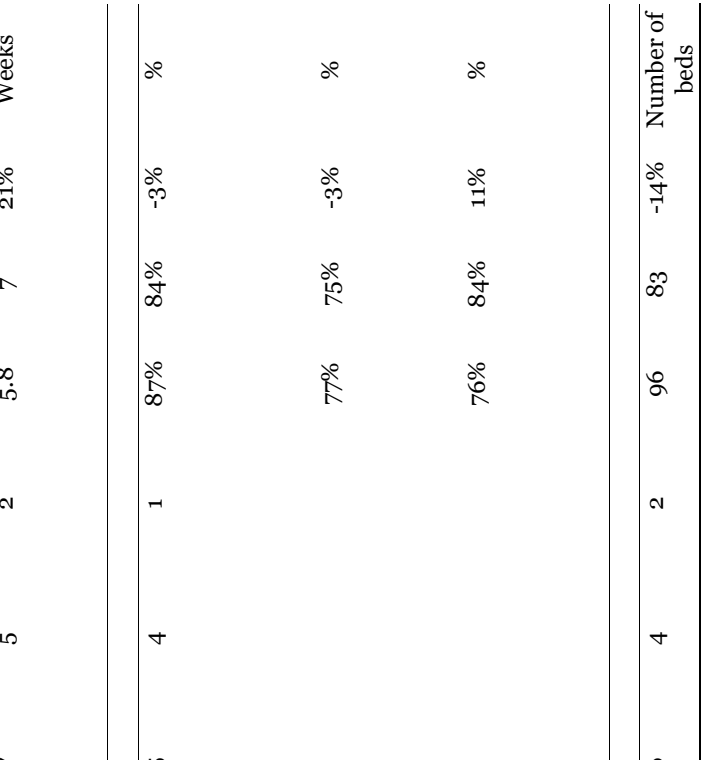

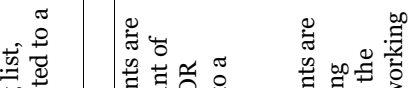
.0.

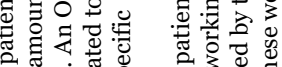

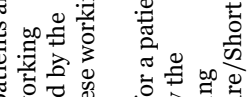

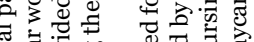

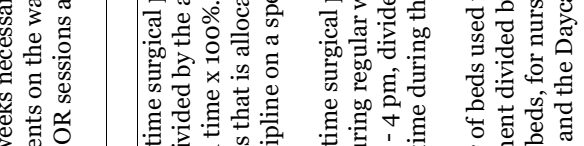

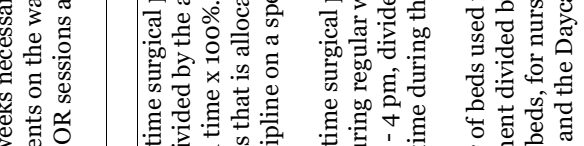

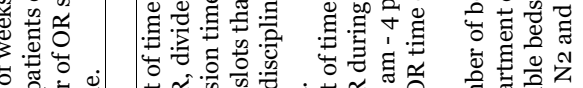

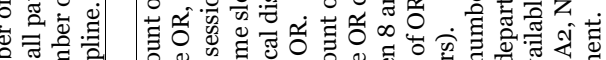
司论

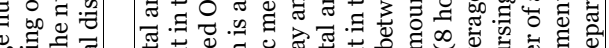

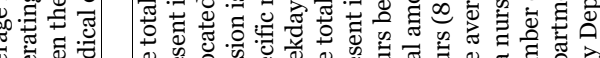
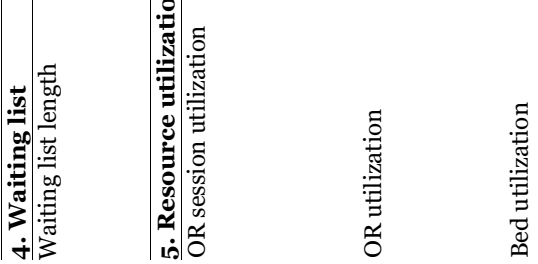

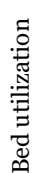

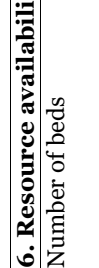


Lateness in the OR, i.e. the average number of late ORs and the percentage of days with surgeries running late, decreased slightly by $2 \%$ and $4 \%$ respectively. The difference between the planned and realized surgery time increased by $7 \%$.

Variability did not change much on average, except for the waiting list variability, as shown by Table 5.6. The waiting list length has become more variable, by $19 \%$. Table 5.6 also shows that the maximum values for OR utilization, OR session utilization and bed utilization have all decreased by $9 \%$ to $20 \%$.

\section{DISCUSSION}

In this study changes that followed the introduction of a HPC are described in terms of the network structure, i.e. integration and differentiation, rules, coordination and performance of the hospital. With regard to performance, the number of beds has decreased and the related bed utilization has increased. In addition, peak values in resource utilization decreased. However, not all performance indicators that Slingeland Hospital mentioned prior to the introduction of the HPC have improved. A remarkable increase in waiting list length, cancellations and average variability in the waiting list was observed following the introduction of the HPC.

Integration, thereby focusing on density, increased mainly on the task level for planning tasks in which the OR master schedule is set (task 1), surgeries and beds are planned (task 6) and planning is controlled (task 11). Central planners take a central position for the main planning tasks 6 and 11. The OTC manager has taken a more central position than in the before period, thus contributing to integration. Differentiation based on medical discipline remained after the introduction of the HPC and is observed for tasks 3 and 6, through which surgeons and surgeries are planned.

Rules are applied less locally, i.e. rules from the before period have become the hospitalwide standard or new hospital-wide rules were set. Rules remain mostly in people's minds and there is scarcely any increase in documented rules. Coordination mechanisms remained largely the same after the HPC was introduced, and mainly include standardization of work and mutual adjustment.

The fact that the hospital's performance does not seem to have improved substantially and has even decreased in some ways, is remarkable. Even though the relation between the observed changes cannot be established by this study alone and the period of nine 
months may be too short to assess the hospital-wide impact of the HPC, a number of possible explanations related to integration, differentiation and coordination can be discussed based on this study.

First of all, the HPC plans specific groups of patients, excluding non-surgical patients and certain surgery patients, and it does not control the surgeons' schedules. According to Ludwig et al. ${ }^{8}$ the hospital's efficiency will most likely improve when all departments cooperate instead of some departments, as is the case here.

Second, the HPC does not seem to take demands from the environment, i.e. patient demand, into account more than the outpatient departments did in the before period. Long-term schedules, of surgeons in particular, have remained largely unchanged, and waiting list length is determined mainly by the available capacity. With a patient inflow that is similar in the before and after period and a lowered maximum utilization of OR sessions, the waiting list length logically increases. In addition, both surgeons and outpatient secretaries, who have direct and first contact with patients, have a less central position than in the before period. This appears to be in contrast with both Galbraith ${ }^{19}$ and Lawrence and Lorsch ${ }^{13}$, who state that the organizational structure, i.e. the degree of integration and differentiation, should be tuned to the demands of the environment in order to perform well. In addition, the unchanged long-term schedules still create open loops ${ }^{17}$, which are closed by mutual adjustment, as in the before period ${ }^{15}$. Although now six planners close the loops, instead of the one OTC capacity planner, we believe that the potential causes of instability, e.g. the multitude of rules and the open loops, have shifted from the outpatient departments and the OTC capacity planner to the HPC, but have not been reduced. The increased length of the waiting list and number of cancellations suggest that the network has remained unstable or has become even more unstable.

Based on these observations and the literature, we believe that the introduction of HPC should be part of a system redesign from the perspective of the total system, including network structure, rules and coordination mechanisms. The observed ways of working in Slingeland Hospital show some similarities with the horizontal coordination in Japanese companies as described by Aoki ${ }^{27}$. According to Aoki, horizontal coordination involves collective learning and knowledge sharing based on informal and mostly verbal communication and is considered most effective in dynamic environments. This will be effective only when all agents have a good understanding of the whole work process and organizational goals are internalized. In line with both Aoki ${ }^{28}$ and Galbraith ${ }^{19}$, it appears that with the introduction of the HPC stronger lateral relations have been created, but it is unclear whether there is collective learning, knowledge sharing and full understanding of organization-wide goals. 
Starting with organization-wide goals, we therefore first propose that Slingeland Hospital management specifies desired, expected and realized performance indicators more explicitly. Literature pertaining to performance indicators ${ }^{12}$ and to hospital planning ${ }^{29-32}$ could be used for drawing up expected and desired changes in performance. These goals should then be discussed and shared hospital-wide. By regularly monitoring, evaluating and communicating changes in network structure, rules, coordination mechanisms and performance, expansive learning could be facilitated, a process in which agents produce new forms of work activity 33 based on feedback. Through job rotation ${ }^{27}$ the hospital-wide comprehension of processes is likely to be enhanced, and it could prevent a too strong identification with specific subsystems in which agents work. This is in line with Mintzberg ${ }^{26}$, who advocates for more mutual adjustment and standardization of norms in hospitals. As stated by Aoki ${ }^{27}$ agents could be motivated to act and behave in the interest of the hospital-wide goals by incentives.

Second, the organizational design concepts of integration, differentiation and centralization require further elaboration, first of all in practice. The word 'centre' in HPC implies that centralization of planning was intended. However, according to Mintzberg16 centralization is related to decision power. At Slingeland Hospital, through lack of direct supervision, planning tasks seem instead to be concentrated without power, meaning that planners were grouped and given the competency to perform planning tasks without having actual decision power. At the same time, following the concept of horizontal coordination as described by Aoki ${ }^{27}$, there might not be any need for formal decision power to be assigned to agents for controlling operations. As shown by Van Merode et al. 34 agents are able to influence decision-making processes notwithstanding their formal positions. By concentrating the planners, thus centralizing them further in the network structure by involving them in planning processes from start to end, they might be able to effectively increase their influence further.

In addition, for effective horizontal coordination we believe Slingeland Hospital should pay more attention to differentiation. This means that differentiated tasks are explicitly specified and both central planners, outpatient secretaries, surgeons and anesthesiologists share goals, information and are allowed to 'stop the line' whenever they see issues that might lead to problems. We believe it is important that hospital management explicitly states what organizational model lies behind any further organizational changes.

Similar to the previous two case studies ${ }^{14-15}$ this study is exploratory. Because it concerns a single case study the results may not be applicable to other cases. The findings should be used for 'analytic generalization'23, providing input for future studies. The above- 
mentioned recommendations for practice are relevant input for further research, albeit for the purpose of identifying connections between performance, network structure, integration, differentiation, rules, and coordination mechanisms in general.

More specifically, first the concept of integration as defined in social network and organizational theory needs to be developed further. Based on social network metrics, integration in Slingeland Hospital appears to have increased for some tasks, but according to Lawrence and Lorsch ${ }^{13}$ and Mintzberg ${ }^{16}$, it could be argued that integration did not change, when taking decision power into account.

Second, some network metric changes seem to be attributed to factors other than the introduction of the HPC, as illustrated by the decreased number of unique OR teams and the position of the one neurosurgeon. There is also the limitation of not taking into account interaction frequency between agents, causing low and high frequency interaction to be valued equally. Nevertheless, in line with Beuving and De Vries ${ }^{24}$, we believe that network performance can only be understood when accompanied by an understanding of what happens between the agents in the network.

Third, we believe that the concept of horizontal coordination is worth exploring further, but as mentioned by Aoki ${ }^{27}$, the cost of intensive interaction between multiple agents and time consuming learning processes will pay off only in volatile and dynamic environments, for which a more hierarchical model is not effective. Given the limited attention that is paid to the hospital's environment, more research is required on the dynamics of the environment. In addition, Takt Time Management should be considered in relation to horizontal coordination models. Through Takt Time Management the desired time between units of output is synchronized to the customer's demand, in order to stabilize the system ${ }^{17}$. A multi-agent system which includes horizontal coordination was designed by Munavalli et al. ${ }^{2}$, for example, and could be used to further develop hospitalwide coordination, integration and differentiation.

In conclusion, this study explores the (un)changeable coherence of a hospital network's structure, rules, coordination mechanisms and performance, which is important input for further studies. Future studies could be performed in hospital settings, but also in other organizations that provide healthcare on a regional or national level, i.e. including other hospitals and the supply chain partners of hospitals. Given the fact that the accessibility and affordability of healthcare systems clearly have been under even more pressure since the Covid-19 pandemic, the relation between integration, differentiation, coordination and the stability of healthcare networks and organizations is highly relevant and demands further research. 


\section{REFERENCES}

1. Drupsteen J, Van der Vaart $\mathrm{T}$ and Van Donk DP. Integrative practices in hospitals and their impact on patient flow. International Journal of Operations \& Production Management 2013; 33: 912-933.

2. Kodner DL and Spreeuwenberg C. Integrated care: meaning, logic, applications and implications - a discussion paper. International Journal of Integrated Care 2002; 2(4). http://doi.org/10.5334/ijic.67.

3. Lega F, Marsilio $M$ and Villa $S$. An evaluation framework for measuring supply chain performance in the public healthcare sector: evidence from the Italian NHS. Production Planning \& Control 2013; 24: 931-947.

4. Aronsson H, Abrahamsson M and Spens K. Developing lean and agile health care supply chains. Supply Chain Management: An International Journal 2011; 16: 176-183.

5. Borges GA, Tortorella G, Rossini M and Portioli-Staudacher A. Lean implementation in healthcare supply chain: a scoping review. Journal of Healthcare Organization and Management 2019; 33(3): 304-322.

6. De Vries J and Huijsman R. Supply Chain Management in health services: an overview. Supply Chain Management: An International Journal 2011; 16: 159-165.

7. Litvak N, Van Rijsbergen M, Boucherie RJ, et al. Managing the overflow of intensive care patients. European Journal of Operational Research 2008; 185: 998-1010.

8. Ludwig M, Van Merode GG and Groot W. Principal agent relationships and the efficiency of hospitals. Eur J Health Econ 2010; 11: 291-304.

9. Van Merode GG, Groothuis S and Hasman A. Enterprise resource planning for hospitals. International Journal of Medical Informatics 2004; 73(6): 493-501.

10. Villa S, Barbieri M and Lega F. Restructuring patient flow logistics around patient care needs: implications and practicalities from three critical cases. Health Care Manag Sci 2009; 12(2): 155-165.

11. Morgan D and Astolfi R. Financial impact of the GFC: health care spending across the OECD. Health Economics, Policy and Law 2015; 10: 7-19.

12. Van der Ham A, Boersma H, Van Raak A, Ruwaard D and Van Merode G.G. Identifying Logistical Parameters in Hospitals: Does literature reflect integration in hospitals? A scoping study. Health Serv Manage Res 2019; 32(3); 158-165.

13. Lawrence PRL, Lorsch JW, Differentiation and Integration in Complex Organizations, Administrative Science Quarterly 1967; 12: 1-47.

14. Van der Ham A, Van Merode F, Ruwaard D and Van Raak A. Identifying Integration and Differentiation in a Hospital's Logistical System: A social network analysis of a case study. BMC Health Serv Res 2020; 20: 857. DOI: 10.1186/s12913-020-05514-w.

15. Van der Ham A, Van Raak A, Ruwaard D and Van Merode GG. Explaining Integration and Differentiation in a Hospital's Logistical System by Identifying Coordination Mechanisms, Journal of Health Organization and Management 2021;36(9): 66-84.

16. Mintzberg H. Structures in Five: designing effective organizations. Englewood Cliffs: PrenticeHall, 1983 . 
17. Munavalli JR, Rao SV, Srinivasan A, Manjunath U and Van Merode GG. A Robust Predictive Resource Planning under Demand Uncertainty to Improve Waiting Times in Outpatient Clinics. Journal of Health Management 2017;19:563-583.

18. Ren Y, Kiesler S and Fussell SR. Multiple Group Coordination in Complex and Dynamic Task Environments: Interruptions, Coping Mechanisms, and Technology Recommendations. Journal of Management Information Systems 2008;25:105-130.

19. Galbraith J. Organization Design: An Information Processing View. Interfaces 1974; 4(3): 2836. Retrieved October 15, 2020, from http://www.jstor.org/stable/25059090.

20. Benchmark Coppa Consultancy. Online database. Accessed 11 July 2018.

21. Van Hulst, B, Blank J. Nederlandse ziekenhuizen te groot voor verdere schaalvoordelen. Economisch-Statistische Berichten 2017;102(4749):226-228.

22. Slingeland Ziekenhuis. Landelijke interesse voor aanpak opschaling Slingeland Ziekenhuis. Slingeland website 2020. Accessed 5 March 2021.

23. Yin RK. Case study research - Design and Methods. 5e edition. Thousand Oaks: Sage Publications, 2014.

24. Beuving J, De Vries G. Doing Qualitative Research: The Craft of Naturalistic Inquiry. Amsterdam: Amsterdam University Press, 2015.

25. Smith M, Ceni A, Milic-Frayling N, Shneiderman B, Mendes Rodrigues E, Leskovec J, Dunne C, NodeXL: a free and open network overview, discovery and exploration add-in for Excel 2007/2010/2013/2016, from the Social Media Research Foundation: https://www.smrfoundation.org; 2010.

26. Mintzberg H. Managing the myths of health care. Oakland: Berrett-Koehler Publishers, 2012.

27. Aoki M. Toward an Economic Model of the Japanese Firm. Journal of Economic Literature 1990; 28(1): 1-27.

28. Aoki M. Horizontal vs. Vertical Information Structure of the Firm. American Economic Review, American Economic Association 1986; 76(5): 971-983.

29. Demeulemeester E, Belien J, Cardoen B and Samundra M. Operating Room Planning and Scheduling. In: Denton BT, editor. Handbook of Operations Management: Methods and Applications. International series in Operations Research \& Management Science, New York, NY: Springer Science + Business Media, 2013.

30. Hulshof JH, Kortbeek N, Boucherie RJ, Hans EW and Bakker PJM. Taxonomic classification of planning decisions in healthcare: a structured review of the state of art in OR/MS. Health Systems, 2012;1:129-175.

31. Zhu S, Fan W, Yang S, Pei J, Pardalos PM. Operating room planning and surgical case scheduling: a review of literature. Journal of Combinatorial Optimization. 2019;37:757-805.

32. Munavalli, JR, Rao SV, Srinivasan A and Van Merode G.G. An Intelligent real-time scheduler for outpatient clinics: A multi-agent system model. Health Informatics Journal 2020; 26(4): 2383-2406. doi: 10.1177/1460458220905380.

33. Engeström Y. Expansive Learning at Work: toward an activity theoretical reconceptualization. Journal of Education and Work 2001;14: 133-156.

34. Van Merode GG, Nieboer A, Maarse $\mathrm{H}$ and Lieverdink H. Analyzing the dynamics in multilateral negotiations. Social Networks 2004: 26: 141-154. 


\section{APPENDIX 5.1 INVOLVED AGENTS PER TASK}

\begin{tabular}{|c|c|c|c|c|c|c|c|c|c|c|c|c|}
\hline 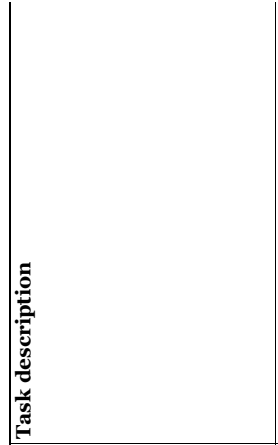 & 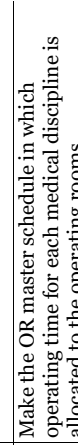 & 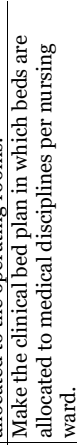 & 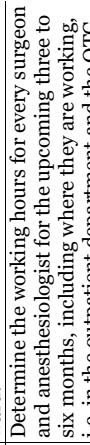 & 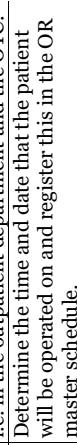 & 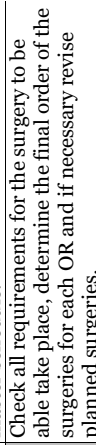 & 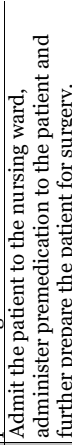 & 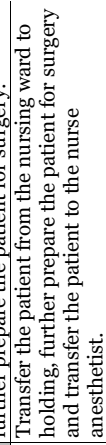 & 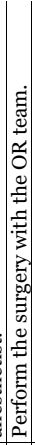 & 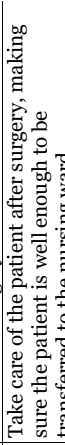 & 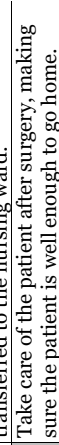 & 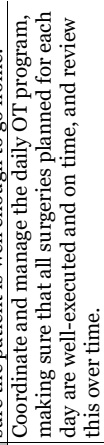 & \\
\hline & $\pi$ & & & & $x$ & $\star x$ & & & & $\star x$ & & n \\
\hline .әреә [ шеә] р.гем & & $x$ & & & $x$ & $x$ & & & & $x$ & & $\theta$ \\
\hline & $\pi$ & & & & & & & & & & & 0 \\
\hline ssoq ue[d paq [eว!u!IJ & o. & $x$ & & $x$ & $x$ & & & & & & & $\infty$ \\
\hline & $\pi$ & & & & & $x$ & $x$ & & $x$ & $x$ & & $\theta$ \\
\hline os.mu p.re $M$ & e & & & & $x$ & $x$ & $x$ & & $x$ & $x$ & & 10 \\
\hline & $x$ & & $x$ & $x$ & & & & $x$ & & $x$ & $x$ & 0 \\
\hline uoว8.ins & $x$ & & $x$ & $x$ & & & & $x$ & & $x$ & $x$ & 0 \\
\hline & $\pi$ & & & & & & & & $x$ & & $x$ & $a$ \\
\hline әS.Inu К.Іәмоәәу & e & & & & & & & & $x$ & & $x$ & 4 \\
\hline & $\approx$ & & & & & & & & & & & 0 \\
\hline 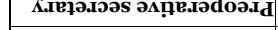 & e & & & & $x$ & & & & & & & 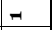 \\
\hline & $\approx$ & & $x$ & $x$ & & & & & & & & N \\
\hline 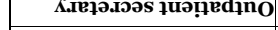 & 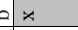 & & $x$ & $x$ & $\star$ & & & & & & $x$ & 10 \\
\hline & $\pi$ & & & & & & & & & & $x$ & - \\
\hline .әреә [ Чвә] ОLO & e & & & & $x$ & & & & & & $x$ & N \\
\hline & $\approx$ & & & & $x$ & & & & & & & -1 \\
\hline 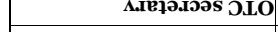 & & & & & $x$ & & & 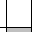 & & & & $\rightarrow$ \\
\hline & $\pi$ & & & & $x$ & & & $x$ & & & $x$ & $\infty$ \\
\hline as.inu yo & o & & & & & & & $x$ & & & $x$ & N \\
\hline & $x$ & & & $x$ & & & & & & & $x$ & $\infty$ \\
\hline .ə8еนеแ DLO & & & & & & & & & & & & 0 \\
\hline & $\pi$ & & & & $x$ & & & & & & $x$ & a \\
\hline .ореч!р.10о0 Кер 2LO & o & & & & $x$ & & & & & & $x$ & N \\
\hline & $x$ & & & & & & & & & & & - \\
\hline .əuUE [d K!! & $x$ & $x$ & & $x$ & $x$ & & & & & & $x$ & 10 \\
\hline & $\pi$ & & & & & & $x$ & & & & $x$ & a \\
\hline as.Inu su!pIOH & e & & & & & & $x$ & & & & $x$ & a \\
\hline 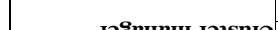 & $\approx$ & & & & & & & & & & & 0 \\
\hline 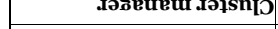 & e $x$ & & & & & & & & & & & - \\
\hline & $\pi$ & $x$ & & $x$ & $x$ & & & & & & & $m$ \\
\hline 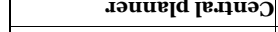 & e & & & & & & & & & & & 0 \\
\hline & $\pi$ & & & & & & & $\star x$ & & & & -1 \\
\hline 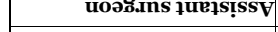 & o & & & & & & & $\star x$ & & & & -1 \\
\hline 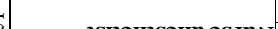 & $\approx$ & & & & & $x$ & $x$ & $x$ & $x$ & & $x$ & Lo \\
\hline 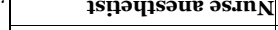 & e & & & & & $\star x$ & $x$ & $\star x$ & $x$ & & $x$ & L \\
\hline соя & $x$ & & $x$ & & & & & $x$ & $x$ & & $x$ & Lم \\
\hline $15 ! \sigma 0[0 ! 5841580 \mathrm{~V}$ & 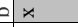 & & $x$ & & & & & $x$ & $x$ & & $x$ & Ln \\
\hline $\begin{array}{l}\frac{y}{y} \\
\frac{y}{\pi} \\
\frac{\pi}{4}\end{array}$ & 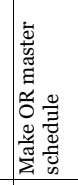 & 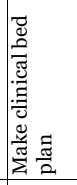 & 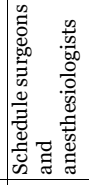 & 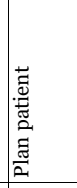 & 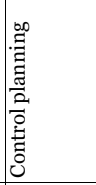 & 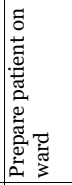 & 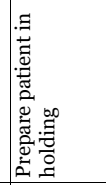 & 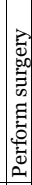 & 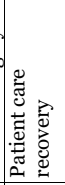 & 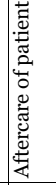 & 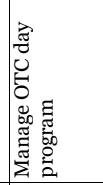 & 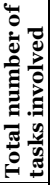 \\
\hline & |- & a & $m$ & $\mid 0$ & $\exists$ & I & $\$$ & $|=|$ & 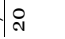 & ה & กิ & \\
\hline
\end{tabular}




\section{APPENDIX 5.2: SOCIAL NETWORKS}

\section{A5.2.1 The entire social network}

\section{Before}
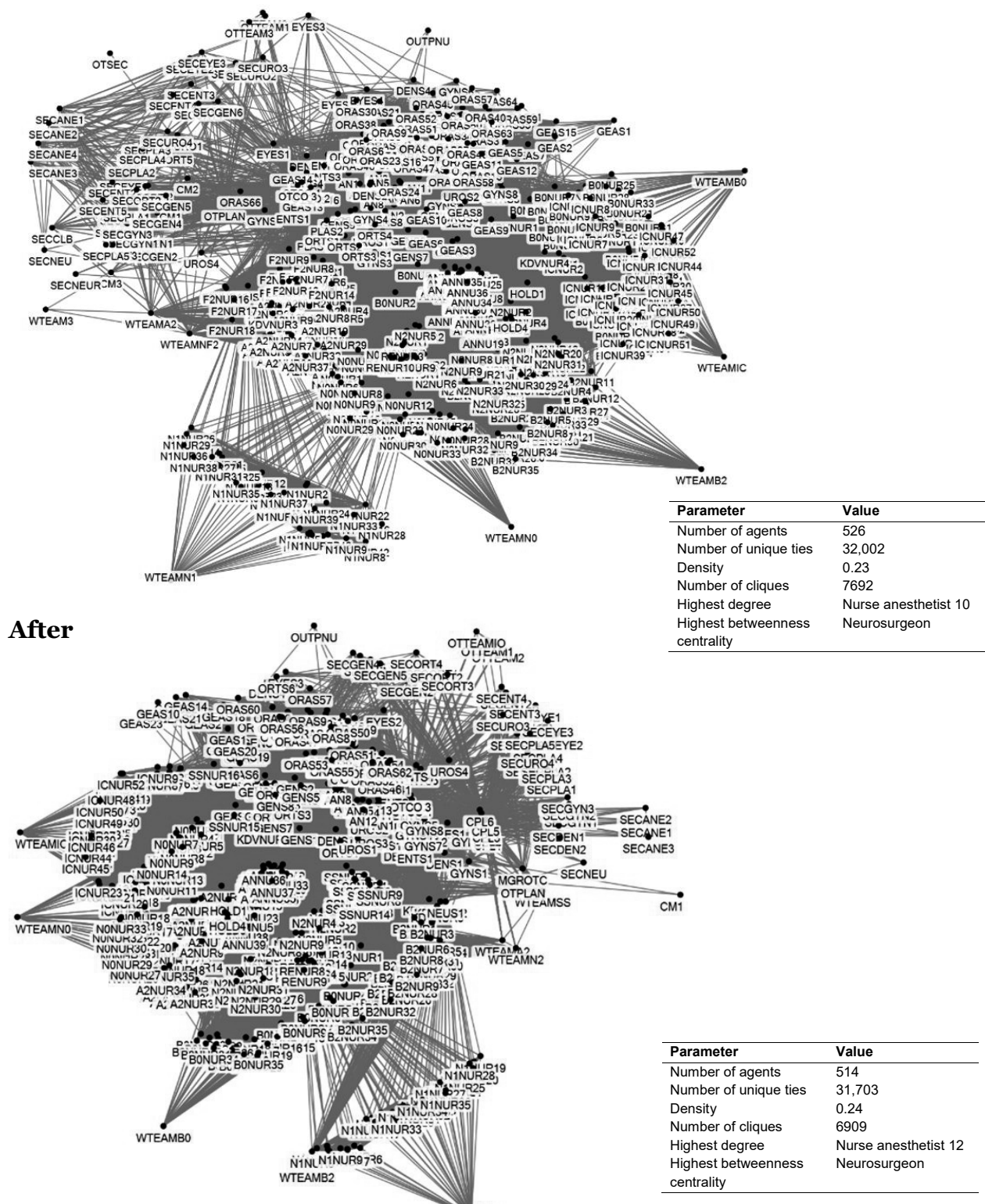

Figure A5.2.1 Before and after social networks and metrics for the entire network. 


\section{A5.2.2 Task 1: Make OR master schedule}

\section{Before}
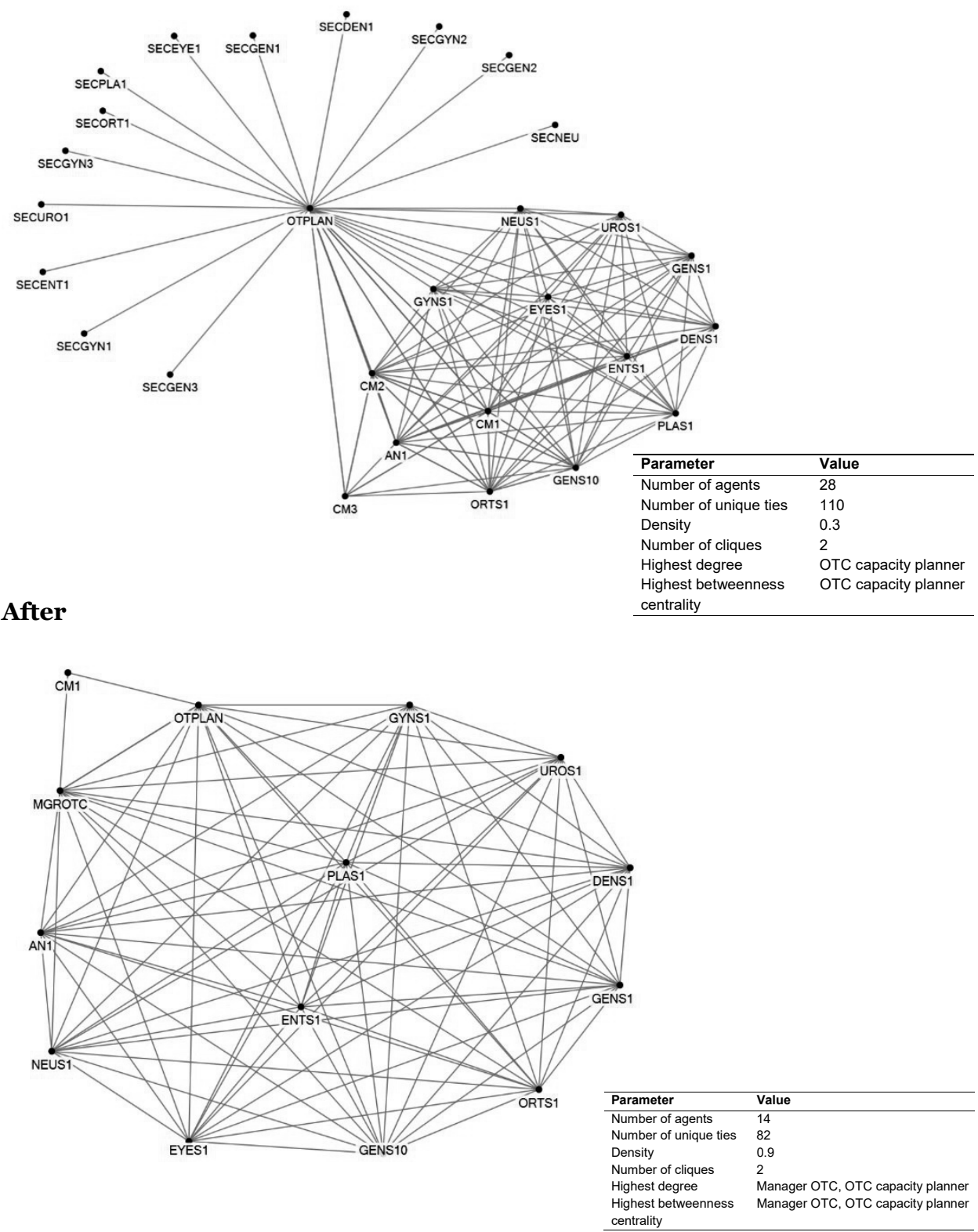

Figure A5.2.2 Before and after social networks and metrics for task 1 . 


\section{A5.2.3 Task 2: Make clinical bed plan}

\section{Before}

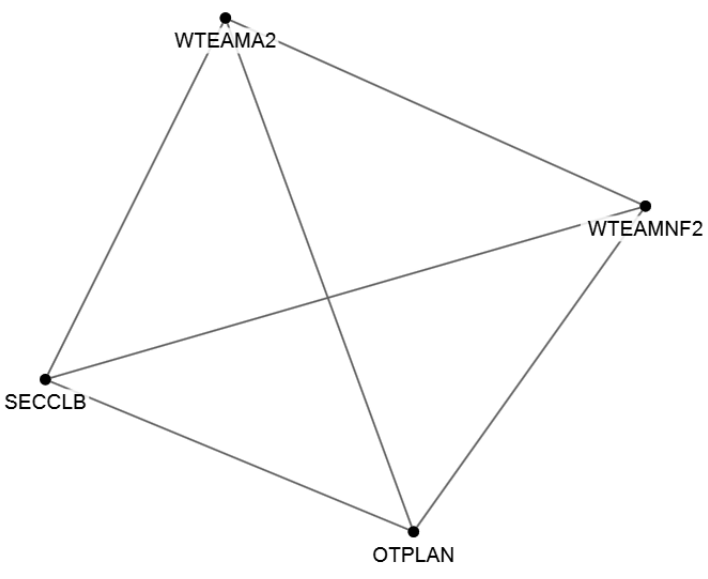

\begin{tabular}{ll}
\hline Parameter & Value \\
\hline Number of agents & 4 \\
Number of unique ties & 6 \\
Density & 1 \\
Number of cliques & 1 \\
Highest degree & N/A \\
Highest betweenness & N/A \\
centrality &
\end{tabular}

\section{After}

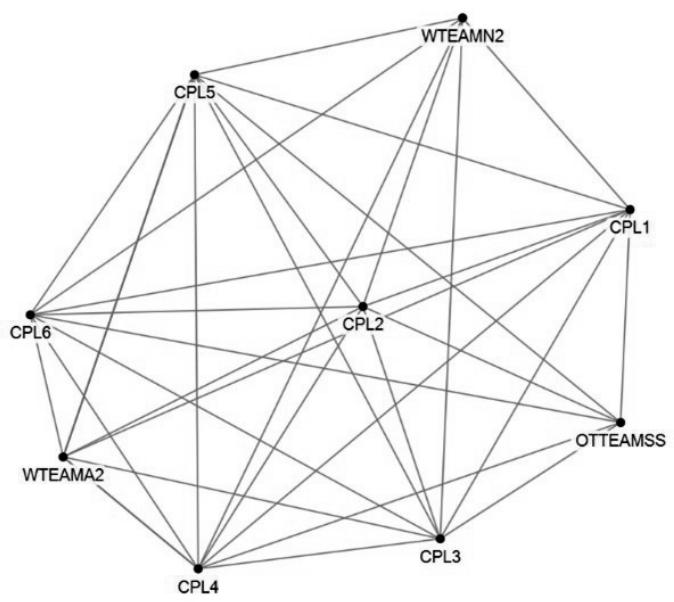

\begin{tabular}{ll}
\hline Parameter & Value \\
\hline Number of agents & 9 \\
Number of unique ties & 33 \\
Density & 0.9 \\
Number of cliques & 3 \\
Highest degree & N/A \\
Highest betweenness & All central \\
centrality & planners \\
\hline
\end{tabular}

Figure A5.2.3 Before and after social networks and metrics for task 2. 


\section{A5.2.4 Task 3: Schedule surgeons and anesthesiologists}

\section{Before}

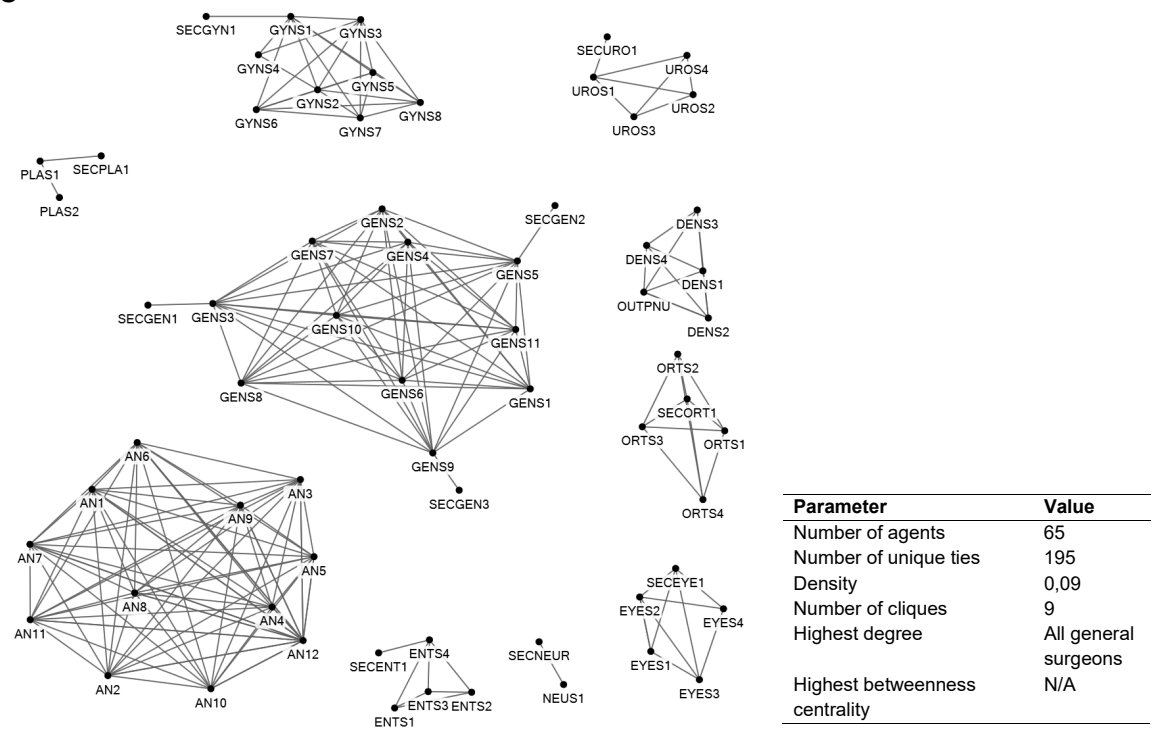

\section{After}
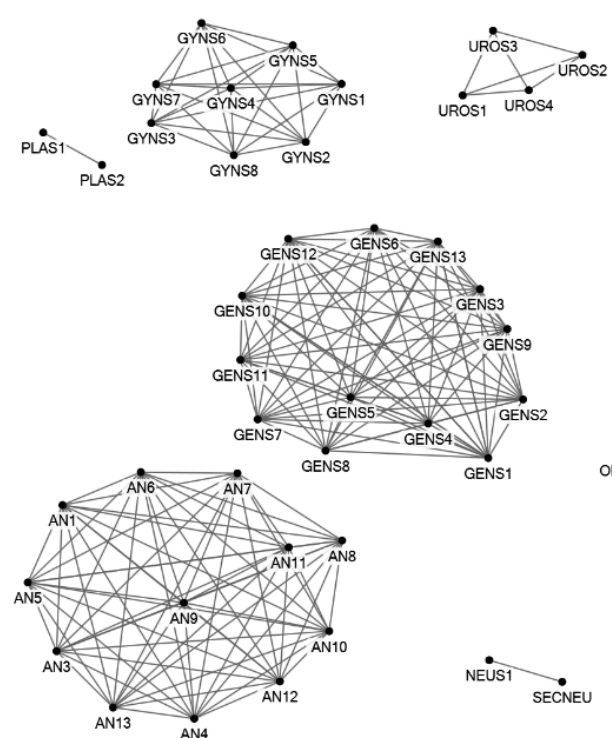
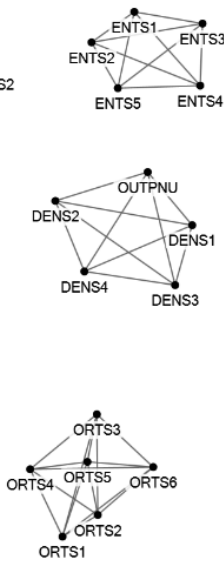

Figure A5.2.4 Before and after social networks and metrics for task 3 . 


\section{A5.2.5 Task 6: Plan patient}

\section{Before}

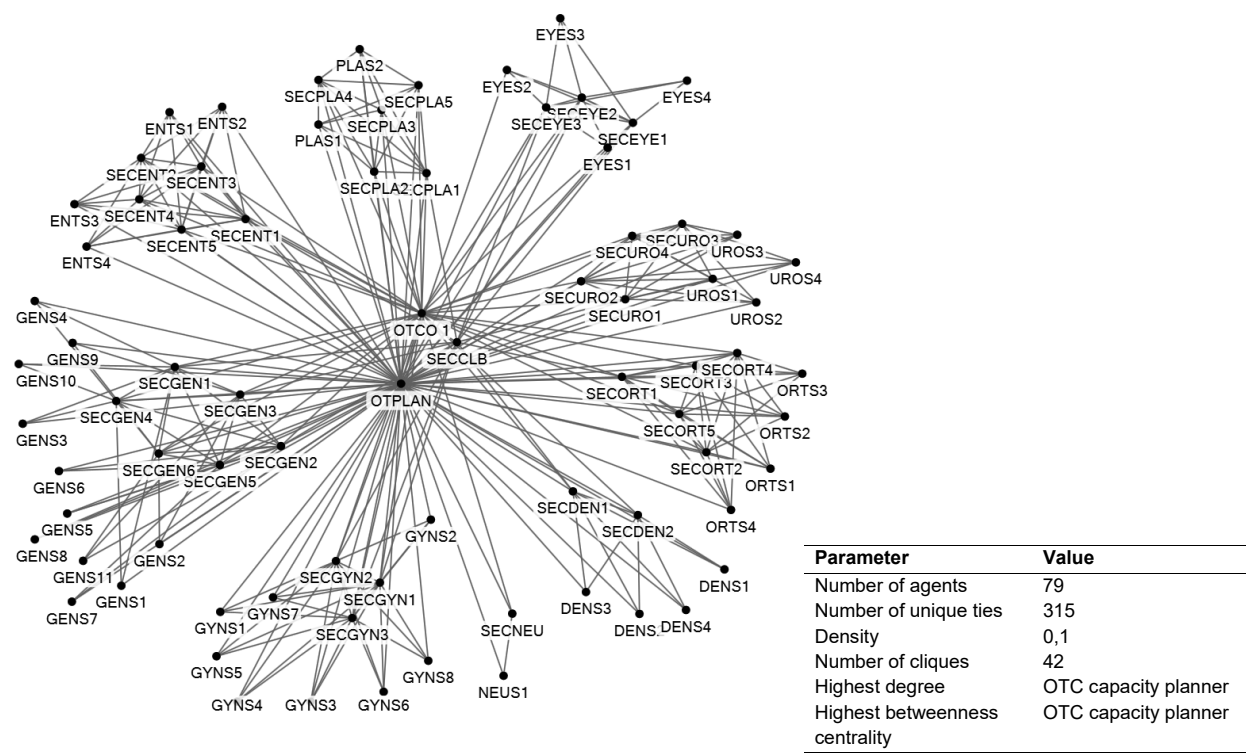

\section{After}

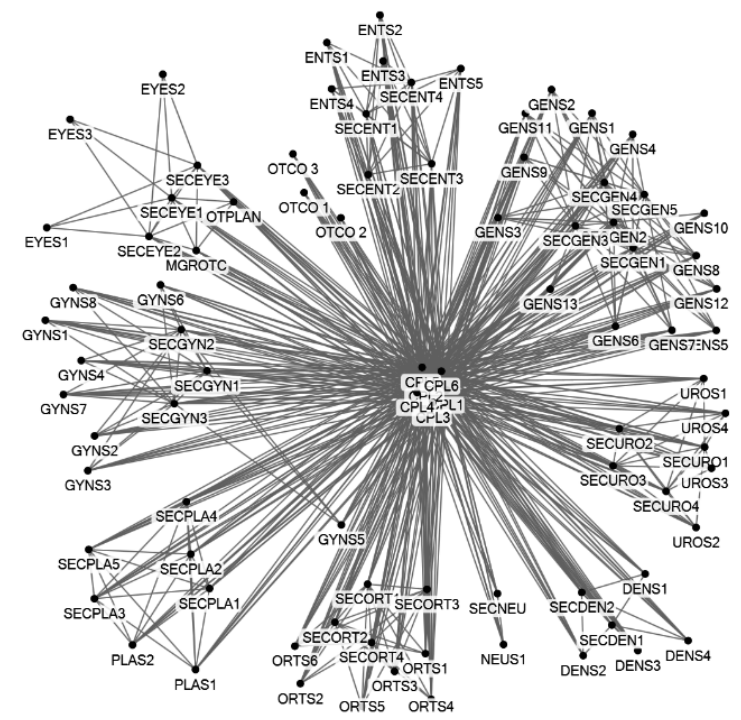

\begin{tabular}{ll}
\hline Parameter & Value \\
\hline Number of agents & 88 \\
Number of unique ties & 715 \\
Density & 0,2 \\
Number of cliques & 50 \\
Highest degree & All central planners \\
Highest betweenness & All central planners \\
centrality & \\
\hline
\end{tabular}

Figure A5.2.5 Before and after social networks and metrics for task 6 . 


\section{A5.2.6 Task 11: Control planning}

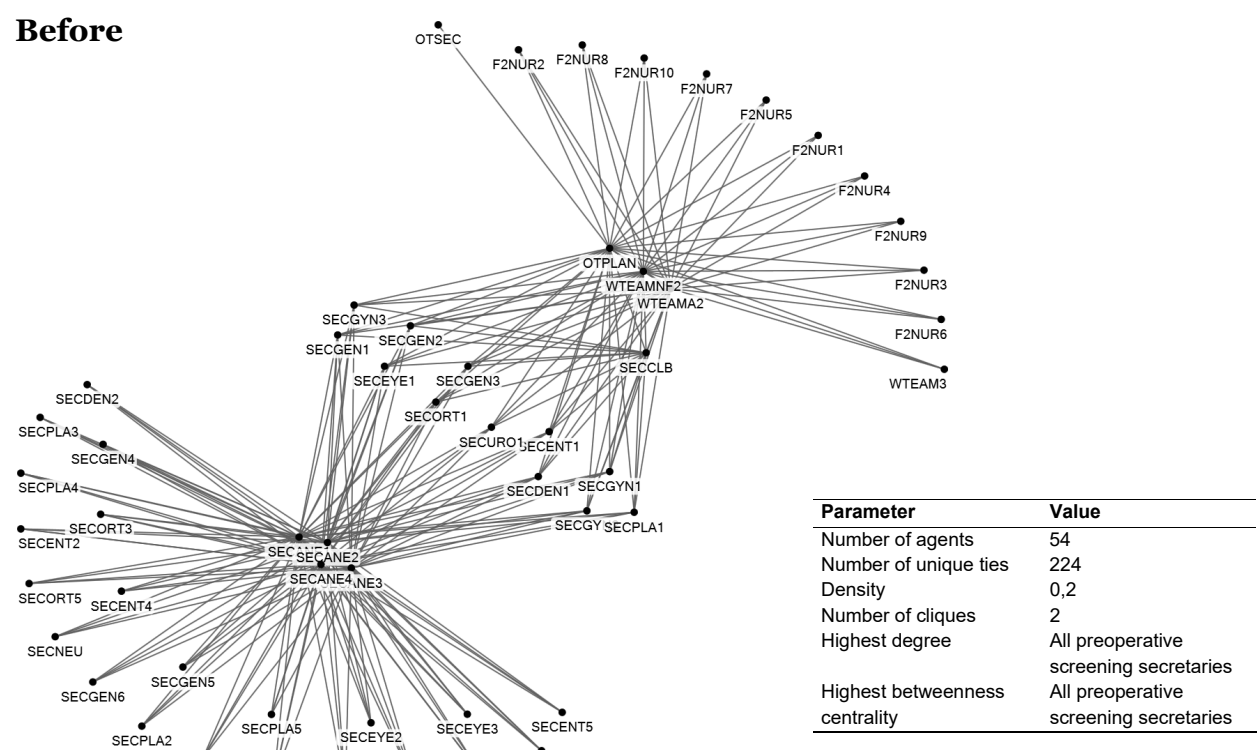

After

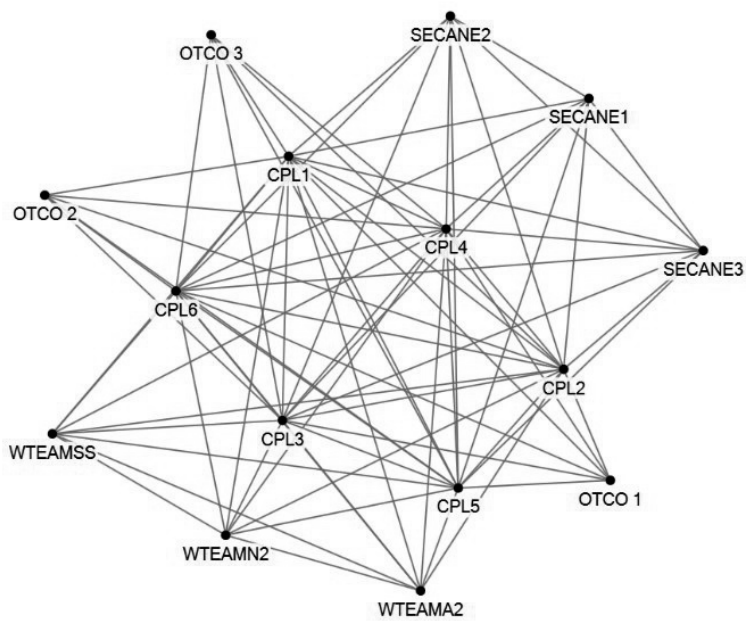

\begin{tabular}{ll}
\hline Parameter & Value \\
\hline Number of agents & 15 \\
Number of unique ties & 75 \\
Density & 0,7 \\
Number of cliques & 5 \\
Highest degree & All central planners \\
Highest betweenness & All central planners \\
centrality & \\
\hline
\end{tabular}

Figure A5.2.6 Before and after social networks and metrics for task 11 . 


\section{A5.2.7 Task 14: Prepare patient on ward}
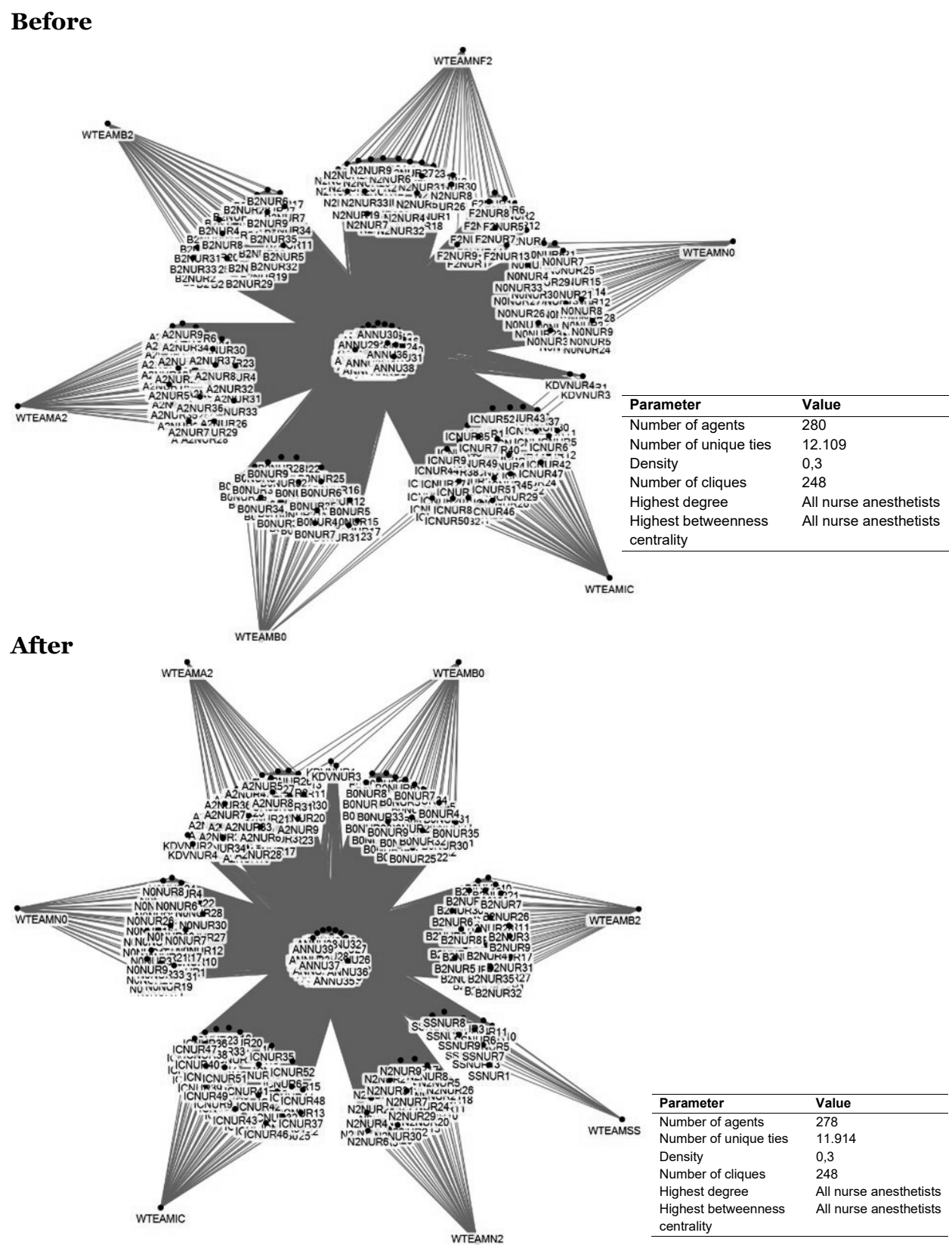

Figure A5.2.7 Before and after social networks and metrics for task 14 . 


\section{A5.2.8 Task 15: Prepare patient on holding}
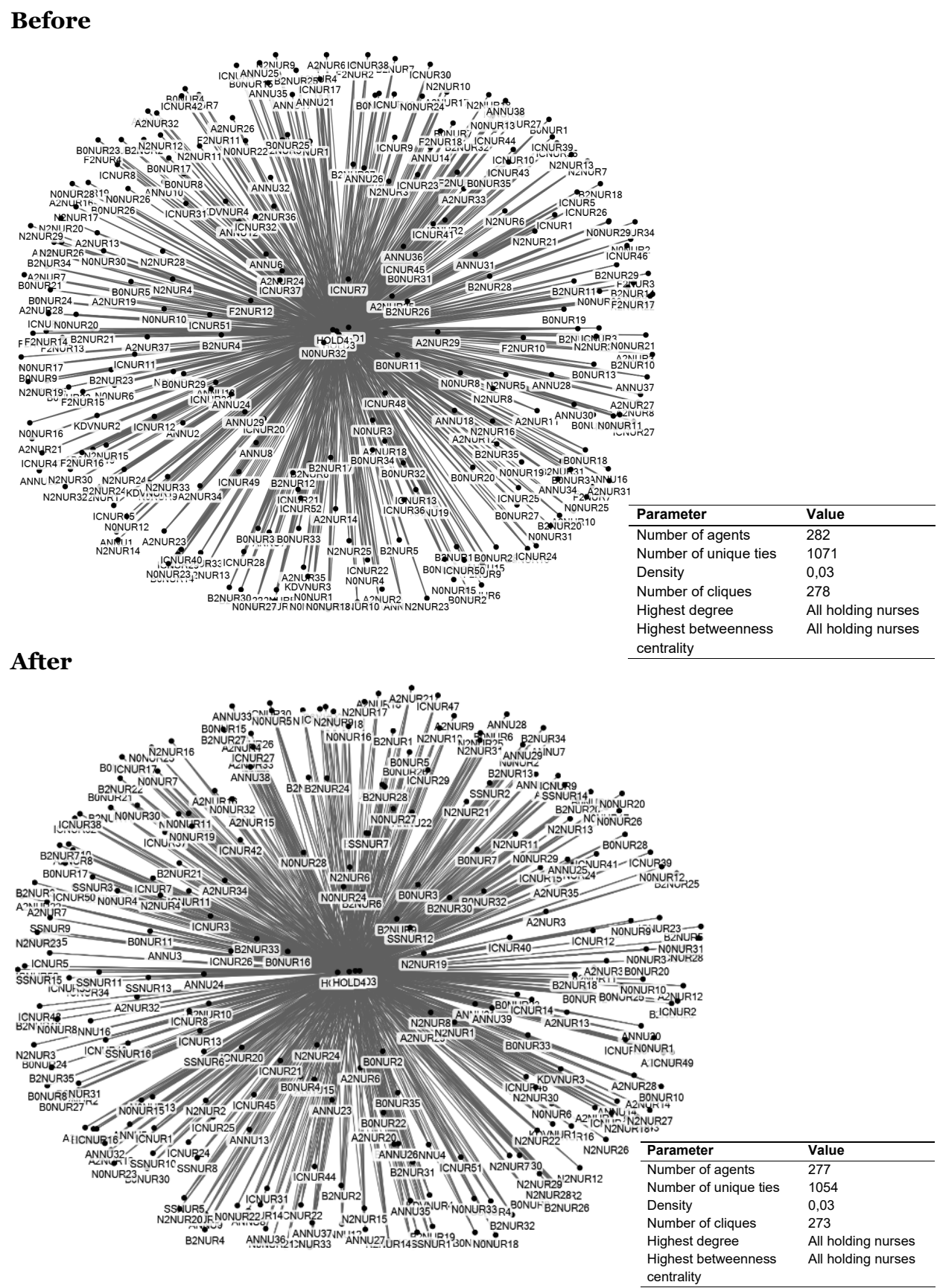

Figure A5.2.8 Before and after social networks and metrics for task 15 . 


\section{A5.2.9 Task 17: Perform surgery}

\section{Before}

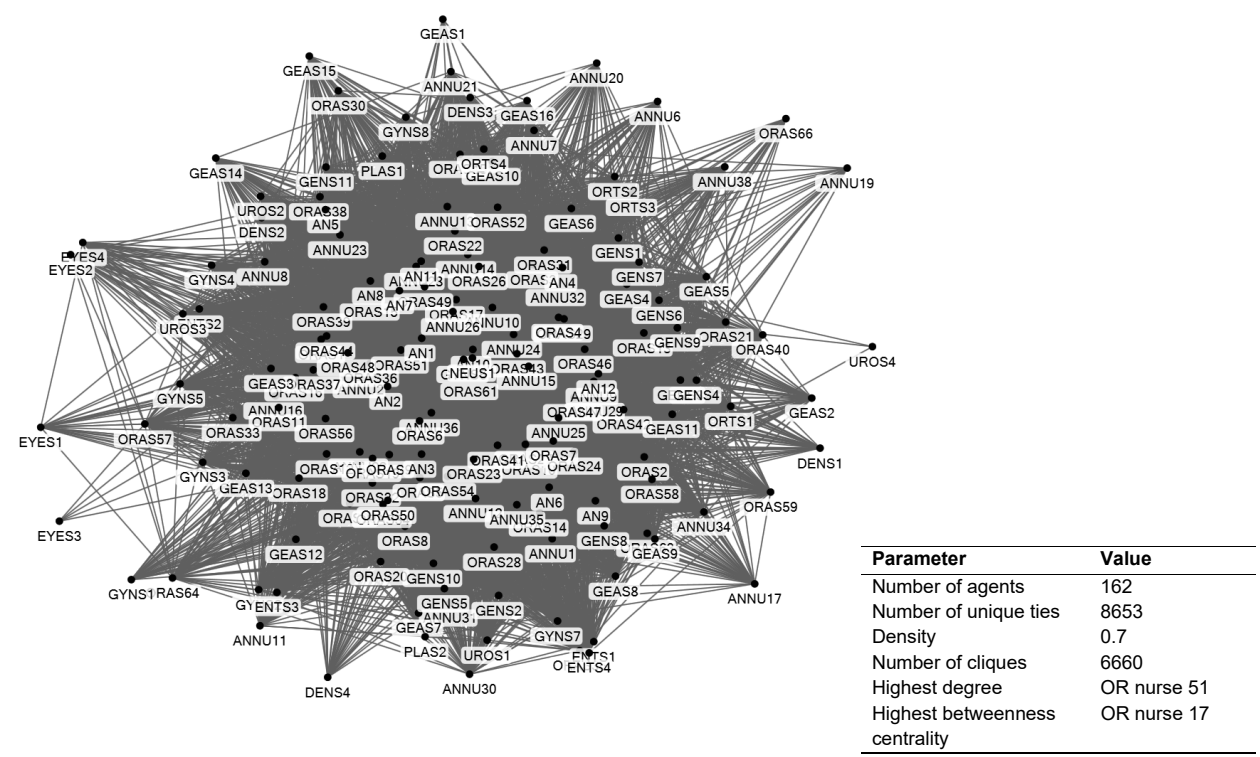

After

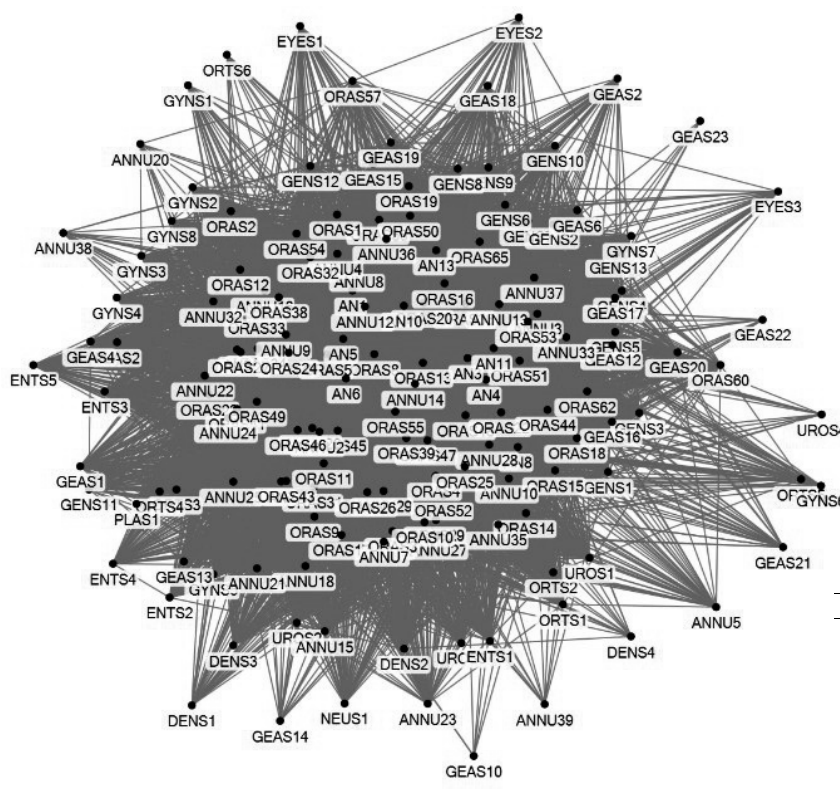

\begin{tabular}{ll}
\hline Parameter & Value \\
\hline Number of agents & 157 \\
Number of unique ties & 8183 \\
Density & 0.7 \\
Number of cliques & 5881 \\
Highest degree & Nurse anesthetist 12, \\
& OR nurse 48 \\
Highest betweenness & OR nurse 25 \\
centrality & \\
\end{tabular}

Figure A5.2.9 Before and after social networks and metrics for task 17 . 


\section{A5.2.10 Task 20: Patient care Recovery}

\section{Before}
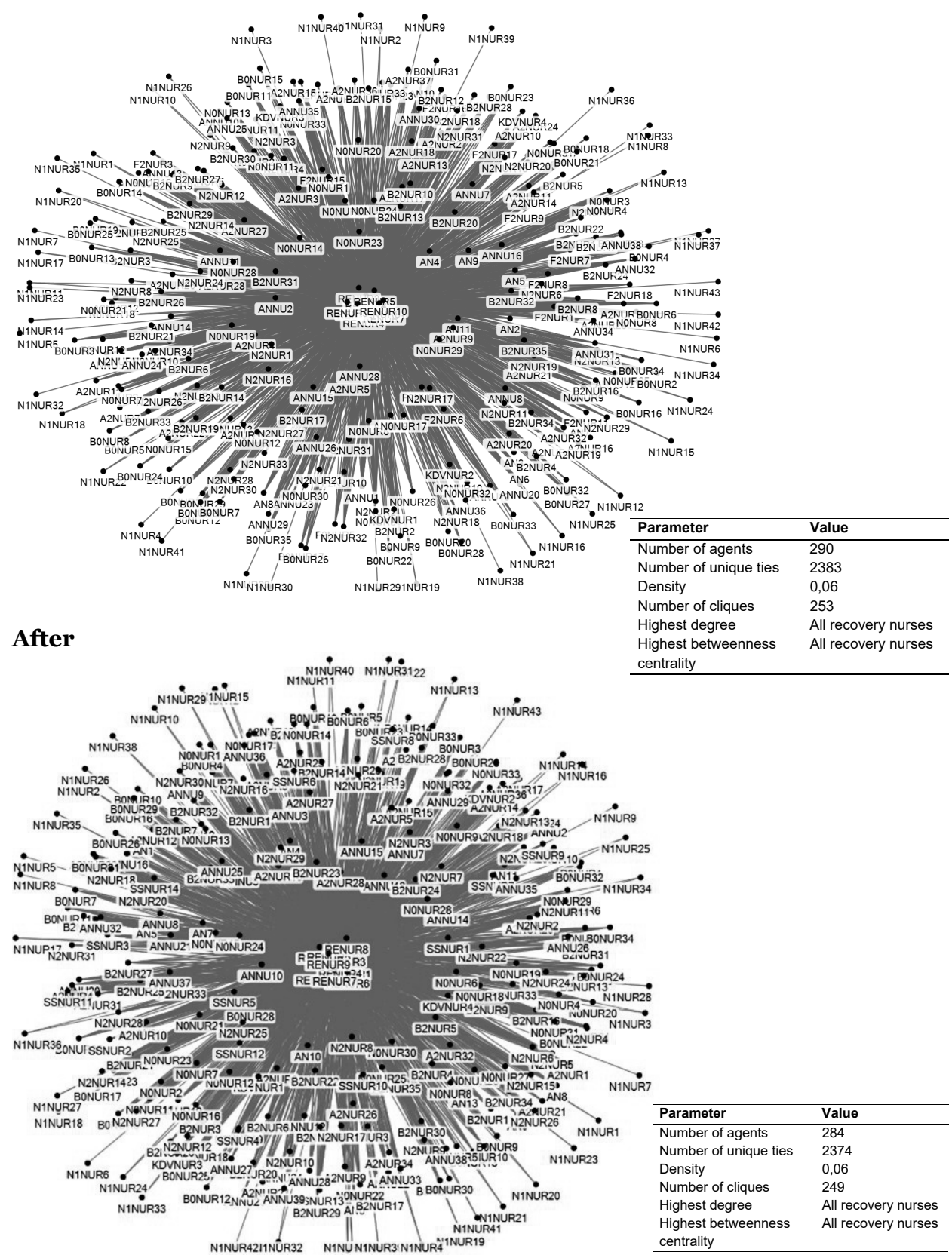

Figure A5.2.10 Before and after social networks and metrics for task 20. 


\section{A5.2.11 Task 21: Aftercare patient}

\section{Before}

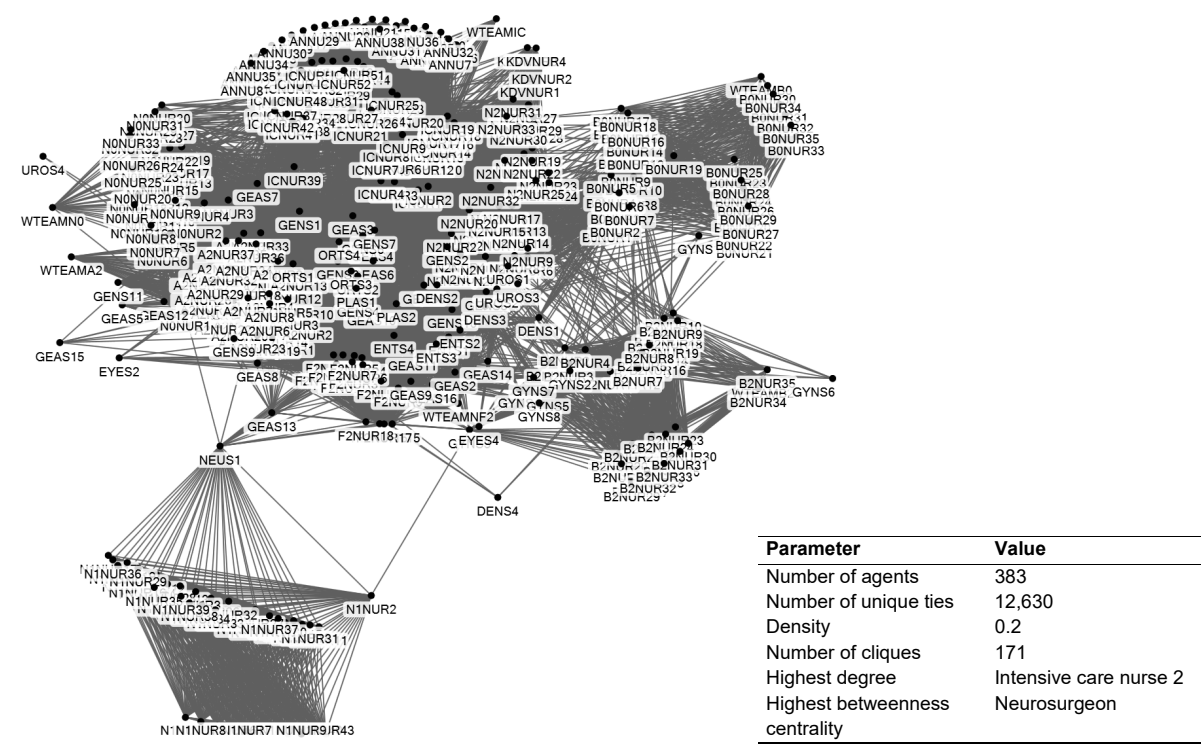

After

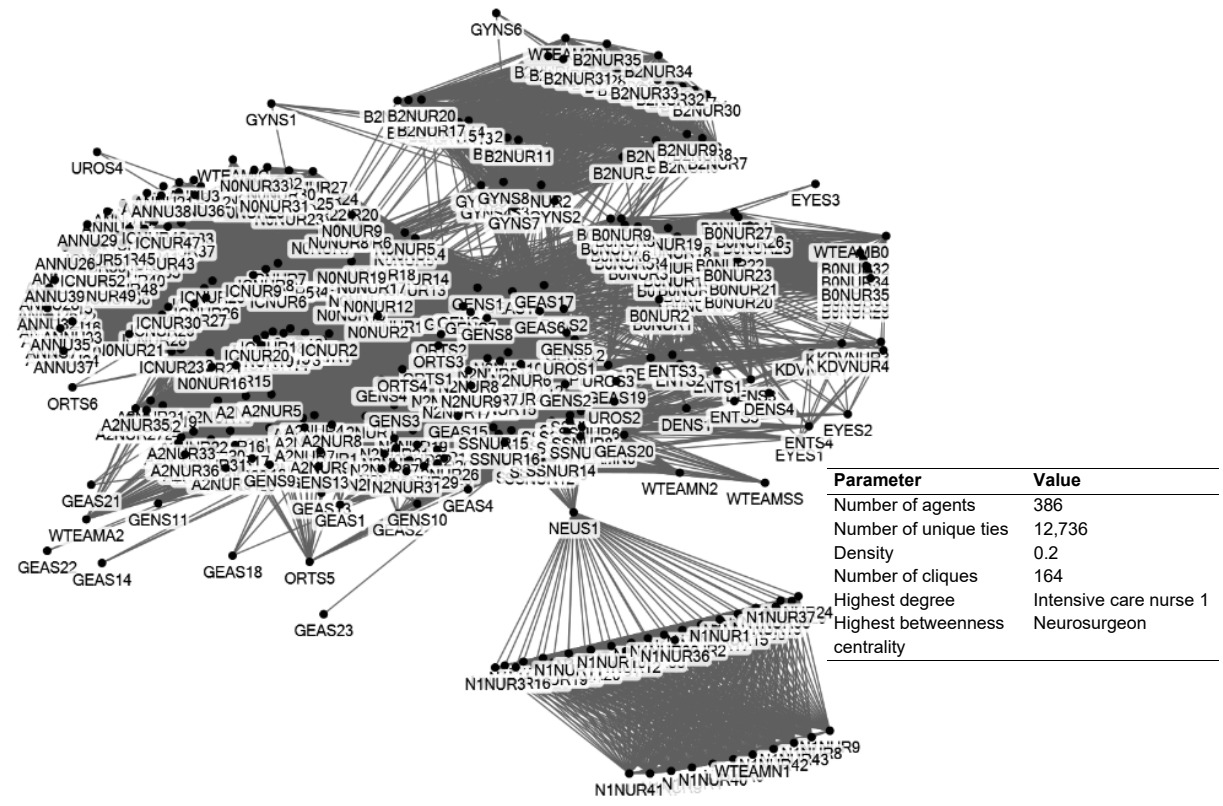

Figure A5.2.11 Before and after social networks and metrics for task 21 . 


\section{A5.2.12 Task 22: Manage OTC day program}

\section{Before}
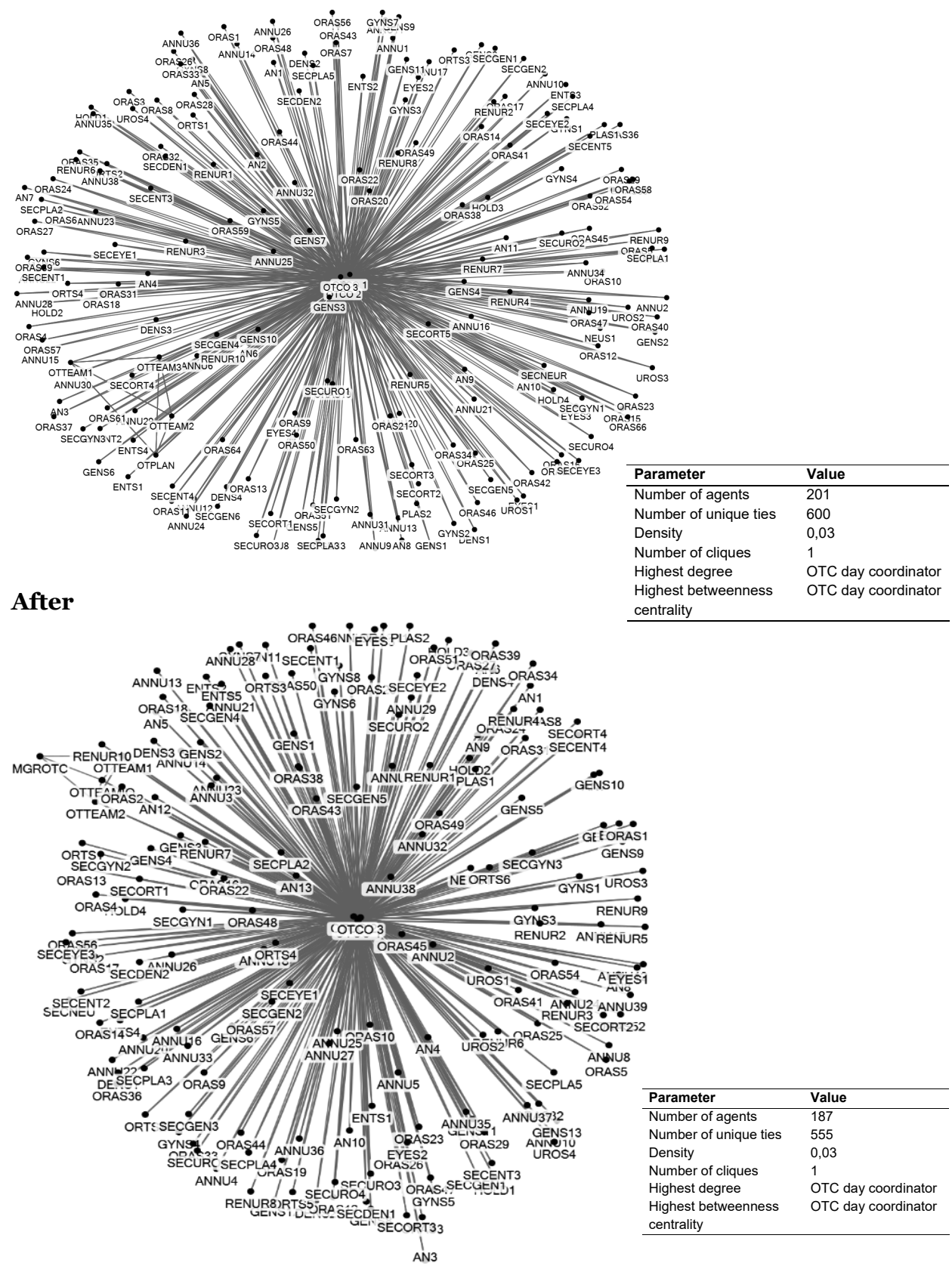

Figure A5.2.12 Before and after social networks and metrics for task 22 . 


\section{A5.2.13 Description of agent codes in social networks}

\begin{tabular}{|c|c|}
\hline Agent code & Description \\
\hline A2NUR & Ward A2 nurse \\
\hline $\mathrm{AN}$ & Anesthesiologist \\
\hline ANNU & Nurse anesthetist \\
\hline BoNUR & Ward Bo nurse \\
\hline B2NUR & Ward B2 nurse \\
\hline $\mathrm{CM}$ & Cluster Manager \\
\hline $\mathrm{CPL}$ & Central planner \\
\hline DENS & Dental surgeon \\
\hline ENTS & Ear Nose Throat surgeon \\
\hline EYES & Eye surgeon \\
\hline F2NUR & Ward F2 nurse \\
\hline GEAS & Assistant surgeon \\
\hline GENS & General surgeon \\
\hline GYNS & Gynecological surgeon \\
\hline HOLD & Holding nurse \\
\hline ICNUR & Intensive care nurse \\
\hline KDVNUR & Pediatric ward nurse \\
\hline MGROTC & OTC Manager \\
\hline NoNUR & Ward No nurse \\
\hline N2NUR & Ward N2 nurse \\
\hline NEUS & Neurosurgeon \\
\hline ORAS & OR nurse \\
\hline ORTS & Orthopedic surgeon \\
\hline OTCO & OTC day coordinator \\
\hline OTPLAN & OTC capacity planner \\
\hline OTTEAM & Team leader OTC \\
\hline OUTPNU & Outpatient department nurse \\
\hline PLAS & Plastic surgeon \\
\hline RENUR & Recovery nurse \\
\hline SECANE & Secretary Anesthesia \\
\hline SECDEN & Secretary Dental Surgery outpatient department \\
\hline SECENT & Secretary ENT outpatient department \\
\hline SECEYE & Secretary Ophthalmology outpatient department \\
\hline SECGEN & Secretary General surgery outpatient department \\
\hline SECGYN & Secretary Gynecology outpatient department \\
\hline SECNEU & Secretary Neurology outpatient department \\
\hline SECORT & Secretary Orthopedics outpatient department \\
\hline SECPLA & Secretary Plastic surgery outpatient department \\
\hline SECURO & Secretary Urology outpatient department \\
\hline SSNUR & Short Stay nurse \\
\hline UROS & Urology surgeon \\
\hline WTEAMA2 & Ward team leader A2 \\
\hline WTEAMIC & Ward team leader Intensive Care \\
\hline
\end{tabular}




\section{APPENDIX 5.3: RULES AND COORDINATION MECHANISMS}

All rules in the before and after period are presented. A rule applied in the before period either remains to exist in the after period, does not exist in the after period, is new or is adapted, in which case the adaptations to the rule are described. 


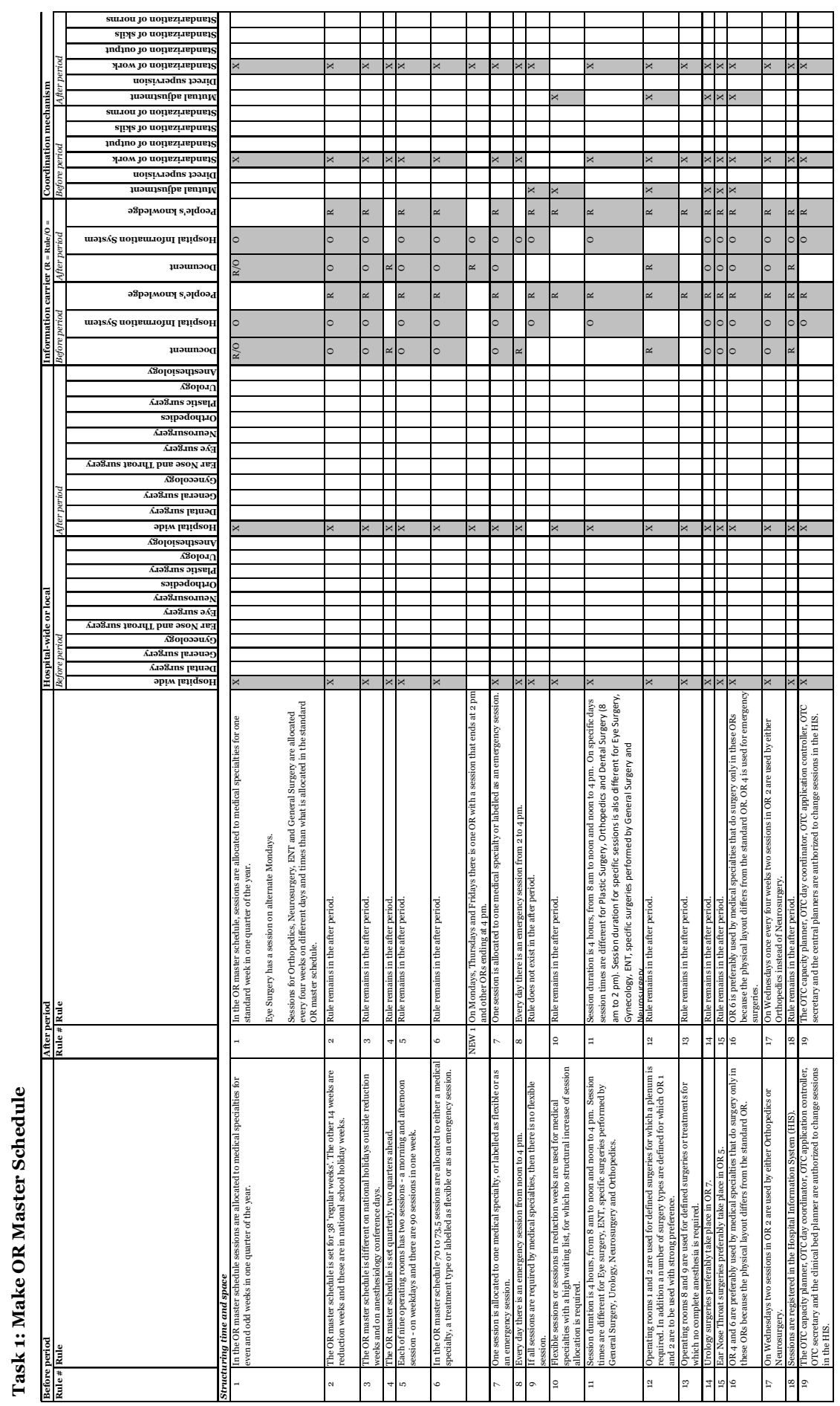




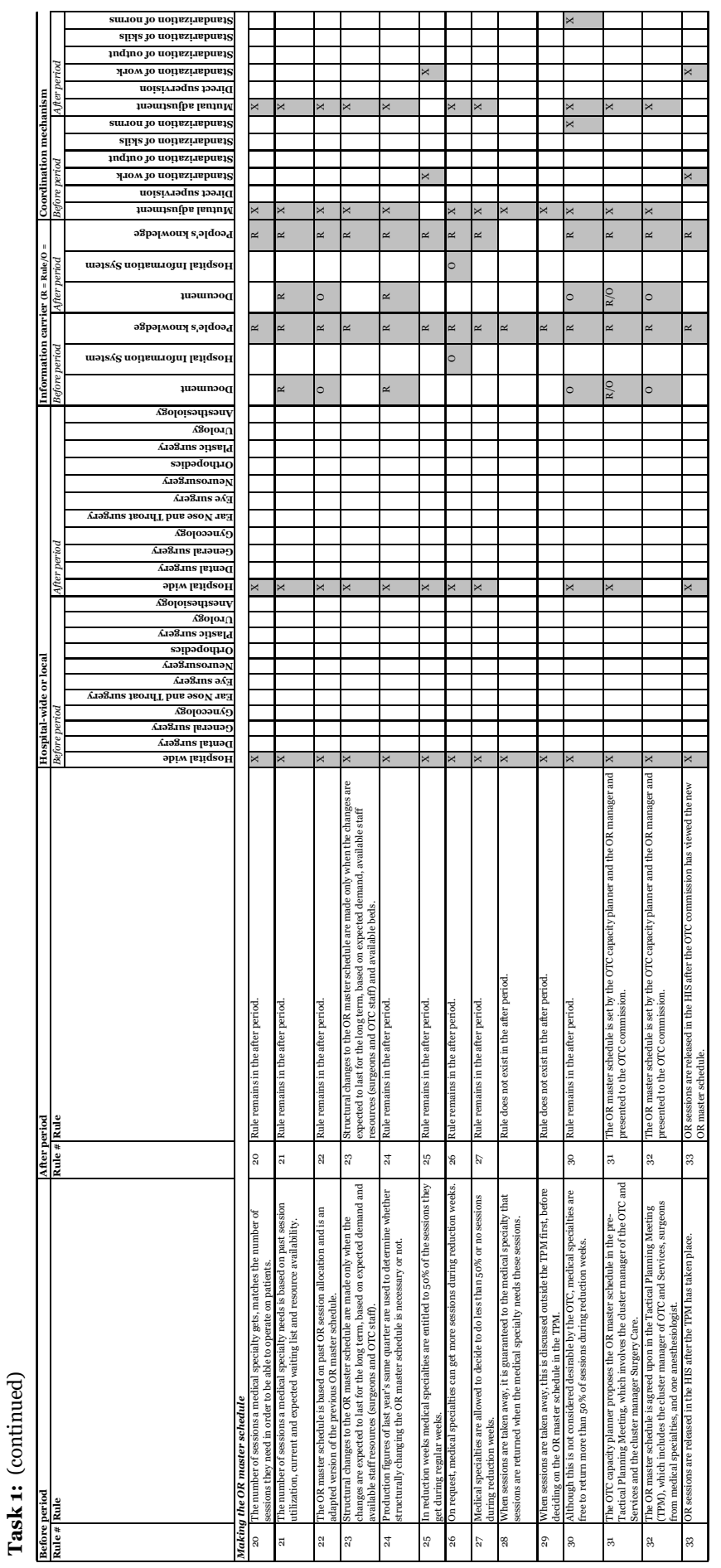




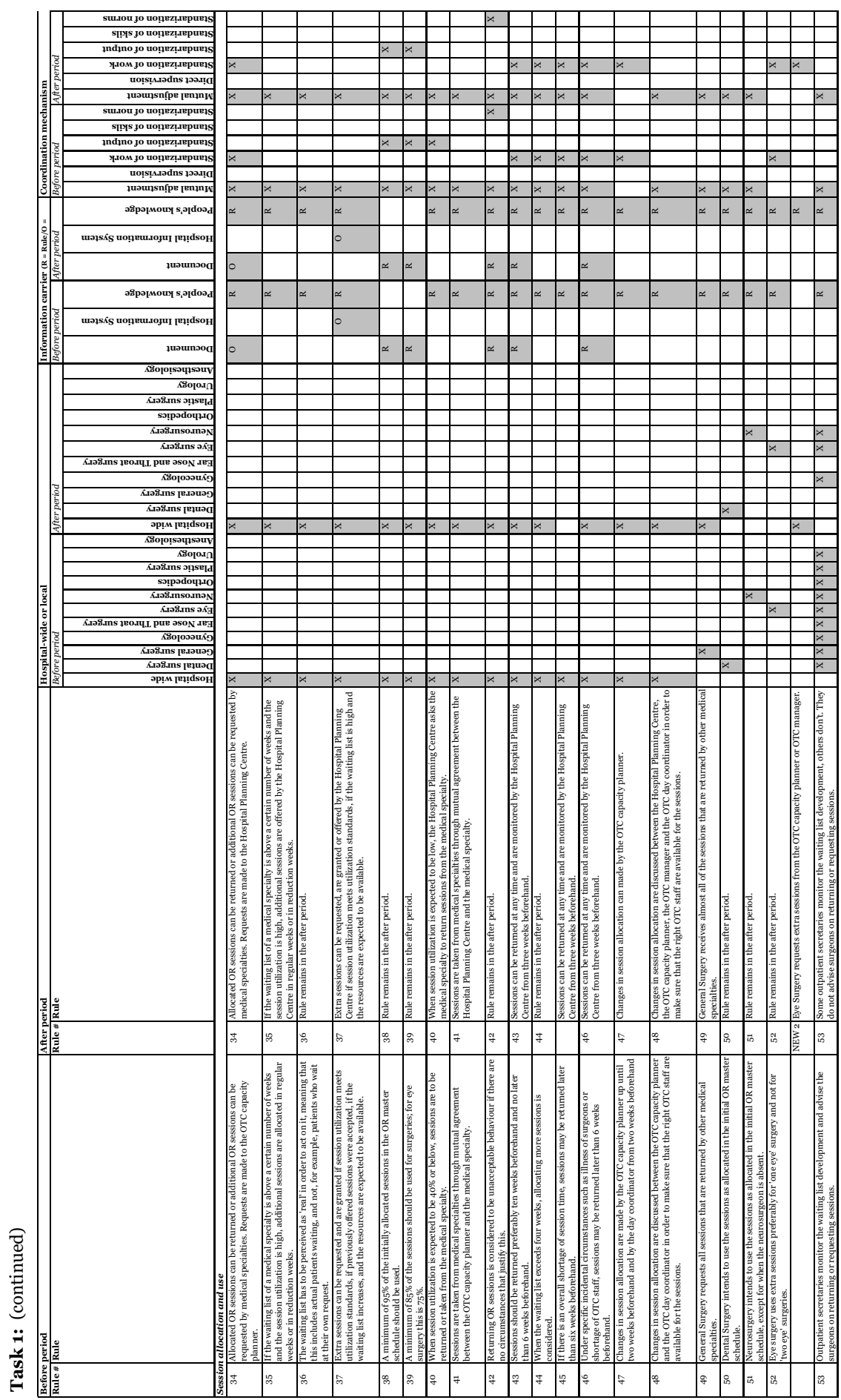




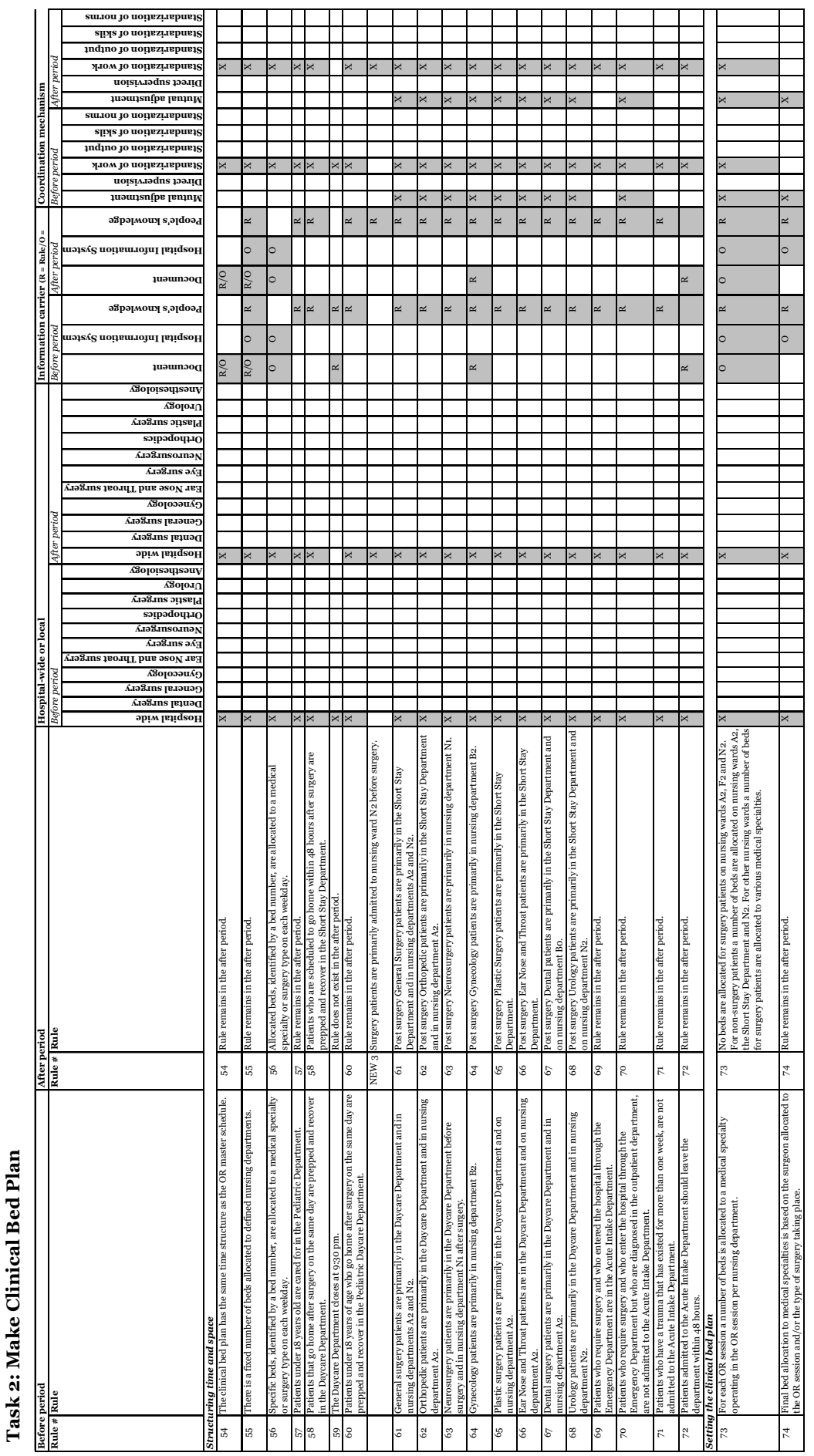




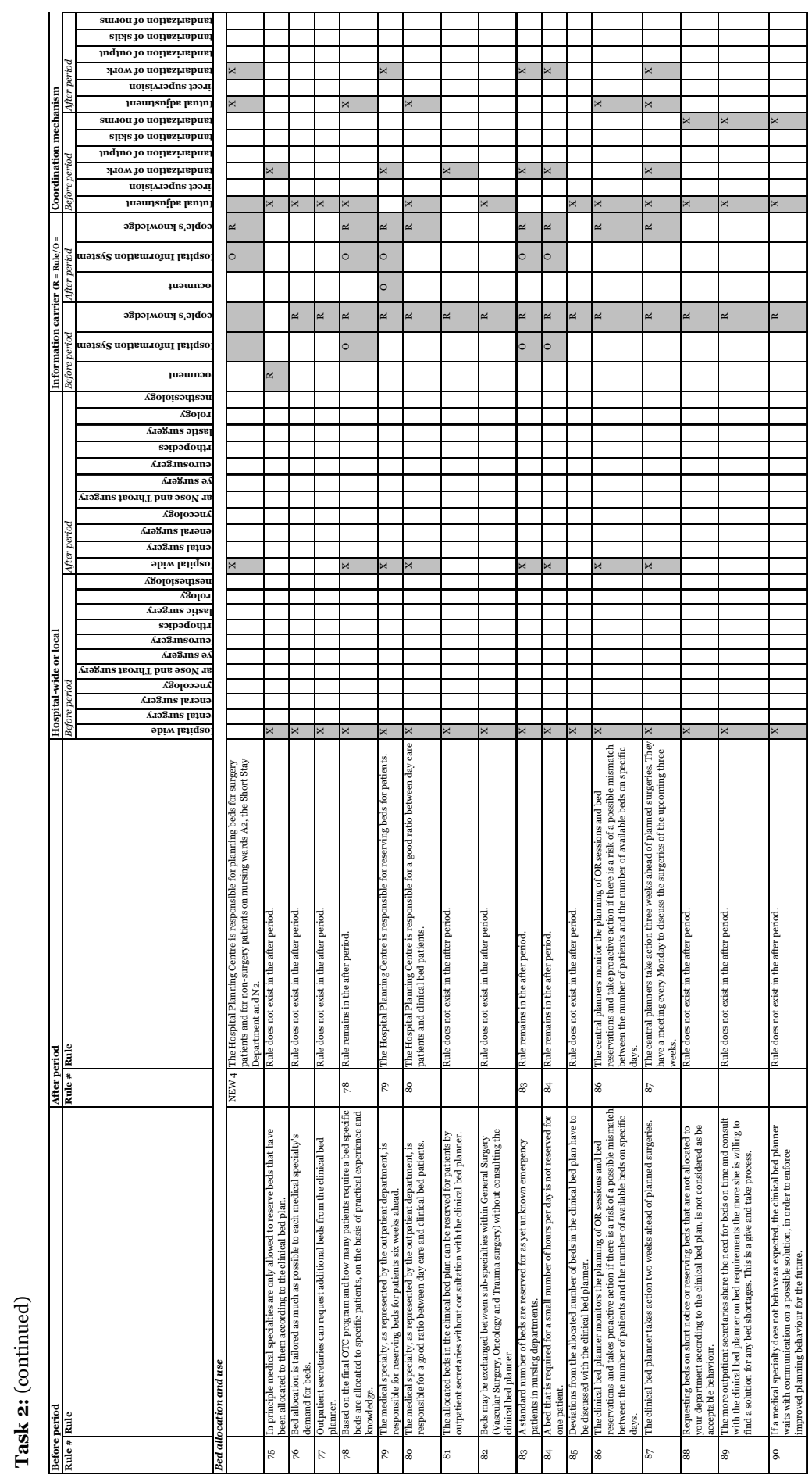




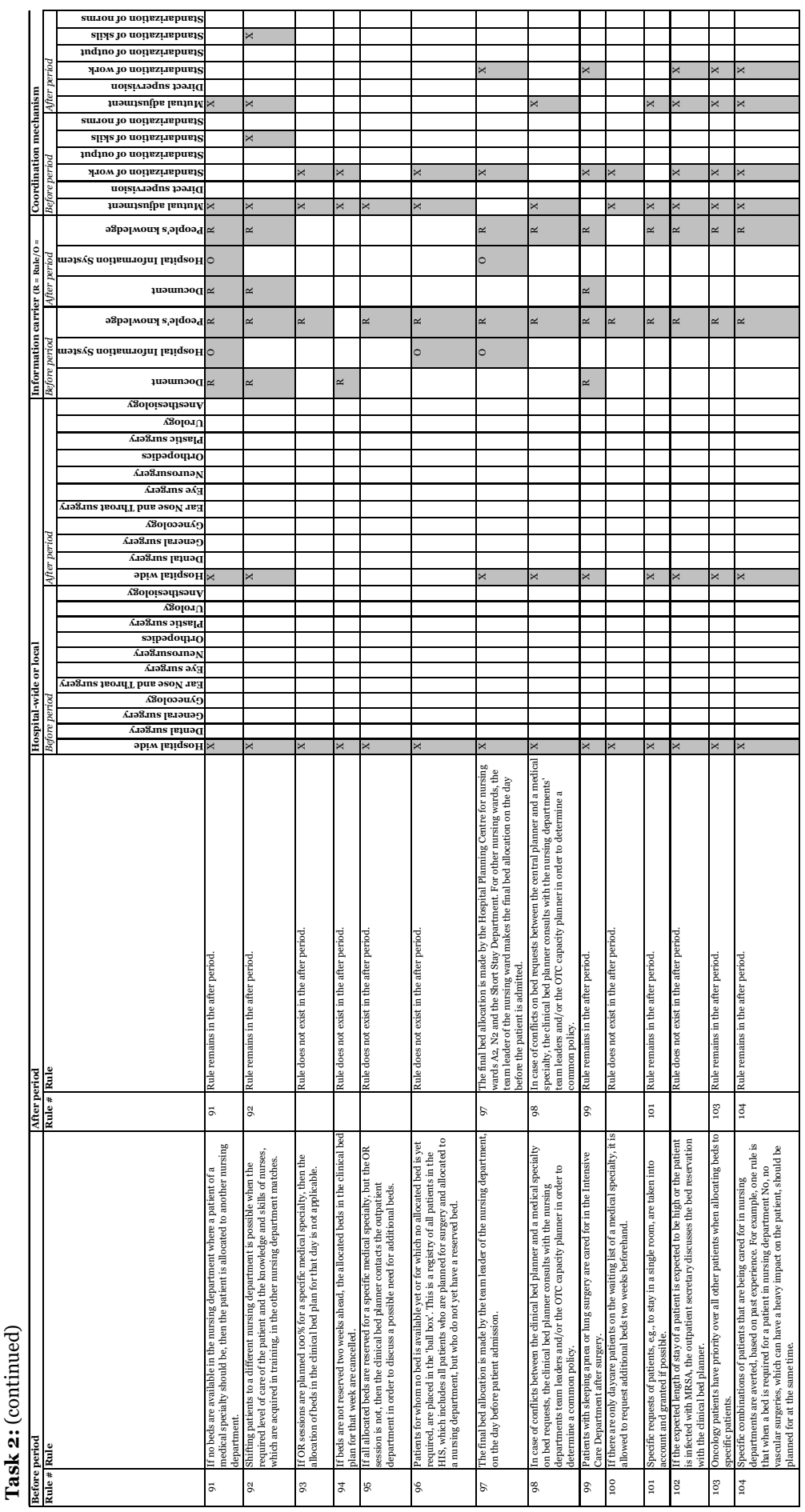




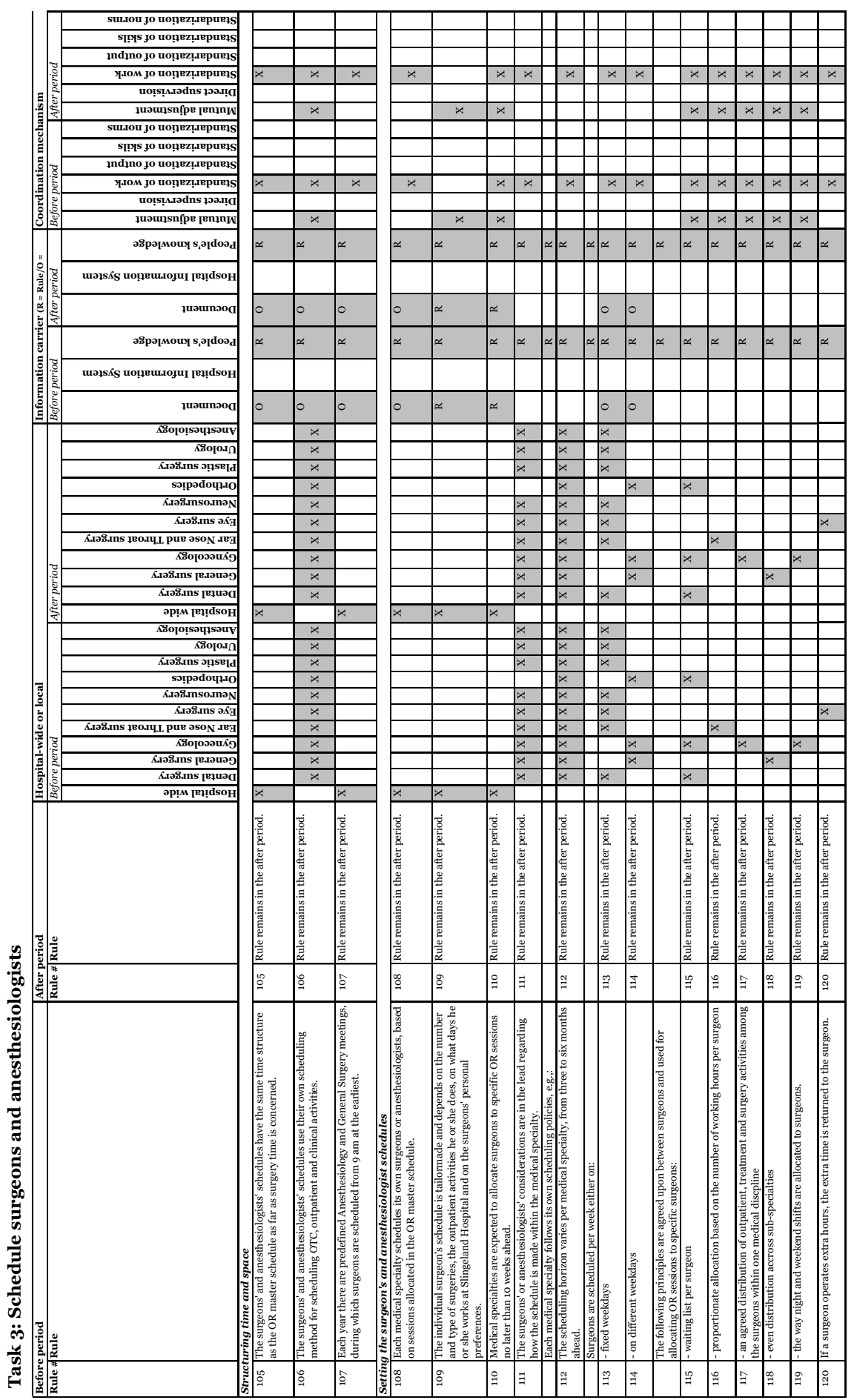




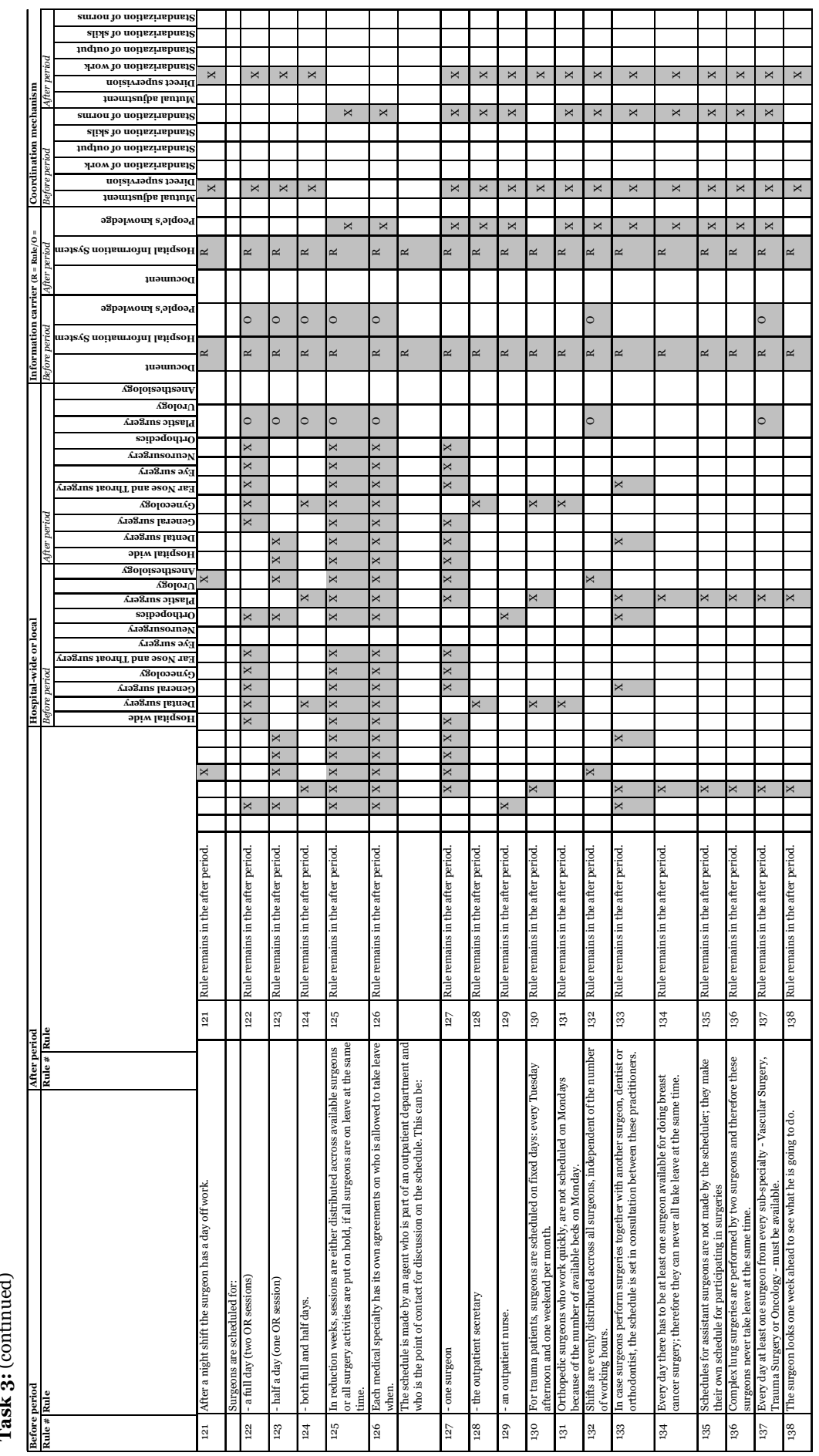




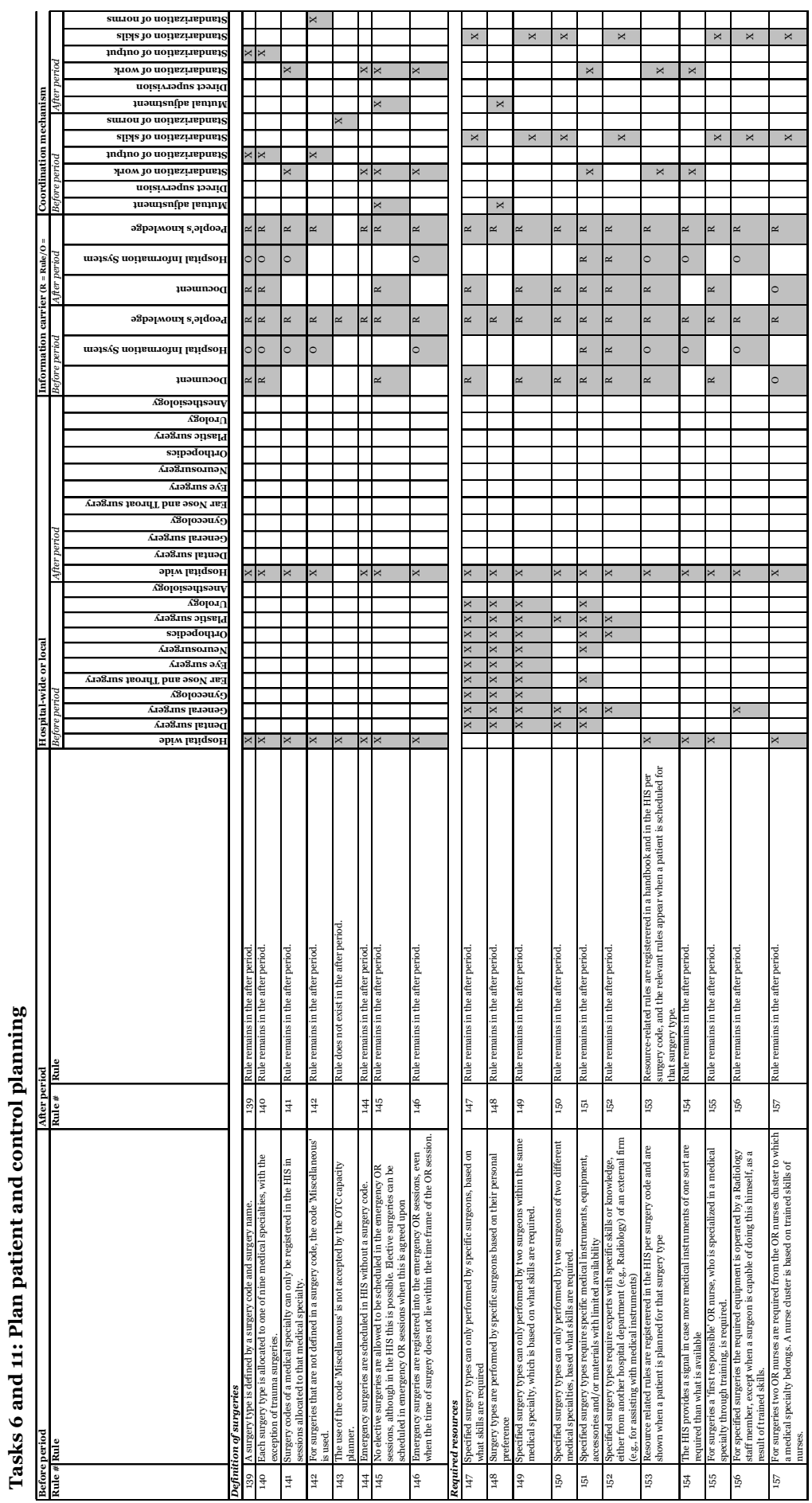




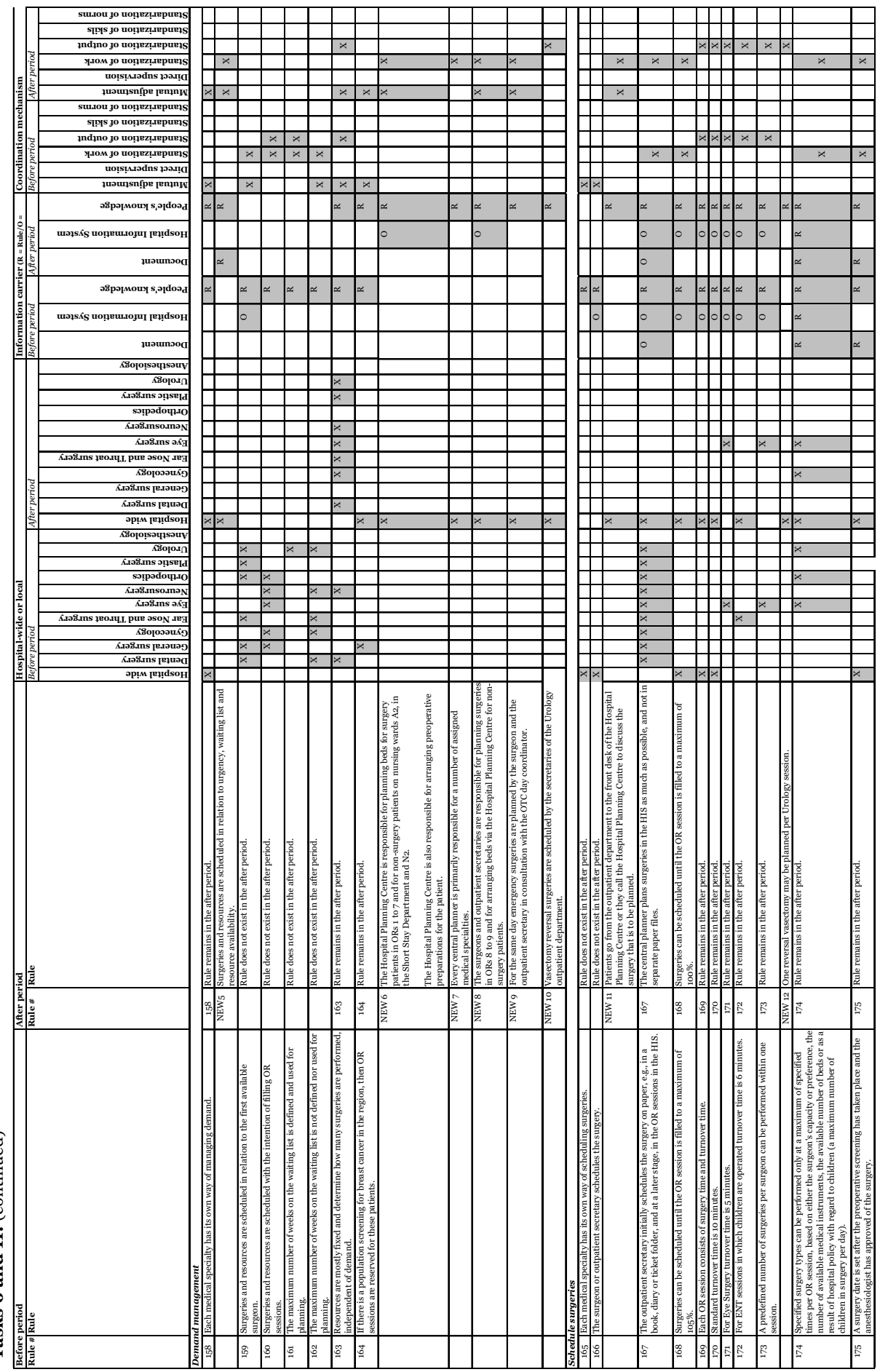




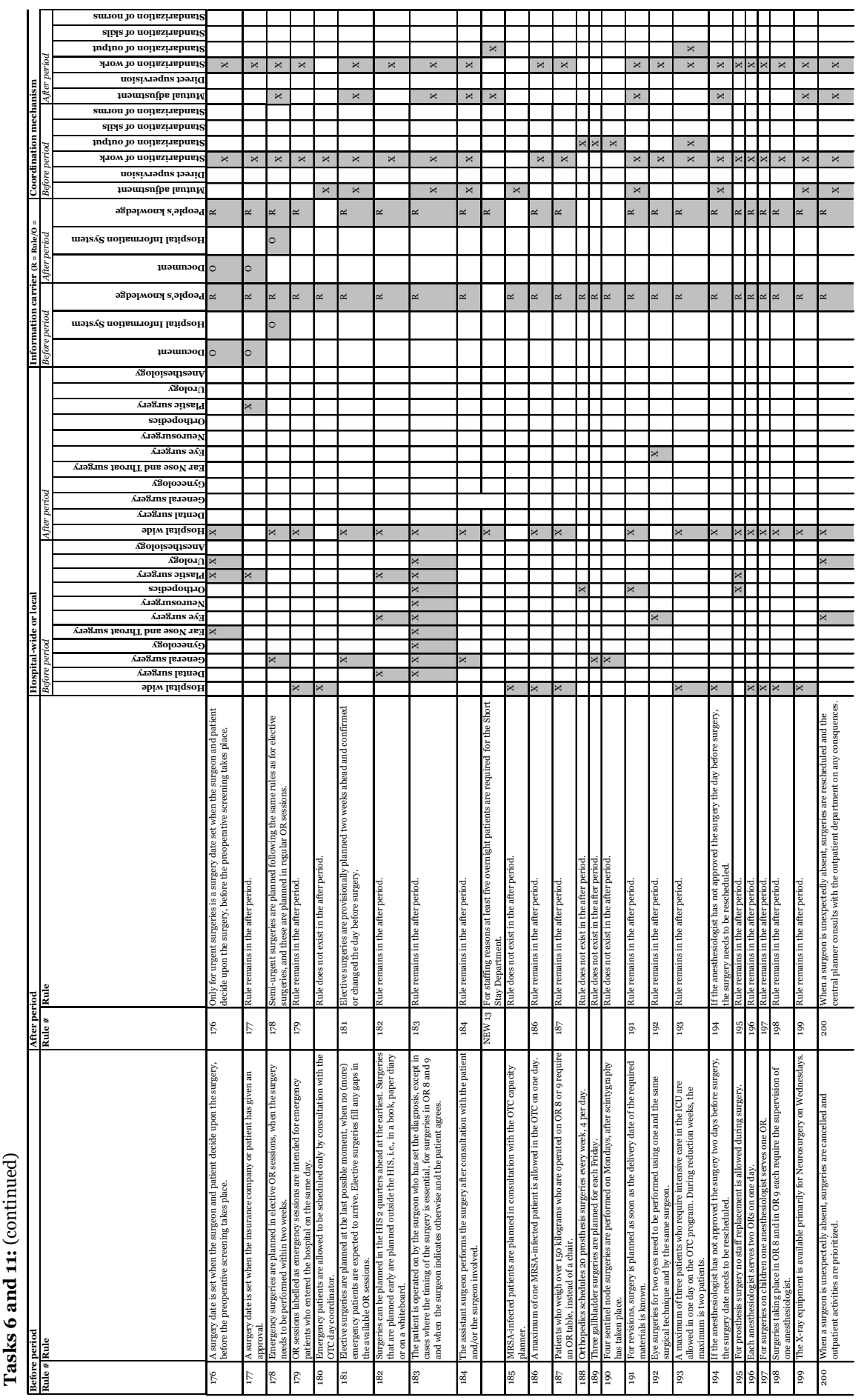




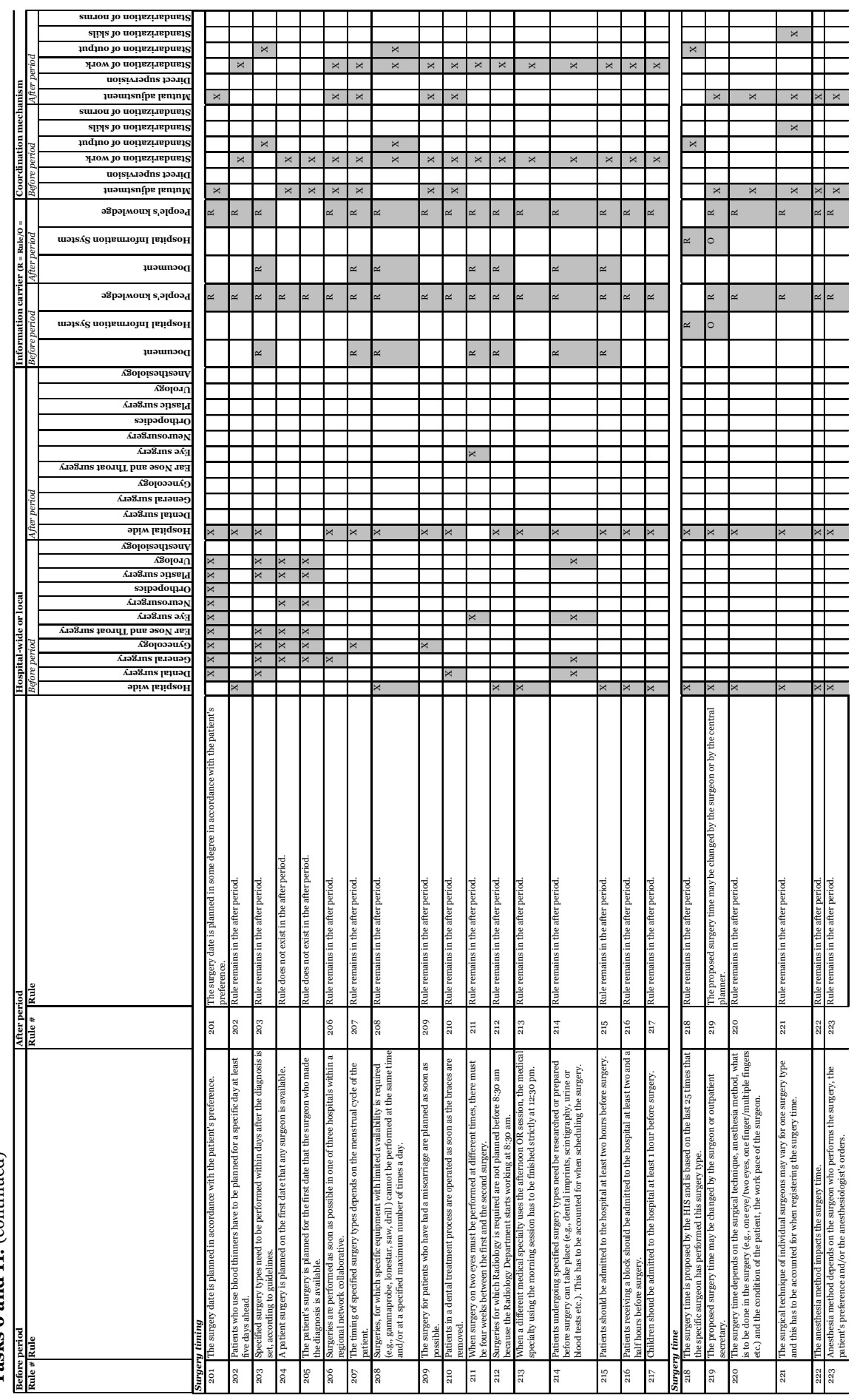




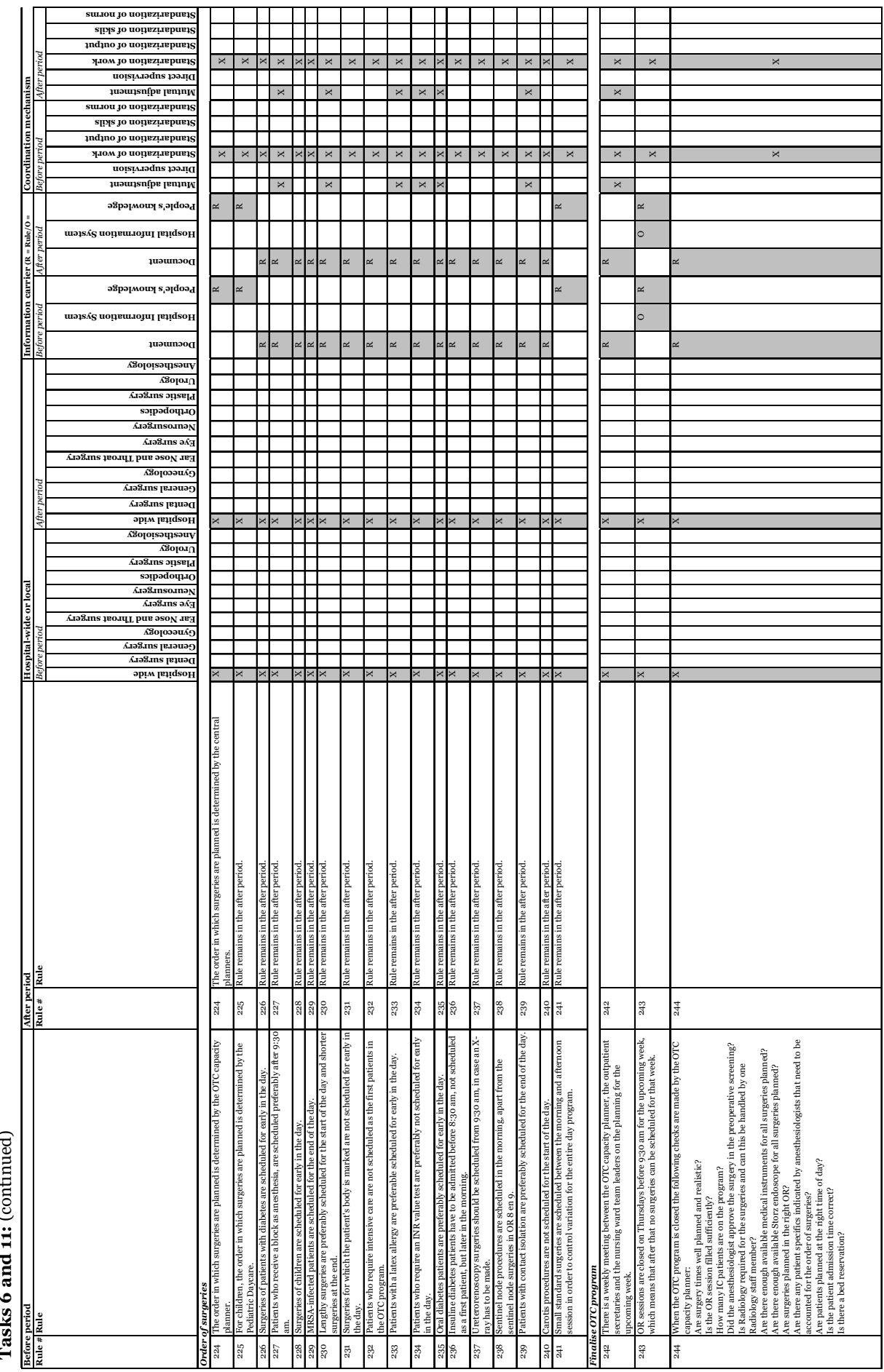




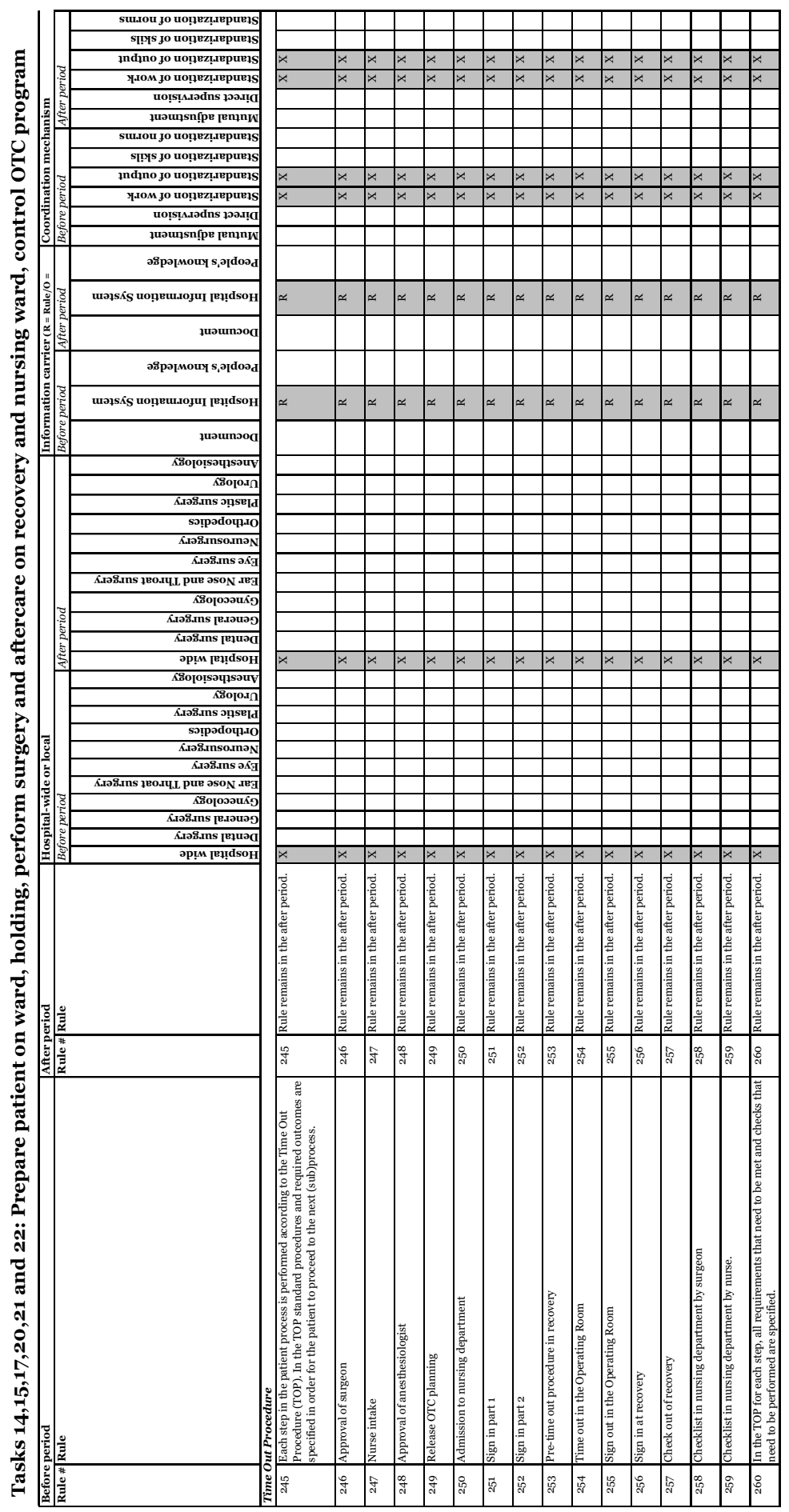




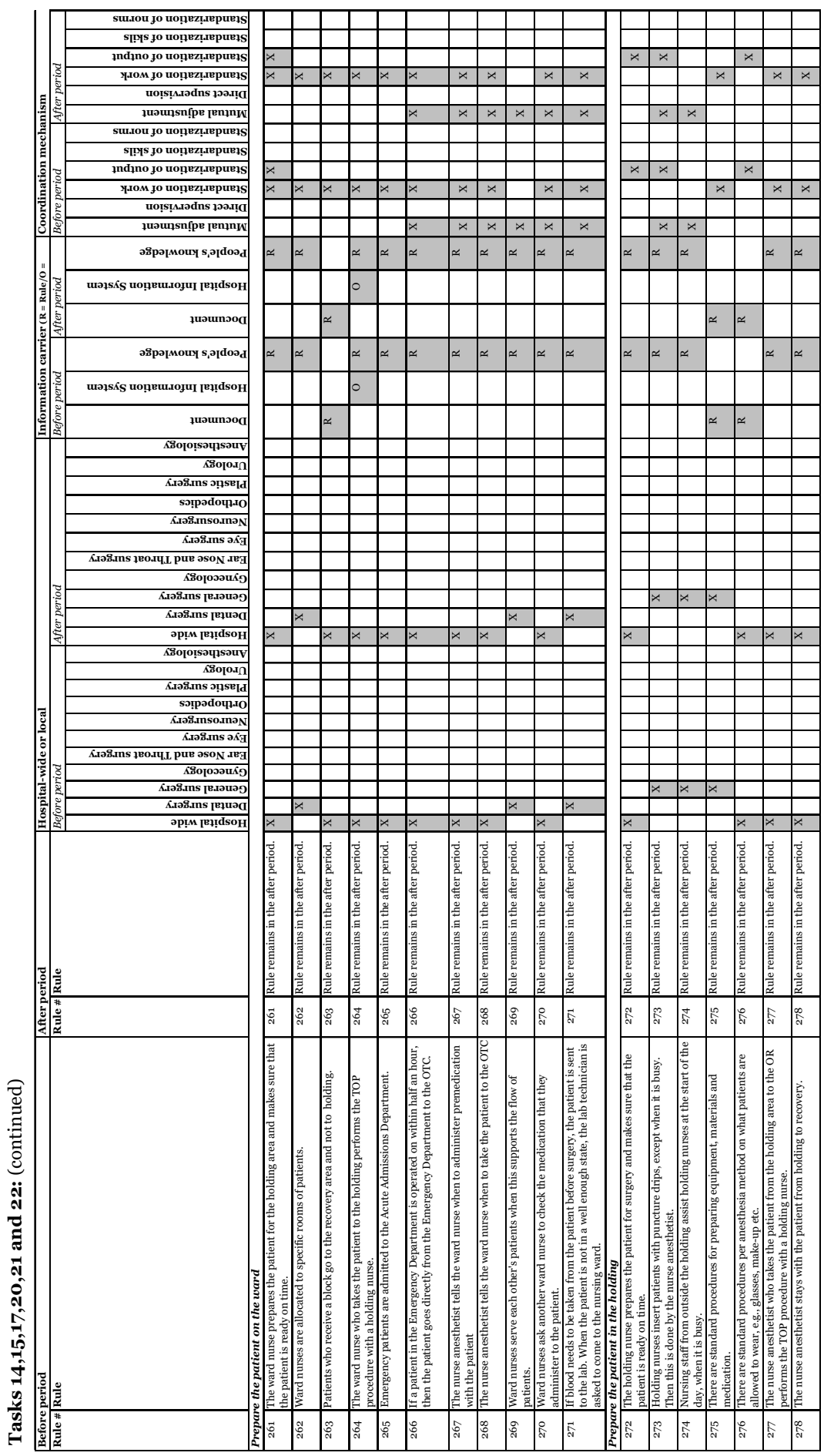




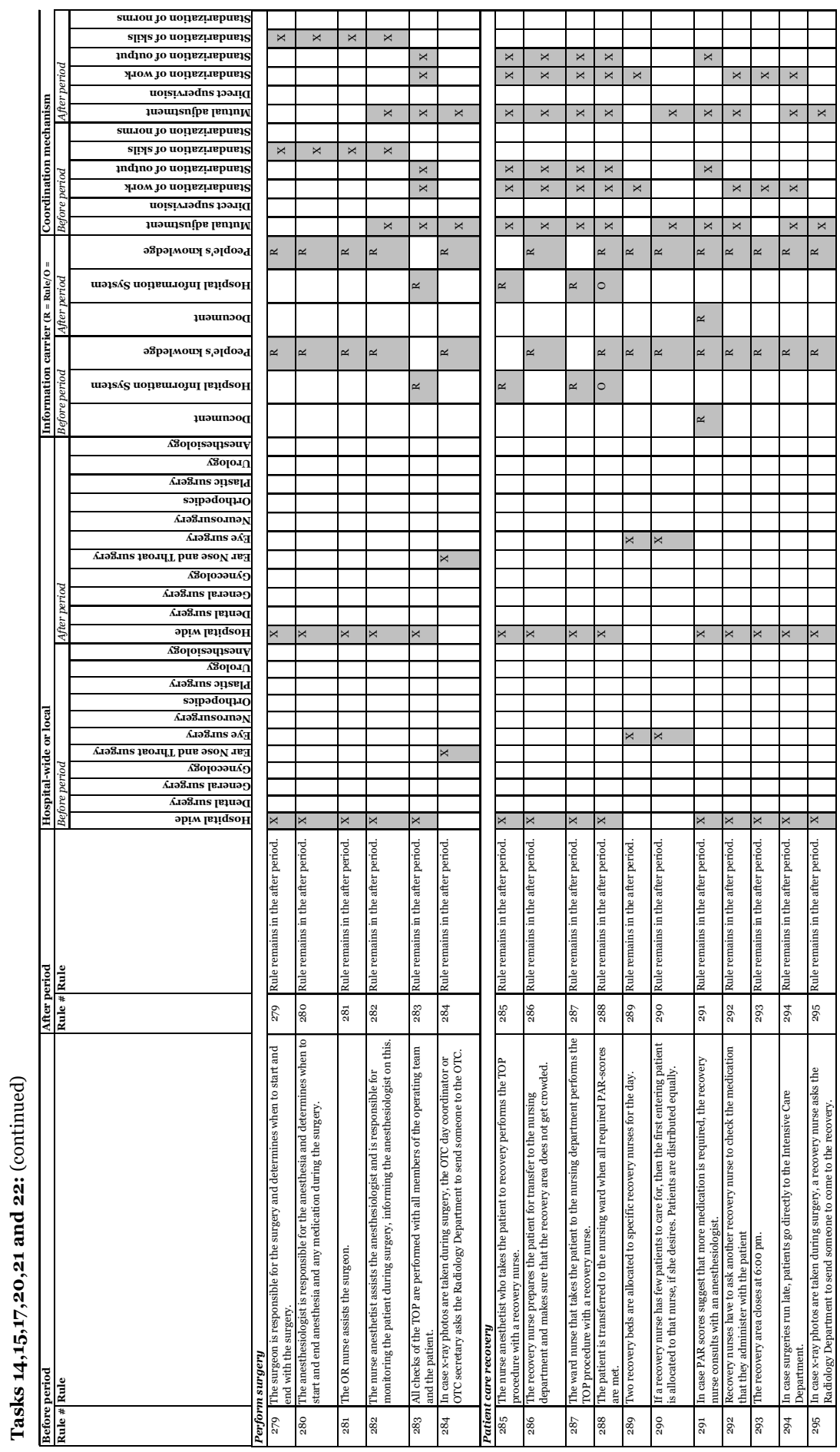




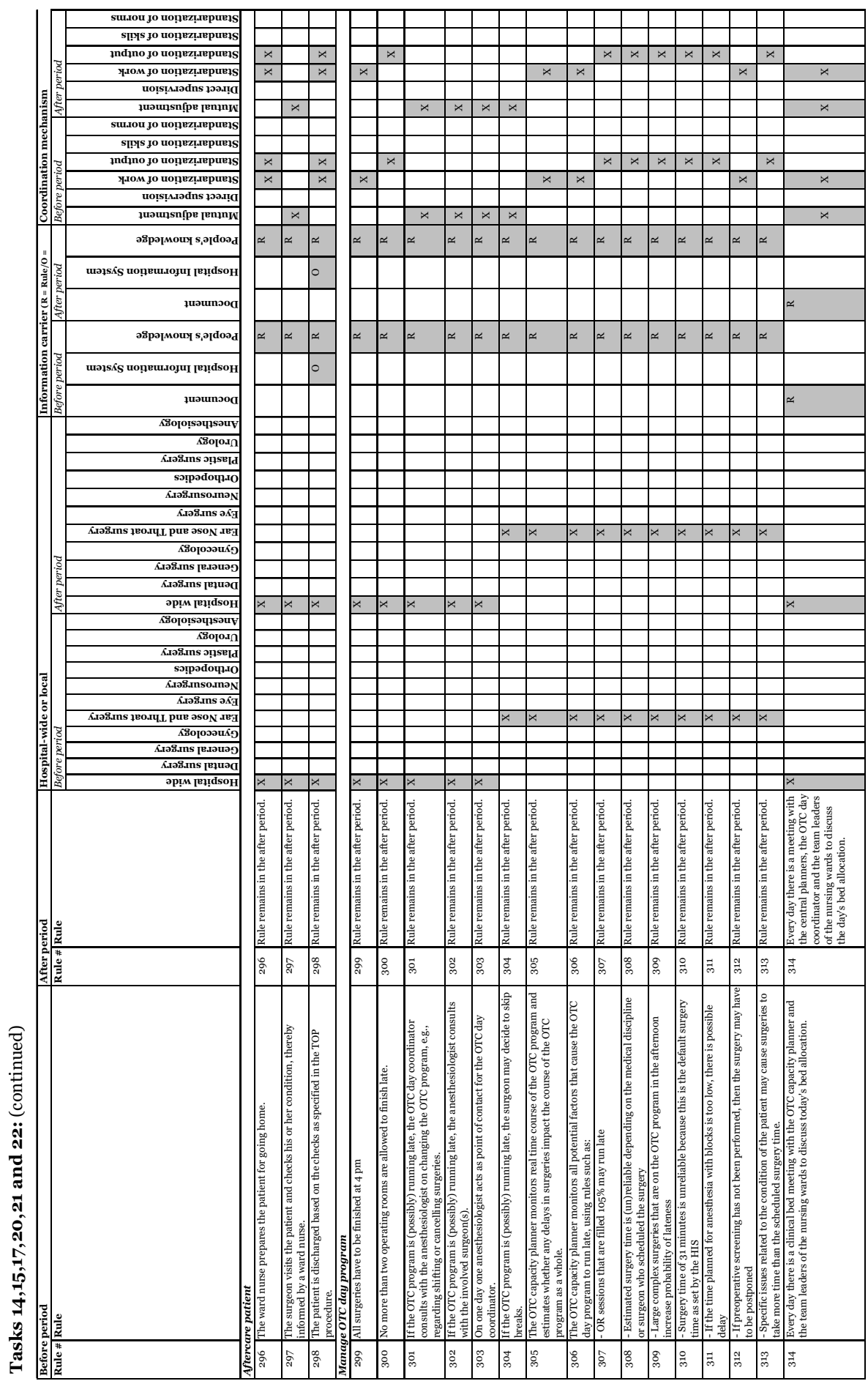




\section{APPENDIX 5.4: PERFORMANCE INDICATORS}

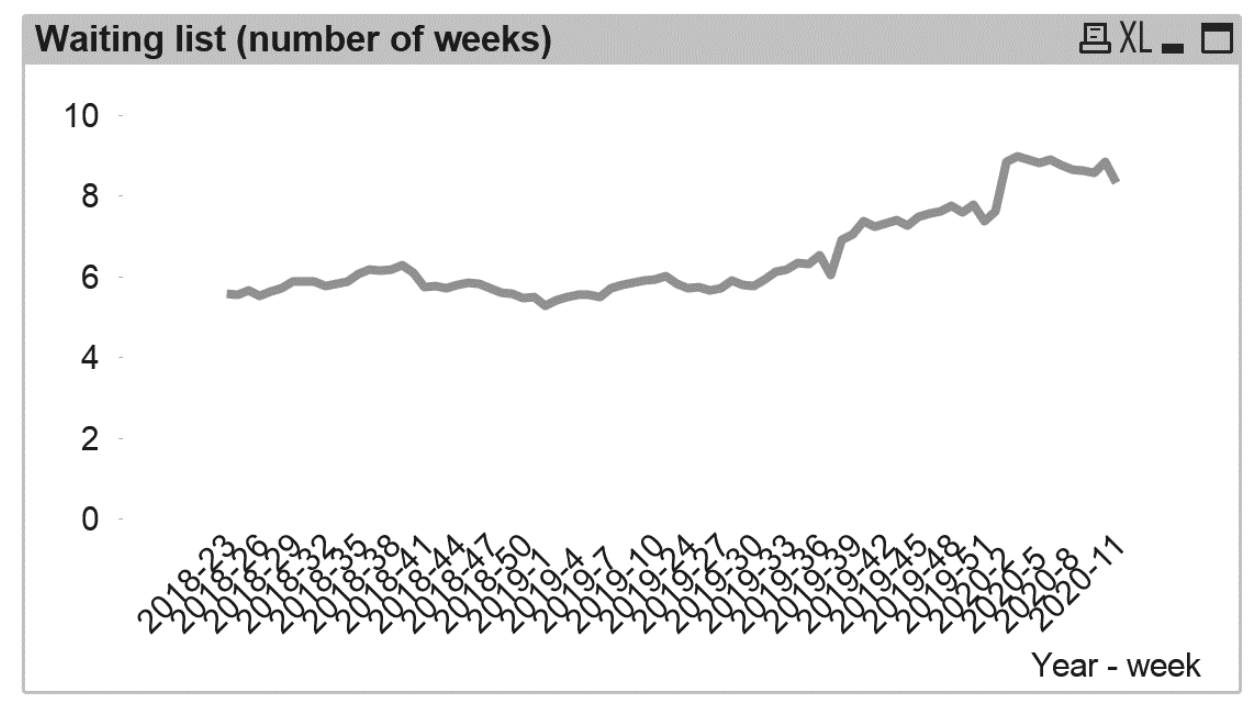

Figure A5.4.1 Waiting list development.

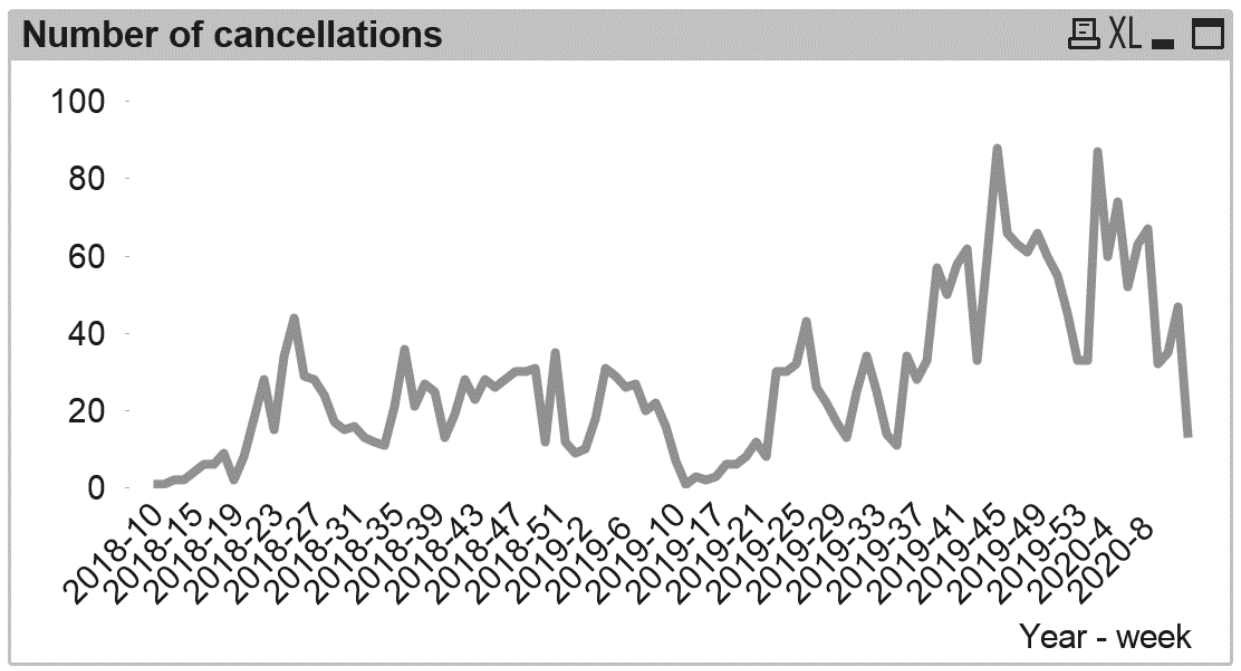

Figure A5.4.2 Number of cancellations. 
Table A5.4.1 Registered reasons for cancellation in the before and after period.

\begin{tabular}{|c|c|c|c|c|c|}
\hline \multirow[t]{2}{*}{ Reason for cancellation } & \multicolumn{2}{|c|}{ Before } & \multicolumn{2}{|c|}{ After } & \multirow[t]{2}{*}{ Change } \\
\hline & Number & $\%$ & Number & $\%$ & \\
\hline Entered incorrectly in system & 338 & $34 \%$ & 921 & $49 \%$ & $172 \%$ \\
\hline Patient wishes different OR date & 216 & $22 \%$ & 262 & $14 \%$ & $21 \%$ \\
\hline OTC program too large & 75 & $7 \%$ & 49 & $3 \%$ & $-35 \%$ \\
\hline No preoperative approval & 59 & $6 \%$ & 60 & $3 \%$ & $2 \%$ \\
\hline Illness patient & 56 & $6 \%$ & 57 & $3 \%$ & $2 \%$ \\
\hline Cancelled in consultation with parents/physician & 54 & $5 \%$ & 55 & $3 \%$ & $2 \%$ \\
\hline Patient cancelled surgery & 31 & $3 \%$ & 54 & $3 \%$ & $74 \%$ \\
\hline Cancelled for emergency surgery & 30 & $3 \%$ & 86 & $5 \%$ & $187 \%$ \\
\hline Absent surgeon & 29 & $3 \%$ & 11 & $1 \%$ & $-62 \%$ \\
\hline No Intensive Care bed available & 20 & $2 \%$ & 18 & $1 \%$ & $-10 \%$ \\
\hline Cancelled because of MRSA bacteria & 17 & $2 \%$ & 3 & $0 \%$ & $-82 \%$ \\
\hline OTC program too small & 15 & $1 \%$ & 17 & $1 \%$ & $13 \%$ \\
\hline Reservation removed & 11 & $1 \%$ & 2 & $0 \%$ & $-82 \%$ \\
\hline No medical instruments available & 8 & $1 \%$ & 10 & $1 \%$ & $25 \%$ \\
\hline Medical condition observed when patient on OR & 8 & $1 \%$ & 4 & $0,2 \%$ & $-50 \%$ \\
\hline No approval from co-practitioner & 7 & $1 \%$ & 4 & $0,2 \%$ & $-43 \%$ \\
\hline Patient did not stop medication & 6 & $1 \%$ & 4 & $0,2 \%$ & $-33 \%$ \\
\hline Surgery date is yet unknown & 4 & $0.4 \%$ & 214 & $11 \%$ & $5250 \%$ \\
\hline No available nurse anesthetist & 3 & $0.3 \%$ & 2 & $0,1 \%$ & $-33 \%$ \\
\hline Admission stop & 3 & $0.3 \%$ & 5 & $0,3 \%$ & $67 \%$ \\
\hline Patient has eaten/drunk before surgery & 3 & $0.3 \%$ & 4 & $0,2 \%$ & $33 \%$ \\
\hline Patient has been operated on & 3 & $0.3 \%$ & 1 & $0,1 \%$ & $-67 \%$ \\
\hline Ilness surgeon & 3 & $0.3 \%$ & 7 & $0,4 \%$ & $133 \%$ \\
\hline No implants available & 1 & $0.1 \%$ & & $0,0 \%$ & $-100 \%$ \\
\hline Lack of staff in the OTC & 1 & $0.1 \%$ & 15 & $1 \%$ & $1400 \%$ \\
\hline Surgery is combined with other surgery & 1 & $0.1 \%$ & 2 & $0,1 \%$ & $100 \%$ \\
\hline Equipment broke down & 1 & $0.1 \%$ & 6 & $0,3 \%$ & $500 \%$ \\
\hline Patient went home & 1 & $0.1 \%$ & & $0,0 \%$ & $-100 \%$ \\
\hline Medical diagnosis changed & & & 5 & $0,3 \%$ & \\
\hline Patient has not responded & & & 2 & $0,1 \%$ & \\
\hline Patient cannot be contacted & & & 4 & $0,2 \%$ & \\
\hline Patient did not show up & & & 3 & $0,2 \%$ & \\
\hline
\end{tabular}





\section{CHAPTER 6}

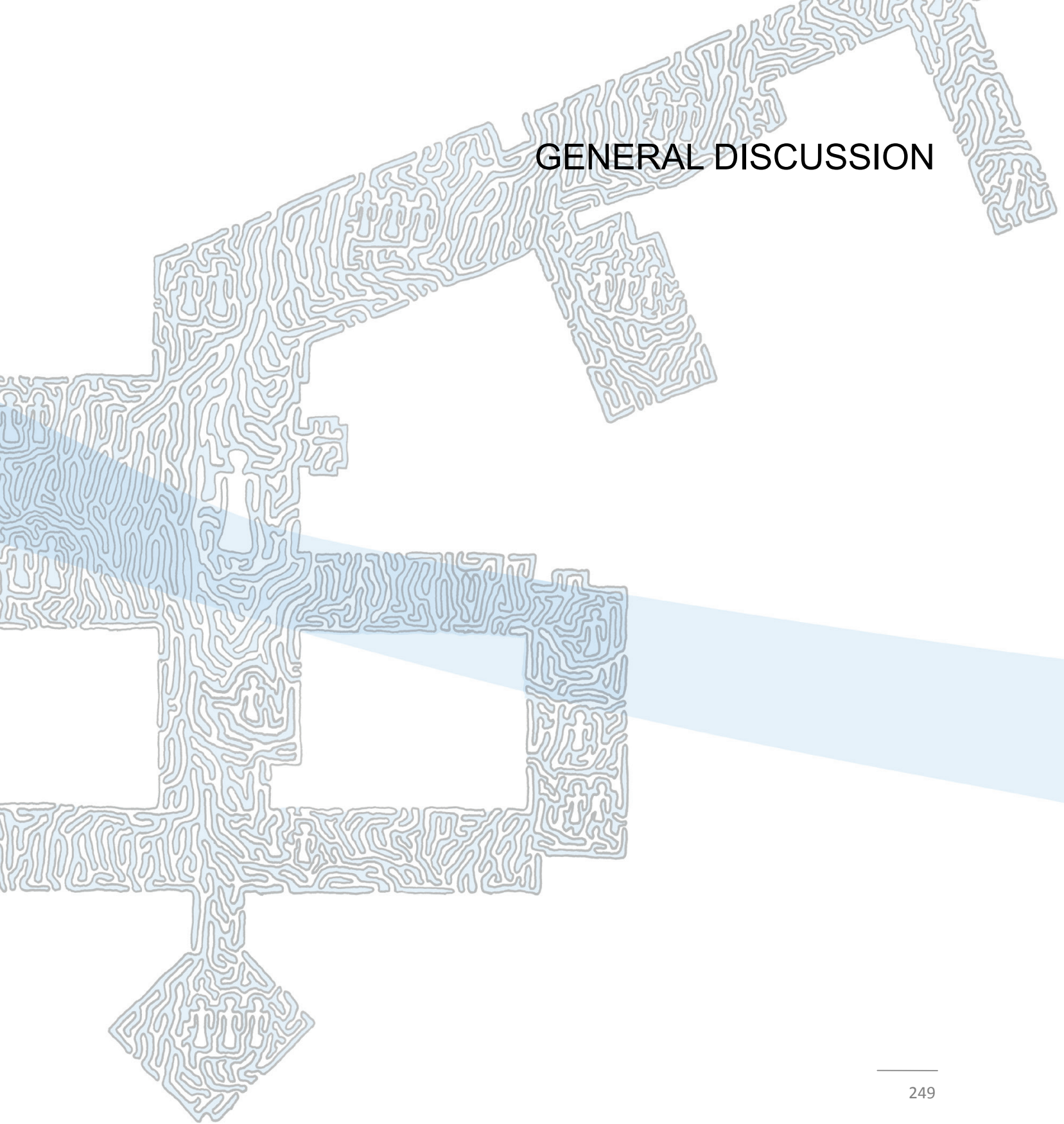





\section{GENERAL DISCUSSION}

"We often achieve our success through the collaborations we have and the bonds we have among ourselves, which are very good. When I am involved in planning issues, I often succeed in planning, not so much because there is capacity somewhere, but because of the cooperation and the fact that everyone is willing to cooperate. You get results because of good relationships and not necessarily due to the right configuration of the system."

This statement was made by the Operating Theatre Complex (OTC) capacity planner of Slingeland Hospital in 2018 and has a similar ambiguity with regard to hospital logistics as the statements of the surgeon of the same hospital in Chapter 1. The surgeon states that on the one hand, hospital logistics can be planned, because he perceives patient demand as stable and predictable, and at the same time, he indicates that planning ahead makes no sense as things change all the time. The OTC capacity planner indicates that on the one hand planning succeeds because of good collaboration, and at the same time she believes that the system is poorly configurated.

As stated in Chapter 1, the aim of this thesis is to thoroughly understand how a hospital's logistical system works, i.e., to what extent there is integration and differentiation and how rules and coordination mechanisms shape the hospital's network structure. By deepening and developing the concept of integration, we aim to operationalize the concept better for hospital practice, thereby explaining the apparent ambiguities in hospital operations as illustrated by the OTC capacity planner's and surgeon's statements.

In this final chapter, we will first present the main findings and then reflect on these from a theoretical and methodological perspective. Accordingly, future directions for practice, policy and research will be recommended.

\section{MAIN FINDINGS}

First of all, a scoping study (Chapter 2) was conducted in order to understand the state of affairs in hospitals with respect to logistics and integration. More specific, logistical parameters that are mentioned in the international literature with regard to hospital logistics were identified, as well as the way literature reflects integration in hospitals. The scoping study shows that in international literature, there is fragmentation with regard to 
hospital logistics. In literature, 106 logistical parameters are identified, which are studied in the context of 92 subsystems, i.e., parts of hospitals with tasks related to specific departments, flows or processes. Among the most mentioned logistical parameters were length of stay, waiting time, resource utilization and lead time. Studies focus mostly on patient flows and a minority of selected articles concern material or staff flows. One percent of the selected papers focus on both patient and material flows. Thus, although in many of the 287 studied papers integration was advocated, hospital logistics is barely studied in a hospital-wide setting including all departments, flows and processes. A clear view on how integration could enhance hospital performance could not be derived from international literature on hospital logistics.

In our first case study (Chapter 3), the extent to which integration and differentiation exist in practice was studied through social network analysis. For organizing and performing surgeries, 23 logistical tasks that are performed in-hospital were identified. Tasks are performed by 635 different agents of 26 different agent types, who interact via 31,499 ties. Agent types include a ward nurse, a surgeon, and an OTC capacity planner among others.

Agents are involved in different tasks both related to patient, material and staff flows, suggesting integration. Integration is further observed by the $65 \%$ of all agents who participate in multiple cliques, both for the performance of one task and across related tasks. Secondly, a number of centrally positioned cliques, which connect more peripherally positioned cliques, demonstrate integration. Thirdly, there are relatively large differences between agents degrees and betweenness centrality, indicating the existence of brokers performing integrative activities. Several agents act as brokers, i.e., they have a central position between otherwise separated groups of agents or subsystems, thus contributing to integration. Nurse anesthetists and nurses in the nursing wards, holding and recovery are most central, based on degree and betweenness centrality. The OTC day coordinator and the OTC capacity planner are the only two central agents in the network whose primary tasks involve coordination and planning, which are typical broker tasks. Agents with hierarchical positions, e.g. team leaders or managers, contribute relatively little to integration, based on their low degree and betweenness centrality.

With regard to differentiation, network density and cliques of agents performing the same task were identified. It was observed that with a network density of 0.16 , that is the percentage of ties agents have in relation to the number of ties they could have if they were all connected, the hospital network integration is relatively low. Low network integration suggests that there are agents or groups that are less connected, 
demonstrating the presence of subsystems and differentiation. Groups of agents who share the same task or knowledge were identified, as illustrated by the 8,698 cliques that were found. Differentiation results from task segmentation based on medical disciplines, organizational units, length of stay and patient characteristics, i.e., age and condition.

The social network analysis of Chapter 3 identifies the network structure and the agents' positions. What happens between agents and why they interact this way is explained in Chapter 4. In Chapter 4 the rules and coordination mechanisms observed in the social network analysis are identified. Rules result from defined or accepted ways of performing tasks and can be documented, exist in people's minds, or both. Rules can be hospital-wide or local, i.e., used by a particular department, group of people or person. Coordination mechanisms, which are based on these rules, require interactions between agents. Different coordination mechanisms result in different interaction patterns, resulting in a certain network structure, i.e., integration and differentiation.

For planning and performing surgeries, 314 rules were found, of which the majority (70\%) apply hospital-wide. However, rules are not always generally known as these are largely undocumented; $31 \%$ of all rules are written down in documents and $7 \%$ are in the hospital's information system. Moreover, $82 \%$ of all documents concern local or personal documents, such as checklists and memos, or were delivered in internal presentations. As a consequence, rules are often shared throughout the hospital through social interaction. As a consequence, $85 \%$ of all rules exist predominantly in people's minds.

Task performance is mostly coordinated through standardization of work (67\%) and mutual adjustment (49\%). In the early stages of planning, there is mainly mutual adjustment using hospital-wide rules; whereas closer to the day of surgery, there is more standardization of work, based on both hospital-wide and local rules. The scheduling of surgeons and anesthesiologists is mainly based on locally standardized working procedures that physicians agree upon within their own medical discipline.

It was observed that planning processes start with long-term schedules, which are based on largely fixed time and space structures. These schedules are not based on future patient demand, resulting in a push system ${ }^{1}$, which creates open loops. Open loop systems are affected by their environment, but do not utilize feedback, nor take action to improve the workflow, which potentially leads to instability ${ }^{2}$. In the shorter term, these schedules are subsequently adapted to the circumstances through negotiation by agents in the social network, using pull ${ }^{1}$ principles, thereby closing the loops. The interaction between agents mainly serves to observe the expected future as well as the current state of the system, and 
to continuously adapt the hospital's system, taking into account the rules. Most agents interact shortly before or on the day of surgery.

The network changed in 2019 when the Hospital Planning Centre (HPC) was introduced, as described in Chapter 5. This chapter evaluates whether integration, differentiation, coordination mechanisms and performance change after this organizational intervention. First of all, the overall network integration increased slightly (4\%), based on density. This means that the number of ties between agents in relation to the number of ties they could have if they were all connected, has increased. On a task level, network integration remained the same for eight tasks, while a clear increase in network density was observed for three tasks: for making the OR master schedule (209\%), for planning patients (83\%) and for controlling the planning (356\%). In addition, the OTC manager gained a more central position, and the OTC capacity manager took a much less central role, as most of her tasks were taken over by six central planners who had taken central positions. Differentiation based on medical discipline, length of stay and patient characteristics remained.

After the HPC was introduced, there are $7 \%$ more hospital-wide and $38 \%$ less local rules, as several rules became the hospital-wide standard or new hospital-wide rules were set. Rules remained for $85 \%$ in people's minds, and there was an increase of $2 \%$ in documented rules. Coordination mechanisms also remained largely the same after the HPC was introduced, being mainly standardization of work (70\% after, compared to $67 \%$ before) and mutual adjustment (47\% after, compared to $49 \%$ before).

Bed utilization increased by $11 \%$, and peak values for bed and OR utilization decreased. Remarkable increases in waiting list length of $21 \%$ and cancellations of $88 \%$ were observed following the introduction of the HPC. Variability in bed and OR utilization remained the same, while waiting list variability increased by $19 \%$.

\section{THEORETICAL REFLECTIONS}

As stated in Chapter 1, the research undertaken for this thesis focuses on integration and differentiation as it is observed in practice. Theory was mainly used as an instrument, firstly, to position our research perspective, secondly, to understand integration and differentiation, thirdly, as theory for data analysis, and fourthly, to relate the findings from hospital practice to existing theories. In this section, we first reflect on how the findings relate to the concept of integration and differentiation as it is described in a hospital context in literature. 


\section{The concepts of integration, differentiation and fragmentation}

With regard to the concept of integration, we agree with others ${ }^{3-5}$ that integration involves the alignment of activities along the patient or material flow for which coordination of operations between different members is required. In addition, we have taken a process orientation for this study, which is common for many studies in this field ${ }^{6}$. Integration is important because more efficient hospitals score high on cooperation, while efficient departments within a hospital do not necessarily contribute to the hospital's overall efficiency ${ }^{7}$. In literature, the oft mentioned functional organization of medical disciplines was also found in the case studies (Chapters 3 to 5). However, while literature states that there is a lack of integration in hospitals, integration was observed in our case studies. Integration is achieved by agents who interact in social network structures, thereby connecting the different subsystems through coordinative activities.

In literature, fragmentation is often directly attributed to a lack of integration, thereby suggesting that integration is good on its own. But, similar to Munavalli et al. ${ }^{2}$, who warn us not to use words such as 'lean', 'push and pull' normatively, the concept of integration should not be used normatively either. What is the appropriate integration or differentiation depends on the demands from the environment that the hospital needs to respond to, which is in line with Lawrence and Lorsch ${ }^{8}$. As defined in Chapter 1, differentiation refers to 'the state of segmentation of the organizational system into subsystems'8. Differentiation is a result of a division of tasks among groups of agents. There is fragmentation when task performance in subsystems is not aligned when this is necessary for the organization to be able to respond to the environment's needs. When task alignment is not necessary, there is differentiation, but no fragmentation. In line with Lawrence and Lorsch ${ }^{8}$, we therefore believe that integration should not be seen as the opposite of fragmentation.

\section{Integration and differentiation in hospital practice}

To the best of our knowledge, our study is the first to identify hospital-wide integration and differentiation for hospital logistics using social network analysis. This research, therefore, responds to the statement that most studies are theoretical, not empirical, and fail to address the entire hospital supply chain or network (Chapter 2). As a consequence, the findings with regard to integration and differentiation, as found in these hospital case studies, cannot be directly related to other hospital case studies in literature. We will therefore reflect on integration and differentiation in hospital practice, based on social network and organizational theory that was developed outside a hospital context. 
In line with several authors $5,7,9$ who refer to the functional organization of medical disciplines as a cause for a lack of integration, this study clearly shows that there is differentiation in hospitals. Differentiation comes naturally in hospitals, as it is inextricably linked to medical and nursing tasks for which specific knowledge and experience are required in relation to the many different patient groups that are serviced. Differentiation is complex because of multiple differentiation principles. Besides on medical discipline, differentiation is based on length of stay, patient characteristics and division of labour. Subsystems result from one of more differentiation principles and surgeons and anesthesiologists perform tasks in multiple subsystems.

Whether integration is lacking, is just right or there is too much of it, depends on how interdependent differentiated tasks are, and to what extent integration is required to meet the demands of the environment. From this study, it has become clear that subsystems depend on one another, because tasks performed in subsystems are time related, i.e., these are sequential or to be synchronized, or they share the same resources. Integration appears to be developed because of these dependencies, when open loops are detected mainly by nurses, surgeons, anesthesiologists and coordinators. They detect (potential) instability that results from misaligned tasks or mismatches between planned patients and required resources. They accordingly perform integrative tasks by interacting with others, thus acting as brokers. The potential causes for instability are mostly revealed to agents shortly before, or on the day of surgery. As a result of their integrative (inter)actions, they have gained a central position in the network, which is more central than agents with formal hierarchical positions.

Thus, integration and differentiation in hospitals do not seem to be designed or planned beforehand in conjunction with each other. They - and in particular, integration - seem to be developed when the need for it emerges. This is in line with Lawrence and Lorsch's statement that 'when the environment requires both a high degree of subsystem differentiation and a high degree of integration, integrative devices will tend to emerge.' 8 As a result of differentiation and the resulting interdependent subsystems, there is a 'felt need for joint decision making's. Following this line of reasoning, the HPC may have emerged as well. The findings suggest that the HPC was planned and designed to a limited extent, because rules remained largely undocumented and coordination mechanisms remained the same. Tummers et al. ${ }^{10}$ found evidence that agents with high autonomy adapt organizational structure to fit their own work needs. Perhaps, a hospital's organizational structure develops in the way described by Tummers et al. ${ }^{10}$. 
At the same time, this study demonstrates that in particular differentiation seems to be partly immutable. From Chapter 5, it was observed that after the introduction of the HPC the scheduling of surgeons remained differentiated, and because surgeons' schedules were not aligned, there was still fragmentation. Considering the fact that hospital performance did not increase after the introduction of the HPC, we believe a more conscious and deliberate approach to achieving integration and differentiation is needed.

\section{A deliberate approach to integration and differentiation}

Considering the suggestions of several researchers that logistics in a hospital could be very hard to oversee ${ }^{3,6,11-13}$ and statements that network structures are effective for dealing with complex issues ${ }^{14,15}$, achieving integration through social relations might be indispensable for a hospital to function effectively. However, this study shows that, even though the observed self-organizing and adaptive abilities may be a strength of the hospital, performance does not increase by the agents' initiatives alone. Certainly, the integration, as found here is 'right' in the sense that it is there for several reasons. In other words, the ways through which integration is achieved would probably not have existed if there was no need for it. But the fact that integration is there and that it has emerged from the need for alignment does not necessarily mean that the hospital has achieved the right degree of integration and differentiation, nor that integration will always be there as some sort of rule of nature. We believe that we should not merely trust that integration will emerge whenever it is needed, but that a more deliberate and conscious approach towards achieving integration is required for several reasons.

Firstly, whereas differentiation is naturally there in hospitals, as pointed out by many authors ${ }^{4,7}$, integration is not so self-evident. If there are no agents who feel or see the need or responsibility to coordinate and align activities, or if they are temporarily absent, there are no other mechanisms in place to make sure that the required integration is achieved and that loops are closed. And, even if these agents are there, the alignment of tasks can be extremely challenging and, as the OTC capacity planner's statement lightly indicates, it could lead to frustration with how the systems works. This could even lead to the rejection of the idea that the system is functioning properly, thereby ignoring the qualities of the social network altogether.

Secondly, from Chapter 5 we observe that more integration has not led to an overall higher performance. This is partly because open loops are partly 'programmed' into the system, with largely local undocumented working procedures and long term schedules that are not based on future patient demand. The phenomenon of open loops has also 
been identified by Munavalli² who proposes real-time planning methods for closing the loops. We believe that the introduction of the HPC is a step in the right direction for effectively closing the loops, because network integration has increased in some parts of the network, i.e., there are more central agents who connect subsystems. However, we also believe that integration is lacking, because not all differentiated tasks are aligned by the HPC, when they should be. The HPC plans specific patient groups, thereby excluding non-surgery patients who need beds in the same nursing wards as surgery patients. Also, surgeons' schedules are not controlled or coordinated by the HPC. As argued in Chapter 5, there should be hospital-wide integration and horizontal coordination, as described by Aoki $^{16}$. Integration should be strengthened by creating hospital-wide understanding of the whole work process by all agents and their internalizing the organizational goals.

In addition, we agree with Galbraith ${ }^{17}$ that the social network should be viewed as an information processing system. From our findings we conclude that information needs are fulfilled both by social interaction and the hospital information system, i.e., the social network exists in an addition to the more formal information systems. In line with Van Merode et al.4, information systems can facilitate differentiated task performance under less dynamic circumstances, and for alignment of differentiated complex tasks under changing circumstances, social interaction is required in addition to that.

Because, according to Lawrence and Lorsch, integration and differentiation are essentially antagonistic's, trade-offs have to be made explicitly with regard to several topics. In our case studies, we observed that both planning standards and mutual adjustment are used, that there is both long term forecasting and short term planning and fine-tuning, based on both central and decentralised control. If we consider each topic to have two extreme ends, then the extent to which one or the other is required depends on the demands of the environment. Environments' demands can vary per medical discipline and change over time. For example, in our study period, eye surgery appeared to have a relatively stable demand for performing mainly cataract surgeries in one OR, while trauma surgeries involve more uncertainty, require a short-term orientation and less structured interaction structures ${ }^{8}$. Both medical disciplines may require - and have in our case study - a different degree of integration and differentiation. Essentially integration and differentiation are dynamic concepts, as circumstances will continue to change, and agents will see or identify new integration needs over time. We believe learning processes are essential to continuously achieve the right degree of integration and differentiation. Through expansive learning, as described by Engeström ${ }^{18}$, engaged agents that have differentiated tasks produce new patterns of activity, driven by their shared responsibility for patients. According to Aoki ${ }^{15}$, horizontal coordination involves collective learning and 
knowledge sharing based on informal and mostly verbal communication, for example, by job rotation ${ }^{16}$, which will increase the hospital-wide comprehension of processes.

\section{Connecting existing theories on planning and integration}

In summary, integration in hospitals is essentially about closing loops, for which a certain degree of integration, differentiation and coordination mechanisms based on rules are required. The degree depends on what is required from the environment. There is a vast amount of literature with regard to planning performance measurement, simulation modelling and mathematical algorithms that offer solutions for developing planning rules on a subsystem level, as shown in Chapter 2. Organization theory offers many organizational concepts and models, such as presented by Aoki ${ }^{16}$, Galbraith ${ }^{17}$, Lawrence and Lorsch ${ }^{8}$, Mintzberg ${ }^{19}$ and Provan ${ }^{20}$, that could be used for more deliberate design of organisational structures and coordination mechanisms. These organizational concepts should be connected to operations research concepts. In particular, Takt Time Management as described and applied by Munavalli et al. ${ }^{21}$ offers a complementary coordination mechanism to the mechanisms offered by organization theory. We believe that these theories are not conflicting, nor mutually exclusive, but should be integrated into effective evidence based hospital management practices.

\section{METHODOLOGICAL REFLECTIONS}

For this study, both social network analysis and a hospital-wide case study approach including naturalistic inquiry were combined. In this section, the case study approach and, in particular data triangulation, social network analysis and the hospital-wide approach are reflected upon.

\section{Case study and data triangulation}

The three case studies are based on the case study research method devised by Yin ${ }^{22}$. Data were collected from multiple sources and analyzed through data triangulation. Data were collected from four different sources: the Hospital Information System (HIS), documentation, observations and interviews. Each source proved to be useful and is therefore necessary to identify interaction relations between the agents, rules and coordination mechanisms.

From this research, we found that it is important to collect and analyse data iteratively and discuss this repeatedly with hospital staff. This iterative process of data collection, 
analysis, verification and validation starts with collecting and analysing HIS data and documents on working procedures. The analysis of HIS data and documents provides an overview of the hospital processes and output, and it reveals which data are available for establishing relations between agents. For example, in Slingeland Hospital the members of the surgery team for each surgery were registered. From this, the ties between agents who perform surgery were established. Having analyzed HIS data and documents, observations were performed. Before conducting an observation, a memo was written on what to expect during the observation based on the HIS data and documents. In doing this, any discrepancies between the reality of the data and real life were found. Such discrepancies were then discussed during interviews, which were mostly held after the observations.

The iterative nature of data triangulation is best illustrated by the following example. During observations in the nursing wards no surgeons were observed visiting the nursing department. Hence, this interaction was not found from data or from observations. Later, during an interview, a surgeon explained his activities and interactions with other agents when patients are in the nursing ward after surgery. From this interview and the HIS data collected earlier, the nursing wards that each surgeon's patients stayed in could be identified.

For interviews on rules and coordination mechanisms data dashboards proved very useful (Chapter 3). Data dashboards included data that most interviewees had not seen before, such as the number of surgeries per surgeon, yearly and weekly patterns of OR sessions and surgeries, waiting list development and the number of patients who stayed on each nursing ward, among other things. Discussing these data with hospital staff proved very useful for discovering the unwritten rules. In addition, interviewees often provided explanations for the facts, or hypotheses on what was suggested by data, thereby contributing to data triangulation. Data triangulation is thus performed several times until, at some point, no new facts or explanations are found.

\section{Social network analysis}

With regard to social network analysis, the main contribution of this study lies in the fact that social network analysis was used to provide a hospital-wide overview of integration and differentiation. Through data triangulation ${ }^{22}$ of data from different sources, social networks per task could be constructed and then combined into a hospital-wide network for surgery patients. In particular, social network analysis has proven very useful to visualise the changed networks following the introduction of the HPC. Social network analysis facilitates revealing the coherence in the system when existing relations change, thereby also revealing what remains the same. This phenomenon is described by Jullien 
as 'dé-coincidence'23. In particular, the visual diagrams of the (changed) social networks on task level provide a clear overview of network structures and central or peripheral positions of agents.

Secondly, in this study the concepts and metrics that social network theory offers were further operationalised in relation to integration and differentiation, thus contributing to existing social network studies. The main metrics used for integration and differentiation are density, the number of cliques, clique overlap, betweenness centrality and centralization. Low network density and the presence of cliques suggest differentiation. Interestingly, at the same time cliques that include agents from multiple subsystems, e.g., from the different medical disciplines for making the OR master schedule, show integration. High betweenness centrality of agents and clique overlap suggest integration through brokerage. In addition, centralization was established, showing that agents may derive power from having central positions in networks, because they are best informed and have connections with agents that others do not have.

Thirdly, this study demonstrates that modelling organizational changes in social networks reveals to what factors changes, such as the introduction of the HPC, can be attributed. For example, in our case study (Chapter 5), we found that less cliques existed after the introduction of the HPC, which was mainly attributed to a lower number of unique OR teams performing surgeries. Also, the number of operating surgeons or assisting OR nurses impacts metrics for integration, such as density. In theory, more part-time working nurses would therefore decrease integration values.

Fourthly, in contrast to some authors who state that certain network structures work effectively ${ }^{20,24}$, we conclude from our case studies that SNA should be accompanied by naturalistic inquiry in order to establish the coordination mechanisms and rules that explain network structures. Without observing the agent's behaviour, established ties between agents are neutral in the sense that an existing tie does not reveal whether agent interaction is effective or counterproductive. Without knowing what the interaction is about, interaction could be about debating issues and not solving any conflict, or about aligning the work. Through naturalistic inquiry, the nature of the interaction was established in our study.

Even though social network theory needs further development in relation to organisational concepts, in line with other researchers ${ }^{24-26}$, we believe that social network theory has great potential for addressing complex issues such as hospital logistics and operations. For this study, network concepts and metrics have proven to be very useful for 
comparing different networks that have similar tasks or for networks that evolve over time. In addition, we agree with De Vries and Beuving ${ }^{27}$ that social network analysis should be accompanied by studying agents rules and coordination activities in order to understand integration and differentiation.

\section{Hospital-wide approach}

A hospital-wide approach is clearly challenging, as reported by many other researchers $3,6,11-13$. The development of empirical hospital-wide research approach was the main aim from a methodological perspective. In order to be able to use this methodology in practice, it was decided to conduct a single case. Hospital-wide research is time consuming, because researchers need to build up a social network of their own in the hospital, and data has to be collected from a large number of departments and agents. Data collected from different sources can be conflicting, and any inconsistencies need to be resolved through data triangulation ${ }^{22}$ and validation with hospital agents. This could easily lead to a long research period, which carries the risk that the hospital changes take place faster than the research can keep up with. As a result of unforeseen events, the evaluation period in the final case study (Chapter 5) was relatively short, when the Covid19 pandemic changed hospital planning dramatically. When selecting cases and during research, one needs to be aware of such changes and accordingly adapt the research approach to the circumstances as they present themselves.

Clearly, a single case needs replication in other hospitals in order to establish integration and differentiation in hospital settings and to generalize the mechanisms that were found in this study. Besides the fact that integration and differentiation are contingent, social networks could be influenced by organizational or even regional culture, by hospital scale or by the personalities of the agents involved. Therefore, the findings of this study should be used for 'analytic generalization'22, which means that the lessons learned provide input to working hypotheses for future research.

\section{FUTURE DIRECTIONS}

For both practice and research, the existing theories from the logistics and the related operations research field, organization theory and social network theory should be used together for future studies and experiments regarding hospital management, organizational concepts, planning and operations. We will address future directions more specifically for policy, practice and research in this section. 


\section{Implications for policy and practice}

For hospital practice, the concepts and findings in this study provide a foundation on which to build further. The most important recommendation is to organize integration and differentiation more deliberately and not depend only on personal initiatives of individual agents. Our case studies showed that hospital performance seems to be vulnerable (Chapter 3 and Chapter 4), and even though the introduction of the HPC (Chapter 5) appears to be an important step towards a more robust integration, performance has not yet increased as desired.

Our second recommendation is to use a system-wide perspective for system redesign for improving effectiveness, including in network structure, rules and coordination mechanisms. At the same time, and because of the system-wide perspective, hospitalwide system redesign is complex, takes time and cannot be done in one piece. Consequently, any step taken in the redesign and implementation process may not increase performance right away. This does not necessarily mean that the concept that is implemented is failing, but that most likely the system is not well enough understood yet. Using the methodology as developed in this study, successive implementations can be evaluated, so that new future interventions can be made based on more knowledge on how the system behaves.

Because of not being able to completely oversee a hospital system at once, nor at all times, we believe that adopting a stepwise learning approach for both everyday business and implementation of new concepts is important. Clearly there are challenges to achieve integration and differentiation, because it is contingent, and there are many antagonistic elements in the related concepts of rules, coordination mechanisms and performance indicators. In addition, the sub environments of the hospital which are not included in this study need to be better understood for refining integration and differentiation.

A system-wide learning perspective also implies that the concept of optimization can be problematic, as what is optimal for one subsystem may not be optimal for others, and what is optimal at one moment in time may not work at a future time. We therefore recommend not to focus on optimization, but on system stabilization, which can be operationalised by lead-time and waiting time for patient flows and resource utilization.

Hospital leadership should play an important role in deliberately organizing integration and differentiation. Hospital leadership includes monitoring the hospital's environment on a strategic, tactical and operational level, detecting improvement areas, setting 
performance goals and deciding on any new ways of working, systems or organizational structure. For this, there also needs to be a balance between providing directives and giving space to agents' own initiatives, depending on the environment's demands. At least, it should be clear, for example, who is allowed to introduce new ways of working and how much standardization of formalization is required under what circumstances. A potentially helpful method for this could be 'Hoshin Kanri'; literally translated from Japanese, 'Hoshin' means compass and 'Kanri' is management or control ${ }^{28}$. This method aims to align goals at strategic, tactical and operational levels through continuous coordination and is described by Winasti et al. ${ }^{28}$ and Tennant and Roberts ${ }^{29}$. Both vertical and horizontal alignment are important in a well performed Hoshin Kanri process.

Hospital leadership should also involve, or create, the right subsystems by connecting the right agents, and make sure that together they evaluate changes made and use lessons learned for the future.

Social network analysis can help leaders in this in several ways. First, to identify the central agents who can be of help for influencing the network and, second, to identify any need to reshape the network by connecting the agents who are needed for more integration. The leadership can also be of great value for central agents who face the challenge of connecting subsystems, thereby continuously solving conflicts. If the leadership explicitly supports these central agents, their task will be (and will feel) less challenging. Moreover, rewarding agents who base their actions on a total system perspective will most likely have a positive impact on hospital effectiveness, as suggested by $\mathrm{Aoki}^{16}$.

\section{Implications for research}

The aforementioned stepwise approach for improving hospital performance also applies for research. For researchers, it is barely possible to examine a hospital in its entirety, given the fact that ideally the research is conducted within a limited time period during which the hospital is more or less in a steady state. However, by selecting an aspect system - in this case, the part of the hospital system that services surgery patients - a hospital-wide research perspective can be used. Social network analysis has proven to be useful for identifying hospital-wide integration and differentiation.

In future research, therefore, we propose to use social network analysis when implementing organizational changes. Changes could be evaluated in a similar way as in the case study in Chapter 5 or through action research ${ }^{30}$. We should then be able to assess, for example, whether having many or a few cliques in a hospital is more effective; 
how density or betweenness centrality is related to performance; or, whether more explicit standardization of norms, as suggested by Mintzberg31, leads to different interaction patterns and, accordingly, to different integration and differentiation. By evaluating performance accordingly, more knowledge will be developed on effective network structures and governance of networks.

In this research, it should be considered to include interaction frequency and timing of interaction, as this could lead to more insights on how integration and differentiation work in hospitals. In addition, it is important to find ways to take into account processes other than logistical processes, such as financial, medical, human resource management or contracting processes. Tasks related to these processes take place in other subsystems that are related to different hospital sub environments such as insurance companies or professional associations of medical disciplines. Integration and differentiation for the hospital as a whole could be explained by such processes and the behaviour of the related subsystems.

Last but not least, we believe it is important to develop social network theory by connecting its concepts and metrics to the concepts of integration and differentiation. Replication of this study will contribute to theory building as well as experiments with the implementation and evaluation of organizational concepts.

In conclusion, the foundation laid in this thesis with regard to integration and differentiation should be further explored and refined. Future studies could be performed in hospital settings and, also, in other organizations that provide healthcare, or partnerships of healthcare organizations who collaborate within a certain region or, even nationwide. In addition, it would be interesting to study integration and differentiation under various changing circumstances, for example, in times of a pandemic or the more common flu epidemics, hospital mergers or hospital building renewal. 


\section{REFERENCES}

1. Hopp WJ and Spearman ML. Factory Physics: foundations of manufacturing management. New York: Irwin/McGraw-Hill, 2001.

2. Munavalli JR. Real-time scheduling in outpatient clinics. PhD thesis, Maastricht University, 2017. https://doi.org/10.26481/dis.20171101jrm.

3. Aronsson $\mathrm{H}$, Abrahamsson $\mathrm{M}$ and Spens K. Developing lean and agile health care supply chains. Supp Chain Manag 2011; 16:176-183.

4. Van Merode GG, Groothuis S, Hasman A. Enterprise resource planning for hospitals. Int $J$ Med Inform. 2004; 73:493-501.

5. Villa S, Prenestini A and Guisepi I. A framework to analyze hospital-wide patient flow logistics: evidence from an Italian comparative study. Health Policy 2014; 115:196-205.

6. De Vries $\mathrm{J}$ and Huijsman R. Supply chain management in health services: an overview. Supp Chain Manag 2011; 16:159-165.

7. Ludwig M, Van Merode GG and Groot W. Principal agent relationships and the efficiency of hospitals. Eur J Health Econ 2010; 11:291-304.

8. Lawrence PRL, Lorsch JW. Differentiation and integration in complex organizations. Adm Sci Q. 1967; 12:1-47.

9. Drupsteen J, Van der Vaart T and Van Donk DP. Integrative practices in hospitals and their impact on patient flow. Int J Op Prod Manag 2013; 33:912-933.

10. Tummers GER, van Merode GG, Landeweerd JA. Organizational Characteristics as Predictors of Nurses' Psychological Work Reactions. Organization Studies. 2006; 27(4):559-584. doi:10.1177/0170840605059455.

11. Ellram LM and Cooper MC. Supply chain management: it's all about the journey, not the destination. J Supply Chain Manag 2014; 50: 8-20.

12. Bhattacharjee P and Ray PK. Patient flow modelling and performance analysis of healthcare delivery processes in hospitals: a review and reflections. Comput Ind Eng 2014; 78: 299-312.

13. Matta ME and Patterson S. Evaluating multiple performance measures across several dimensions at a multi-facility outpatient center. Health Care Manage Sci 2007;1 0:173-194.

14. Benham-Hutchins M, Clancy TR. Social networks as embedded complex adaptive systems. JONA 2010; 40:352-6.

15. Provan KG, Kenis P. Modes of network governance: structure, management, and effectiveness. $J$ Public Adm Res Theory. 2008; 18(2):229-52.

16. Aoki M. Toward an Economic Model of the Japanese Firm. Journal of Economic Literature 1990; 28(1):1-27.

17. Galbraith J. Organization Design: An Information Processing View. Interfaces 1974; 4(3): 2836.

18. Engeström, Y. Expansive Learning at Work: toward an activity theoretical reconceptualization. Journal of Education and Work 2001; 14:133-156.

19. Mintzberg H. Structure in Fives: Designing Effective Organizations. Englewoods Cliffs: Prentice Hall, 1983.

20. Provan KG, Sebastian JG. Networks within networks: service link overlap, organizational cliques, and network effectiveness. Acad Manag J. 1998; 41(4):453-63. 
21. Munavalli JR, Rao SV, Srinivasan A and Van Merode GG. An Intelligent real-time scheduler for outpatient clinics: A multi-agent system model. Health Informatics Journal 2020; 26(4):23832406, doi: 10.1177/1460458220905380.

22. Yin RK. Case study research - Design and Methods. 5th ed. Thousand Oaks: Sage Publications, 2014.

23. Jullien F. Dé-cöncidence. D'ou viennent l'art et l'existence. Paris: Éditions Grasset et Fasquelle, 2017.

24. Kilduff M, Tsai W. Social networks and organizations. London: SAGE, 2003. Accessed 6 Sept 2018.

25. Monge PR, Contractor N. Emergence of communication networks. In: Jablin FM, Putman LL, editors. The new handbook of organizational communication. Thousand Oaks: Sage publications, 2011.

26. Benton DC, Pérez-Raya F, Fernández MP, González-Jurado MA. A systematic review of nurserelated social network analysis studies. Int Nurs Rev 2015; 62:321-39.

27. Beuving J and De Vries G. Doing Qualitative Research: The Craft of Naturalistic Inquiry. Amsterdam: Amsterdam University Press, 2015.

28. Winasti W, Van Merode F, Berrevoets L. Het raamwerk en het proces van capaciteitsmanagement. In: Capaciteitsplanning in de Zorg. Houten: Springer Media, 2021.

29. Tennant C, Roberts P. Hoshin Kanri: A tool for strategic policy deployment. Knowledge and Process Management 2001; 8(4): 262-269.

30. Meyer J. Using qualitative methods in health related action research. BMJ 2000; 320:178.

31. Mintzberg H. Managing the Myths of Health Care. Oakland: Berrett-Koehler Publishers, 2012. 



\section{SUMMARY}

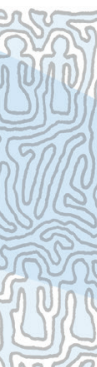<smiles></smiles>

(ia)

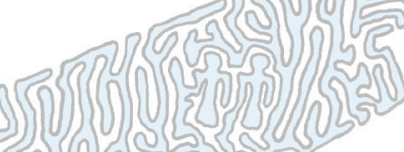

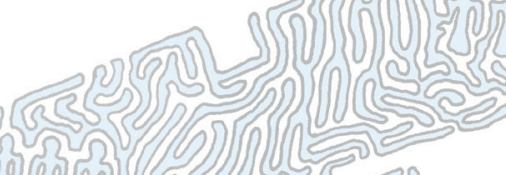

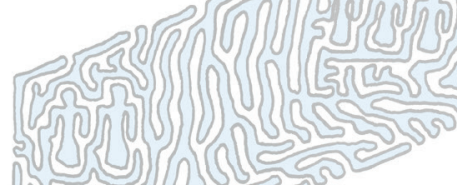

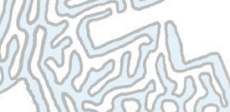

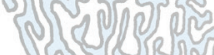
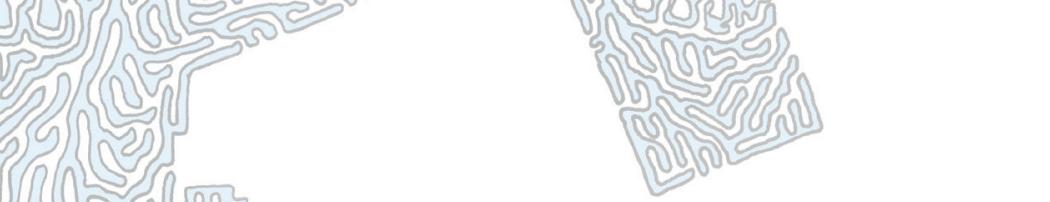

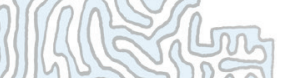

20?
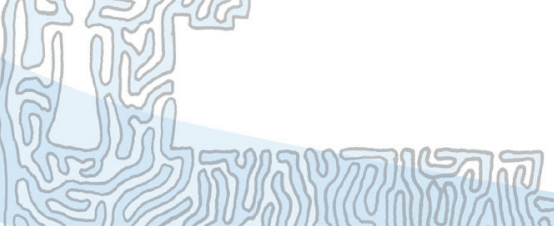

39000

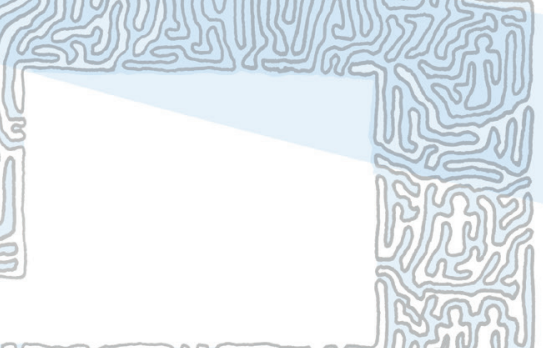

$\sqrt{00} \sin 0$
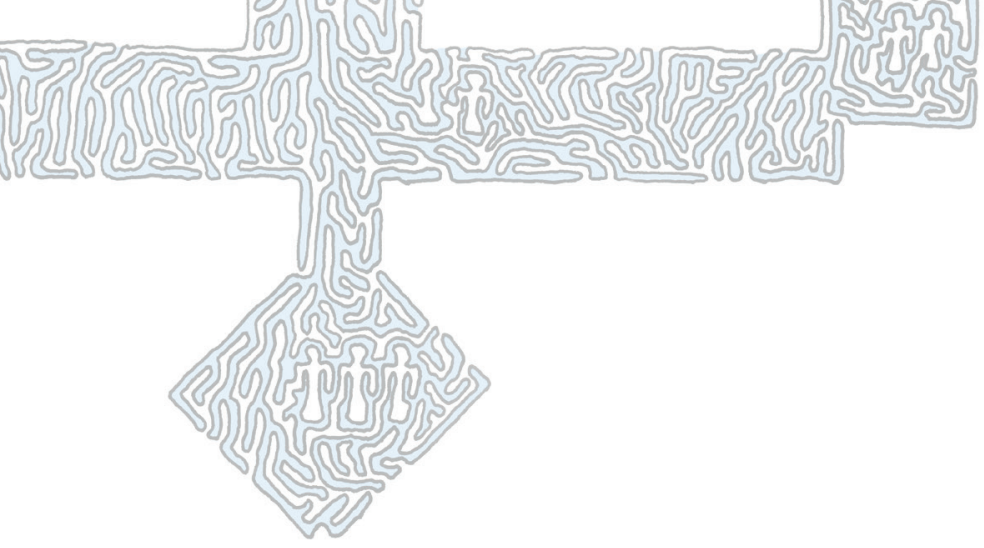



\section{SUMMARY}

In response to worldwide concerns regarding increasing healthcare expenditure and the recent pressure on hospital capacity during the Covid-19 pandemic, governments, healthcare organizations, researchers and other parties involved in healthcare are looking for ways to maintain and improve the accessibility and affordability of healthcare. In particular, hospitals receive attention because they are a major cost item in healthcare systems, and the fact that they were stretched beyond their capacity during the Covid-19 pandemic had a major impact on societies worldwide.

Integration, that is the hospital-wide alignment and coordination of tasks and activities, is considered essential for hospital performance. Although several theories on integration exist, the question of how integration is achieved in hospital practice is relatively unaddressed. A full understanding of factors that determine the course of reality in hospitals is important to be able to effectively transform hospital logistics and operations. The aim of this thesis, therefore, is to thoroughly understand how a hospital's logistical system works, in particular how integration is achieved.

Chapter 1 introduces the topic of this thesis and the concepts used. Firstly, based on contingency theory, integration and differentiation are both considered essential for effective performance of organizations'. Integration is 'achieving unity of effort among the various subsystems in the accomplishment of the organization's task'. Differentiation refers to 'the state of segmentation of the organizational system into subsystems'1. Secondly, concepts and metrics from social network analysis are introduced. Thirdly, the concepts of rules and coordination mechanisms are described, as both social network theory and literature pertaining to integration often mention coordination as a core activity.

Based on these concepts, Chapter 1 explains that the research for this thesis was conducted in four research steps, starting with understanding the state of affairs in hospitals with respect to logistics and integration (step 1). Then, three case studies in Slingeland Hospital were conducted which describe (step 2) how a hospital's logistical system works in practice and, in particular, to what extent there is integration and differentiation, and which explain (step 3) integration and differentiation by studying the rules and coordination mechanisms and which then evaluate (step 4) whether integration, differentiation, coordination mechanisms and performance change after the introduction of a hospital planning centre (HPC). 
Chapter 2 describes the results of a scoping study that identifies the logistical parameters mentioned in international research on hospitals and indicates whether literature reflects system integration.

The scoping study shows that in international literature there is fragmentation with regard to hospital logistics. Studies also show integration, although this takes place mainly within the subsystems of hospitals, i.e., within parts of hospitals with tasks related to specific departments, flows or processes. Therefore, from international literature on hospital logistics, a clear view on how integration could enhance hospital performance could not be derived. From this scoping study, it was concluded that more knowledge regarding the degree of integration and performance indicators is required for better hospital performance.

Chapter 3 describes how a hospital organizes logistical processes. The agents and the interactions involved are identified, and the extent to which there is differentiation and whether these tasks are coordinated and aligned, thus achieving integration, is established. Integration and differentiation are described in terms of concepts and metrics from social network analysis.

This first case study shows that 23 tasks are executed by 635 different agents who interact through 31,499 ties, i.e., interaction links. Agents include outpatient secretaries, ward nurses, surgeons and an OTC capacity planner among others. The social network of the hospital demonstrates both integration and differentiation. Nurses, surgeons and anesthesiologists have central network positions and perform integrative tasks, and two central agents who mainly coordinate the tasks in the network, have no hierarchical position towards other agents. Agents with hierarchical positions, e.g., team leaders or managers, contribute relatively little to integration, based on their network positions.

With regard to differentiation, groups of highly connected agents performing the same task were identified. Differentiation results from task segmentation based on medical disciplines, organizational units, length of stay and patient characteristics.

This exploratory study reveals the network structure of a hospital and sets a basis for further research on how integration is achieved in hospital practice. In addition it discusses in what way organization theory concepts and social network analysis could be used in conjunction with one another.

Chapter 4 carries the case study presented in Chapter 3 further, by explaining integration and differentiation through identifying the rules and coordination mechanisms that agents in a hospital network use. Rules result from defined or accepted ways of performing tasks and can be documented, exist in people's minds, or both. Coordination mechanisms, which are based on these rules, require interactions between 
agents. Different coordination mechanisms result in different interaction patterns, resulting in a certain network structure, i.e., integration and differentiation.

For planning and performing surgeries, 314 rules were found, of which the majority applies hospital-wide. Because rules are often undocumented, they are not always generally known. Moreover, $82 \%$ of all documents concern local or personal documents such as checklists and memos or were delivered in internal presentations. As a consequence, rules are often shared throughout the hospital through social interaction, as most rules exist predominantly in people's minds.

Coordination mostly takes place through standardization of work and mutual adjustment. In the early planning stages for a surgery procedure, mutual adjustment based on hospital-wide rules is dominant. Closer to the day of surgery, local rules are used and open loops are closed through mutual adjustment, thus achieving integration. Open loops are created by long term schedules that are not based on future patient demand. Open loop systems are affected by their environment, but do not utilize feedback nor take action to improve the workflow, which potentially leads to instability. On the day of surgery, there is mainly standardization of work and output, based on hospital-wide rules.

Both Chapters 3 and 4 discuss the hospital's stability and potential vulnerability and propose to further develop Slingeland Hospital's logistical system in order to increase its robustness.

Chapter 5 describes the results of the evaluation of the hospital's social network, rules, coordination mechanisms and performance after a hospital planning centre (HPC) was introduced.

Following the introduction of the HPC, bed utilization increased with peak utilization of beds and operating rooms decreasing, and increases were observed in the waiting list, in cancellations and in waiting list variability. More integration was observed for specific planning tasks, but not for the hospital network as a whole. Differentiation based on medical discipline, organizational unit, length of stay and patient characteristics remained. More hospital-wide and fewer local rules exist, and these have remained largely undocumented, i.e., exist in people's minds. Coordination mechanisms both before and after the introduction of the HPC are mainly mutual adjustment and standardization of work. Based on these observations and literature, Chapter 5 proposes further development and system redesign from a system-wide perspective that includes network structure, rules and coordination mechanisms.

Chapter 6 presents the main findings of this thesis, reflects on these from a theoretical and methodological perspective and discusses implications for policy, practice and research. From a theoretical perspective, the concepts of integration, differentiation and 
fragmentation are discussed. The appropriate integration or differentiation depends on the demands from the environment that the hospital needs to respond to. In hospital practice, essentially, integration is about closing loops, for which a certain degree of integration, differentiation and coordination mechanisms based on rules, are required. Integration and differentiation in hospitals, however, do not seem to be designed or premeditated beforehand in conjunction with each other, and this could lead to instability. A more deliberate approach towards integration and differentiation is proposed, which includes stepwise learning aimed at system stabilization under changing circumstances. Hospital leadership is important for this to succeed.

It is recommended to conduct more empirical studies, based on theory with regard to planning, performance measurement, simulation modelling and mathematical algorithms, organization theory and social network theory. Accordingly, recommendations are presented on how to conduct such research, which includes hospital-wide or even healthcare network case study research using social network analysis and naturalistic inquiry.

\section{REFERENCE}

1. Lawrence PRL, Lorsch JW. Differentiation and integration in complex organizations. Adm Sci Q. 1967; 12:1-47. 





\section{SAMENVATTING}

Wereldwijd zoeken overheden, zorginstellingen, kennisinstellingen en andere organisaties betrokken bij de gezondheidszorg naar manieren om de toegankelijkheid en betaalbaarheid van zorg te garanderen en te verbeteren. Lang voordat de Covid-19 pandemie uitbrak, waren er al grote zorgen over toenemende zorgkosten, waarbij veel aandacht uit ging naar ziekenhuizen, omdat zij relatief veel kosten. Door de pandemie werden de grenzen aan het oprekken van ziekenhuis capaciteit pijnlijk duidelijk, met grote gevolgen voor samenlevingen wereldwijd.

Tegen deze achtergrond wordt er al geruime tijd gepleit voor meer integratie in ziekenhuizen, dat wil zeggen meer ziekenhuisbrede afstemming en coördinatie van taken en activiteiten. Het idee dat integratie leidt tot effectiever en efficiënter functioneren van ziekenhuizen wordt breed gedeeld in de wetenschap en er bestaan diverse theorieën over. Tegelijkertijd is een nog onbeantwoorde vraag hoe integratie in de ziekenhuis praktijk tot stand komt. Om ziekenhuizen effectief te verbeteren is het belangrijk om volledig te begrijpen hoe ziekenhuizen eigenlijk werken. Het doel van dit proefschrift is daarom om te ontdekken hoe het logistieke systeem van een ziekenhuis functioneert, en dan in het bijzonder hoe integratie tot stand komt.

In hoofdstuk 1 worden de concepten van dit proefschrift geïntroduceerd. Het gaat daarbij ten eerste om integratie en differentiatie, die op basis van de contingentietheorie beide als essentieel beschouwd worden voor de effectiviteit van organisaties ${ }^{1}$. Integratie is 'het bereiken van eenheid van inspanning tussen de verschillende subsystemen bij het vervullen van de taak van de organisatie'. Differentiatie verwijst naar 'de mate van segmentatie van het organisatiesysteem in subsystemen'1. Ten tweede worden concepten uit sociale netwerk theorie geïntroduceerd. Tenslotte worden regels en coördinatiemechanismen toegelicht; coördinatie wordt zowel in sociale netwerk theorie als in de literatuur over integratie genoemd als kern activiteit.

Vervolgens worden in hoofdstuk 1 de vier stappen van het onderzoek voor dit proefschrift toegelicht. Het onderzoek is gestart met een inventarisatie van de stand van zaken in de literatuur met betrekking tot logistiek en integratie in ziekenhuizen (stap 1). Vervolgens zijn in het Slingeland Ziekenhuis Slingeland drie case studies uitgevoerd. De eerste case study (stap 2) beschrijft hoe het logistieke systeem van een ziekenhuis in de praktijk werkt en dan vooral in hoeverre er sprake is van integratie en differentiatie. De tweede case study (stap 3) verklaart de integratie en differentiatie door de regels en coördinatiemechanismen te bestuderen. In de laatste case study (stap 4) wordt 
geëvalueerd in hoeverre integratie, differentiatie, regels, coördinatiemechanismen en effectiviteit veranderen na de introductie van een centraal planbureau in het ziekenhuis.

Hoofdstuk 2 beschrijft de resultaten van een scoping study. In deze literatuur studie worden logistieke parameters die worden genoemd in internationaal onderzoek naar ziekenhuizen, geïdentificeerd. De scoping study laat zien dat in internationale literatuur sprake is van fragmentatie ten aanzien van ziekenhuis logistiek. Studies adresseren integratie wel, maar dan voor het merendeel in de context van subsystemen in ziekenhuizen, dat wil zeggen binnen delen van ziekenhuizen, met taken die verband houden met specifieke afdelingen, logistieke stromen of processen. Uit internationale literatuur komt geen duidelijk beeld naar voren hoe integratie de prestaties van ziekenhuizen zou kunnen verbeteren. Op basis hiervan concluderen wij dat er meer kennis nodig is over integratie en de relatie met prestatie-indicatoren om te komen tot betere ziekenhuis prestaties.

Hoofdstuk 3 beschrijft hoe een ziekenhuis logistieke taken en processen in de praktijk organiseert. Ten eerste zijn de taken, de betrokken agenten en hun interacties geïdentificeerd. Met behulp van sociale netwerkanalyse wordt vervolgens vastgesteld of er sprake is van differentiatie en hoe taken op elkaar worden afgestemd, waardoor er integratie wordt gerealiseerd.

Deze eerste case study laat zien dat 23 taken worden uitgevoerd door 635 verschillende agenten die communiceren via 31.499 interactielijnen. Agenten zijn onder andere polikliniek secretaresses, afdelingsverpleegkundigen, chirurgen en capaciteitsplanners van het operatiekamercomplex. In het sociale netwerk van het ziekenhuis is zowel sprake van integratie als van differentiatie. Verpleegkundigen, chirurgen en anesthesiologen hebben centrale netwerkposities en voeren integratietaken uit. De twee meest centrale agenten, wiens voornaamste taak het is om het netwerk te coördineren, hebben geen hiërarchische positie ten opzichte van andere agenten. Agenten met hiërarchische posities, zoals teamleiders of managers, dragen op basis van hun netwerkposities relatief weinig bij aan integratie.

Met betrekking tot differentiatie zijn groepen van sterk verbonden agenten geïdentificeerd die dezelfde taak uitvoeren. Differentiatie komt voort uit taaksegmentatie op basis van medische disciplines, afdelingen, ligduur en patiëntkenmerken.

Deze verkennende studie legt de netwerkstructuur van een ziekenhuis bloot en vormt daarmee een basis voor verder onderzoek naar de wijze waarop integratie in de ziekenhuispraktijk tot stand komt. Daarnaast wordt besproken op welke manier organisatietheorieconcepten en sociale netwerkanalyse in samenhang met elkaar kunnen worden toegepast. 
Hoofdstuk 4 gaat dieper in op de case study van hoofdstuk 3, door de gevonden integratie en differentiatie te verklaren door de regels en coördinatiemechanismen te bestuderen. In dit hoofdstuk worden de regels en coördinatiemechanismen geïdentificeerd, die de agenten in het ziekenhuisnetwerk gebruiken. Regels zijn het resultaat van gedefinieerde of geaccepteerde manieren om taken uit te voeren en kunnen gedocumenteerd zijn, in het hoofd van agenten zitten, of beide. Coördinatiemechanismen, die op deze regels zijn gebaseerd, vereisen interacties tussen agenten. Coördinatie activiteiten resulteren dus in interactiepatronen, en bepalen daarmee ook een bepaalde netwerkstructuur, dat wil zeggen integratie en differentiatie.

Er zijn voor het plannen en uitvoeren van operaties 314 regels, waarvan het merendeel ziekenhuisbreed geldt. Omdat regels vaak niet vastgelegd zijn, zijn deze niet altijd algemeen bekend. Van de vastgelegde regels is $82 \%$ terug te vinden in lokale of persoonlijke documenten zoals checklists, memo's of in intern gegeven presentaties. Aangezien de meeste regels voornamelijk in het hoofd van de agenten zitten, worden deze vaak via sociale interactie gedeeld.

Coördinatie vindt vooral plaats door standaardisatie van werk en onderlinge afstemming. In vroege planningsfases van een operatieve ingreep vindt onderlinge afstemming vooral plaats op basis van ziekenhuisbrede regels. Dichter op de dag van de operatie worden lokale regels gehanteerd en worden door onderlinge afstemming open loops gesloten, waardoor integratie wordt bereikt. Open loops worden gecreëerd door langetermijnplanningen, die niet zijn gebaseerd op toekomstige vraag van patiënten. Open loop systemen worden beïnvloed door hun omgeving, maar gebruiken geen feedback om te reageren op hun omgeving, wat tot instabiliteit kan leiden. Op de dag van de operatie is er vooral standaardisatie van werk en output, gebaseerd op ziekenhuisbrede regels.

In zowel hoofdstuk 3 als hoofdstuk 4 wordt geconstateerd dat het ziekenhuis systeem mogelijk instabiel en kwetsbaar is. Het is daarom van belang om het logistieke systeem van het Slingeland Ziekenhuis verder te ontwikkelen om de robuustheid ervan te vergroten.

In hoofdstuk 5 worden de resultaten van de evaluatie van het sociale netwerk, de regels, de coördinatiemechanismen en de prestaties van het ziekenhuis na de introductie van een centraal planbureau in het ziekenhuis beschreven. $\mathrm{Na}$ de introductie van de centraal planbureau neemt de gemiddelde bedbezetting toe, terwijl de piekbenutting van bedden en operatiekamers afneemt. De hoogte van de wachtlijst neemt toe, evenals het aantal geannuleerde operaties en de variabiliteit. Er wordt meer integratie waargenomen voor specifieke planningstaken, maar niet voor het ziekenhuisnetwerk als geheel. Differentiatie op basis van medische disciplines, afdelingen, ligduur en patiëntkenmerken blijft bestaan. $\mathrm{Na}$ de introductie van het centraal planbureau neemt het aantal ziekenhuisbrede regels 
toe en vermindert het aantal lokale regels. Wel blijven regels grotendeels in het hoofd van agenten zitten en worden ze niet vastgelegd. Onderlinge afstemming en standaardisatie van werk zijn zowel voor als na de invoering van het centraal planbureau de meest gebruikte coördinatiemechanismen. Op basis van deze observaties en van literatuur wordt aanbevolen om het ziekenhuis verder te ontwerpen en te ontwikkelen vanuit een vanuit een systeem breed perspectief dat netwerkstructuur, regels en coördinatiemechanismen omvat.

Hoofdstuk 6 presenteert de belangrijkste bevindingen van dit proefschrift, reflecteert hier op vanuit theoretisch en methodologisch perspectief en bespreekt implicaties voor beleid, praktijk en onderzoek. Vanuit een theoretisch perspectief gaat het dan vooral om de concepten integratie, differentiatie en fragmentatie. De juiste integratie of differentiatie hangt af van de eisen uit de omgeving waar het ziekenhuis op moet inspelen. In de ziekenhuispraktijk gaat integratie over het sluiten van open loops waarvoor integratie-, differentiatie- en coördinatiemechanismen bestaan, gebaseerd op bepaalde regels. Integratie en differentiatie in ziekenhuizen lijken niet vooraf in samenhang met elkaar te zijn ontworpen of beoogd en dit zou tot instabiliteit kunnen leiden. We stellen een meer bewuste benadering van integratie en differentiatie voor, waarbij stapsgewijs leren en systeemstabilisatie onder veranderende omstandigheden centraal staan. Ziekenhuis management moet hierin een nadrukkelijker rol spelen dan zij in de praktijk nu lijken te doen.

Aanbevolen wordt om meer empirisch onderzoek te doen, daarbij gebruikmakend van bestaande theorie op het gebied van planning, prestatiemeting, simulatie, wiskundige algoritmen, organisatietheorie en sociale netwerktheorie. In aanvulling hierop worden aanbevelingen gedaan voor het uitvoeren van dergelijk onderzoek, waaronder case studyonderzoek in het hele ziekenhuis of zelfs in gezondheidszorgnetwerken met behulp van sociale netwerkanalyse en naturalistisch onderzoek.

\section{REFERENCE}

1. Lawrence PRL, Lorsch JW. Differentiation and integration in complex organizations. Adm Sci Q. 1967; 12:1-47. 




\section{IMPACT}
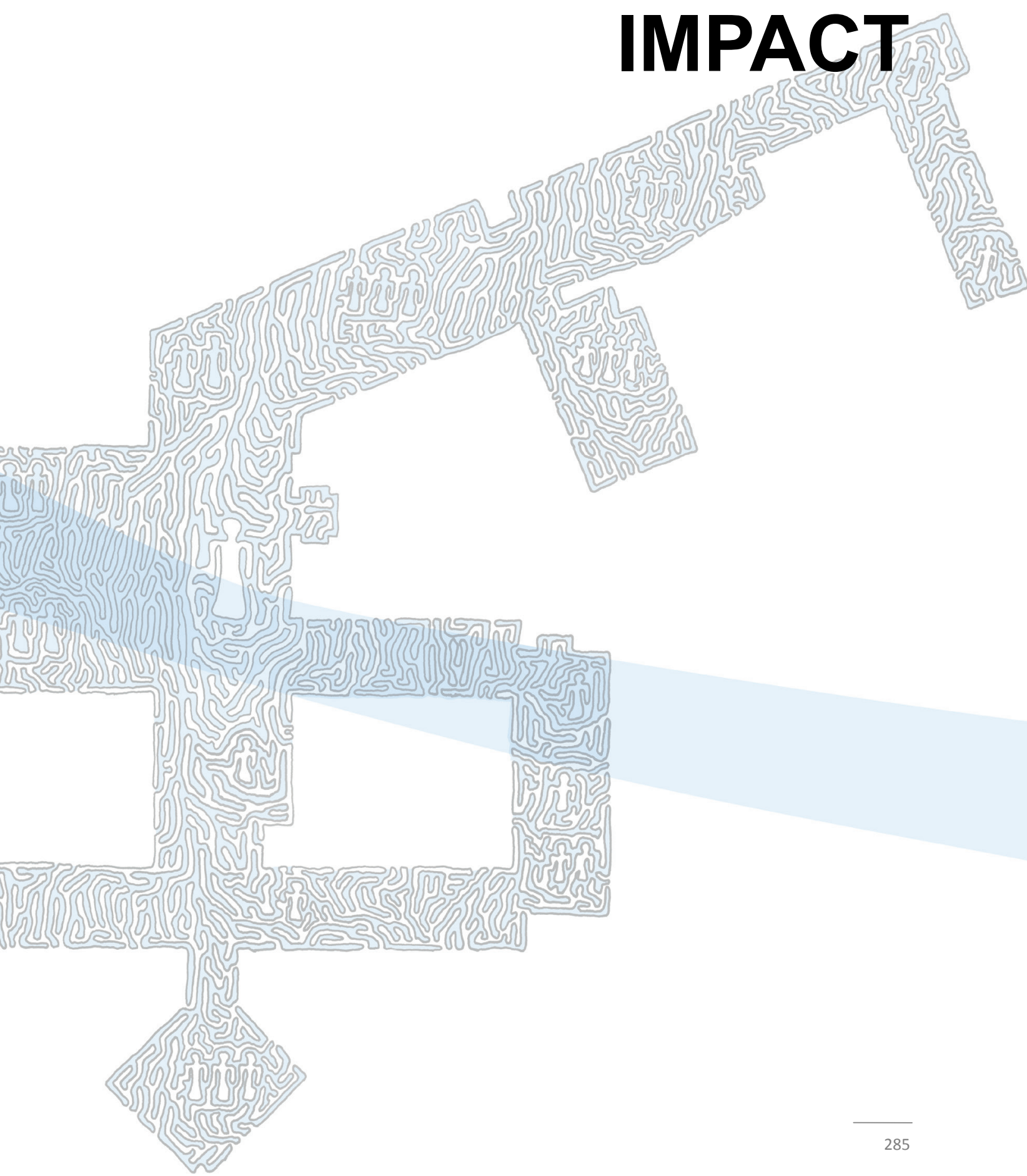



\section{IMPACT}

"I showed up on time on the date of the meeting which I had agreed to join for observation. Ten minutes before it was supposed to start, someone told me that the meeting had been rescheduled and they had arranged for me to join the logistical workers in the OTC central storage room, now! I felt somewhat disturbed and confused, as I was not able to prepare myself for observing logistical workers and didn't know right away exactly what I wanted from the observation. This happens quite often during this research: things are cancelled and then rearranged at the same time and on the spot. I worry a bit that I may look like an ill-prepared idiot. But, probably, the best thing is to accept it as part of the experience, to open my eyes and ears, write it all down, and then learn from it."

This personal diary note, made on 29 January 2018, illustrates what it means to be working in a dynamic environment. For people, who are used to working with plans and concepts - researchers, consultants, (project) managers and others like them - the dynamics in hospital operations can be overwhelming and the seeming lack of control can be hard to accept.

The concerns regarding this way of working are not unfounded, given the widely felt need to increase the affordability and accessibility of healthcare services (Chapter 1) and hospitals in particular. Hospitals are a major cost item in healthcare systems, and during the Covid-19 pandemic hospitals were stretched beyond their capacity to such an extent that it had a major impact on societies worldwide. Many researchers consider the concept of integration important for improving hospital performance. Integration involves aligning and coordinating activities from a hospital-wide perspective to make sure that patients, materials and staff flow smoothly through hospital processes. Activities are integrated when, for example, for a surgery that is planned by the outpatient department, also a bed is also planned for by the nursing ward, both for before and after the surgery is performed.

Although several theories on integration exist, the question of how integration is achieved in hospital practice is relatively unaddressed. A full understanding of factors that determine the course of things in hospital practice is important to be able to effectively transform hospital logistics and operations. The aim of this thesis, therefore, is to thoroughly understand how a hospital's logistical system works, in particular, integration. Theory states that for effective hospital's integration, i.e. alignment and coordination and differentiation, i.e., the division of tasks throughout an organization, are both required. 
To what degree activities can be performed independently of other activities, thereby not requiring integration, depends on the demands that the environment puts on the organization.

The question of how integration is achieved in hospital practice is relatively unaddressed and considered difficult, or even problematic by researchers. This thesis, therefore, contributes to thoroughly understanding how a hospital's logistical system works, in particular with regard to integration and differentiation. This is important, because like for any other system that requires improvement, knowing how the system works, and why, is essential. From the findings of this thesis, an approach is proposed that includes both elements of deliberate, conscious planning based on standards and, also, of adaptability that is based on mutual adjustment. In this chapter the societal and scientific impact and the dissemination and the future of the results in this thesis are explained.

\section{SOCIETAL IMPACT}

First and foremost, from this study we know how a hospital and, in particular, its logistical system works in practice from a system-wide perspective, more particularly for performing surgeries and all that is required to arrange for that. It has become clear that differentiation is more or less 'programmed' or comes naturally because the division of tasks and departments in hospitals is based on medical disciplines, patient characteristics and length of stay. Integration largely emerges through agents who observe potential instability, e.g., unnecessary waiting, a lack of materials or staff for surgeries or patient care, and who mutually adjust in social networks. Most importantly, several of the ways of working and coordination mechanisms found in this study turned out to be insensitive to change. After the hospital planning centre (HPC) was introduced several intended performance improvements were not achieved and open loops and mutual adjustment remained. As a consequence the potential causes for hospital instability seem to have remained.

We believe that the findings on how hospitals function is important for anyone who works in, for, or with hospitals. Whether you work in a hospital daily or work on design and change projects, knowing how and why the system functions is essential to be effective. First, this study provides detailed descriptions of processes, tasks, agents who perform tasks, which rules are used and what interactions that take place. Second, this study shows that integration is achieved by healthcare professionals and a few coordinators and that they coordinate mainly through standardization of work and mutual adjustment, 
based on, often, local and undocumented rules. Third, given the complexity and variability of hospital operations, this thesis proposes a more deliberate, conscious and dynamic approach towards integration and differentiation. This includes stepwise learning aimed at system stabilization under changing circumstances. Fourth, social network analysis and naturalistic inquiry offer concepts and methods for evaluating changes in hospital performance, and these can be used by a diverse audience.

For hospital staff, this thesis can be used to create system-wide awareness on what happens outside their own workplace and department, so that they understand how the system functions as a whole and how they can contribute to this most effectively. It could also be used for preparing future staff, i.e. students in medical and nursing education, to understand the position they will be in as a physician, nurse or coordinator when working in a hospital.

Clearly, for (future) hospital leadership a system-wide understanding of hospitals is important in order to be able to effectively lead and manage smaller or larger parts of the hospital. They need to be aware and understand that changes in one part of the hospital may impact hospital performance as a whole or in other departments. Furthermore, they should play an important role in more deliberately organizing integration and differentiation. This includes monitoring and aligning the hospital's environment on a strategic, tactical and operational level, detecting improvement areas, setting performance goals and deciding on any new ways of working, systems or organizational structure. When they know the social structure of their hospital, they are able to involve the right agents for this. Social network analysis identifies the central agents who can be of help in influencing the network and taking care of any disconnections between agents that are needed to reshape the network. Hospital leadership can also be of great value for central agents who face the challenge of connecting subsystems, thereby continuously solving conflicts. If the leadership explicitly supports or rewards these central agents, their task will be less challenging.

Agents who provide services to healthcare professionals, either externally or internally, can use this thesis for agents designing, developing and implementing for example organizational policies, information technology solutions, financial models, human resource management programs, building designs housing and/or facility services, etc. Their solutions or models can only effectively support the hospital system when they support agent's working processes. In order to do so, integration, differentiation, rules and coordination mechanisms must be understood.

The same applies to agents outside hospitals, such as policy makers, insurance companies, management consultants and supply chain partners, i.e. nursing homes or material suppliers. 


\section{RESEARCH IMPACT}

For this thesis, a case study approach including data triangulation, social network analysis and the hospital-wide approach were combined. Similar to the aforementioned stepwise hospital improvement, hospital-wide research should also be conducted in a stepwise manner.

For a hospital-wide case study, research data should be collected from multiple sources, e.g. the hospital information system, documents, observations and interviews. Data, accordingly, need to be analyzed in an iterative manner, thus discussing findings repeatedly with hospital staff. Clearly, the hospital-wide approach comes with the challenge to achieve results within a restricted period of time. Selecting an aspect system, i.e., the part of the hospital system that services surgery patients, proved valuable, while at the same time, the limitations are recognized.

Social network analysis facilitates analyzing hospital-wide integration and differentiation. Using data triangulation, social networks for each task can be constructed, combined into a hospital-wide network and, most importantly, visualized. The concepts and metrics that social network theory offers can be used to detect integration and differentiation, with the main metrics being density, the number of cliques, clique overlap, betweenness centrality and centralization. Social network analysis should be accompanied by naturalistic inquiry in order to establish the coordination mechanisms and rules that explain network structures.

In future research, social network analysis and naturalistic inquiry can be used for replication of this study in other hospitals and for evaluating organizational changes that have been implemented. By evaluating performance, more knowledge will be developed on effective network structures and governance of networks. Social network theory can, accordingly, be developed further by connecting its concepts and metrics to the concepts of integration and differentiation.

For researchers, the findings of this research are also relevant for the way research is conducted in hospital practice. As illustrated by the diary notes, doing research in hospitals requires mutual adjustment and adaptability skills from researchers. In particular, planning interviews and observations requires a flexible attitude, as these can be rescheduled or rearranged on the spot. For this, a well-prepared research plan is required, which includes both clear and well-defined objectives and research questions, and facilitates agility in doing the research. For example, by preparing interview topic lists for interviewees from all departments beforehand, the researcher is able to conduct any 
interview at any time. At the same time, such topic lists may require adjustment when interviews that were held provide new insights.

\section{DISSEMINATION OF FINDINGS}

Various channels have been used to disseminate the findings of this research. Three out of four papers have been published in international peer reviewed journals, and the fourth paper (Chapter 5) has been submitted for publication as well. The published papers have all been published open access and are accessible to anyone free-of-charge.

In addition to that, the findings of this research have been shared mainly with a practical audience. Naturally, during the case studies, intermediate and final results were shared with Slingeland Hospital, either via email or personally. A 'thank-you' note was given to all Slingeland Hospital staff that participated in the first case study (Chapter 2) and in it the position of the note recipient was highlighted. From the response, it was clear that this was not only appreciated, but several staff members indicated that this made them more aware of their (in that case often central) position. In July 2021, the findings of this research were presented to Slingeland Hospitals Board of Directors and middle management.

For a wider audience, 44 blogs were published between 2017 and 2021 on www.squrious.nl, presenting the research results and reflections on these. The blogs were well read by over a thousand different people, mostly working in or for hospitals. Throughout the entire PhD research, several workshops and presentations were held with consultancy firms and hospitals, among others, often as a result of a blog or through personal relationships in the Dutch healthcare sector of the researchers involved.

Research findings were also presented in a book chapter of 'Capaciteitsplanning in de zorg'2, which was published in 2021 and written for a professional audience of managers, boards, physicians, students and other people involved in healthcare operations management. Also, this research was presented to a professional audience in master classes on capacity planning 2021. 


\section{REFERENCES}

1. Van den Boogaart HA. New Models of Care: focusing on substitution of hospital care with primary care. Trend setting or trend breaking? PhD thesis, Maastricht University, 2021. DOI: 10.26481/dis.20210601eb.

2. Winasti W, Van Merode F, Berrevoets L. Het raamwerk en het proces van capaciteitsmanagement. In: Capaciteitsplanning in de Zorg. Houten: Springer Media, 2021. 





\section{DANKWOORD}

Het proefschrift dat je nu in handen hebt is het topje van de ijsberg, dat wat zichtbaar is van bijna zeven jaar nadenken, lezen, analyseren, gesprekken voeren en schrijven. Veel van wat onder water gebeurde past niet echt in een proefschrift, en daarom neem ik de vrijheid om in het dankwoord een kijkje onder water te nemen.

Ik heb veel interessants gelezen gedurende het promotie traject, maar het boek dat mij echt greep was 'Treatise of Efficacy' van François Jullien. Zijn werk was me aangeraden door Frits van Merode, een liefhebber van Jullien's werk. Er zijn diverse boeken en stukken van deze Franse sinoloog en dit Engelstalige boek was één van de weinige voor mij leesbare stukken. Ondanks mijn aangetrouwde Waalse familie is mijn Frans wat roestig, maar ook in het Engels vond ik het niet bepaald eenvoudige kost. Ik las het in Spanje, in de zomervakantie van 2015, op een moment dat ik wist dat mijn leven een andere wending zou gaan nemen. Ik wist nog niet waar het allemaal heen zou gaan, alleen dát het zo was. En het was inmiddels ook al aan het gebeuren.

In het boek beschrijft Jullien hoe in de Westerse en Chinese oudheid aangekeken werd tegen strategie en effectiviteit. Eén van de dingen die me vooral bij bleef was dat de sleutel tot een effectieve strategie is om te vertrouwen op het potentieel van de situatie, er als het ware door gedragen te worden, terwijl deze zich ontwikkelt. Vrij vertaald heb ik het opgevat als dat je niet moet proberen een situatie te forceren, maar dat je er voor moet zorgen dat je de omstandigheden en de factoren die de loop der dingen beïnvloeden zó goed kent, dat je deze met kleine veranderingen de goede kant op kan sturen. Zoiets als het verleggen van een takje in een rivier, waardoor het water nét even anders gaat lopen. Toen ik het boek las, begreep ik direct dat ik precies dát aan het doen was, alleen leek het in mijn hoofd geen strategie, maar meer iets als 'gewoon maar wat doen' of op zijn best 'experimenteren'.

Een jaar voordat ik kennis maakte met Jullien, in 2014, had ik het 'Handboek Buitenpromoveren' van Floor Basten en Kerstin van Tiggelen gekocht. Het idee om te promoveren was al eens eerder in mijn leven voorbij gekomen, maar toen wist ik niet waar het over zou moeten gaan. Na tien jaar consultancy in diverse ziekenhuizen had ik wel ideeën én inspiratie, waarbij je enige mate van frustratie ook als een soort omgekeerde inspiratie mag zien. Promoveren leek me op dat moment alleen niet voor de hand liggend, omdat ik mijn bezigheden toen - een jong gezin, een eigen bedrijf en veeleisende projecten - al behoorlijk pittig, soms zelfs ondoenlijk vond. Dat vond het handboek trouwens ook. Maar het kopen van het boek bleek een belangrijker stap te zijn, 
dan het lezen ervan. Ik besloot het boek niet uit te lezen, want eigenlijk maakte het me niet echt uit wat erin stond. Nog een paar kleine stapjes later besloot ik om het maar gewoon te gaan doen, promotie onderzoek.

Op de dag van mijn besluit reageerde een vriend met een appje met een Chinese spreuk: 'It's OK to be crazy, but don't be insane'. Ik wist niet waar op de schaal van gekte ik nu precies zat, maar dat ik dit ging doen voelde eigenlijk wel ontzettend goed en dat bleef zo. En mijn toen zesjarige zoon Bjorn zong het aan de lopende band: 'laat het los, laat het gaan!' Disney's Frozen was dé beste film van 2014, voor iedereen onder de 8 jaar dan toch, maar stiekem ook een beetje voor mij.

Ik besloot promoveren eerst maar eens als een hobby te beschouwen; de ene moeder gaat een cursus mindfulness doen of begint een taarten webshop, ik ga promoveren, dacht ik dan maar, een beetje om mijzelf te beschermen tegen al te hoge verwachtingen. Toen ik een jaar later Jullien las, begreep ik dat deze aanloop van kleine stapjes onderdeel waren van een strategie die zeer effectief zou blijken. En de eerste stapjes van het onderzoek bevielen erg goed. Ik kwam in mijn eigen fijne denkbubbel, af en toe even weg van de rauwe realiteit van dat jaar. Heel mindful leek me dat toch wel, erg van deze tijd, dus hoezo gek?

Aanvankelijk leken de omstandigheden voor een succesvol promotie traject in 2015 nou niet bepaald gunstig. Mijn gezin transformeerde in 2015 naar co-ouderschap, een door onszelf op maat gemaakte vorm van gezinsleven op twee adressen. Vanaf het moment van mijn eerste verhuizing eind 2015 - gevolgd door een tweede verhuizing in 2017 - leefde ik als het ware zélf in de logistieke complexiteit van mijn promotie onderzoek. In mijn advieswerk en onderzoek was ik bezig met grootschalige transformatie van ziekenhuizen zoals fusie of nieuwbouw en de impact daarvan op het logistieke systeem. In mijn eigen kleine wereld woonde ik zelf op meerdere locaties, mijn kinderen ook, en de huis-tuin en keuken logistiek was uitdagend en als je niet uit keek, ontwrichtend. Te veel voorraad in het ene huis met de verkeerde spullen, dan weer te weinig, misgrijpen, heen-en-weer fietsen tussen de gezinslocaties....co-ouderschap is geen optimaal logistiek concept. Ik besefte daardoor dat logistiek misschien niet leidend is voor besluitvorming maar wel essentieel is om complexe systemen te laten functioneren. Dat was waar mijn promotie onderzoek ook over moest gaan.

Mijn proefschrift is daarom min of meer 'als vanzelf' uit de omstandigheden voortgekomen. Maar vanzelf gaat natuurlijk niets. Je moet de omstandigheden wel zíen en weten te gebruiken. Wanneer iets tot stand komt weet je dan niet, dat moet blijken. Daarvoor is geduld en vertrouwen in een goede afloop nodig en natuurlijk had ik dat 
vertrouwen lang niet altijd. Mijn dank gaat daarom vooral uit naar iedereen die mij vertrouwen heeft gegeven, door een aanmoediging, door een kritische vraag, of door gewoon even niets te zeggen, het aan te kijken, maar mij vooral niet aan mijn lot over te laten.

Daarvoor dank ik in de eerste plaats mijn promotie begeleiders, Frits van Merode, Arno van Raak en Dirk Ruwaard. Jullie gaven mij vertrouwen, ideeën, praktische tips, adviezen en zetten mij op diverse sporen op een manier zoals Jullien het beschrijft: een plant moet je niet omhoog trekken om te groeien, maar je moet hem voeden.

Frits, voor mij ben jij de inspirator van dit onderzoek en je hebt ontzettend veel van jouw schijnbaar oneindige kennis, onderzoeks- en werkervaring met mij gedeeld. Jouw manier van begeleiden - een mix van ideeën inbrengen, soms een beetje ontregelen, aanmoedigen en soms ook grenzen stellen - heeft veel voor dit onderzoek, en zeker ook voor mij persoonlijk, betekend.

Arno, jou dank ik in de eerste plaats voor het bieden van houvast als ik ergens in het woud van wetenschappelijke methoden of literatuur verdwaald dreigde te raken. Ook zal ik jouw onomwonden enthousiasme voor de sociale netwerk analyse waarmee ik op een kladblaadje langs kwam op het Dubois domein, nooit vergeten.

Dirk, bij de start van ons onderzoeksteam sprak je uit dat een promotie onderzoek een team effort is en ook op diverse andere momenten liet je blijken dat ik er niet alleen voor stond. Jouw scherpe feedback - geen detail ontgaat jou -, en goede tips versterkten dat gevoel. Dank ook voor het achter de schermen regelen van de praktische en administratieve zaken, zoals budget voor opleiding en de proofreading.

Dit onderzoek is echt een team prestatie geworden. Ik dank jullie alle drie voor de altijd inspirerende en boeiende gesprekken, waarin vaak veel gelachen werd, ook niet onbelangrijk bij ondernemingen als deze.

De andere onmisbare pijler van dit onderzoek is het Slingeland Ziekenhuis en dan in het bijzonder René Nummerdor, Annemijn Houwers en Anne Oostendorp. René, dank dat je de deuren van het ziekenhuis open hebt gezet om waar ik maar wilde met mensen te spreken, observaties te doen en data te verzamelen. Annemijn, jouw enthousiasme en doortastendheid om zaken aan te pakken, werkten zeer aanstekelijk op mij. Dank voor je fantastische hulp door me wegwijs te maken in Slingeland Ziekenhuis, met documenten, data en contacten. Anne, dank voor je enorm inzet om mij te helpen met data uit HiX, zelfs als ik tot in den treure vragen bleef stellen over dit of dat data veld. Veel gesprekken die ik met jullie heb gevoerd zullen mij altijd bij blijven.

Ook dank aan vele mensen in het Slingeland die mij in de keuken mee lieten kijken. Het meelopen met artsen, verpleegkundigen, operatiekamer assistenten, anesthesie 
medewerkers, secretaresses, magazijn medewerkers en planners, was enorm verrijkend en heeft veel indruk op mij gemaakt. Mijn dank gaat daarbij vooral uit naar Karin Aalders, Chantal Berendsen, Carla Berntzen, Michiel Bijkerk, Joni Bosman, Chantal Bouwmeester, Randy Buttner, Nellie van de Draai, Jolien Duenk, Janine Egging, Diana Engelen, Johan van Elk, Ton van Engelenburg, Ellis Fiering, Tanja Heeren Coumans, Susan Lemson, Ingrid Lindeboom, Sjoerd van der Meer, Hjalmer de Ruiter, Marja Schuchard, Linda Sloetjes, Gertrud Swart, Rachelle Zonneveld, Loes Scheepers, Lise Westerveld-Rissewijck, Nicole Wisselink en Jolanda Wissing.

Daarnaast waren er diverse mensen die stukken van het promotie traject mee liepen en mij voedden met ideeën, reflecties en meningen over de thematiek van dit proefschrift. In de eerste plaats dank ik Henri Boersma voor zijn hulp bij het eerste artikel en de boeiende gesprekken over onze eerste stappen in het promotietraject.

Mijn dank gaat ook uit naar mijn voormalige 'partners in consultancy' Marcel Bingley, Eric Streefland en Marian Willigenburg. Wij hebben meer dan 10 jaar lief en leed gedeeld in de wondere wereld van de zorg, waarin we met veel ondernemingszin vanuit ons kleine maar fijne bedrijf SQwin grote projecten aanpakten. De ontelbare gesprekken tijdens ons SQwin overleg, vanuit de auto en bij klanten over wat we allemaal wel niet hebben meegemaakt, hebben ook veel voeding gegeven aan dit onderzoek.

Mijn advieswerk in het MUMC+ waar ik gedurende bijna het hele promotie traject als adviseur betrokken was bij Material Management, was zeker ook een grote bron van inspiratie. In het bijzonder wil ik Ellen Voncken, Axel Olislagers, Erik Neijnens, Denis Florack en Hub Ackermans bedanken voor hun belangstelling voor wat mij de afgelopen jaren bezig hield.

Verder dank ik Ard van Dongen, Rob ter Hedde, Rikkert Keldermann, Mohamed El Ouasghiri, Pim Sas en Maartje Zonderland voor hun regelmatige feedback en het gedeelde enthousiasme over deze thematiek.

Gedurende de promotie hebben diverse mensen me geholpen met allerlei hand en span diensten. Brigitte Caenen, ontzettend bedankt voor het regelen van afspraken en administratieve zaken rondom dit onderzoek. Barbara Greenberg, dank voor de proofreading van alle artikelen en het regelen van native speakers Casey O'Dell en Pushba, die het proefschrift vanuit India tegen lazen. Dank aan Tiny Wouters voor de opmaak van het proefschrift. Dank ook aan Roelant Siekman voor de mooie 'oneliner' illustratie van het Slingeland ziekenhuis. Dank aan Erwin Frederiksen die er in Photoshop een mooie boekomslag van gemaakt heeft. 
Tenslotte voel ik grote dankbaarheid naar mijn samengestelde familie. Sander de Moel, ons leven is nu anders 'geïntegreerd en gedifferentieerd' dan toen dit promotie onderzoek startte. Dat het óók nu nog goed functioneert, daar ben ik je enorm dankbaar voor. Marit de Moel en Bjorn de Moel, dank jullie wel voor jullie open blik, nieuwsgierigheid, vrolijkheid en humor. Die zijn voor mij een bron van veerkracht en plezier. Op een moederdag knutsel cadeau met 'mijn allerliefste wens voor mijn moeder is dat ze haar artikel haalt' kan je wel weer even teren.

Ton en Ria van der Ham, dank voor jullie belangstelling voor wat mij bezig houdt en jullie hulp met de diverse verhuizingen en met de kinderen, die, zeker toen ze klein waren, onmisbaar was. Dank ook aan Ria Molenaar, die ook lange tijd een onmisbare schakel was in het 'stabiliseren' van ons drukke bestaan. It takes a good social network to raise a child.

En zonder Erwin Frederiksen had ik deze weg niet durven bewandelen; jouw vriendschap, verwantschap en liefde hebben mij vleugels gegeven. 




\section{ABOUT THE AUTHOR}

Annelies van der Ham was born on June 51975 in Utrecht, the Netherlands. After finishing her 'gymnasium' secondary education at St. Bonifatius College in Utrecht, she lived with a Scottish family in East Kilbride for a year, as part of a cultural exchange program. In Scotland she

obtained her Highers and Advanced Highers at Duncanrig Secondary School in East Kilbride. After her year away she moved back to The Netherlands and obtained a Master's degree in Systems Engineering, Policy Analysis and Management in 1999 at the Technical University of Delft.

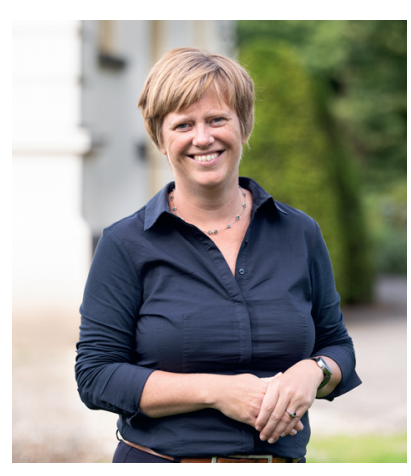
Her thesis was about the optimization of information processes through computer simulation in Haaglanden Medical Centre in The Hague, the Netherlands.

Since 1999 Annelies has continuously worked on improving supply chains and networks. Between 2000 and 2006 she worked for TNO, a large independent research organization in The Netherlands. As a TNO consultant she advised airports, fruit traders, offshore companies, inland skippers and several other commercial businesses on logistical improvement and she designed supply chains and information architectures. She returned to healthcare in 2006 by joining consultancy firm YNNO and started consultancy firm SQwin in 2009, together with five YNNO colleagues. SQwin offered very specific knowhow to healthcare providers on the design, development and implementation of new buildings, information systems and logistical concepts. In 2020 she became an independent consultant, working for hospitals from her own consultancy firm SQurious. From September 2021 she is associated with Turner, a consultancy firm specialized in strategy execution.

In 2015 Annelies initiated the PhD research and has been an external PhD candidate to the Department of Health Services Research, Care and Public Health Research Institute (CAPHRI) at the Faculty of Health, Medicine and Life Sciences of Maastricht University. Her main interests are health care logistics, IT, eHealth and organizational development. In the upcoming years Annelies will continue to work on these topics, both as a postdoc researcher at CAPHRI and as a consultant. 




\section{LIST OF PUBLICATIONS}

\section{Scientific papers in international journals}

Van der Ham A, Boersma H, Van Raak A, Ruwaard D and Van Merode G.G. Identifying Logistical Parameters in Hospitals: Does literature reflect integration in hospitals? A scoping study. Health Serv Manage Res 2019; 32(3): 158-165.

Van der Ham A, Van Merode F, Ruwaard D and Van Raak A. Identifying Integration and Differentiation in a Hospital's Logistical System: A social network analysis of a case study.BMC Health Serv Res 2020; 20: 857. DOI: 10.1186/s12913-020-05514-w.

Van der Ham A, Van Raak A, Ruwaard D and Van Merode F. Explaining Integration and Differentiation in a Hospital's Logistical System by Identifying Coordination Mechanisms. $J$ Health Organ Manag 2021; 36(9): 66-84.

\section{Submitted papers}

Van der Ham A, Van Raak A, Ruwaard D and Van Merode GG. Evaluating Changes in Integration, Differentiation, Rules, Coordination and Performance following the introduction of a Hospital Planning Centre: a case study.

\section{Book chapter}

Van der Ham A. Capaciteitsmanagement en zorglogistiek - van fragmentatie naar samenhang. In: Berden B, Berrevoets L, Van Merode F and Winasti W (eds) Capaciteitsplanning in de zorg. Tweede herziene druk. Houten: Bohn Stafleu van Loghum, 2021. pp. 55-72. 



